\title{
WA/GA-SUBJECTS IN JAPANESE \\ AND SUBDIVISIONS OF TENSE
}

by

Shizuka Torii

\author{
A thesis \\ submitted to the Victoria University of Wellington \\ in fulfilment of the \\ requirements for the degree of \\ Doctor of Philosophy \\ in Linguistics
}

Victoria University of Wellington

2000 


\section{WA/GA-SUBJECTS IN JAPANESE}

\section{AND SUBDIVISIONS OF TENSE}

\section{Shizuka Torii}

This thesis takes a semantically based tense/aspect approach to the long-standing problem of $w a$ - and ga-markings of 'subjects' in Japanese. It argues for a correlation between walga-markings of 'subjects' and tense/aspect interpretations of clauses, as illustrated in (1) below, to shed light on a new dimension of the problem.

a. John-wa ki-ta.

$<$ past $>$

John come-Past

'John came.'

b. John-ga ki-ta.

John come-Past

$<$ 'hot news' perfect $>$

'John has just come/arrived.'

The two types of tense/aspect interpretations correlated with wa- and $g a$-marked subjects are pinned down in terms of (i) two types of 'evaluation time', which are distinguished as 'original' and 'new' (Enç 1987), (ii) two types of R[eference time] (Reichenbach 1947); one that coincides with $\mathrm{S}$ [peech time] but not with $\mathrm{E}$ [vent time] $(\mathrm{R}=\mathrm{S} / \neq \mathrm{E})$, and the other that coincides with $\mathrm{E}$ but not with $\mathrm{S}(\mathrm{R}=\mathrm{E} / \neq \mathrm{S})$, and (iii) two types of 'viewpoint aspect' (Smith 1991); one that presents 'part' of a situation manifested at a precise temporal point (View $\mathrm{part})$ and the other that presents 'all' of a situation without decomposing it (Viewall).

In order to provide syntactic mechanisms to account for the correlation between walga-markings of 'subjects' and the two distinct types of tense/aspect interpretations, I propose two subdivisions of Tense in line with Chomsky's (1995: 240) suggestion that Tense might have "further subdivisions and implications about event structure and perhaps other properties". I assume that the two subdivisions of Tense are functional categories making up an articulated tense structure (above VP) and contain 
distinct semantic features responsible for the distinct tense/aspect interpretations correlated with $w a$ - and $g a$-markings of subjects in Japanese. Being tense categories, they both have $\mathrm{T}[$ ense]-features and D[eterminer]features to be checked by predicates and subject DPs respectively. Due to the distinct semantic content of the two syntactic categories, depending on which T- and D-features predicates and subjects check, we get two distinct types of tense/aspect interpretations of predicates and two distinct types of subjects (which are morphologically distinguished by $w a$ - and $g a$-markings in Japanese). In this analysis, the T- and D-features of a tense category ensure that a subject and a predicate are necessarily of the same semantic type.

The tense system I propose to account for the wa/ga-phenomena unifies tense and aspect to the extent that the wa/ga-phenomena relate to the interpretation of both tense and aspect. A notable consequence of my analysis is that the syntax and semantics of stage- and individual-level predicates (cf. Carlson 1977, Kratzer 1989 and Diesing 1992) fall under the syntax and semantics of tense. The analysis also exhibits some interesting parallelisms to Davis' (1998), in which person features of subjects are related to a temporal structure. In addition, the proposed two subject positions within the articulated tense structure are demonstrated to be tenable across languages.

Furthermore, I show that the reanalysis is extendable to subordinate clause case markings and interpretations, with special attention to factors such as factivity and the distinctions among propositions, states of affairs, and situation-types. 


\section{Acknowledgements}

Acknowledgements had always been my favourite part in any theses that I read, and how much I looked forward to writing my own acknowledgements! But when the time comes, I find myself not knowing how to express my heartfelt gratitude to everyone.

I am most deeply indebted to Elizabeth Pearce, who had made an incredible supervisor for me and without whom this thesis simply would not exist. To begin with, it was Liz's insight that led me to take a tense/aspect approach to the problem of $w a / g a$-subjects in Japanese. Her penetration and a big picture she always held were invaluable guide to me. Moreover, Liz was committed to helping me achieve the goals and quality that I should aim for. She always opened her windows to show me the vivid field of research and encouraged me to go out there, especially to make up the geographical isolation we were working in. She patiently and painstakingly read countless draft versions of my chapters to point out all sorts of errors, from misspellings and infelicities to critical flaws in arguments, and to give me helpful suggestions each time. It is no exaggeration to say that any good of this thesis has come out through Liz's guidance.

Looking back further, I cannot help thinking that it was my destiny that I was in Liz's tutorial when I first took an introductory linguistics course. Even to a rather awkward/unconfident student from Japan (which I think I was), Liz had a very sympathetic and encouraging attitude and showed the fascination of natural languages. The seed (of me as a linguist) was sowed in those early days. While I looked after my seed by supplying water constantly, Liz provided bright and warm sunlight and good powerful fertiliser. With Liz, I simply enjoyed an ideal working relationship of mutual trust and respect and wonderful friendship across all the differences between us.

I also owe tremendously to Laurie Bauer. In my days at Victoria Laurie was my hero, whose intelligence (and sweet smile) I only admired and whose existence itself was an inspiration to me. I also enjoyed a privilege to bathe myself in his clear thinking and genuineness in one-to-one classes in my 
honours year, from which I learnt valuable lessons. Laurie gave me lots of strong support, often behind the scenes but to really make differences.

I would also like to thank Janet Holmes, Chris Lane, Paul Warren, Jane Dudley and other members of the department for their support in various ways, and Martin Paviour-Smith, Yono Skarno, and other fellow students in the department for their company.

It was regrettable that I had to leave Wellington while I was still a student at Victoria, but it was wonderful to become acquainted with the linguists in Auckland, including Sheila Dooley-Collberg, Helen Charters, and Atsuko Kikuchi just to name a few. In particular, I am most obliged to Harry Leder, who generously spent time and energy reading my papers and sharing his knowledge and ideas with me. His MA semantics classes, which Harry let me attend (unofficially), were also very beneficial for me.

I am also grateful for helpful suggestions received on occasions when I have presented various stages of this work, at the 1998 Australian Linguistic Society conference held at the University of Queensland, the 13th New Zealand Linguistic Society conference held at Massey University, and in the seminars and/or workshops at the University of Auckland, the University of Canterbury, and Victoria University of Wellington. Sometimes discussions continued well beyond those occasions and I particularly thank Heidi Quinn, Shigeko Nariyama, Robin Hooper, Kate Kearns, Robin Schafer, and Yoji Hattori, among others, for their interest in my work.

E-mail communications with linguists outside my environment was vital to my study. Especially, I benefited immensely from their papers (often unpublished) which they kindly air-mailed to me. I sincerely thank Tim Stowell, Hamida Demirdache, Lisa Travis, Jim McCloskey, Peter Svenonius, Gerhard Brugger, Patrick Blackburn, and many others for their kindness and professionalism.

The 1997 LSA Linguistic Institute held at Cornell University, Ithaca, NY. was of great value to me. Particularly, the course on the syntax and semantic of tense/aspect taught by Molly Diesing and Sabine Iatridou and the workshop on events as grammatical objects organised by Carol Tenny had immediate influence on this thesis. I also enjoyed meeting individual linguists, 
including Hana Filip, Elizabeth Cowper, Peter Svenonius, Chungmin Lee, and Yasuhiro Shirai, who all contributed to my work in one way or other. I gratefully acknowledge the LSA Fellowship and the Research Grant from Victoria University Faculty of Humanities and Social Sciences, which supported my participation in the Institute.

I am also very thankful that the Victoria University of Wellington Postgraduate Scholarship generously supported my life as a PhD student since 1997. The tutoring positions from the department as well as the English department at the University of Auckland also provided me with financial aid, not to mention the precious experience.

Special thanks go to Ivan, who kept telling me that I must do whatever I wanted to do and provided me with all sorts of support to make my dreams come true. I cannot leave out my parents and sisters either, who are always with me no matter how far away we live. Daisuke also deserves a special mention here. "This is what Mama was doing all the time when you were being a good boy in the VUW student crèche, Drop-In Children's Center in Ithaca, and Next Generation Child Care in Auckland (which 1 also acknowledge here)."

Finally, I am grateful to my examiners, Carlota Smith, Tim Stowell, and Paul Warren, for their valuable comments. Any remaining errors, infelicities or outrageous claims in this thesis are my own. 


\section{Table of Contents}

$\begin{array}{ll}\text { Abstract } & \text { ii } \\ \text { Acknowledgements } & \text { iv }\end{array}$

Chapter 1 : Wa- and $g a$-marked "subjects"

1.1. Introduction 1

1.1.1. The problem of $w a$ - and $g a$-marked "subjects" 1

1.1.2. Delimiting the problem 3

1.1.2.1. The neutral interpretations of $-w a$ and $-g a$

1.1.2.2. What I mean by "subjects" 5

$\begin{array}{ll}\text { 1.2. Subjects and tense } & 10\end{array}$

$\begin{array}{ll}1.2 .1 \text {. Subjects and temporal interpretations } & 10\end{array}$

1.2.2. Subjects and tense in syntax $\quad 14$

1.2.3. Conclusion 18

1.3. Structural hierarchy between $w a$ - and $g a$-marked subjects $\quad 19$

1.3.1. Structural hierarchy suggested by semantic relations $\quad 19$

1.3.2. Syntactic positions of $w a$ - and ga-marked subjects 21

1.3.3. Summary 25

1.4. Summary and outlook 25

Chapter 2 : Two types of evaluation time, $R$, and viewpoint aspect 32

2.1. Two types of evaluation time $\quad 33$

2.1.1. 'Original' versus 'new' evaluation time 33

2.1.2. A contrast in spatiotemporal boundedness 40

2.1.3. Summary 45

2.2. Two types of R 45

2.2.1. Reichenbach's (1947) S, E, and R 45

2.2.2. Two types of evaluation time are two types of R 46

2.2.3. $\mathrm{R}$ aligned with $\mathrm{S}$ and $\mathrm{R}$ distinct from $\mathrm{S} \quad 48$

2.2.3.1. S as the "now" point 49

2.2.4. $\mathrm{R}$ distinct from $\mathrm{E}$ and $\mathrm{R}$ aligned with $\mathrm{E}$

2.2.5. Modifications to Reichenbach's tense representations $\quad 57$

2.2.6. Two types of R and wa/ga-subjects 61

2.2.7. Conclusion $\quad 64$

2.3. $R$ as viewpoint aspect 65

2.3.1. The S-E relation and $\mathrm{R} \quad 65$

2.3.2. $\mathrm{R}$ as viewpoint aspect 66

2.3.3. View all vs. View part $_{\text {and }}$ perfective vs. imperfective 68

2.3.4. Wa/ga-marking of subjects signalling $\mathrm{View}_{\text {all }} / \mathrm{View}_{\text {part }} \quad 74$

2.3.5. Case marking and viewpoint aspects $\quad 76$

2.3.6. Summary 83

2.4. $W a$ - and $g a$-markings in Japanese and the and $a(a n)$ in English 84

2.4.1. Familiar vs. novel 86

$\begin{array}{ll}\text { 2.4.2. Whole vs. part } & 88\end{array}$ 
Appendix to Chapter 2: Present tense 92

1. Overlap relation

2. Two types of present

94

3. Present tense in Japanese

96

Chapter 3: Three-component analysis of aspect 99

3.1. Denotations of -ta, -ru, and -teiru 100

3.1.1. $\mathrm{S}>\mathrm{E}=$ Completed aspect $\quad 101$

3.1.2. $\mathrm{S}<\mathrm{E}=$ Prospective aspect 101

3.1.3. $\mathrm{S}, \mathrm{E}=$ Ongoing aspect $\quad 102$

3.1. Conclusion 103

3.2. Four kinds of aspect $\quad 105$

3.3. Interaction between viewpoints and situation types 106

$\begin{array}{ll}\text { 3.3.1. States vs. non-states } & 107\end{array}$

3.3.2. [+Stage] vs. [-Stage] situations 109

3.3.2.1. [+Stage] situations 110

3.3.2.2. [-Stage] situations 113

3.3.3. Stage-level vs. individual-level predicates $\quad 116$

3.3.4. Visible vs. invisible situations $\quad 119$

3.3.5. Summary 124

3.4. Interaction between situations types and denotations of -ta, $-r u$, and 125

-leiru

3.4.1. Interpretations of -teiru

125

3.4.1.1. [+/-Durative] 125

3.4.1.2. Experiential interpretation of -leiru 130

3.4.1.3. Summary 133

3.4.2. [ $+/-$ Telic] and the interpretation of $-t a \quad 133$

3.4.3. [ $+/$ - Preliminary] and the interpretation of $-r u$

3.4.4. Summary 140

3.5. Conclusion: Three-component analysis of aspect 140

Chapter 4: The phrase structure of tense

4.1. Syntactic representations for the $S-E$ relation and $R$ as a viewpoint aspect

4.1.1. Representation for the S-E relation

4.1.2. Representation for $\mathrm{R}$ as a viewpoint aspect 149

4.1.3. Comparison with Demirdache and Uribe-Etxebarria $\quad 152$ $(1998 \mathrm{a}, \mathrm{b}, \mathrm{c})$

4.1.4. Summary 157

4.2. More on the semantics of the two tense phrases 157

4.2.1. The lower tense phrase and a spatiotemporal location $\quad 157$

4.2.2. The upper tense phrase and a world 162

4.2.3. A world and a spatiotemporal location $\quad 164$ 
4.2.4. Conclusion 166

4.3. Syntactic mechanisms in the temporal structure 166

4.3.1. T-features and D-features 166

4.3.2. Movement 167

4.3.3. Semantic interpretations $\quad 170$

4.3.4. Wa- and ga-markings of subjects 173

4.3.5. Evidence for the structural hierarchy between wa- and ga subjects 176

4.3.6. Summary 182

4.4. Stage- and individual-level predicates in the temporal structure 184

4.4.1. Kratzer (1989) 184

4.4.2. Diesing (1992) 185

4.4.3. Comparisons 186

4.4.3.1. Origin of the distinction: lexicon vs. syntax 187

4.4.3.2. Link between syntax and semantics $\quad 189$

44.3.3. Level of syntactic representation $\quad 190$

4.4.3.4. "Aboutness" relation 191

4.4.3.5. Stage- and individual-level predicates in the temporal structure 193

4.4.4. Conclusion 194

194

195

195

$\begin{array}{ll}\text { 4.5.2. Person split and } w a / g a \text {-split } & 196 \\ \text { 4.5.3. } 1 \& 2 \text { vs. } 3 \text { person subjects, familiar vs. novel subjects, and } 202\end{array}$ individual vs. stage subjects

4.5.4. Conclusions 204

4.6. Two subject positions across languages 205

4.6.1. German, Icelandic, Italian, and Scottish Gaelic 205

4.6.2. English 208

4.7. Implication for first language acquisition $\quad 216$

4.8. Conclusion 218

Chapter 5: Wa/ga-subjects in subordinate clauses 221

5.1. The subordinate puzzle $\quad 222$

5.2. Subordinate $W \quad 226$

5.2.1. Subordinate clauses expressing propositions 226

5.2.1.1. Factive and non-factive clauses 226

5.2.1.2. Factive and non-factive clauses in Japanese 231

5.2.1.3. The differing possibility of wa-marking of subjects 232

5.2.1.4. $W_{\text {lana] }}$ in factive clauses 233

5.2.1.5. $W_{[+]}$in non-factive clauses $\quad 236$

5.2.1.6. Summary 241

5.2.2. Subordinate clauses expressing states of affairs 242

5.2.2.1. Complement clauses of perception verbs 242

5.2.3. Summary 244

5.3. Subordinate $E \quad 244$

5.3.1. Stage-level and individual-level clauses 245

5.3.2. The differing possibility of $g a$-marking of subjects 246 
5.3.2.1. The presence of $g a$-subjects in stage-level clauses 246

5.3.2.2. The absence of $g a$-marked subjects in 248 individual-level clauses

5.3.3. Abstract states of affairs 250

5.3.3.1. Subordinate clauses describing situation-types $\quad 253$

5.3.3.2. Ga-marked subjects in clauses describing 257 situation-types

5.3.3.3. Rethinking time adverbial clauses 259

5.3.4. Summary $\quad 262$

5.4. Conclusion 263

Chapter 6: Concluding remarks 265

$\begin{array}{ll}\text { References } & 274\end{array}$ 


\section{Chapter 1}

\section{$W a$ - and $g a$-marked "subjects"}

\subsection{Introduction}

\subsubsection{The problem of wa- and $g a$-marked "subjects"}

In Japanese, the so-called subject of a clause can be marked by either -wa or $-g a$, as seen in (1) below. A basic question as to what determines the choice between -wa and -ga to mark the subject of a clause has been a genuine challenge. Even to a native speaker, who will certainly know whether the subject should be marked by -wa or -ga in each context, it is hard to find generalizations about the distributions and/or to come up with precise rules for determining the choice between -wa and -ga. Naturally, this problem has attracted the interest of numerous linguists and has been extensively investigated from various theoretical standpoints. $^{1}$

\section{(1) a. John-wa ki-ta. \\ John come-Past \\ 'John came.' \\ b. John-ga ki-ta. \\ John come-Past \\ 'John has just come/arrived.'}

To survey the previous studies very briefly, firstly, there are studies within the traditional kokugo-gaku linguistics (national language studies) (e.g., Miura 1976, Nagano 1972, Yamazaki 1965), among which Mikami (1960, 1972) has been particularly influential in characterizing -wa as teidai no wa "themepresenting $w a^{\text {" }}$ in the context of dai-jutsu kankei "theme-predicate correspondence", while taking -ga as a 'plain' nominative argument. 
Consistent with such a claim, Kuno (1973) argues for -wa as a theme marker and -ga as a neutral description marker. Kuroda (1965, 1972, 1976, 1992b) claims that a wa-marked subject is the logical 'Subject' of a logical 'Predicate', whereas a ga-marked subject is not.

Another view shared by many has been that $-w a$ expresses old information and -ga new information, although exactly what constitute "old" and "new" information have been rather a matter of controversy (e.g., Chafe 1976, Halliday 1967-1968, Haviland and Clark 1974, Inoue 1980, Kuno, 1972, 1973, Prince $1981)^{2}$

Syntacticians have investigated positions for subjects, $w a$ - and $g a$-marked, in the phrase structure of Japanese. Some have argued for a flat structure in which all arguments of the verb, including the subject, whether wa- or $g a$-marked, are immediate daughters of the projection of the verb (e.g., Inoue 1978, Hale 1980, Farmer 1984, Miyagawa 1980), whereas others assume fully configurational structure in which ga-marked subjects occur in [Spec, VP], whereas wa-marked ones (which are often called topics) occur outside and above VP (e.g., Saito 1985, Hoji 1985, Fukui 1986, Kuroda 1988, Kitagawa 1986). There has also been a claim that both $w a$ - and $g a$-marked subjects are adjuncts (Tonoike 1989). ${ }^{3}$

Others take more semantic-based approaches. For example, Shirai (1986) and Endo (1994) consider the issue in the light of the stage/individual distinction (Carison 1977).

All these studies, of which what I have mentioned above is only the tip of an iceberg, certainly provide us with valuable insights into the problem. Nevertheless, we are still yet to see the whole picture and the precise mechanisms to account for $w a / g a$-marking of subjects.

It seems that the $w a / g a$-problem is such a huge monster that we cannot see its whole figure in life-size. Therefore, we examine it part by part (from various

${ }^{1}$ Hinds, Maynard and Iwasaki (1987) collect a range of approaches to the issue.

${ }^{2}$ On this topic, Isoe (1992) provides a summary of previous studies. 
perspectives). When we collect all the parts, we should be able to put them together to project its whole figure. In this analogy, this thesis carves out another part of the $w a / g a$-monster from a novel perspective, namely that of tense and aspect. In this sense, it is just another piece that is to be put together with all the other pieces to project the entire picture of the wa/ga-monster. However, I believe that it is such a vital part of the $w a / g a$-monster close to its heart that the analysis of its role makes a big contribution to the construction of the whole picture.

\subsubsection{Delimiting the problem}

There are some encumbrances in the $w a / g a$-problem, which I need to clear first.

\subsubsection{The neutral interpretations of $-w a$ and $-g a$}

Firstly, both -wa and -ga have two possible interpretations to yield. Observe in (2) below that the wa-marked John can be taken neutrally as a topic (without being contrasted), or taken as being contrasted with somebody who did not come. In Kuno's (1973) terms, they are distinguished as "thematic" and "contrastive". In (3) below, the ga-marked John can be taken neutrally to yield the interpretation of a straightforward announcement of the event of John's arrival, or taken as being in focus to yield the interpretation that it is John (but nobody else) who came. In Kuno's terms, they are distinguished as "neutral description" and "exhaustive listing".

(2) John-wa ki-ta.

John come-Past

a. 'John came.' <thematic>

b. 'John came (but somebody did not).' <contrastive $>$

${ }^{3}$ Tateishi (1991) provides a summary of various syntactic analyses. 
(3) John-ga ki-ta.

John come-PAST

a. 'John has just come/arrived.' <neutral description>

b. 'John (and only John) came.' 'It is John who came.' <exhaustive-listing>

Note that the (a) readings obtain when the phrases marked by -ga and $-w a$ do not receive prominent intonation, whereas the (b) readings obtain when they receive prominent intonation. That is, if there is a stress on John, the wa-marked John in (2) above is taken as being contrasted with somebody who did not come. Otherwise, i.e., without a stress on John, there is no such implication or presupposition about somebody else who did not come, and the wa-marked John is simply taken as a topic. Similarly, the ga-marked John in (3) above is interpreted as being in focus if there is a stress on John, but otherwise interpreted neutrally. I take the readings obtained without a stress as the basic (unmarked) readings of $-w a$ and $-g a$ and strictly distinguish them from the other readings obtained with a stress. In order to gain an understanding of the basic contrast between -wa and $-g a$, I focus on the neutral interpretations, i.e., the "thematic" interpretation of -wa and the "neutral description" interpretation of - $g a$.

$$
\begin{array}{ll}
\text { Interpretations of -wa and -ga (based on Kuno 1973) } \\
\begin{array}{ll}
\text { Neutral interpretation } & \text { Focus interpretation } \\
-w a \text { "thematic" } & \text { "contrastive" } \\
\text { (contrastive focus) }
\end{array} \\
-g a \text { "neutral description" } & \begin{array}{l}
\text { "exhaustive-listing" } \\
\text { (presentational focus) }
\end{array}
\end{array}
$$

Since I exclude the focus interpretations from discussion, the issues concerning the focus interpretations and/or the relationships between the neutral and the focus interpretations are not addressed in the major part of this thesis. I assume that those issues essentially depend on gaining an understanding of how the neutral interpretations work, which is what I take as a goal of this thesis. Nevertheless, some indications about the focus 
interpretations are detected in the analyses of the neutral interpretations and they will be briefly sketched at the end of the thesis in Chapter 6 (as well as in a footnote in Chapter 4).

\subsubsection{What I mean by "subjects"}

Secondly, there is a question of what I mean by "subject". The notion of "subject" is fundamental and a broad range of disparate phenomena seem to require reference to the notion, as McCloskey (1997) says. The subject properties include the followings, as summarized by McCloskey.

(5) i. The subject is the characteristic bearer of certain kinds of semantic roles (prototypically AGENT and perhaps also CAUSE and, more controversially EXPERIENCER).

ii. The subject is more prominent than any other argument of the main verb. Its prominence is manifested in a variety of phenomena:

a. the subject may bind reflexive and reciprocal pronouns appearing in other argument-positions but may not itself (if it is a reflexive or a reciprocal) be bound by elements in other argument positions.

b. the subject, at least in the typical case, takes wider scope than an element in any other argument-position.

c. a subject, if it has the right semantic properties, licenses a Negative Polarity Item in some other argument-position. A Negative Polarity Item in subject-position cannot, however, be licensed by an appropriate element in another argument-position.

iii. Subjects are typically formally marked - positionally and/or morphologically. Morphological marking may be on the subject itself (in the form of a case) or on the main inflectional element of the clause (in the form of agreement morphology).

iv. It has sometimes been claimed that every sentence must have a subject. This is not obviously correct, but it is clearly correct in some broad sense 
for some languages. There is no other argument-type or syntactic position for which this claim can be made with even remote plausibility.

v. Subjects are almost always nominal. There is a well-known set of difficulties for this general claim (subject clauses if they exist, cases in English such as Under the sink would be a good place to hide, locative inversion construction) but the general fact is so striking that it cannot be ignored.

vi. There are many grammatical operations which create surface subjects, by promoting nominals from other positions or ranks (passive, subject-tosubject raising, unaccusative advancement, Tough Movement and so on).

(McCloskey 1997: 197-198)

McCloskey says that in the recent development of generative theories these properties are 'distributed across a range of distinct (but derivationally linked) syntactic entities and positions' so that 'it is not even clear that there is any derived or defined notion which captures the traditional intuition of what a subject is' (p.197).

Without discussing the issues of what a subject is, in this thesis I use the term "subjects" rather informally. Basically, in order to focus on the contrast between the neutral readings of $w a$ - and ga-marked arguments, I use the term "subjects" to refer to arguments that can be neutrally marked by either -wa or -ga in a Japanese sentence. In some typical cases, subject arguments can alternatively marked by -wa or - $g a$ (to yield the neutral interpretations), as seen in (1) above. In other cases, however, subject arguments can be marked neutrally only by one of the two, i.e., -wa or -ga. For example, in (6) below, the subject can be marked by $-w a$ neutrally but not neutrally by $-g a$, as indicated by the hash. That is, if marked by $-g a$, the subject is necessarily interpreted as being in focus. On the other hand, in (7) below, the subject can be marked by -ga but not by -wa. (The reasons for these differing availability of $w a$ - and $g a$-markings of subjects will be discussed in due course.) 
(6) John-wa/\#gagakusei da.

'John is a student.'

student Cop(Pres)

(7) Dareka-*wa/ga nai-tei-ru.

someone cry-Prog-Pres

'Someone is crying.'

I thus use the term "subjects" to roughly refer to those wa- or ga-marked arguments that yield the neutral interpretations. However, there are some arguments that are neutrally ga-marked and yet I do not take them into account in this thesis. For example, in (8) below, eiga 'movie' is neutrally ga-marked (and contrastively wa-marked, as indicated by the hash) but such an example will not be discussed in the major part of this thesis. ${ }^{4}$

\footnotetext{
${ }^{4}$ However, since the $g a$-marking of such a theme argument yields the neutral interpretation, it is hoped ultimately to be incorporated in the system which accounts for the basic walga contrast.

Note that such theme arguments are marked with -ga only when the predicates are stative, and are marked with $-o$ elsewhere. The examples in (i)-(iii) below show that the alternation between $o$ - and ga-markings of objects depends roughly on whether the predicates describe activities (the (a) sentences) or static states (the (b) sentences) (cf. Kuno 1973, II.4).
}

(i) a. Taro-wa eigo-0 narat-tei-ru.

English study-Prog-Pres

'Taro is studying English.'

b. Taro-wa eigo-ga deki-ru.

English be good at-Pres

'Taro is good at English.'

(ii) a. Taroo-wa Hanako-o aishi-tei-ru.

'Taroo loves Hanako.'

love-Prog-Pres

b. Taroo-wa Hanako-ga suki-da.

'Taroo likes Hanako.'

like-Cop(Pres)

(iii) a. Mary-wa piano-o hi-ku.

piano play-Pres

'Mary plays the piano.'

b. Mary-wa piano-ga hik-e-ru

piano play-can-Pres

'Mary can play the piano.' 
(8) Eiga-\#wa/ga suki-des-u.

movie like-Polite-Pres

'(I) like movies.'

The exclusion of such an example may be justified by the lack of some fundamental subject properties. For instance, the semantic role of eiga is THEME rather than AGENT, CAUSE or EXPERIENCER (cf. (5i) above). There is in fact another argument, i.e., experiencer argument, that is understood to be there, though not overtly expressed, and that is taken as the subject in (8).

Moreover, such a theme argument lacks the characteristic prominence of a subject, being unable to bind a reflexive (cf. (5iia) above). Observe in (9) below that Taroo can be referred back to by the reflexive zibun but Hanako cannot. According to the analysis that the Japanese reflexive zibun requires that its antecedent be a subject, Taroo is the subject but Hanako is not. (I have added to Farmer's example a hash on the -ga marking Taroo to indicate that it necessarily yields the focus interpretation and $-w a$ to mark Taroo to yield the neutral interpretation.)

(9) Taroo ${ }_{\mathrm{i}}$-wa/\#ga Hanako $\mathrm{j}_{\mathrm{j}}$-ga zibun zi, $_{\mathrm{j}}$-no guruupu de ichiban suki da. self-'s group in the best like Cop 'Taroo ${ }_{\mathrm{i}}$ likes Hanako $\mathrm{j}_{\mathrm{j}}$ the best in self' $\mathrm{s}_{\mathrm{i},{ } \mathrm{j}}$ group.'

(Farmer 1985:9)

However, it is important to note here that it is not the semantic role THEME that disqualifies an argument from being a subject. For example, in the passive construction in (10b) below, the theme argument, Hanako, rather than the agent, Taroo is taken as the subject.

(10)a. Taroo-wa/gaHanako-o but-ta.

'Taroo hit Hanako.'

-Acc hit-Past 
b. Hanako-wa/ga $\begin{aligned} \text { Taroo-ni } & \text { but-are-ta. } \\ \text {-Dat } & \text { hit-Pass-Past }\end{aligned}$

'Hanako was hit by Taroo.'

Moreover, with the so-called unaccusative verbs, subjects are theme arguments (cf. Petlmutter 1978, Burzio 1986). For example, the John's in (11a) and (11b) below are equally taken as subjects but John, the argument of arrive, in (11a) is considered a theme, while John, the argument of sleep, in (11b) is an agent.

(11)a. John-wa/ga ki-ta.

come-Past

'John came/has just come.'

b. John-wa/ga ne-ta.

sleep-Past

'John slept/has just slept.'

Whilst it is the case that the problem of the connections between semantic roles and subject realizations goes well beyond the scope of this thesis, it is also the case that semantic roles make up just one of the multiple factors that have bearing on what may be called a 'subject', as indicated in (5) above. Since there are no coherent categories that always determine the subjecthood, it is sometimes hard to clearly define the reasons for inclusion and exclusion of certain examples in and from consideration, though my basic stance is to take arguments that can be neutrally marked by either -wa or -ga in a Japanese sentence as 'subjects'.

Another point to note is that one common approach to the subject notion especially in Japanese is to assume that subjects are ga-marked phrases. This is based on the assumption that subject is a grammatical relation which correlates with the grammatical case, nominative, and that $-g a$ is the nominative case marker in Japanese. As a result of restricting the use of the term 'subject' only to gamarked phrases, $w a$-marked phrases have often been distinguished as 'topics' and analyzed independently from ga-marked phrases. (e.g., Kuroda 1965, Kuroda 1988, Saito 1986, Fukui 1986, Kitagawa 1986). However, my task is to 
investigate the conditions under which $w a$ - or $g a$-marking is applied to one and the same argument. ${ }^{5}$ For this purpose, I take an approach that unifies $w a$-marked and $g a$-marked phrases.

\subsection{Subjects and tense}

Within the boundary I have set above, this thesis investigates the problem of $w a$ - and ga-marked subjects in Japanese from a novel perspective of tense and aspect, and sheds light on a new dimension of the problem. It carries out a finegrained semantic analysis of the basic tense/aspect system in Japanese in relation to wa/ga-marking of subjects and argues that there is a correlation between $w a / g a$-marking of subjects and tense/aspect interpretations. The systematic correlation found and defined between the two is further developed into syntactic representations and mechanisms in line with the current theories in generative research.

Although such a semantically based tense/aspect approach to the problem of wa/ga-subjects is novel, it has been indicated, though implicitly, in various ways in a range of previous research on the topic. In this section, I review some of the previous analyses which are suggestive of a correlation between subjects and tense in semantic interpretations (e.g., Maynard 1987, Kuroda 1992b) and in syntax (e.g., Takezawa 1987, Koizumi 1994).

\subsubsection{Subjects and temporal interpretations}

Maynard $(1980,1987)$ sees the choice between $-w a$ and $-g a$ as a device to express the perspective of the speaker (or the narrator) toward the events described, which is called "staging". In examining data taken from modern narrative stories, Maynard (1987) points out that wa-marked and ga-marked

\footnotetext{
${ }^{5}$ Isoe (1992) takes the same stance.
} 
subjects are characterized by different durations of time for which the referents are supposed to be on stage by an interlocutor:

'It is as if the narrator places participants at different spots on the narrative stage for different durations of time in the consciousness of the narrator and his/her intended audience, the reader. More specifically, the thematized participants [wa-marked subjects] are expected to remain on stage for $a$ longer period of time and this serves to provide points of reference for the development of the thematic flow' (p. 61),

whereas

'[non-thematized] participants [ga-marked subjects] do not stay on the stage for a long time; their status is characterized by frequent appearance, disappearance and/or reappearance at various phases of the plot development.' (p. 62)

(italicization by Torii)

As I highlighted with italics in the quotation above, while wa-marked subjects are taken to remain on stage for a longer period of time, $g a$-marked subjects are not taken to stay on the stage for a long time. That is, a difference between $w a$ - and ga-marked subjects is captured in terms of the temporal durations of their referents in the consciousness of an interlocutor.

Kuroda (1992b) makes a similar point in regard to definite and indefinite noun phrases, which in fact seem to correspond to $w a$ - and $g a$-marked subjects. He claims that the referent of an indefinite specific noun phrase is strictly dependent on the perception with respect to which it is recognized, while the cognitive existence of the referent of a definite noun is independent of a particular perception in which it happens to be recognized. Putting this in terms of time, he says that the referent of an indefinite specific noun phrase, whose cognitive 
existence does not extend beyond the confines of this perception in time, is lost in time (unless it is recalled or retained to become a potential referent of a definite noun phrase), while the referent of a definite description subsists in time, that is, through time (p. 36).

Although Kuroda's claim is concerned with definite and indefinite noun phrases, the contrast he is illuminating seems to exist between wa-marked and $g a$ marked subjects (as much as it does between definite and indefinite noun phrases). In particular, Kuroda himself notes that the bare noun marked by $g a$ in (10b) below can be taken as either a definite or an indefinite cat (i.e., the cat or a cat). But no matter whether it is taken as a definite or an indefinite cat, the life span of the ga-marked cat in (12b) is short, in fact instantaneous, atemporal. ${ }^{6}$ On the other hand, the referent of the wa-marked cat in (12a) is necessarily taken as transcending and subsisting beyond the confines of the perception in which it is recognized.

(12)a. Neko-wa asoko-de nemut-tei-ru. the cat there-at sleep-Prog-Pres

'The cat is sleeping over there.'

b. Neko-ga asoko-de nemut-tei-ru. the/a cat there-at sleep-Prog-Pres 'The/A cat is sleeping over there.'

Moreover, when the subject is a proper name as in (13) below, whether it is marked with -wa or $-g a$, it is definite in the sense that a proper name has a definite referent. However, the ga-marked John in (13b) does not outlive the event perceived and described in the sentence, while the wa-marked John in (13a) does. ${ }^{7}$

\footnotetext{
${ }^{6}$ It may sound contradictory that something definite (i.e., the referent presupposed) cognitively does not outlive the confine of a particular perception. However, while definiteness is concerned with whether the referent is familiar or novel in the discourse, what is at stake here is the temporal interpretation of a subject noun phrase. In my view, these two things are independent from each other.

Incidentally, in 2.4 below I will discuss the extent to which wa- and ga-markings of subjects in Japanese correspond to the definite and indefinite articles, the and a/an, in English.

${ }^{7}$ See footnote 6 above.
} 


\section{(13)a. John-wa asoko-de nemut-tei-ru. there-at sleep-Prog-Pres \\ 'John is sleeping over there.'
b. John-ga asoko-de nemut-tei-ru. there-at sleep-Prog-Pres
'John is sleeping over there.'

Therefore, I take Kuroda's claim to be effective with regard to wa- and $g a$ marked subjects. That is, the cognitive existence of the referent of a ga-marked subject is bounded in time, while the cognitive existence of the referent of a wamarked subject subsists beyond the boundaries of time.

Note that $w a$ - and $g a$-marked subjects thus distinguished in terms of temporal boundedness correspond to Carlson's (1977) 'individuals' and 'stages' respectively.

A stage is conceived as being, roughly, a spatially and temporally bounded manifestation of something. ..... An individual, then, is (at least) that whateverit-is that ties a series of stages together to make them stages of the same thing.

(Carlson 1977: 68)

A $g a$-marked subject corresponds to a stage, because it is bounded in time (and space). A wa-marked subject corresponds to an individual because it subsists beyond the boundaries of time (and space).

These parallelisms between $g a$-marked subjects and 'stages' and between $w a$-marked subjects and 'individuals' are also suggested in Shirai (1986) and Endo (1994). They shall be further elucidated in the course of analysis, particularly in $2.3 .5,2.4 .2,3.3 .3,4.3 .3,4.4$, and 5.3 below. 


\subsubsection{Subjects and tense in syntax}

A correlation between subjects and temporal properties has also been indicated in syntactic terms.

It has been a standard assumption that subjects are somehow associated with Tense in syntax. The Government-Binding theory has long held to the notion that the $+/$ - finite characteristic of Tense is implicated in nominative Case assignment/checking. In the Minimalist framework (Chomsky 1992, 1995), Tense is assumed to contain a D-feature which selects for a subject, as well as a Tfeature which selects for VP. Research on Japanese has also shown complying findings (e.g., Takezawa 1987, Koizumi 1994b).

Takezawa (1987) points out that in Japanese the nominative Case, i.e., $g a$ marking, is not possible on the subject of a small clause, where there is no tense morpheme, as shown in $(14 \mathrm{~b}){ }^{8,9}$

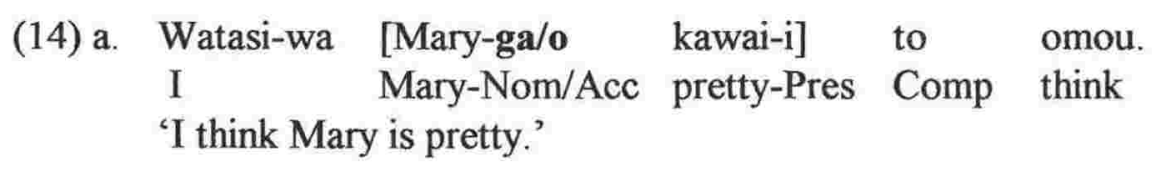
b. Watasi-wa [Mary-*ga/o kawai ku] omou. I Mary-Nom/Acc pretty Infin think 'I think Mary is pretty.'

(cited in Endo 1994: 90)

In addition, Takezawa observes that stative transitive predicates allow the Nominative-Accusative pattern, as in (15a), and the Dative-Nominative pattern, as in (15b), but do not allow the Dative-Accusative pattern, as in (15c). ${ }^{10}$

\footnotetext{
${ }^{8}$ Kawaiku in (14b) is a non-finite form of kawai-i ('pretty'). Strictly speaking, -ku may be considered as a tense morpheme, albeit [-T]. Therefore, Takezawa's claim should be taken as that the subjects of clauses cannot be nominatively marked (by -ga) in [-T] contexts.

${ }^{9}$ Endo (1994) points out cases where no tense morpheme appears and yet the nominative Case $g a$ is possible for the subject NP, e.g.,:
}

(i) [John-ga akuyaku] -no eiga John-Nom villain role -Gen movie 'the movie in which John plays the role of a villain" 
(15)a. Nominative-Accusative

John-ga eigo-o hanas-eru (koto)

John-Nom English-Acc speak-Potential (fact)

'(the fact that) John can speak English'

b. Dative-Nominative

John-ni eigo-ga hanas-eru (koto)

John-Dat English-Nomspeak-Potential (fact)

'(the fact that) John can speak English'

c. Dative-Accusative

*John-ni eigo-o hanas-eru (koto)

John-Dat English-Acc speak-Potential (fact)

'(the fact that) John can speak English'

(cited in Kawasaki 1991: 133)

On the basis of these data, Takezawa argues that a tensed clause must have at least one nominative noun phrase, i.e., ga-marked noun phrase, and that Tense is the category that assigns the nominative Case in Japanese.

It is important to note that Takezawa's argument is based on the sentences embedded in a small clause (in (14) above) and in a koto factive clause (in (15) above). Although the ga-marked phrases receive the neutral interpretation in those embedded contexts ( when the embedded sentences stand alone, the ga-marked phrases cannot receive the neutral interpretation and the focus interpretation is forced. (In fact, it has been a long-standing mystery why the interpretation of - $g a$ thus differs in matrix and embedded contexts (e.g., Kuno 1973, Kuroda 1987, Shirai 1986). I will undertake the task of explaining this contrast between matrix and embedded sentences in Chapter 5 of this thesis. The reasons for the unavailability of the

${ }^{10}$ Compare (15a) with (iiib) in footnote 4 above. Firstly, in (15a) the subject is ga-marked to yield the neutral interpretation, while in (iiia) in footnote 4 above the subject is wa-marked to yield the neutral interpretation. This difference is due to the contexts in which they occur, i.e., (15a) is a factive clause embedded under koto, while (iiia) is a stand-alone clause. Secondly, the direct object is $O$-marked in (15a) and ga-marked in (iiia). Although the $o$-marking of eiga in (15a) is interchangeable with $g a$-marking, in this context $o$-marking seems preferable perhaps because of the preceding $g a$-marking of the subject. In (iiia), $g a$-marking is far more preferable to $o$-marking (at least to the author). (See footnote 11 below.) 
neutral interpretation of -ga in matrix contexts will be discussed in 3.3. below.) For those phrases to yield the neutral interpretation in matrix contexts, they are rather marked with -wa, as shown in (16) and (17), which are the 'stand alone' clauses comparable to the embedded clauses in (14a) and (15a) above. ${ }^{11}$

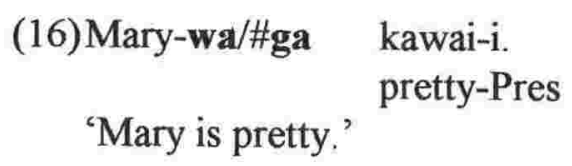

\section{(17)John-wa/\#ga eigo-o hanas-eru \\ English-Acc speak-Poten \\ 'John can speak English'}

Notice in (16) and (17) that those 'stand alone' clauses are all tensed and yet may have no $g a$-marked argument (at least not overtly), as a result of $w a-$ marking replacing $g a$-marking. This poses a problem to Takezawa's claim. It suggests that $w a$-marking of arguments alternative to ga-marking should also be taken into account.

Like Takezawa, Koizumi (1994b) also maintains that Tense is responsible for the nominative Case marking or ga-marking in Japanese, though he is more concerned with nominatively marked objects. Koizumi argues that the Casechecking position of the nominative object must be higher than the negation because the nominative object has scope over the negation (unlike the accusative object) but that it must be lower than the canonical subject position, which is assumed to be the Spec of AGRs. This leads him to claim that the Nominative Case of the nominative object is licensed by Tense under Spec-head agreement.

Furthermore, Koizumi defines the checking domain of Tense so as to include the Spec of AGRs and AGRsP-adjoined positions in addition to the Spec of Tense, as shown in (18) below. This provides an account for the fact that in the multiple subject construction, where a single clause contains more than one

${ }^{11}$ In (17), although the $o$-marking of eiga seems acceptable, ga-marking is more natural (at least to the author). (See footnote 10 above.) 
subject, the "major subject" (which is the left-most, outer subject) and the "regular subject" (which is the inner subject), as well as the nominative object, can be marked with the nominative $-g a$, as seen in (19) below. He states that an NP is marked with -ga only if it is Case-licensed in the Checking domain of Tense. ${ }^{12}$

(18)[AGrsp MS-ga [AGRsP SU-ga [TP OB-ga [NegP (or AP) [AGRoP OB-o [vp ...]]]]]] $(\mathrm{MS}=$ major subject, $\mathrm{SU}=($ regular $)$ subject, $\mathrm{OB}=$ object $)$

(Koizumi 1994: 223)

\section{(19) John-ga imooto-ga huransugo-ga hanas-e-ru. young.sister French speak-can-Pres}

'It is John that his sister can speak French.'

(Koizumi 1994: 224)

However, ga-marked subjects can alternatively be marked by $-w a$. Especially, "major subjects" marked by $-g a$ receive the exhaustive-listing (or focus) interpretation, and they are rather marked by -wa to receive an unmarked interpretation (of topic), as shown in (20) below. ${ }^{13}$

${ }^{12}$ To account for an interpretive difference among ga-marked NPs, Koizumi (1994b) distinguishes AGRsP-adjoined positions from [Spec, AGRsP] and [Spec, TP] as the Broad Checking Domain of Tense, as opposed to the Narrow Checking Domain of Tense. He claims that a ga-marked NP receives the exhaustive-listing interpretation if it is Case-licensed in the Broad Checking Domain of Tense, and the neutral-description interpretation otherwise. This means that the "major subject" receives the exhaustive-listing interpretation, while the "regular subject" and the nominative object receive the neutral interpretation. Certainly, the English translation of (19) that it is John that his sister can speak French fits in with his explanation.

In my view, however, a ga-marked NP in the "regular subject" position does not receive the neutral interpretation but rather the exhaustive-listing (or focus) interpretation. In the case of (19), not only John but also sister is taken as being in focus. A more literal translation of (19) would be that it is John, who has a sister who can speak French. The point is that both John and sister have wide scope over the nuclear clause that (who) can speak French. This becomes relevant when I assume the position of Neg between the position for wa-marked subjects and that for ga-marked subjects in 1.3.2 (cf. footnote 18).

${ }^{13}$ The $g a$-marked "regular subjects" and objects can also be marked by -wa alternatively, but $w a$-marked "regular subjects" and objects necessarily yield the contrastive interpretation, failing to yield the neutral topic interpretation. 
(20) John-wa imooto-ga huransugo-ga hanas-e-ru.
young sister French

'As for John, it is his sister who can speak French.'

Thus, both Takezawa and Koizumi argue for a link between Tense and $g a$ marking in the syntax but overlook the fact that ga-marked subjects can alternatively be marked by $-w a$. Although it is understandable that they separate 'subjects' from 'topics' on the basis of the presence or absence of the nominative ga-marking, it is important in my view that even when marked by -wa (not as 'subjects' but as 'topics'), they are still the same arguments which would be regarded as 'subjects' if marked by -ga. From this point of view, it is desirable if we can unify $g a$-marked and $w a$-marked "subjects" in our analysis. One possibility suggested here is to expand the claimed syntactic relation between Tense and $g a$ marking into a relation between Tense and both $g a$ - and wa-markings. Such an analysis will have an advantage of resolving a problem with regard to Takezawa's claim that a tensed clause may have no ga-marked argument (but a wa-marked argument instead), as shown in (16) and (17) above.

\subsubsection{Conclusion}

To sum up, Maynard (1987) and Kuroda (1992b) point out that wa- and gamarked subjects exhibit distinct temporal properties in their interpretations. Takezawa (1987) and Koizumi (1994) argue for a link between Tense and gamarking in the syntax. When we collate those two kinds of argument, there is a discrepancy in that while both $w a$ - and ga-marked subjects are shown to have certain temporal properties in the semantic interpretations, only ga-marked ones are claimed to be associated with the formal element Tense in the syntax. I take this discrepancy as a result of bias that subjects are necessarily nominatively marked (by -ga in Japanese) and oversight that these $g a$-marked 'subjects' can alternatively be $w a$-marked (without having to give rise to the contrastive interpretation). I am inclined to the view that "subjects", both ga-marked and wa- 
marked, are somehow associated with certain temporal properties in syntax, as they are in their interpretation.

Chomsky (1995: 240) suggests that Tense might have "further subdivisions and implications about event structure and perhaps other properties," in addition to the division of $[+/$-finite]. We might suppose that $w a$-marked and ga-marked subjects are associated with the subdivisions of Tense, and further, that the two different Tenses are responsible for the distinct temporal interpretations which $w a-$ marked and $g a$-marked subjects receive.

Under this scenario, the task is to investigate the subdivisions of Tense, which are related to $w a$ - and $g a$-marked subjects, and then to explicate the syntactic association between Tenses and subjects. I take this avenue in this thesis.

\subsection{Structural hierarchy between $w a$ - and $g a$-marked subjects}

In pursuing the above line of investigation, I assume that there are two subject positions in the phrase structure of Japanese, one for wa-marked subjects and the other for $g a$-marked subjects, and further that wa-marked subjects occupy a higher position than $g a$-marked subjects. Such assumptions are grounded in previous research on the topic, which I shall review in this section.

\subsubsection{Structural hierarchy suggested by semantic relations}

A structural hierarchy between $w a$-marked and $g a$-marked subjects has been suggested in terms of the semantic relations they hold to the predicates (e.g., Kuroda 1965, 1972, 1976, 1992b, Uetake 1991-1992). Although in different frameworks and different terminology, many essentially claim that a sentence with a wa-marked subject is interpreted as having a topic-comment structure, where the subject is first recognized as the topic, about which a comment follows, while a sentence with a $g a$-marked subject lacks such a structure. 
In terms of a theme and rheme dichotomy, the difference between the two sentences in (1) above is represented as in (21) below, where $T$ and $R$ stand for theme and theme respectively (e.g., Uetake 1991-1992). ${ }^{14}$

(21)a. John-waki-ta.

T R

b. John-ga ki-ta.

$\mathrm{R}$

While (21a), corresponding to (1a), contains a theme-rheme structure, i.e., a topic-comment structure, (21b), corresponding to (1b), is a themeless sentence and interpreted as a straightforward announcement of the event of John's arrival.

Kuroda $(1965,1972,1976,1992 b)$ expresses this in terms of the BrentanoMarty distinction of 'judgement forms' (Brentano 1924, Marty, 1908, 1916-1918, $1940,1950 \mathrm{a}, \mathrm{b})$. He argues that a sentence with a $w a$-marked subject expresses a categorical judgement, while a sentence with a ga-marked subject expresses a thetic judgement, as seen in the examples in $(12 \mathrm{a}, \mathrm{b})$ above, which are repeated in $(22 \mathrm{a}, \mathrm{b})$ below. As a thetic judgement, $(22 \mathrm{~b})$ simply expresses recognition of the existence of a situation in which a/the cat is sleeping in a certain place. Although (22a) might be used to describe the same situation, as a categorical judgement, it draws attention to the cat, and then says of the cat that it is sleeping there.

(22)a. Neko-wa asoko-de nemut-tei-ru. the cat there-at sleep-Prog-Pres

'As for the cat, it is sleeping over there.'

b. Neko-ga asoko-de nemut-tei-ru. the/a cat there-at sleep-Prog-Pres

'The/A cat is sleeping over there.'

${ }^{14}$ Simply following Uetake (1991-1992), (21b) would be assigned two ' $R$ 's, as shown in (i) below. However, I rather take it that the whole sentence constitutes one ' $R$ '.

(i) $\frac{\text { John-ga }}{\mathrm{R}} \frac{\text { ki-ta. }}{\mathrm{R}}$ 
Using the term 'Subject' (with a capital S) to refer to the logical subject of a logical predicate, which is to be distinguished from the syntactic subject of a clause, Kuroda claims that a categorical judgement consists of two distinct cognitive acts, "one the act of recognition of that which is to be made the Subject, and the other, the act of affirming or denying what is expressed by the predicate about the Subject" (Kuroda 1972: 154). On the other hand, a thetic judgement expresses a simple recognition of the existence of an actual situation without the cognitive act of recognition of the Subject. That is, while every sentence should necessarily have a syntactic subject, it may or may not have a Subject (with a capital S). And the sentences with a Subject express a categorical judgement, whereas those without a Subject express a thetic judgement.

Essentially, in Japanese, wa-marked subjects are recognized as Subjects, but ga-marked subjects are not. Therefore, sentences with wa-marked subjects are taken as expressing a categorical judgement, whereas sentences with wa-marked subjects are taken as expressing a thetic judgement.

Notice that Kuroda's Subject corresponds to a 'theme' or a 'topic' and that a categorical judgement with a Subject corresponds to a theme-rheme structure or a topic-comment structure, whereas a thetic judgement without a Subject lacks such a structure. Kuroda claims that a categorical judgement with the SubjectPredicate structure represents a Predication, whereas a thetic judgement without such a structure represents a (non-predicational) description.

Such a structural difference recognized with respect to $w a$-marked and $g a$ marked subjects suggests a structural hierarchy between the two. That is, the structural position of $w a$-marked subjects should be higher than that of $g a$-marked subjects.

\subsubsection{Syntactic positions of $w a$ - and $g a$-marked subjects}

Such a structural hierarchy between $w a$ - and $g a$-marked subjects has also been indicated by the syntactic positions in which they are claimed to appear (e.g., Tateishi 1991, Endo 1994). 
As I have discussed in 1.1.2. above, most syntactic investigations have separated $w a$-marked and $g a$-marked subjects as 'topics' and 'subjects' respectively and often applied independent analyses to each of them (e.g., Kuroda 1965, Kuroda 1988, Saito 1986, Fukui 1986, Kitagawa 1986, Tateishi 1991). ${ }^{15}$ 'Subjects', which are assumed to be necessarily marked by -ga, have been argued to occur inside VP. For Fukui (1986) and Kuroda (1988), 'subjects' are generated in [Spec, VP] and remain there at S-structure. For Kitagawa (1986), 'subjects' are generated in [Spec, IP] but interpreted as VP-internal arguments at LF (as a result of affix raising at LF). On the other hand, 'topics', which include wa-marked subjects, have been argued to occur outside and above VP, whether by movement (e.g., Fukui 1986 and Kuroda 1988) or by base generation (e.g., Kuno 1973, Saito 1986, Kuroda 1987), and whether in an adjoined position (e.g., Fukui 1986, Kuno 1973, Saito 1986, Kuroda 1987, 1988) or in a specifier position of CP, IP, etc. (e.g., Tateishi 1991).

Putting all these together, we get a syntactic configuration in which 'topics' (which are marked by $-w a$ ) are in a higher position than 'subjects' (which are marked by $-g a$ ), at a certain level of representation. Since we take both wamarked and ga-marked arguments as "subjects" as long as they are recognized as having the same argument role with respect to the predicate, we can interpret the above as that wa-marked subjects appear in a higher position than ga-marked subjects.

Endo (1994) argues more directly that $w a$-marked and ga-marked NPs appear in a VP-external and a VP-internal position respectively, to reflect the scopal difference between the two. Following Diesing's (1992) mapping hypothesis that the IP area of a clause (external to the VP) maps onto a restrictive clause and that the VP maps onto the nuclear scope, Endo explains that wamarked NPs receive a quantificational interpretation because they appear in a VP-

${ }^{15}$ Tateishi (1991) incorporates the syntax of 'topics' in that of 'subjects'. 
external position, whereas g $a$-marked NPs receive an existential reading because they appear in a VP-internal position, as shown in (23).

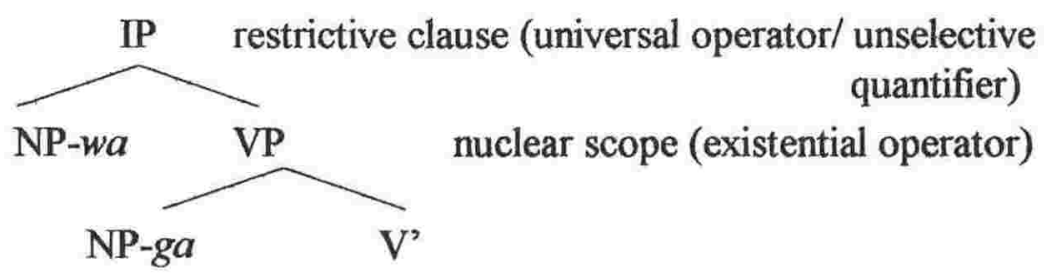

Note that Diesing's (1992) mapping hypothesis is originally used to represent the semantic difference between individual-level and stage-level predicates in syntactic terms (cf. Carlson 1977, Kratzer 1989). Just as Endo puts $w a$-marked and ga-marked NPs in a VP-external and a VP-internal position respectively, Diesing has put the subjects of individual-level predicates and those of stage-level predicates in those respective positions. Therefore, Endo's analysis points to a parallelism between $w a$-marked subjects and subjects of individuallevel predicates and that between $g a$-marked subjects and subjects of stage-level predicates. These parallelisms will be elucidated in this thesis.

Such a structural hierarchy between $w a$ - and $g a$-marked subjects is further supported by their compatibility and incompatibility with negation. Return to the $w a / g a$-pair of sentences in (1) above. The sentence (1a) with a wa-marked subject can be negated (without affecting the interpretation of the subject, i.e., the same topic interpretation), as shown in (24) below. ${ }^{16}$ On the other hand, (1b) with a gamarked subject cannot be negated without affecting the interpretation of the subject. As indicated by the hash on $-g a$ in (25b) below, with negation a $g a$ marked subject cannot yield the neutral interpretation and the focus interpretation is forced. In other words, while we can say John has just arrived (25a), it is not possible to say that 'John has just not arrived' (25b). ${ }^{17}$

\footnotetext{
${ }^{16} \mathrm{Ko}$ - in (24b) (and also in (25b) below) is a phonological variant of the verb 'to come'.

${ }^{17}$ It seems possible to say 'John has not just arrived', as opposed to 'John has just not arrived'. However, even the former does not yield the so-called 'hot news' perfect interpretation. Essentially, the 'hot news' perfect is not available with negation.
} 
(24)a. John-wa ki-ta.

John come-Past

'John came.'

b. John-wa ko-nakat-ta.

John come-Neg-Past

'John did not come.'

(25)a. John-ga ki-ta.

John come-Past

'John has just come/arrived.'

b. John-\#ga ko-nakat-ta.

John come-Neg-Past

'It is John who did not come.'

This contrast can be explained if we assume that Neg is situated between the position in which a $w a$-marked subject appears and the position in which a gamarked subject appears. ${ }^{18}$ In (24b) above, it is grammatical that the subject takes wide scope over negation, because it is $w a$-marked and therefore appears structurally higher than negation. On the other hand, in (25b) the subject cannot take wide scope over negation, because it is $g a$-marked and therefore appears structurally lower than negation. This will be taken up for detailed discussion in 4.3 .5 below.

${ }^{18}$ Note that Koizumi (1994) assumes the position of Neg between the position for nominative objects and that for accusative objects, as shown in (18) above, reproduced in (i) below.

(i) [AGRsP MS-ga [AGrsp SU-ga [TP OB-ga [NegP (or AP) [AGRoP OB-o [VP ...]I]]]] $(\mathrm{MS}=$ major subject, $\mathrm{SU}=($ regular $)$ subject, $\mathrm{OB}=$ object $)$

(Koizumi 1994: 223)

Although Koizumi's subject positions are all situated higher than Neg, in my view they do not include a position for $g a$-marked subjects which truly yield the neutral interpretation. In other words, I take both the AGRsP-adjoined position and [Spec, AGRsP] in Koizumi's analysis as equivalent to a position for $w a$-marked subjects in my analysis, and envisage another subject position exclusively for neutral ga-subjects somewhere below Neg. 


\subsubsection{Summary}

To sum up, the structural/scopal hierarchy between wa-marked and gamarked subjects has been indicated in both semantic and syntactic terms. It is collectively suggested that there are (at least) two positions for "subjects" in the phrase structure of Japanese, one for $w a$-marked subjects and the other for $g a$ marked subjects, and further that wa-marked subjects occupy a higher position than $g a$-marked subjects at least at the level which is responsible for scopal interpretation.

These observations will form the basis of my analysis. As well, they raise a question as to why and how subjects are realized in two distinct syntactic positions, i.e., what is the mechanism to put subjects in two distinct positions. In order to be able to answer this question, we also need to define what the exact positions for $w a$-marked and $g a$-marked subjects are in the phrase structure of Japanese.

\subsection{Summary and outlook}

In the preceding sections, I have drawn a couple of important insights into the problem of $w a / g a$-subjects from the range of previous work on the topic. The first insight was a possible interrelation between $w a / g a$-subjects and tense, which has been suggested in both semantic and syntactic terms. The second insight was a structural/scopal hierarchy between $w a$-marked and ga-marked subjects, which has also been suggested in both semantic and syntactic terms. While these insights lay the basis of my analysis and support the avenue I take, they also raise questions including the following:

(26) i. Why do $w a$-marked and ga-marked subjects exhibit distinct temporal properties? 
ii. What precisely are the syntactic positions for $w a$-marked and $g a$ marked subjects in the phrase structure of Japanese?

iii. Why and how are the subjects of clauses realized in two different positions? I.e., what determines the syntactic position in which the subject of a clause appears?

As a way of approaching these questions, I form a working hypothesis that $w a$ - and $g a$-marked subjects are associated with certain temporal properties in syntax, or with some subdivisions of Tense, as suggested by Chomsky (1995: 240), which are responsible for the distinct temporal interpretations they receive. In order to investigate the hypothesized subdivisions of Tense associated with waand $g a$-marked subjects, I carry out a fine-grained semantic analysis of the basic tense system in Japanese, especially in relation to wa- and ga-marking of subjects.

In examining tenses, we soon find that tenses are so closely related with aspects that the two are hardly separable, especially in the Japanese morphological system of tense and aspect. Accordingly, I take the inseparable tense/aspect system as the target of my investigation.

Needless to say, a considerable amount of research has been carried out on tense/aspect in Japanese. However, there is no general agreement about the basic tense/aspect system operating in Japanese. Traditional grammarians were interested in distinguishing two basic tenses, the non-past tense expressed by the affix $-r u$ and the past tense expressed by the affix $-t a$, and in identifying distinct functions and usages of each of them (e.g., Suzuki 1977). ${ }^{19}$ Some have argued that the two affixes, $-r u$ and $-t a$, are aspect formatives (rather than tense formatives) indicating incompletion and completion of an event or the imperfective and perfective aspects (e.g., Kunihiro 1967). In addition to -ru and ta, Kindaichi $(1950,1955)$ includes -teiru (and -teita) in his studies on tense and

${ }^{19}$ Okawa (1990) provides a summary of Suzuki (1977) and other previous studies on tense and/or aspect in Japanese. 
aspect in Japanese. ${ }^{20}$ Subsequently, Okuda (1976) and Suzuki (1988) contrast -ru and -teiru as aspect markers and $-r u$ and $-t a$ as tense markers.

While those studies on tense and aspect within the traditional kokugo-gaku linguistics focused on simple sentences, studies in the generative framework have been mainly concerned with the tense/aspect phenomena in subordinate clauses (e.g., Kuno 1973, Nakau 1976, Ogihara 1989, Nakamura 1994). Especially, they are interested in such phenomena as the so-called sequence of tense and doubleaccess reading, which exhibit interesting contrasts between Japanese and other languages like English. Although those studies on subordinate clauses make useful contributions to our understanding of the tense/aspect system in Japanese, it is a problem that the basic tense and aspect system operating in simple sentences has not been further investigated and has thus been left unsettled. There certainly is a need to return to simple sentences and establish the basis of the tense and aspect system in Japanese.

This thesis examines the tense/aspect interpretations in simple sentences in relation to $w a$ - and $g a$-markings of subjects. By so doing, it reveals that the Japanese tense/aspect system revolves around two types of evaluation time, two types of $\mathrm{R}$, or two types of viewpoint aspect, which correlate with $w a$ - and gamarkings of subjects.

It also shows that those affixes such as $-r u$ and $-t a$, which have been considered as either tense or aspect markers, are both tense and aspect markers, which carry inseparable tense/aspect meanings. Furthermore, those tense/aspect markers are used to express either tenses (such as past and future) or aspects (such as perfect and proximate future), due to the availability of two types of evaluation time, $\mathrm{R}$ or viewpoint aspect.

To investigate the three main questions raised in (26) above, this thesis develops in the organization as follows.

${ }^{20}$ In particular, Kindaichi's classification of verbs on the basis of the meanings of teiru-forms has been notable. 
Chapter 2 begins by distinguishing two types of evaluation time, referring to the traditional analysis of tense as a sentential operator (e.g., Prior 1967, Montague 1974). It shows that $w a$ - and $g a$-markings of subjects are correlated with the two types of evaluation time which are distinguished as 'original' and 'new'.

Compared with Reichenbach's (1947) three temporal primitives, S[peech time], E[vent time], and R[eference time], the two types of evaluation time correspond to two types of $\mathrm{R}$; one that coincides with $\mathrm{S}$ but not with $\mathrm{E}(\mathrm{R}=\mathrm{S} / \neq$ $\mathrm{E})$ and the other that coincides with $\mathrm{E}$ but not with $\mathrm{S}(\mathrm{R}=\mathrm{E} / \neq \mathrm{S})$.

I further argue that the two types of evaluation time, or $R$, are two types of viewpoint aspect operating in Japanese. The original evaluation time or $\mathbf{R}=\mathbf{S} / \neq$ E corresponds to a viewpoint aspect that focuses 'part' of a situation manifested at a precise temporal point $\left(\right.$ View $_{\text {part }}$ ), whereas a new evaluation time or $\mathrm{R}=\mathrm{E} / \neq$ $\mathrm{S}$ corresponds to one that focuses 'all' of a situation without decomposing it (Viewall).

Crucially, due to the availability of two types of evaluation time, two types of $\mathrm{R}$, or two types of viewpoint aspect signaled by wa- and ga-marking of subjects, the same predicate with the same tense/aspect marker can yield two distinct temporal and aspectual interpretations in correlation with $w a$ - and $g a$ marking of the subject. (For example, in (1) above, the predicate ki-ta 'comePast' translates as 'came' when the subject is marked with -wa in (1a) but as 'has just come/arrived' when the subject is marked with -ga in (1b).)

While Chapter 2 focuses on the role of tense in relation to the wa/gamarking of subjects in Japanese, Chapter 3 shifts the focus to aspect in order to get a balanced view as well as to provide a thorough analysis. Mainly, the aspect oriented analyses in Chapter 3 confirm the main findings from the tense oriented analyses in Chapter 2. That is, the same predicate with the same tense/aspect marker(s) can yield two distinct temporal and aspectual interpretations due to the availability of two types of evaluation time, $\mathrm{R}$, or viewpoint aspect, which are signalled by $w a$ - and $g a$-markings of subjects. At the same time, however, they 
also show that the nice contrast between $w a$ - and ga-sentences as observed in Chapter 2 does not always show up due to the other interacting factors.

I conclude that the temporal and aspectual interpretation is compositional of three different 'aspects', namely viewpoint (grammatical) aspect, situation type (lexical aspect), and S-E aspect, which are expressed at different parts of a sentence. The three-component analysis enables us to account for a variety of temporal and aspectual interpretations yielded by one and the same tense/aspect marker, assuming that those markers are not just homophonous but interacting with situation types and viewpoint aspects.

In order to provide syntactic mechanisms to account for the correlation between wa/ga-markings of 'subjects' and the two distinct types of tense/aspect interpretations, Chapter 4 investigates a syntactic interrelation between subject marking and tense, particularly following the findings from Chapter 2. I propose two subdivisions of Tense in line with Chomsky's (1995: 240) suggestion that Tense might have "further subdivisions and implications about event structure and perhaps other properties". I assume that the two subdivisions of Tense are functional categories, which $\mathrm{I}$ call $W$ and $E$, and which project $W \mathrm{P}$ and $E \mathrm{P}$, and make up an articulated tense structure (above VP). Crucially, $W$ and $E$ contain distinct semantic features responsible for the distinct tense/aspect interpretations correlated with $w a$ - and ga-markings of subjects in Japanese. Being tense categories, both $W$ and $E$ have T[ense]-features and $\mathrm{D}$ [eterminer]-features to be checked by predicates and subject DPs respectively. Due to the distinct semantic content of the two tense categories, depending on whose $\mathrm{T}$ - and $\mathrm{D}$-features predicates and subjects check, we get two distinct types of tense/aspect interpretations of predicates and two distinct types of subjects (which are morphologically distinguished by $w a$ - and ga-markings in Japanese). In this analysis, the T- and D-features of a tense category ensure that a subject and a predicate are necessarily of the same semantic type. The tense system I propose to account for the $w a / g a$-phenomena unifies tense and aspect to the extent that the phenomena are shown to be concerned with the notions of both tense and aspect. 
A notable consequence of my analysis is that the syntax and semantics of stage- and individual-level predicates fall under the syntax and semantics of tense. Compared with the previous analyses of Kratzer (1989) and Diesing (1992), while my analysis maintains the spirit of those previous analyses, it exhibits both empirical and theoretical advantages in terms of (i) the origin of the distinction: lexicon vs. syntax, (ii) the link between syntax and semantics, (iii) the level of representation, (iv) the "aboutness" relation, and (v) the stage/individual distinction within the tense structure.

The analysis also exhibits some interesting parallelisms to Davis' (1998), in which person features of subjects are related to a temporal structure. Comparing Davis' (1998) person split between $1 \& 2$ subjects and 3 subjects and the wa/gasplit of subjects in Japanese, I argue that the properties that really distinguish between the two classes of subjects associated with two temporal projections are the referential familiarity vs. novelty in the discourse and the totality vs. temporality of the referent in our perception, which are closely interrelated.

Moreover, although I argue for two subject positions within the articulated tense structure specially to account for the phenomena of wa/ga-subjects in Japanese, I demonstrate that the proposed two subject positions are tenable across languages, even where there is only a limited distinction of two kinds of subjects, as observed in English. In addition, the proposed analysis has an interesting implication for the first language acquisition.

Lastly, Chapter 5 examines how the analysis proposed in Chapter 4 can be applied in subordinate clauses, especially because $w a$ - and $g a$-markings of subjects differ in matrix and subordinate clauses. It investigates some of the clearly distinct types of subordinate clauses, with special attention to factors such as factivity and the distinctions among propositions, states of affairs, and situation-types. Unique properties to subordinate clauses are identified and they are designated in terms of the specifications of $W$ and $E$. A possible account for the mysterious ga-marking of subjects in some subordinate clauses (e.g., Kuno 1973, Kuroda 1987, Shirai 1986 ) is provided. Importantly, although there are some peculiarities to 
subordinate clauses, basically the same mechanisms operate in the same functional structure in both main and subordinate clauses. That is, $w a$ - and $g a$-markings of subjects are associated with the semantic properties of the functional heads $W$ and $E$ in subordinate clauses as well.

Chapter 6 provides a summary of the thesis and some indications for future research. 


\section{Chapter 2}

\section{Two types of evaluation time, $R$, and viewpoint aspect}

In 1.2.1. in the previous chapter, I introduced the observation by Maynard (1987) and Kuroda (1992b) that wa- and ga-markings of subjects are correlated with distinct temporal interpretations given to subject NPs. Extending on this observation, in this Chapter I argue for a correlation between wa/ga-marking of subjects and distinct tense/aspect interpretations of clauses. In order to pin down the two types of tense/aspect interpretations correlated with $w a$-and $g a$-marked subjects, I employ the notions of evaluation time derived from Prior (1967) and Montague (1974), R[eference time] of Reichenbach (1947), and viewpoint aspect of Smith (1991).

Section 2.1 distinguishes two types of evaluation time as the 'original' evaluation time $t$ and a 'new' evaluation time $t^{\prime}$ and shows that ga-marking of subjects correlates with $t$, whereas wa-marking of subjects correlates with $t^{\prime}$. An important difference between the two types of evaluation time is that while the original evaluation time $t$ refers to a precise temporal point, a new evaluation time $t^{\prime}$ refers to a more loosely defined time.

To further identify the properties of $t$ and $t^{\prime}$, Section 2.2 compares them with Reichenbach's (1947) three temporal primitives, S[peech time], E[vent time], and R[eference time]. Both corresponding to Reichenbach's R, the two types of evaluation time, $t$ and $t^{\prime}$, divide $\mathrm{R}$ into two types. The original evaluation time $t$ corresponds to an $R$ that coincides with $S(R=S)$ but not with $E(R \neq E)$, whereas a new evaluation time $t^{\prime}$ corresponds to an $\mathrm{R}$ that coincides with $\mathrm{E}(\mathrm{R}=\mathrm{E})$ but not with $\mathrm{S}(\mathrm{R} \neq \mathrm{S})$. Accordingly, ga-marking of subjects is correlated with $\mathrm{R}=\mathrm{S} / \neq \mathrm{E}$, and $w a$-marking of subjects is correlated with $\mathrm{R}=\mathrm{E} / \neq \mathrm{S}$. Crucially, due to the two types of evaluation time or the two types of $\mathrm{R}$, wa/ga-minimal pairs of sentences (with the same tense/aspect markers) receive distinct temporal and aspectual interpretations.

Following the discussion of the two types of $\mathrm{R}$, Section 2.3 argues that $\mathrm{R}$ aligned with either $\mathrm{S}$ or $\mathrm{E}$ is a viewpoint aspect, which presents 'part' or 'all' of a situation. An R aligned with S operates as a viewpoint aspect which presents 'part' of 
a situation manifested at a precise temporal point, i.e., View part. On the other hand, an $\mathrm{R}$ aligned with $\mathrm{E}$ operates as a viewpoint aspect which presents 'all' of a situation without decomposing it, i.e., View all. View all and View part are comparable with the socalled perfective and imperfective aspects in that they distinguish between all and part in the domain of situations. However, while perfective and imperfective are generally considered as being expressed by verbal morphology, Viewall and View part as they operate in Japanese are signalled by subject marking morphemes, $-w a$ and $-g a$, respectively.

Lastly, Section 2.4 briefly discusses that $w a$-and ga-markings to designate the part-whole distinction of subjects in Japanese correspond in part to the use of the articles, the and $a(n)$, in English.

\subsection{Two types of evaluation time}

\subsection{1. 'Original' versus 'new' evaluation time}

In the traditional analysis of tense as a sentential operator, as in Prior (1967) and Montague (1974) among others, the interpretation of a sentence with past tense, for example, is accounted for by the rule (1).

(1) The interpretation of a past tense sentence:

Where $\varphi$ is a sentence [and PAST is the past operator], PAST $\varphi$ is true at time $t$ iff there is a time $t^{\prime}$ such that $t^{\prime}<t$ and $\varphi$ is true at $t^{\prime}$.

( $<$ ' indicates that what is on the left-hand side of the symbol temporally precedes what is on the right-hand side of it.)

(adapted from Enç 1987: 633)

According to (1), a past tense sentence, say John ate an apple, is true at the utterance time $t$ iff there exists a time, $t^{\prime}$, prior to $t$, such that John eats an apple is true at $t^{\prime}$.

Enç (1987: 633) notes the following properties of such treatments:

(a) Tense is a sentential operator, 
(b) Tense manipulates the times in the metalanguage, that is, the temporal indices of the model in model-theoretic treatments,

(c) The interpretation of tense involves an existential quantifier over times,

(d) Tense introduces a new time,

(e) This new time stands in a certain relation (determined by the tense) to the original evaluation time,

(f) The new time becomes the evaluation time, and

(g) The original evaluation time is lost.

Among these, I am particularly interested in the properties in (d)-(g), which suggest that there are two types of evaluation time. The utterance time $t$ is said to be the 'original' evaluation time, probably because it naturally comes into being every time something is uttered and it is most natural that the truth of an utterance is dependent on the time of utterance. On the other hand, another time $t^{\prime}$ is specially introduced by tense to take over the power of utterance time $t$ as evaluation time and make a 'new' evaluation time.

In the above example, John ate an apple, the truth of the sentence is evaluated at the utterance time $t$, but the event described in the sentence is verified at another time $t^{\prime}$, which is introduced by tense and temporally located prior to $t$. In other words, the truth of the sentence at $t$ depends on the verification of the described event at $t$ '. The term 'evaluation time' refers to such a time at which the event being spoken of is verified, rather than the time at which the truth of a sentence is evaluated.

However, it is not always the case that an event is verified at $t^{\prime}$ distinct from the utterance time $t$. Consider a sentence like John is eating an apple (right now). The sentence is true at $t$ if the event described in the sentence, i.e., John's eating an apple, is verified at $t$. In such a case, there is no need at all for another time $t^{\prime}$ to be introduced. Thus, for some sentences, the utterance time $t$ alone is sufficient for the temporal interpretation, while for other sentences, another time $t^{\prime}$ needs to be introduced.

Interestingly enough, wa- and $g a$-markings of subjects in Japanese correlate with these two cases, i.e., the cases in which the original evaluation time $t$ alone is sufficient for the temporal interpretation and the cases in which another time $t^{\prime}$ makes 
a new evaluation time. When the subject is marked with $-w a$, the truth of a sentence is dependent on a new evaluation time $t^{\prime}$, which stands in a certain relation (determined by the tense) to the original evaluation time $t$, in the sense that the event described in the sentence must be verified at $t^{\prime}$. On the other hand, when the subject is marked with - $g a$, the truth of a sentence is solely dependent on the original evaluation time $t$ without recourse to another time $t^{\prime}$.

Compare the interpretations given to (2a) and (2b) below.

(2) a. John-wa ki-ta.

John come-Past

'John came.'

b. John-ga ki-ta.

John come-Past

'John has just come/arrived.'

The sentence (2a) with a wa-marked subject is interpreted as asserting that the event of John's coming took place at a certain time in the past. ${ }^{1}$ That is, the truth of (2a) is taken as relative to a time which is located prior to the time of utterance. On the other hand, (2b) with a $g a$-marked subject is interpreted as describing a present situation in which John has just arrived (and John is here right now). ${ }^{2}$ Although John's arrival must have taken place before the moment of utterance, the event is perceived and described as having just been completed from the perspective of the utterance time. ${ }^{3}$ In this sense, the truth of (2b) is directly dependent on the utterance time. This suggests that (2b) with a $g a$-marked subject is a case in which the utterance time $t$ alone is sufficient for the temporal interpretation, while (2a) with a

\footnotetext{
${ }^{1}$ For the speakers of Japanese, to uniquely get the neutral interpretation of the wa-marked subject (rather than the contrastive interpretation), imagine that (2a) is uttered as an answer to a question, e.g., Did John come to the party?

${ }^{2}$ For the speakers of Japanese, to uniquely get the neutral interpretation of the ga-marked subject (rather than the focus interpretation), put an interjection such as oya 'oh, look' before the sentence (2b).

${ }^{3}$ Because the event described with the present perfect must have taken place before the moment of utterance, in the Priorean analysis of tense as a sentential operator, the interpretation of the present perfect is accounted for by the same rule which accounts for the simple past tense, as in (1) above. This point will soon be discussed in the following.
} 
$w a$-marked subject is a case in which another time $t^{\prime}$, which is located prior to $t$, is required for the temporal interpretation. ${ }^{4}$

Note the use of the present perfect in the English translation of (2b). While the English present perfect has a few (or several) distinct interpretations (the number depends on analyses), the present perfect in (2b) contrasted to the simple past in (2a) is necessarily of the type with the 'just' reading. I use the term 'hot news', due to McCawley (1971), to refer to this particular interpretation of the English present perfect. ${ }^{5,6}$

It has been noted (e.g., Dowty 1979, Blackburn 1994: 89) that the distinction between the simple past and the present perfect has not been captured in standard tense logic or the Priorean analysis of tense as a sentential operator. That is, the interpretation of the present perfect is presumably accounted for by the same rule that accounts for the simple past tense, as in (1) above. This is a problem if we are to account for linguistic phenomena rather than the "physical" locations of events in

\footnotetext{
${ }^{4}$ However, if a time adverb such as kinoo 'yesterday' or san-ji ni 'at three o'clock' occurs with (2b), (2b) is not interpreted as describing a present situation but clearly a past situation. In such cases, a past situation is described in a 'flashback', as though we are back at that particular spatiotemporal location in the past. Therefore, although the truth of the sentence is not dependent on the 'real' present moment or the utterance time, it is dependent on a 'pseudo-present'. I take a view that $t$ refers to a time recognized as the present in the discourse, which is typically the utterance time but can be other temporal moments (see 2.2.3.1 below).
}

${ }^{5}$ It seems that the 'hot news' interpretation is often overlooked in the discussion of present perfect due to its similarity to the resultative interpretation (see Smith 1991, Brugger 1997a). However, the former is to be distinguished from the latter. Compare the sentences in (i) below.

(i) a. John has (already) come/arrived. <resultative>
b. John has (just) come/arrived.
$<$ 'hot news'>

A difference between the resultative interpretation (ia) and the 'hot news' interpretation (ib) is that in the former the property of having arrived is ascribed to the subject John, whereas in the latter having arrived is not taken as a property ascribed to John but simply as a present state of affairs (of which John is an argument).

Crucially, the resultative perfect is translated into Japanese with a wa-marked subject, whereas the 'hot news' perfect is translated with a ga-marked subject, as shown in (ii) below.

(ii) a. John-wa moo ki-ta.

already come-Past

'John has already come/arrived.'

b. John-ga ki-ta.

come-Past

'John has (just)come/arrived.'

${ }^{6}$ This suggests that -ta is not simply a marker for past tense. I will discuss this point later in 3.1. 
temporal "reality". In other words, as "real" objects, both events described in the simple past and in the present perfect must be located at a certain time in the past. However, as a grammatical object, an event described in the present perfect is not located at a certain past time as an event described in the simple past is. While the existence of a certain past time $t^{\prime}$, at which the described event takes place, is an essential and a central part of the interpretation of the simple past tense, it is rather an implicature in the interpretation of the present perfect. In the simple past, an event is located at a past time $t^{\prime}$ away from $t$. To interpret the simple past, we cognitively go back to a particular time in the past. In the sense that the described event is to be verified at $t^{\prime}$, the truth of the simple past is dependent on $t^{\prime}$. By contrast, the interpretation of the present perfect does not require our going back to a particular time in the past. Even though the event must have taken place before the moment of utterance, described with the present perfect, it is not located at a past time $t^{\prime}$. Rather, an event described with the present perfect pivots on the utterance time $t$. The present perfect essentially expresses the completed state of an event manifested at the moment of utterance $t$. In the sense that the asserted completion of an event is to be verified at $t$, the truth of the present perfect is dependent on $t$. According to this view, the simple past and the present perfect are distinguished by the two types of evaluation time, $t$ and $t^{\prime}$, on which the truth of a sentence is dependent. ${ }^{7}$

Let us examine a couple more $w a / g a$-pairs of sentences. The examples in (3) below have $-r u$ instead of $-t a$ in (2) above. The sentence (3a) with a wa-marked subject receives a future reading that John will come sometime in the future. On the other hand, (3b) with a $g a$-marked subject is interpreted as describing a present situation in which John is visibly coming to the place of utterance at the time of utterance. ${ }^{8}$ Thus, the truth of (3b) with a $g a$-marked subject is dependent on the utterance time $t$, while the truth of (3a) with a $w a$-marked subject is dependent on another time $t^{\prime}$ (which is after $t$ ).

\footnotetext{
${ }^{7}$ At this stage, the notion of evaluation time is roughly assumed to refer to the time at which the truth of a sentence is verified, evaluated, or dependent. As my analysis develops, it becomes possible to redefine it as the time at which the portion of an event (i.e., part or whole of an event) is asserted to exist (cf. 2.3 below). (I am indebted to an examiner for pointing this out for me.)

${ }^{8} \mathrm{Ki}$ - in (2) and $k u$ - in (3) are phonological variants of the verb 'to come'.
} 
(3) a. John-wa ku-ru.

John come-Pres

'John will come.'

b. John-ga ku-ru.

John come-Pres

'John is coming. (Here comes John.)'

The same contrast is observed even when the predicate is in the -teiru present progressive form, as in (4) below. ${ }^{9}$ Both (4a) and (4b) express a present ongoing situation of John's writing a book. However, while (4b), whose subject is marked with $-g a$, can only be uttered on the spot where the speaker perceives the actual situation in which John is writing a book, (4a), whose subject is marked with -wa, can be uttered even when John is not actually writing at the time of speech. For example, (4a) can be uttered in a speech situation where you are introducing John, who is standing next to you (and hence not writing a book), as in "This is John. John is writing a book". This suggests that (4a) does not have to mean that John is actually writing a book at the moment when the sentence is uttered (though it can well be uttered when John is actually writing too), while (4b) strictly conveys that there is an actual situation in which John writes a book in progress right in front of the speaker at the moment of speech.

(4)
a. John-wahon-o kai-tei-ru.
book-Acc write-Prog-Pres
'John is writing a book.'
b. John-ga hon-o kai-tei-ru. book-Acc write-Prog-Pres
'John is writing a book (right in front of us).'

\footnotetext{
${ }^{9}$-Teiru is a complex affix, which as a whole is taken as the so-called progressive form. The exact make up of -teiru is controversial. It can be analyzed as the connective -te + the present progressive $-i r u$, the connective $-t e+$ the progressive $-i+$ the present tense $-r u$, or the progressive $-t e i+$ the present tense $-r u$. On the basis that we also have -teita for the past progressive as opposed to -teiru for the present progressive, I gloss $-t e i$ as progressive and $-r u$ and $-t a$ as present and past respectively (without committing to such a morphological analysis). In my discussions, however, I treat the whole string of morphemes, -teiru/ta, on a par with a single morpheme such as -ta and -ru, as they behave similarly in my analysis.
} 
This contrast between (4a) and (4b) can be illustrated by the range of temporal adverbials which can or cannot cooccur with each sentence. Adverbials such as saikin 'these days' and itsumo 'always' are compatible with (4a) but not with (4b), as shown in (5) below. (The hash on -ga in (5b) indicates that the addition of one of these adverbials to ( $4 \mathrm{~b}$ ) forces the focus interpretation of the ga-marked subject. ${ }^{10}$ )
(5) a. Saikin/itsumo
John-wa
hon-o
kai-tei-ru. these days/always
book-Acc write-Pres-Prog
'John is writing a book these days./John is always writing a book.'
b. Saikin/itsumo these days/always

$$
\begin{array}{lll}
\text { John-\#ga } & \begin{array}{l}
\text { hon-o } \\
\text { book-Acc }
\end{array} & \begin{array}{l}
\text { kai-tei-ru. } \\
\text { write-Prog-Pres }
\end{array}
\end{array}
$$

The compatibility of (4a) with saikin 'these days' or itsumo 'always' makes it clear that (4a) does not convey that John is actually writing a book at the moment when it is uttered. Thus, while the truth of (4b) with a $g a$-marked subject is totally dependent on the utterance time $t$, that of (4a) with a wa-marked subject is not strictly dependent on $t$ but rather dependent on another time $t^{\prime}$, which embraces $t$ in it.

Note that both (4a) and (4b) can take ima 'now', as shown in (6) below, and that with ima 'now' both have to mean that John is now writing.
(6) a. Ima John-wahon-o kai-tei-ru. now book-Acc write-Prog-Pres
'John is writing a book now.'
b. Ima John-ga hon-o kai-tei-ru. now book-Acc write-Prog-Pres 'John is writing a book now.'

Nevertheless, we can still observe the same contrast between (6a) and (6b). The sentence (6a) will hold true even if John is sipping his coffee in the middle of writing at the time when the sentence is uttered, whereas (6b) will be evaluated as false if it is uttered when John is sipping his coffee in the middle of writing. In other words, while (6b) strictly requires that John be actually writing at the moment of utterance for the sentence to be true, the truth of (6a) is evaluated more loosely at a loosely defined

\footnotetext{
${ }^{10}$ With the focus interpretation of the $g a$-marked subject, $(5 b)$ gives an interpretation that it is John who is writing a book these days/it is John who is always writing a book.
} 
present time which includes the utterance time. (The word ima 'now' itself is interpreted in two ways. It is taken as referring to a precise temporal point of the present which corresponds to the moment of utterance in (6b) and to a loosely defined present time which includes the utterance time in (6a).) Thus, while the truth of (6b) is totally dependent on the utterance time $t$, that of $(6 a)$ is rather dependent on another time $t^{\prime}$, which is a loosely defined present time embracing the utterance time $t^{11}$

Thus, $g a$ - and wa-markings of subjects constantly correlate with the two types of evaluation time, $t$ and $t^{\prime}$, respectively. When the subject is marked with -ga, the truth of a sentence is dependent on the utterance time $t$. When the subject is marked with - wa, the truth of a sentence is dependent on another time $t^{\prime}$.

\subsubsection{A contrast in spatiotemporal boundedness}

The subtle but sound contrast observed between the interpretations of (6a) and (6b) above indicates that, while a sentence with a ga-marked subject is interpreted as being strictly bounded at a particular spatiotemporal location, a sentence with a wamarked subject is interpreted more loosely. In this subsection, I show that the original evaluation time $t$, which a sentence with a $g a$-marked subject is dependent on, refers to a well defined point in time, whereas a new evaluation time $t^{\prime}$, which a sentence with a $w a$-marked subject is dependent on, does not single out a precise temporal point but rather refers to a more loosely defined time. ${ }^{12,13}$

Now, imagine a situation in which John is standing over there. If you know that John has been standing over there for some time and still see him standing over there,

\footnotetext{
${ }^{11}$ Although I omit the discussion of the past progressive-teita, it also exhibits the contrast between $t$ and $t^{\prime}$ with $w a$ - and $g a$-marking of the subjects if we take a view that $t$ refers to a time recognized as the present in the discourse, which is typically the utterance time but can be other temporal moments (see 2.2.3.1 below).
}

${ }^{12}$ The point-like quality of $t$ and the looseness of $t$ ' may be expressed by saying that $t$ is a point in time, whereas $t$ ' is a time interval. However, even a well defined point like the moment of utterance can also be conceived as having an interval (or a duration). Therefore, I rather do not rely on these terms to distinguish the characteristics of $t$ and $t^{\prime}$.

${ }^{13}$ Note that a $t$ referring to a punctual temporal point and a clause's being dependent on $t$ do not entail that the event described in the clause is punctual (as opposed to durative or ongoing). For example, a clause describing a durative event as progressing is dependent on a punctual temporal point $t$, in the sense that the event is perceived and described as progressing from the perspective of a punctual temporal point. 
you will say (7a), in which the subject John is marked with -wa. But if you have just noticed for the first time that John is standing over there, you will say (7b), in which the subject John is marked with -ga.

(7) a. John-wa asoko ni tat-tei-ru.

there at stand-Prog-Pres

'John is standing over there.'

b. John-ga asoko ni tat-tei-ru.

there at stand-Prog-Pres

'John is standing over there.'

This suggests that (7a) with a wa-marked subject implies a duration of the described situation, whereas (7b) with a ga-marked subject describes the situation more transiently. In other words, the situation described in ( $7 \mathrm{~b})$ is spatiotemporally bounded at the time and place of utterance, whereas that in (7a) is not.

This contrast in spatiotemporal boundedness is in fact constantly observed between $w a$ - and $g a$-sentences, irrespective of the tense/aspect markers attached to the predicates. Let us return to the examples (2) and (3) above, which have the $t a$ form and the $r u$-form of a verb. The examples are repeated in (8) and (9) below.

(8) a. John-waki-ta.

John come-Past

'John came.'

b. John-ga ki-ta.

John come-Past

'John has just come. (Here comes John.)'

In (8a) with a wa-marked subject, whose truth is dependent on another time $t^{\prime}$, the event of John's coming described in the sentence is interpreted as having taken place at a certain time in the past. The focus of the sentence is that the event did take place sometime in the past, and the exact time of the event is rather irrelevant. That is to say, the temporal interpretation of (8a) is not dependent on a precise temporal point in the past (e.g., when the clock struck one yesterday), but rather on a more 
loosely defined past time (e.g., sometime yesterday). ${ }^{14}$ This suggests that $t^{\prime}$ does not refer to a precise temporal point but rather to a loosely defined time.

On the other hand, (8b) with a $g a$-marked subject, which is dependent on the utterance time $t$, is interpreted as describing a present situation in which John has just arrived. It tells us that here we have got a completed event (of John's coming) right in front of us (and therefore John is here). In other words, it describes the event of John's coming as having been just completed. To perceive and describe an event as having been just completed, we need to stand at a specific point of reference such as the precise temporal point of speech. The completion of an event described in (8b) is thus spatiotemporally bounded at the time and place of utterance.

A similar contrast is observed with $-r u$ in (9).

(9) a. John-wa ku-ru.

John come-Pres

'John will come.'

b. John-ga ku-ru.

John come-Pres

'John is coming (on his way).'

The $w a$-sentence (9a), whose truth is dependent on $t^{\prime}$, asserts that the event of John's coming will take place sometime in the future. Just like (8a), which is concerned with the occurrence of an event sometime in the past, (9a) is concerned with the occurrence of an event sometime in the future, and the exact time of the event is rather irrelevant. The temporal interpretation of $(9 a)$ is not dependent on a precise temporal point in the future (e.g., when I sneeze in my office tomorrow), but rather on a more loosely defined future time (e.g., sometime tomorrow). ${ }^{15}$

On the other hand, the $g a$-sentence $(9 \mathrm{~b})$, which is dependent on $t$, is interpreted as describing a present situation in which John's coming or John's arrival is about to take place. In the sense that the event is perceived and described as being on the

\footnotetext{
${ }^{14}$ Note that even when a sentence as a whole is dependent on $t^{\prime}$ which does not refer to a precise temporal point, it is possible to include a temporal adverbial such as 'at one o'clock' which refers to a precise temporal point. However, such a point adverbial does not have scope over $t$ ', on which a sentence is dependent. In other words, the evaluation time $t^{\prime}$ is outside the scope of a point adverbial. I will illustrate this point later in this subsection.

${ }^{15}$ See footnote 14 above.
} 
verge of happening at the moment of speech, the situation described in $(9 \mathrm{~b})$ is spatiotemporally bounded at the time and place of utterance.

Thus, sentences with wa-marked subjects are taken as spatiotemporally loose or unbounded, whereas sentences with ga-marked subjects are taken as spatiotemporally bounded. This is because sentences with wa-marked subjects are dependent on $t^{\prime}$, which refers to a loosely defined time, whereas sentences with $g a$ marked subjects are dependent on $t$, which strictly refers to a punctual temporal point.

Since $t$ refers to a precise temporal point, a point adverbial is expected to be compatible with sentences which are dependent on $t$. On the other hand, since $t^{\prime}$ refers to a loosely defined time, a point adverbial is not expected to be compatible with sentences which are dependent on $t^{\prime}$. However, a point adverbial, for example, $i c h i$-ji juugo-hun $n i$ 'at one fifteen', can occur not only in a sentence dependent on $t$ but also in a sentence dependent on $t^{\prime}{ }^{16}$

(10)a. John-wa ichi-ji juugo-hun ni ki-ta.
one o'clock fifteen-min. at come-Past 'John came at $1: 15$.'

b. Ichi-ji juugo-hun ni John-ga ki-ta. one o'clock fifteen-min. at come-Past 'At 1:15, John has just arrived.'

Notice, however, that it is more natural to put ichi-ji juugo-hun ni 'at one fifteen' after the wa-marked subject (rather than before that) in (10a), whereas in (10b) it has to be inserted before the ga-marked subject to get the neutral interpretation. ${ }^{17}$ (If inserted after the ga-marked subject, the ga-marked subject is interpreted as being in focus.) As this suggests (if the scopal relation is mirrored in the syntax), (10a) yields a reading such that as for John, it is the case that he

${ }^{16}$ The use of the present perfect in the English translation in (10b) is ungrammatical in standard English but acceptable in some varieties of English, including recent Australian English as shown by Engel \& Ritz 2000. I choose the present perfect rather than the simple past in translating (10b) because the sentence has the 'hot news' reading. Note also that (10b) is a case in which the evaluation time $t$ refers to a 'pseudo-present' rather than to the 'real' present moment or the utterance time (see 2.2.3.1 below).

${ }^{17}$ These positions of point adverbials with respect to $w a$ - and $g a$-marked subjects will be discussed in 4.3 .5 below in relation to the negation effects which I have mentioned in 1.3.2 above. 
came/arrived at $1: 15$, whereas $(10 \mathrm{~b})$ yields a reading such that at $1: 15$ it was the case that John has just come/arrived. That is, a point adverbial takes wide scope over a $g a$-marked subject, but a $w a$-marked subject is outside its scope.

This scopal difference can be explained by such notions as event time modification and reference time modification in Brugger's (1997b) terms. In (10b) above, with a $g a$-marked subject and dependent on $t$, the point adverbial modifies $t$, which is the evaluation time for the sentence in my terms but the reference time in Brugger's terms. With a point adverbial modifying the evaluation (reference) time, we get a reading such that at 1:15 it was the case that John has just come/arrived. On the other hand, in (10a) above, with a wa-marked subject and dependent on $t^{\prime}$, the point adverbial modifies the time of the situation described by the predicate, i.e., the event time. In this case, the evaluation time $t^{\prime}$ is outside its scope. Therefore, we get a reading such that as for John, it is the case that he came/arrived at 1:15. Thus, the scope of a point adverbial seems to differ, depending on whether the sentence is dependent on $t$ or $t^{\prime}$.

Just as a point adverbial can occur not only in a sentence dependent on $t$ but also in a sentence dependent on $t^{\prime}$ (though without modifying $t^{\prime}$ ), a non-point adverbial can occur not only in a clause dependent on $t^{\prime}$ but also in a clause dependent on $t$. For example, kinoo 'yesterday' can occur in sentences with either a $w a$ - or a $g a$-marked subject, as seen in (11) below. However, while kinoo 'yesterday' modifies the evaluation time $t^{\prime}$ for (11a), it does not directly modify the evaluation time $t$ for (11b), though $t$ is under the scope of kinoo 'yesterday'. Therefore, (11a) is interpreted as asserting that the event of John's eating ice cream took place yesterday. On the other hand, (11b) is interpreted as describing or reporting an actual situation in which John eats ice cream, that occurred at a certain time yesterday, in retrospect, i.e., a "flashback". ${ }^{18}$

(11)a. Kinoo John-wa aisukuriimu-o tabe-ta.
yesterday ice cream-Acc eat-Past
'John ate ice cream yesterday.'

${ }^{18}$ The example (11b) is a case in which the evaluation time $t$ refers to a 'pseudo-present' (see 2.2.3.1 below). 
b. Kinoo John-ga aisukuriimu-o tabe-ta. yesterday ice cream-Acc eat-Past 'John ate ice cream yesterday.'

Thus, although $t$ refers to a punctual temporal point and $t^{\prime}$ refers to a loosely defined time, whether a sentence is dependent on $t$ or $t^{\prime}$ does not restrict the type of temporal adverbials. Both point and non-point adverbials can occur in sentences dependent either on $t$ or $t^{\prime}$. Crucially, however, the occurrence of a point or a nonpoint adverbial does not affect the temporal interpretation of a sentence, in the sense that a sentence dependent on $t$ (i.e., a sentence with a ga-marked subject) is necessarily interpreted as being bounded at a punctual spatiotemporal location, whereas a sentence dependent on $t^{\prime}$ (i.e., a sentence with a $w a$-marked subject) is necessarily taken as spatiotemporally loose or unbounded.

\subsubsection{Summary}

To sum up this section, there are two types of evaluation time, the utterance time $t$ and another time $t^{\prime}$, which are distinguished as the original and a new evaluation time respectively. A sentence with a ga-marked subject is necessarily dependent on $t$, while a sentence with a $w a$-marked subject is necessarily dependent on $t^{\prime}$. An important difference between the two types of evaluation time is that while the original evaluation time $t$ refers to a punctual temporal point, a new evaluation time $t^{\prime}$ refers to a more loosely defined time.

\subsection{Two types of $R$}

To further identify the properties of $t$ and $t^{\prime}$, in this section, I compare them with Reichenbach's (1947) three temporal primitives, S, E, and R.

\subsubsection{Reichenbach's (1947) S, E, and R}

Within the Reichenbachian framework, a tense is represented as a complex of three temporal entities (or 'times'), temporally ordered with respect to one another (whether one precedes, follows, or coincides with the other(s)). The first, denoted by $\mathrm{S}$, refers deictically to the utterance time and is, therefore, called "speech time". The 
second, $\mathrm{E}$ denotes the time of the event instantiated by the predicate of the clause and is, therefore, called "event time". The third, R stands for "reference time" and serves as a 'point of view' (particularly for perfect tenses). The basic English tenses, for example, are given the following representations in (12), where a line between two points signifies that the leftmost point is interpreted as temporally earlier than the other and a comma signifies that two points are contemporaneous (Hornstein 1990). ${ }^{19}$

$\begin{array}{llll}\text { present } & \text { S,R,E } & \text { present perfect } & \text { E_S,R } \\ \text { past } & \text { E,R_S } & \text { past perfect } & \text { E_R_S } \\ \text { future } & \text { S_R,E } & \text { future perfect } & \text { S_E_R }\end{array}$

(Hornstein 1990: 15, based on Reichenbach 1947: 290)

The question is how the two types of evaluation time, $t$ and $t^{\prime}$, correspond to these temporal primitives, $\mathrm{S}, \mathrm{E}$, and $\mathrm{R}$. In the following, I define the properties of $t$ and $t^{\prime}$ in terms of Reichenbach's $\mathrm{S}, \mathrm{E}$, and $\mathrm{R}$.

\subsection{2. $t$ and $t^{\prime}=\mathbf{R}$}

Firstly, both $t$ and $t^{\prime}$ correspond to $\mathrm{R}$. That is, what I have been calling evaluation time is essentially the same as what Reichenbach calls reference time (R).

Let me begin by reviewing the origin of $\mathrm{R}$. Reichenbach introduces $\mathrm{R}$, showing that $\mathrm{R}$ is required to account satisfactorily for the semantics of perfect tenses. For example, consider the sentence He had left in (13a) below. In interpreting the sentence, we necessarily recognize the existence of a reference point, apart from the time of speech (S), with respect to which the time of the event of John's leaving (E) is located. The time of the event $(\mathrm{E})$ is interpreted as being prior to this time, which is interpreted as being prior to the time of speech (S). That is, there is a time mediating between $\mathrm{S}$ and E, which serves as "a point of view". Reichenbach calls this point-ofview time $\mathrm{R}$ or reference time. With $\mathrm{S}, \mathrm{E}$ and $\mathrm{R}$, the temporal interpretation of (13a)

\footnotetext{
${ }^{19}$ There are actually 13 possible distinct combinations of S, E and R, of which 6 are represented in (12).
} 
is represented as in (13b) below. Thus, $\mathrm{R}$ was originally invented for the semantics of perfect tenses, which necessarily involve the notion of "point of view".

(13) a. John had left.
b. E R S

(Giorgi and Pianesi 1991: 190, based on Reichenbach 1947: 290)

However, Reichenbach considered $\mathrm{R}$ as a formal device which must be always instantiated, even when it did not appear to be immediately connected to a semantic interpretation. For example, the temporal interpretation of John will leave (tomorrow) in (14a) does not involve the notion of "point of view". The tense in this sentence simply tells us that the time of the event of John's leaving is after the time of utterance. However, its representation still involves R, as seen in (14b).

(14) a. John will leave (tomorrow).

b. $\mathrm{S}-\mathrm{R}, \mathrm{E}$

(tomorrow)

(Giorgi and Pianesi 1991: 190, based on Reichenbach 1947: 290)

In such a case, $\mathrm{R}$ is simply stuck together with $\mathrm{E}{ }^{20}$ With a time adverbial, say tomorrow, $\mathrm{R}$ is taken as the time specified by the time adverb, and the event of John's leaving is interpreted to take place at that time. Therefore, $\mathrm{R}$ and $\mathrm{E}$ coincide, and $\mathrm{S}$ precedes the bundle of $\mathrm{R}$ and $\mathrm{E}$. (Even without an overt time adverbial, the temporal interpretation of John will leave is represented with R exactly like (14b) above.)

Thus, while $\mathrm{R}$ in (13b) above has its own place and a clear function as a point of view, $\mathrm{R}$ in (14b) appears rather unessential. Crucially, however, those two R's have a common function, that is, they both designate the time on which the truth of a clause is dependent, i.e., the evaluation time at which the event being talked about is to be verified. In (13) above, the truth of John had left is dependent on the time

${ }^{20}$ Note that Reichenbach's (1947: 290) original representation for the simple future has R attached to $S$ (rather than to E), as shown in (i).

(i) $\mathrm{S}, \mathrm{R} \_\mathrm{E}$ 
indicated by $\mathrm{R}$, in the sense that the completion of the event of John's leaving described in the clause is to be verified at the time indicated by $\mathbf{R}$ (which is located prior to the time of speech). In (14) above, the truth of he will leave is dependent on a certain time in the future, which may be overtly specified by a time adverb such as tomorrow. This future time, at which the event of John's leaving described in the clause is to be verified, is also represented with $\mathbf{R}$. This suggests that Reichenbach's $\mathrm{R}$ corresponds to the evaluation time in my terminology, which refers to a time on which the truth of a clause is dependent in the sense that the event described in the clause is to be verified at that time. If $\mathrm{R}$ is the evaluation time, then by distinguishing two types of evaluation time, $t$ and $t^{\prime}, \mathrm{I}$ am dividing $\mathrm{R}$ into two types, one that corresponds to $t$ and the other that corresponds to $t^{\prime}$.

\subsection{3. $R$ aligned with $S$ and $R$ distinct from $S$}

Now, recall the original evaluation time $t$ is the utterance time. That is, $t$ corresponds to $\mathrm{S}$. On the other hand, a new evaluation time $t^{\prime}$ is another time distinct from the utterance time. That is, $t^{\prime}$ is distinct from $\mathrm{S}$. Since both $t$ and $t^{\prime}$ correspond to $\mathrm{R}$, this means that $\mathrm{R}$ corresponding to $t$ coincides with $\mathrm{S}(\mathrm{R}=\mathrm{S})$, whereas $\mathrm{R}$ corresponding to $t^{\prime}$ is distinct from $\mathrm{S}(\mathrm{R} \neq \mathrm{S})$.

For a simple illustration, compare John is eating an apple now and John ate an apple yesterday in (15) and (16) below. In (15), the evaluation time is the speech time, at which the event of John's eating an apple described in the sentence is to be verified. Therefore, $\mathrm{R}$ and $\mathrm{S}$ coincide. ${ }^{21}$ In (16), the evaluation time is a time distinct from the speech time. The event of John's eating an apple described in (16) is to be verified at a certain time prior to the speech time, i.e., yesterday. Therefore, $\mathrm{R}$ and $\mathrm{S}$ are distinct.

(15) John is eating an apple now.

(16) John ate an apple yesterday.

$$
\mathbf{R}=\mathbf{S}
$$

$$
\mathrm{R} \neq \mathrm{S}
$$

${ }^{21}$ As I have shown earlier, such a sentence as (15) has two possible interpretations, i.e., the $t$ and $t$ ' interpretations. Here, however, the example is used to illustrate a typical case in which $t$ is the evaluation time, simply ignoring the alternative $t$ ' interpretation. 
$\mathrm{R}$ that coincides with $\mathrm{S}$ corresponds to the utterance time $t$ serving as the evaluation time, whereas $\mathrm{R}$ that is distinct from $\mathrm{S}$ corresponds to another time $t^{\prime}$ serving as the evaluation time. Thus, the two types of evaluation time, $t$ and $t^{t}$, distinguish between two types of $R$; one that coincides with $S(R=S)$ and the other that is distinct from $\mathrm{S}(\mathrm{R} \neq \mathrm{S})$.

\subsubsection{S as the "now" point}

Having said that whether $\mathrm{R}$ coincides with $\mathrm{S}$ or not is a criterion for distinguishing the two types of evaluation time, $t$ and $t^{t}$, let me elaborate on the notion of S here. It has been pointed out (e.g., Hornstein 1990) that S, besides referring deictically to the speech time, in some contexts can also refer to a certain time specified by other sentences in the discourse or can connect the tense representation of a subordinate clause with that of the main one. I take the view that $\mathrm{S}$ refers to a time recognized as the present in the discourse, which is typically the utterance time, but in narrative types of contexts, other temporal moments can be recognized as the present as an outcome of other sentences in the discourse establishing a 'pseudo-present'. A typical example of 'pseudo-present' is observed in the following narrative.

(17) It was 1812 , just before the Battle of Borodino. The anticipation of the coming struggle is palpable. Napoleon has just woken. He is getting ready to inspect the troops and see that they are ready for the battle that will determine the fate of Europe.

(Hornstein 1990: 11)

It has an effect of taking us back to a point in time and space, where the Battle of Borodino is about to take place. As a result, this particular spatiotemporal point is recognized as the "now" point, though it is clearly a past time relative to the time of speech, i.e., a 'pseudo-present'.

The notion of 'pseudo-present' in narratives can be extended to complex sentences, in which the subordinate clause specifies a particular spatiotemporal location as a reference point for the main clause. For example, in a sentence When 
Mary entered the room, John had just woken, the subordinate clause When Mary entered the room designates the spatiotemporal location at which Mary entered as a point of reference for the main clause John had just woken. The subordinate clause has an effect of taking the interlocutors back to the particular spatiotemporal location in the past. As a result, it functions as the "now" point, or becomes a temporary 'pseudo-present'.

If we take $S$ as referring to a time recognized as the present, the time at which Mary entered the room is S. This S is clearly not the 'real' present, at which the sentence is uttered, but a 'pseudo-present', which temporally anchors the main clause John had just woken. Notice that in the Reichenbachian system, such a time is represented by $\mathbf{R}$, which serves as a point of view and mediates between the 'real' $\mathrm{S}$ and $\mathrm{E}$ (see (13) above). By taking $\mathrm{S}$ as referring to the "now" point, which may or may not be the actual speech time, we result in reducing the function of Reichenbach's R. Essentially, S as the "now" point, which serves as a temporal anchor, absorbs $\mathrm{R}$ as a point of view. With such an $\mathrm{S}$, the temporal interpretation of the main clause John had just woken is represented as in (18b), where R and S are put together.

(18)a. (When Mary entered the room, John had just woken.

b.

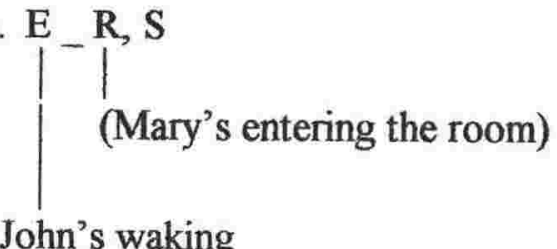

John's waking

The fact that the $S$ in the representation (18b) is distinct from the 'real' $S$, which refers to the time of speech, is to be captured in the relation between the main and subordinate clauses. As shown in the two level representation in (19b) below, the main clause $\mathrm{S}$ corresponds to the subordinate clause $\mathrm{E}$, i.e., the time of Mary's 
entering the room, which is located prior to the 'real' $\mathrm{S}^{22,23}$

(19)a. When Mary entered the room, John had just woken.

b. Mary's entering the room

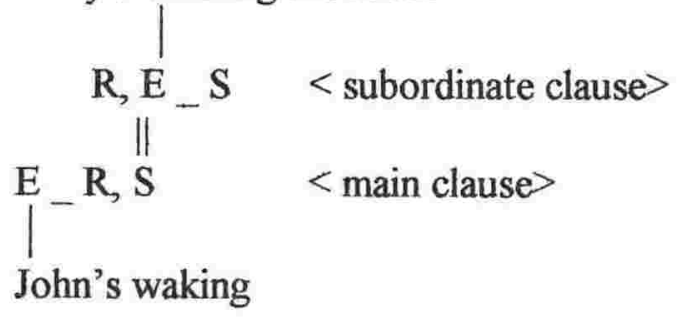

A result of using S not only for the 'real' present moment (i.e., the speech time) but also for a 'pseudo-present' is that all perfect tenses, whether present, past, or future perfect, are represented identically as E_R,S (or equivalently E_S,R). This presents a sharp contrast to the traditional Reichenbachian representations, which clearly distinguish present, past, and future perfect, as shown in (20).

$$
\begin{aligned}
& \text { Present perfect E_S,R } \\
& \text { Past perfect E_R_S } \\
& \text { Future perfect S_E_R (E_S_R } \quad \text { S,E_R) }
\end{aligned}
$$

In the traditional representations, $\mathrm{S}$ and $\mathrm{R}$ stand for the 'real' present moment and the point of view for the perfect interpretation respectively, and they are temporally ordered with respect to each other. By contrast, in the identical representation E_R,S for all perfect tenses, the relation between $\mathrm{S}$ and $\mathrm{R}$ or between the 'real' present moment and the point of view is significantly depreciated (especially when the two

\footnotetext{
${ }^{22}$ Note that I connect the subordinate clause $\mathrm{E}$ and the main clause $\mathrm{S}$ rather than the two R's. This differs from Reichenbach (1947: 293) which maintains a principle that demands the permanence of the reference point: "although the events referred to in the clauses may occupy different time points, the reference point should be the same for all clauses". Since the E and S connected in my representation coincide with R's, it seems practically no different even if I connect the two R's. However, I take the role of R quite differently and give it a somewhat secondary status in the tense representations, as will be shown as we proceed. Therefore, it is more compatible with my view that $\mathrm{E}$ and $\mathrm{S}$ rather than the two R's are connected.

${ }^{23}$ The representation R,E_S given to the subordinate clause represents the temporal interpretation of the sentence Mary entered the room. Crucially, however, the sentence Mary entered the room and the time adverbial clause When Mary entered the room do not yield the same temporal interpretation. This is taken up in 5.3.3.3 below.
} 
are distinct, as in past and future perfect). Essentially, the temporal relation between $\mathrm{S}$ and $\mathrm{R}$ is eliminated from the core representation of perfect tenses. It is rather represented as the relation between two S's, one for the 'real' present moment, i.e., the speech time, and the other for the 'pseudo-present' serving as a point of view for the perfect interpretation, in two separate representations connected to each other.

In effect, the traditional representation for the past perfect, E_R_S, can be seen as amalgamation of the two-level representation in (19b) above. Similarly, the traditional representations for the future perfect, S_E_R, E_S_R and S,E_R, can be seen as amalgamation of the two-level representation in (21b) below. ${ }^{24}$

(21)a. When Mary enters a room, John will have just woken.

b. Mary's entering the room

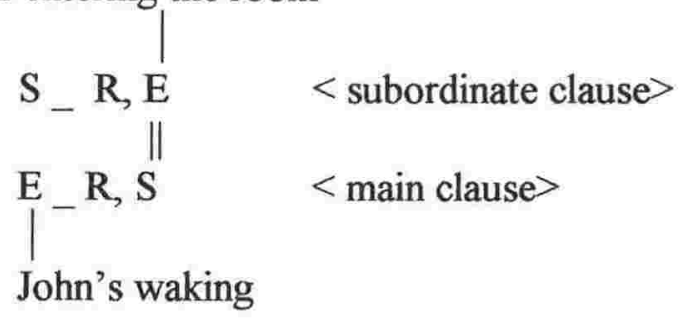

Note that the three distinct representations, E_S_R, S,E_R, and S_E_R, assigned to the future perfect in Reichenbach's system have been criticized as "an artefact of the notation rather than a significant fact about language" (Comrie 1985: 26). That is, there seems to be no language which has a distinct morphological realization for each such representation, and yet Reichenbach's system is forced to distinguish the three representations. As a solution to this problem, Comrie (1985) and Hornstein (1990) propose splitting the three-place relation into two distinct relations between $\mathrm{S}$ and $\mathrm{R}$ and between $\mathrm{R}$ and $\mathrm{E}$ and representing the future perfect as (S_R) - (E_R) (where the symbol - denotes relational composition). By introducing two distinct relations, a direct relationship between $E$ and $S$ is underspecified. Now, notice that the two-level representation in (21b) above essentially achieves the same. That is, the subordinate clause $\mathrm{S}$ (i.e., the 'real' speech time) and the main clause $\mathrm{E}$ do not have to be ordered.

\footnotetext{
${ }^{24}$ See footnote 22 and 23 above.
} 
Another point to note is that the past perfect and the future perfect cannot occur in isolation. That is, they necessarily occur with a subordinate clause or in a context which specifies the 'now' point or a 'pseudo-present' that serves as a point of view required for the perfect interpretation. Since the temporal location of the 'now' point (as a point of view) in relation to the 'real' present moment (or the actual speech time) is only specified in such an adverbial context, it is appropriate to represent it at another level subordinate to the main representation, as in (19b) and (21b) above.

Such a secondary status given to the relation between the main clause $S$ (for a point of view) and the subordinate clause $S$ (for the 'real' speech time) is also justified by the fact that the relation between the two is often not grammatically expressed, for example, in Japanese, Chinese, Malay, and Vedic (see Kiparsky 1995a).

Thus, with the extended use of $\mathrm{S}$ as the "now" point, which may or may not be the actual speech time, it is possible that Reichenbach's representations for the past perfect and the future perfect are reduced to a representation identical to that for the present perfect, i.e., E_R,S. By such reduction, we can capture the common essential semantics of the present, past, and future perfect, while the differences are accounted for by distinct collateral representations appropriately connected to the identical core representation (as seen in (19) and (21) above).

Note, however, that the perfect tense representation under discussion applies to the 'hot news' interpretation (e.g., John has just sneezed.) but not necessarily to other interpretations of perfect such as the existential interpretation (e.g., John has been to the States several times.), the continuative interpretation (e.g., John has been sick for a week.), and the resultative interpretation (e.g., John has already gone.). Therefore, the use of the term 'perfect' here is perhaps misleading. The target of my analysis is not 'perfect' in general but rather the 'hot news' interpretation in particular. The possible confusion here seems due to a matter of taxonomy. In English, a few (or several) distinct semantic interpretations are classed together as 'perfect', because they happen to take the same grammatical form, i.e., 'have + past participle (-en)'. In Japanese, however, there is no form corresponding to the English 'perfect'. That is, the distinct semantic interpretations conveyed by the 'perfect' form in English do not 
share a grammatical form in Japanese. For example, there are expressions such as -takoto-ga-aru (-Past-fact-Nom-exist), -tei-ru (-Prog-Pres), -tesimat-ta (-completePast), among others, to yield the existential, the continuative, and the resultative interpretation of the English 'perfect' respectively. Without much, if anything, in common, there seems no need to account for those distinct semantic interpretations uniformly in analyzing Japanese (and some other languages such as Chinese). Rather, Japanese has a common grammatical form -ta to yield the simple past and the 'hot news' interpretations (which I claim to be correlated with wa-marked and ga-marked subjects respectively). Thus, 'perfect' is a useful classification in describing English but not Japanese. The focus of my discussion and analysis is the 'hot news' interpretation, which happens to be expressed by the 'perfect' in English and by the 'past' in Japanese.

It is crucial to my analysis that the representation for perfect tenses necessarily has an $\mathrm{R}$ that coincides with $\mathrm{S}$, because the 'hot news' interpretation of perfect correlates with $g a$-marking of subjects in Japanese, which I am claiming to correlate with an $\mathrm{R}$ that coincides with $\mathrm{S}$, corresponding to the original evaluation time $t$. Observe in (22) below that when the subject is marked with $-w a$, the main clause receives the simple past interpretation, with the subordinate clause taken as modifying the time of situation (22a). When the subject is marked with $-g a$, on the other hand, the main clause receives the 'hot news' (past perfect) interpretation, with the subordinate clause taken as specifying the "now" point which serves as a point of view $(22 b){ }^{25,26,27}$
(22)a. John-wa [Mary-ga
heya-ni hait-ta
toki]
oki-ta.
room-to enter-Past
when
wake-Past
'John woke when Mary entered the room.'

\footnotetext{
${ }^{25}$ In (22a), the wa-marked subject is taken as being outside the scope of the time adverbial conveyed by the subordinate clause, and therefore it is more natural to put the time adverbial after the subject (rather than before the subject). In (22b), on the other hand, the time adverbial takes wide scope over the $g a$-marked subject, and therefore it appears before the subject.
}

${ }^{26}$ Note that the subordinate subject is marked with - $g a$, which suggests that the subordinate clause should not yield the $\mathrm{R}=\mathrm{E}$ interpretation. I will take this up in 5.3.3.3 below.

${ }^{27}$ In both (22a) and (22b), there may or may not be a causal relation between the event of Mary's entering the room described in the subordinate clause and that of John's waking described in the main clause. 

b. [Mary-ga
heya-ni hait-ta
toki]
John-ga
oki-ta.
room-to enter-Past when
wake-Past
'When Mary entered the room, John had just woken.'

Note however that it is not natural for the 'hot news' reading to occur in such a context with a subordinate clause. In my view, the very nature of 'hot news' is not congenial with subordinate modification. The 'hot news' reading obtains more naturally if the subordinate and main clauses are presented as two independent sentences occurring successively as in a narrative context. It is also probably due to the nature of 'hot news' that I cannot think of an example of the future perfect in Japanese which exhibits ga-marking of the subject. For example, I cannot readily translate the English sentence (21b) above into Japanese. This leads us to question whether the interpretation of the future perfect in $(21 \mathrm{~b})$ is to be recognized as the hot news' or rather the resultative.

Returning to the essential distinction between $\mathrm{R}$ that coincides with $\mathrm{S}$ and $\mathbf{R}$ that is distinct from $\mathrm{S}$, the former (i.e., $\mathrm{R}=\mathrm{S}$ ) signifies that the described situation is located at the "now" point, whereas the latter (i.e., $R \neq S$ ) signifies that the described situation is somewhat remote from the "now" point. Furthermore, with some modifications to Reichenbach's system, I maintain that $\mathrm{R}$ coinciding with $\mathrm{S}$ functions as a reference point from which the event is viewed and in relation to which the time of the event $(\mathrm{E})$ is located, whereas $\mathrm{R}$ distinct from $\mathrm{S}$ lacks the function of a "point of view" for the semantic interpretation.

\subsection{4. $\mathbf{R}$ distinct from $\mathbf{E}$ and $\mathbf{R}$ aligned with $\mathbf{E}$}

Having distinguished the two types of $\mathbf{R}$ corresponding to the two types of evaluation time, $t$ and $t^{\prime}$, in terms of their relations to $\mathrm{S}$, i.e., $\mathrm{R}=\mathrm{S}$ and $\mathrm{R} \neq \mathrm{S}$, let us now examine them in terms of their relations to $E$. Typically, $R=S$ is found in the representations for perfect tenses, as in (23a) below, whereas $\mathrm{R} \neq \mathrm{S}$ is found in the representations for simple (i.e., non-perfect) tenses, as in (23b). In (23a), the $\mathbf{R}$ that coincides with $S$ functions as a reference point in relation to which the time of the event $(E)$ is located, and $E$ is located prior to that. In (23b), on the other hand, the $R$ that is distinct from $\mathrm{S}$ coincides with $\mathrm{E}$. 
(23)a. E_R, S

b. $R, E \_S$ e.g., John-ga ki-ta.

John come-Past

'John has just come/arrived.'

e.g., John-wa ki-ta.

John come-Past

'John came.'

Bertinetto (1986) distinguishes $\mathrm{R}$ that follows $\mathrm{E}$ in the perfect tenses from $\mathrm{R}$ that is interpreted as simultaneous with $\mathrm{E}$. He narrows down the use of the term ' $\mathrm{R}$ ' only to refer to the former kind of $\mathrm{R}$ and introduces ' $\mathrm{L}$ ' ('event localizing function') to refer to the latter kind of $R$. While ' $R$ ' fixes the internal reference which is intrinsically (intensionally) required for semantic interpretation, ' $L$ ' chronologically specifies the location of $\mathrm{E}$ extrinsically (extensionally) as it is not intrinsically required.

Thus, whether $\mathrm{R}$ coincides with $\mathrm{E}$ or not seems no less important a criterion for distinguishing the two types of $\mathrm{R}$ than whether $\mathrm{R}$ coincides with $\mathrm{S}$ or not. While $\mathrm{R} \neq$ E functions as a "point of view" and is responsible for the perfect interpretation, $\mathrm{R}=$ E lacks the function of a "point of view" and gives rise to the interpretations of simple (i.e., non-perfect) tenses. (In my analysis, $\mathrm{R} \neq \mathrm{E}$ gives rise to the progressive and the proximate future interpretations as well as the perfect interpretation, as it will be shown as we proceed.)

Crucially, in my view, the distinction between $\mathrm{R}=\mathrm{S}$ and $\mathrm{R} \neq \mathrm{S}$ and that between $\mathrm{R}=\mathrm{E}$ and $\mathrm{R} \neq \mathrm{E}$ are essentially interrelated. $\mathrm{R}=\mathrm{S}$ necessarily corresponds to an $\mathrm{R} \neq \mathrm{E}$, as is the case in (23a) above, whereas $\mathrm{R} \neq \mathrm{S}$ necessarily corresponds to $\mathrm{R}=\mathrm{E}$, as is the case in (23b) above. That is, the two types of evaluation time, $t$ and $t^{\prime}$, correspond to $\mathrm{R}=\mathrm{S}$ and $\mathrm{R} \neq \mathrm{S}$, and also to $\mathrm{R} \neq \mathrm{E}$ and $\mathrm{R}=\mathrm{E}$ respectively.

(24)a. $t: \quad \mathrm{R}=\mathrm{S}$

$$
\neq \mathrm{E}
$$

b. $t^{\prime}: \quad \mathrm{R} \neq \mathrm{S}$

$$
=\mathrm{E}
$$




\subsubsection{Modifications to Reichenbach's tense representations}

According to my analysis above, $\mathrm{R}$ is either aligned with $\mathrm{S}$ but not with $\mathrm{E}$, or aligned with $\mathrm{E}$ but not with $\mathrm{S}$. However, this is not necessarily the case with Reichenbach's tense representations.

Firstly, in Reichenbach's representations for the past perfect (E_R_S) and the future perfect (S_E_R, E_S_R or S,E_R), R is not aligned with $\mathrm{S}$ or E. As discussed in 2.2.3.1. above, I argue that these representations could be and should be reduced to a representation identical to that for the present perfect, i.e., E_R,S, for both empirical and theoretical reasons. In the identical representation E_R,S for all perfect tenses, S signifies the "now" point, which may or may not be the actual speech time. The differences among the present, past, and future perfect are to be accounted for by the subordinate representations, whose $\mathrm{E}$ is connected with the $\mathrm{S}$ in the main representation, as seen in (19) and (21) above. The temporal location of the $\mathrm{S}$ as the "now" point in the main representation is thus specified by the relation to the $\mathrm{S}$ as the actual speech time in the subordinate representation. This way, all perfect tenses have $\mathrm{R}$ that coincides with $\mathrm{S}$ but not with $\mathrm{E}$.

Secondly, Reichenbach's representation for the present tense, S,R,E, has R that coincides with both $\mathrm{S}$ and $\mathrm{E}$. My analysis of two types of $\mathrm{R}$ leads us to divide this representation for the present tense into two distinct representations, as shown in (25) below. I take it that (25a) has R 'aligned with' S, whereas (25b) has R 'aligned with' E.

(25)a. (R, S), E

b. $S,(R, E)$

Notice that although Reichenbach used the notation ',' to represent a temporal relation of overlap or simultaneity, I have been in fact twisting its meaning when using it to connect R with $\mathrm{E}$ or S. I maintain Reichenbach's original meaning of ,, i.e., a temporal relation of overlap or simultaneity, only for that used outside the parentheses in the present tense representations in (25) above. (See Appendix to this chapter for the discussion of the relation of overlap or simultaneity in the present tense.) I do not take the other uses of ", , including those inside the parentheses in 
(25), as representing a temporal relation. This essentially means that '? used to connect $\mathrm{R}$ with $\mathrm{E}$ or $\mathrm{S}$ does not represent a temporal relation.

Notice that $\mathrm{S}$ and $\mathrm{E}$ are 'real' times in the sense that they designate the time of a particular event, i.e., the event of speech and the event described in the clause respectively. $\mathbf{R}$ is different. It is not a time in itself. In effect, it assigns a function to a time. In the representation ( $R, X)$, where $\mathrm{X}$ is $\mathrm{S}$ or $\mathrm{E}, \mathrm{R}$ is a function of $\mathrm{X}$. In other words, $\mathrm{X}$ functions as R. I defer discussing what the function of $\mathrm{R}$ is to the following section 2.3. In order to represent a functional relation between $\mathbf{R}$ and $\mathbf{X}$ more appropriately, I further modify the representations in (25), using $X(R)$ in place of (R, $\mathrm{X})$, as shown in (26).

(26)a. S(R), E

b. $\mathrm{S}, \mathrm{E}(\mathrm{R})$

Following this, I replace 'R,S's and 'R,E's in other representations, besides the present tense, with ' $\mathrm{S}(\mathrm{R})$ ' and ' $\mathrm{E}(\mathrm{R})$ ' as they do not represent a temporal relation but rather a functional relation. For example, the simple past representation ' $E, R_{-} S$ ' is replaced by ' $E(R) \ldots S$ ', and the present perfect representation ' $E \_S, R$ ' is replaced by ' $E_{-} S(R)$ '.

Returning to (26) above, the two distinct representations for the present tense divide the semantic interpretation of the present tense into two. With $S(R)$, which signifies that the speech time functions as the reference time, the described situation is verified at the time of speech. Therefore, 'S(R), E' represents a dynamic present interpretation that at the moment of speech, the described situation is actively occurring and progressing. On the other hand, with $\mathrm{E}(\mathrm{R})$, which signifies that the event time functions as the reference time, the described situation is verified at the time of situation. Therefore, ' $\mathrm{S}, \mathrm{E}(\mathrm{R})$ ' represents a static present interpretation that There is a situation that temporally overlaps with the utterance of the sentence and continues throughout in space and time beyond the speech time. (The distinct interpretations due to $S(R)$ and $E(R)$ will be elucidated when I develop the role of $R$ in 2.3 below.) 
The difference between the ' $S, E(R)$ ' and ' $S(R), E$ ' interpretations can be illustrated by the examples in (4) above. Recall that although both (4a) and (4b) express a present ongoing situation of John's writing a book, they crucially differ in that (4a) does not necessarily mean that the described situation is actually taking place at the exact moment of speech, whereas (4b) strictly conveys that the described situation is actually occurring and progressing at the present moment. In other words, (4a) describes a static present situation that continues throughout in space and time, whereas (4b) describes a dynamic present situation that is actively progressing. To differentiate these two interpretations, I use the term 'present' to refer to the static interpretation of a present situation which is connected throughout in space and time, and the term 'progressive' to refer to the dynamic interpretation as of a present situation which is advancing cumulatively or step-by-step. In these terms, ' $\mathrm{S}, \mathrm{E}(\mathrm{R})$ ' represents the present, whereas ' $S(R), E^{\prime}$ ' represents the progressive. ${ }^{28}$

Another point to note with respect to my representations in (26) above is that $\mathrm{S}$ appears necessarily on the left hand side of a relation, whereas E appears necessarily on the right hand side, whether they are on their own or together with $\mathrm{R}$. This is because I fix the positions of 'times' so that what is on the left hand side of a relation is always the reference point with respect to which what is on the right hand side is temporally located. That is, it is necessarily the case that $\mathrm{S}$ functions as a "point of

${ }^{28}$ This distinction between the present and progressive interpretations applies to Kuroda's famous examples in (i) below, which are used to illustrate categorical and thetic judgements.

(i) a. Neko-wa asoko-de nemut-tei-ru.

cat there-at sleep-Prog-Pres

'The cat is sleeping over there.' <categorical judgement >

b. Neko-ga asoko-de nemut-tei-ru. cat there-at sleep-Prog-Pres

'The/A cat is sleeping over there.' <thetic judgement >

The sentence (ia) conveys that the cat is and has been sleeping over there continuously, whereas (ib) describes a situation progressing at the present moment in which a/the cat is sleeping over there.

Thus, the difference between (ia) and (ib) is expressed in terms of whether $\mathrm{R}$ is aligned with $\mathrm{E}$ (i.e., $\mathrm{S}, \mathrm{E}(\mathrm{R})$ or with $\mathrm{S}$ (i.e., $\mathrm{S}(\mathrm{R}), \mathrm{E})$ in my analysis, while it is also captured by the distinction between categorical and thetic judgements. 
view" from which an event is viewed and with respect to which the time of the event, $\mathrm{E}$, is located. ${ }^{29}$

This leads to another modification of Reichenbach's representations. In Reichenbach's representations, the temporal ordering of 'before/after' is represented by the notation " _, which signifies what is on its left is temporally earlier than what is on its right. Therefore, the past tense and the future tense, for example, are distinguished by swapping the positions of what appears on the left and the right of ¿, as shown in (27) below. However, in both the past and the future tenses, S serves as a reference point with respect to which the bundle of $\mathrm{E}$ and $\mathrm{R}$ is temporally located. In order to fix the positions of 'times' so that what is on the left hand side is always the reference point with respect to which what is on the right hand side is temporally located, I introduce the notations ' $<$ ' and ' $>$ ' for the relations 'before' and 'after' respectively. As a result, both the past and the future tenses have $\mathrm{S}$ on the left hand side and the bundle of $\mathrm{E}$ and $\mathrm{R}$ on the right hand side, as shown in (28) below. It is important that $\mathrm{S}$ functions as a reference point in the modified representations. That is, it is not $\mathbf{R}$ that functions as a reference point. This casts a serious question as to the status of $\mathrm{R}$, which originally stands for the reference time. I shall develop the role of $\mathrm{R}$ from a different perspective in Section 2.3 below.

While I put aside the issue of what $R$ really is for the moment, I have argued above that $\mathrm{R}$ is not a time but rather a function. I have proposed that in order to clearly represent a functional relation distinct from a temporal relation, a representation such as ' $E, R$ ' should be replaced by ' $E(R)$ '. With this, the representations in (28) are further modified into (29).

\begin{tabular}{|c|c|c|}
\hline past & $E, R \quad S$ & future \\
\hline past & $\mathrm{S}>\mathrm{E}, \mathbf{R}$ & future \\
\hline
\end{tabular}

past $\mathrm{S}>\mathrm{E}, \mathrm{R}$

\footnotetext{
${ }^{29}$ This is important especially when it comes to the syntactic representation of tense. As will be discussed in 4.1.1 below, Zagona (1990) and Stowell $(1994 a, b)$ take the view that tense is a relation between two times, one of which is given and serves as a reference point, with respect to which the other is located. They syntactically express this in the phrase structure of tense, in which the time serving as a reference point appears in the external argument position of Tense, whereas the other time appears in the internal argument position, and Tense temporally locates its internal argument in relation to its external argument.
} 
(29) past $\mathrm{S}>\mathrm{E}(\mathrm{R})$

future $S<E(R)$

After all these modifications, we now have three temporal relations, ", (simultaneous), '>' (after), and ' $<$ ' (before), to connect either $\mathrm{S}(\mathrm{R})$ and $\mathrm{E}$, or $\mathrm{S}$ and $\mathrm{E}(\mathrm{R})$. Consequently, we have the following six possible tense representations:

$$
\text { (30) } \begin{array}{rl}
\mathrm{S}(\mathrm{R}), \mathrm{E} & \mathrm{S}, \mathrm{E}(\mathrm{R}) \\
\mathrm{S}(\mathrm{R})>\mathrm{E} & \mathrm{S}>\mathrm{E}(\mathrm{R}) \\
\mathrm{S}(\mathrm{R})<\mathrm{E} & \mathrm{S}<\mathrm{E}(\mathrm{R})
\end{array}
$$

Note that these could be used compositionally so that the present, past, and future perfects are distinguished as in (31).
a. Present perfect
b. Past perfect
c. Future perfect<smiles>O=S(S)(S)=[R19]F</smiles>
$\mathrm{S}(\mathrm{R})>\mathrm{E}$
$\mathrm{S}>\mathrm{E}(\mathrm{R})$
$\begin{aligned} \quad & \text { S(R) }>\mathrm{E} \\ & \| \\ \mathrm{S}<\mathrm{E}(\mathrm{R}) & \end{aligned}$

\subsubsection{Two types of $\mathbf{R}$ and $w a / g a-s u b j e c t s$}

Since the two types of $R, R=S(\neq E)$ and $R=E(\neq S)$, correspond to the two types of evaluation time, $t$ and $t^{\prime}$, they are also correlated with $g a$ - and wa-markings of subjects in Japanese. Among the six tense representations in (31) above, those three with $\mathrm{S}(\mathrm{R})$ (corresponding to $t$ ) are expected to obtain with ga-marked subjects and the other three with $\mathrm{E}(\mathrm{R})$ (corresponding to $t^{\prime}$ ) are expected to obtain with wamarked subjects. This is indeed borne out by the two distinct interpretations given to the $w a / g a$-minimal pairs of sentences in 2.1 above.

In (4) above, which is repeated in (32) below, the sentence with a wa-marked subject yields the present interpretation, which is represented by ' $S, E(R)$ ', and the sentence with a ga-marked subject yields the progressive interpretation, which is represented by 'S(R), E'. 
(32)a. S, E(R) (present)

John-wahon-o kai-tei-ru.

book-Acc write-Prog-Pres

'John is writing a book.'

(e.g., these days)

b. $\mathbf{S}(\mathbf{R}), \mathbf{E}$ (progressive)

John-ga hon-o kai-tei-ru.

book-Acc write-Prog-Pres

'John is writing a book.'

(right now)

In (2) above, which is repeated in (33) below, the sentence with a wa-marked subject yields the simple past reading, which is represented by ' $S>E(R)$ ', and the sentence with a ga-marked subject yields the 'hot news' perfect reading, which is represented by ' $S(R)>E$ '.

(33)a. $\mathbf{S}>\mathbf{E}(\mathbf{R})$ (past)

John-wa ki-ta.

John come-Past

'John came.'

b. $\mathbf{S}(\mathbf{R})>\mathbf{E}$ ('hot news' perfect)

John-ga ki-ta.

John come-Past

'John has just arrived.'

In (3) above, which is repeated in (34) below, the sentence with a wa-marked subject yields the future reading, which is represented by ' $S<E(R)$ ', and the sentence with a $g a$-marked subject yields the 'on the verge' (proximate future) reading, which is represented by ' $\mathrm{S}(\mathrm{R})<\mathrm{E}$. ${ }^{30}$

$$
\begin{gathered}
\text { (34)a. } \mathbf{S}<\mathbf{E}(\mathbf{R}) \text { (future) } \\
\text { John-wa ku-ru. } \\
\text { come-Pres } \\
\text { 'John will come.' }
\end{gathered}
$$

${ }^{30}$ It is also possible that (34a) receives a habitual reading, i.e., John comes (repeatedly). In order to be able to account for this interpretation, i.e., ' $\mathrm{S}, \mathrm{E}(\mathrm{R})$ ', we probably need to assume that the affix $r u$ can convey a relation ',' as well. It is also arguable that the interpretation of (34b) is represented by ' $S(R), E$ '. See Appendix to this chapter (Section 3). 
b. $\mathbf{S}(\mathbf{R})<\mathbf{E}$ (proximate future)

John-ga ku-ru.

come-Pres

'John is coming. (Here comes John.)'

Thus, the temporal relation between $\mathrm{S}(\mathrm{R})$ and $\mathrm{E}$ is expressed in sentences with $g a$-marked subjects, while the temporal relation between $\mathrm{S}$ and $\mathrm{E}(\mathrm{R})$ is expressed in sentences with wa-marked subjects.

Now, take notice of the affixes attached to the verbs. In (32), (33) and (34) above, we have -teiru, $-t a$, and $-r u$ respectively. On the basis of these observations, we can reasonably assume that in Japanese the temporal relation ", (simultaneous) is conveyed by -teiru, ' $>$ ' (after) is conveyed by -ta and ' $<$ ' (before) is conveyed by $r u^{31}$ Then, -teiru conveying the relation ", gives rise to the dynamic progressive interpretation when it occurs with a ga-marked subject and the relation ', ' is taken as connecting $S(R)$ and $E$, and to the static present interpretation when it occurs with a $w a$-marked subject and ', is taken as connecting $\mathrm{S}$ and $\mathrm{E}(\mathrm{R}){ }^{32,33}$ The affix -ta conveying the relation '>' yields the 'hot news' perfect interpretation when it occurs with a $g a$-marked subject and the relation ' $>$ ' is taken as connecting $\mathrm{S}(\mathrm{R})$ and $\mathrm{E}$, and the simple past interpretation when it occurs with a $w a$-marked subject and '>> is taken as connecting $\mathrm{S}$ and $\mathrm{E}(\mathrm{R})$. The affix $-r u$ conveying the relation ' $<$ ' yields the 'on the verge' (proximate future) interpretation when it occurs with a ga-marked subject and the relation ' $<$ ' is taken as connecting $S(R)$ and $E$, and the future interpretation when it occurs with a $w a$-marked subject and ' $<$ ' is taken as connecting $\mathrm{S}$ and $\mathrm{E}(\mathrm{R})$.

\footnotetext{
${ }^{31}$ Such an assumption that $-t a$, $-r u$, and -teiru convey temporal relations, '>' (after), '<' (before), and ',' (simultaneous) is not trivial. Although in this chapter I work with this assumption, in Chapter 3, especially in 3.1, I show that these affixes can also be considered to denote aspectual meanings such as 'completed', 'prospective' and 'ongoing'.

${ }^{32}$ See footnote 9 above. Strictly speaking, it is the -tei part of -teiru that should be regarded as conveying the relation ',', as -teita also conveys ',' (The difference between -teiru and -teita is whether the relation ",' revolves around the present moment or a particular moment in the past.)

${ }^{33}$ In addition to these ongoing process interpretations, -teiru can also yield the result state interpretation and the experiential interpretation, which will be discussed in 3.4 .1 below.
} 
(35) Verbal affixes, subject markers, and temporal relations

\begin{tabular}{|c|c|c|c|}
\hline & & $w a$ & $g a$ \\
\hline -teiru & , & $\begin{array}{l}\mathrm{S}, \mathrm{E}(\mathrm{R}) \\
\text { (present) }\end{array}$ & $\begin{array}{l}\mathrm{S}(\mathrm{R}), \mathrm{E} \\
\text { (progressive) }\end{array}$ \\
\hline$-t a$ & $>$ & $\begin{array}{l}\mathrm{S}>\mathrm{E}(\mathrm{R}) \\
\text { (past) }\end{array}$ & $\begin{array}{l}\mathrm{S}(\mathrm{R})>\mathrm{E} \\
\text { ('hot news' perfect) }\end{array}$ \\
\hline$-r u$ & $<$ & $\begin{array}{l}\mathrm{S}<\mathrm{E}(\mathrm{R}) \\
\text { (future) }\end{array}$ & $\begin{array}{l}\mathrm{S}(\mathrm{R})<\mathrm{E} \\
\text { (proximate future) }\end{array}$ \\
\hline
\end{tabular}

\subsubsection{Conclusion}

To sum up this section, I have shown that the two types of evaluation time, $t$ and $t^{\prime}$, are both comparable to Reichenbach's reference time $\mathrm{R}$ and distinguish two types of it. The original evaluation time $t$ corresponds to $\mathrm{R}$ which coincides with $\mathrm{S}(\mathrm{R}$ $=\mathrm{S})$ and is distinct from $\mathrm{E}(\mathrm{R} \neq \mathrm{E})$. On the other hand, a new evaluation time $t^{\prime}$ corresponds to $R$ which is distinct from $S(R \neq S)$ and coincides with $E(R=E)$. As the two types of evaluation time, $t$ and $t^{\prime}$, correlate with $g a$ - and $w a$-markings of subjects, the two types of $\mathrm{R}, \mathrm{R}=\mathrm{S} / \neq \mathrm{E}$ and $\mathrm{R} \neq \mathrm{S} /=\mathrm{E}$, correlate with $g a$ - and wamarkings of subjects in Japanese. Due to the two types of evaluation time or the two types of $\mathrm{R}, w a / g a$-minimal pairs of sentences (with the same tense/aspect markers) receive distinct temporal and aspectual interpretation.

At a more theoretical level, defining the properties of $t$ and $t^{\prime}$, originated from the Priorean analysis of tense as a sentential operator (see (1) above), in terms of Reichenbachian $\mathrm{S}, \mathrm{E}$, and $\mathrm{R}$, the analysis shows an intersection between the two distinct approaches to tense. Essentially, $\mathrm{S}$ in the Reichenbachian model corresponds to $t$ in the Priorean model at which the utterance is evaluated, and $\mathrm{E}$ in the Reichenbachian model corresponds to $t^{\prime}$ in the Priorean model at which the event being spoken of is verified. While Priorean tense logic gives a clear account of Reichenbach's S and E (Blackburn 1994: 88), it totally obscures Reichenbach's R. I took an approach that Reichenbach's $\mathrm{R}$ is comparable to both $t$ and $t^{\prime}$ in the Priorean model. As a result, Reichenbach's $\mathrm{R}$ is divided into two types, one that corresponds to $t$, i.e., $\mathrm{R}=\mathrm{S}$, and the other that corresponds to $t^{\prime}$, i.e., $\mathrm{R}=\mathrm{E}$.

My analysis also casts a question as to the status of $\mathrm{R}$ in the tense representations. Although $\mathrm{R}$ originally stands for the reference time, in my analysis it 
is $\mathbf{S}$ (rather than $\mathbf{R}$ ) that necessarily functions as a reference point, with respect to which $\mathrm{E}$ is temporally located. In the following section, I shall develop the role of $\mathrm{R}$ from a different perspective.

\section{3. $\mathbf{R}$ as viewpoint aspect}

\subsubsection{The $\mathbf{S}-\mathbf{E}$ relation and $\mathbf{R}$}

It has been rather noticeable that in our new tense representations in (40) above, $R$, which is necessarily attached to either $S$ or $E$, no longer has its own place as a 'time' that stands in a certain relation to other times. Essentially, each representation has just two 'times', $\mathrm{S}$ and $\mathrm{E}$, which are connected by a certain topological relation. $\mathrm{R}$ attached to $\mathrm{S}$ or $\mathrm{E}$ designates a function of $\mathrm{S}$ or $\mathrm{E}$, depending on which a given $\mathrm{S}-\mathrm{E}$ relation yields distinct interpretations.

To clearly represent this, we can remove $\mathbf{R}$ from the core tense representation to an additional level. That is, at the core of our tense representations, we have a simple temporal relation between $\mathrm{S}$ and $\mathrm{E}$, to which $\mathrm{R}$ is attached at another level, aligning with either $\mathrm{S}$ or $\mathrm{E}$. Using a variable $\bullet$ for the relations ' $>$ ', ' $<$ ', and ',', the representations in (35) above are reduced to the following two representations. ${ }^{34}$
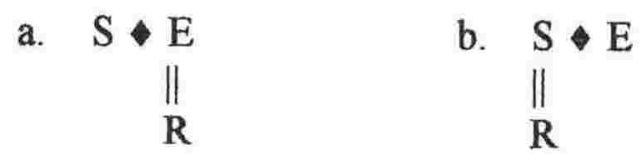

The representations (36a) and (36b) stand for the wa-column and the ga-column in (35) above respectively. Notice that at the level of S-E relation, there is no difference between (36a) and (36b), i.e., between the wa-column and the ga-column in (35) above. The only difference between them is the alignment of $\mathrm{R}$, which is either with $\mathrm{E}$

\footnotetext{
34 Just to remind readers, the $\mathrm{R}$ aligned with $\mathrm{E}$ in (36a) corresponds to a new evaluation time $t$, whereas the $\mathrm{R}$ aligned with $\mathrm{S}$ in (36b) corresponds to the original evaluation time $t$. An $\mathrm{R}$ aligned with $\mathrm{S}$ signifies that the truth of a clause is dependent on the present moment. With such an $\mathrm{R}$, the described situation is taken as an immediate present situation. On the other hand, an $\mathrm{R}$ distinct from $\mathrm{S}$ signifies that the truth of a clause is dependent on another time distinct from the present moment In this case, the described situation is seen as somewhat remote from the present moment.
} 
or with $\mathrm{S}$. This makes it clearer that an identical S-E relation yields distinct temporal and aspectual interpretations depending on whether $\mathrm{R}$ is aligned with $\mathrm{E}$ or $\mathrm{S}$.

\subsection{2. $R$ as viewpoint aspect}

I propose that $\mathrm{R}$ aligned with either $\mathrm{S}$ or $\mathrm{E}$ functions as a viewpoint aspect. Smith (1991: 91) draws an analogy that a viewpoint is like the lens of a camera, which focuses a scene to make it visible to the receiver. A viewpoint focuses the situation talked about in a sentence. It focuses all or part of a situation. Information in focus has the status of 'visibility'. Only visible information is asserted.

This is exactly what $\mathbf{R}$ does. Depending on whether it is aligned with $\mathrm{S}$ or $\mathrm{E}, \mathrm{R}$ focuses all or part of the situation talked about in a sentence. An $R$ aligned with $S$ designates the time of speech (referred to by S) as the time of reference. More precisely, it designates a temporal point recognized as the "now" point in the speech context as a reference point. A situation is viewed and described precisely from the perspective of this punctual temporal point, which is referred to by $\mathrm{S}$ and designated by $\mathrm{R}$ as a reference point. Assume that a situation is an entity which exists over time. Then, a situation perceived at a punctual temporal point is only a partial manifestation of a situation as a whole. Thus, an $\mathrm{R}$ aligned with $\mathrm{S}$ functions as a viewpoint which focuses 'part' of a situation manifested at a precise temporal point.

On the other hand, an $\mathrm{R}$ aligned with $\mathrm{E}$ designates the time of the situation (referred to by E) as the time of reference. That the situation time serves as the reference time means that the described situation is to be verified at the time of the situation. That is, the whole situation is put in focus (without being decomposed into parts). Thus, an $\mathrm{R}$ aligned with $\mathrm{E}$ functions as a viewpoint which focuses 'all' of a situation as a single whole.

To conceptualize the distinction between a punctual manifestation of a situation (which $\mathrm{I}$ claim $\mathrm{R}=\mathrm{S}$ focuses) and a situation as a single whole (which $\mathrm{I}$ claim $\mathrm{R}=\mathrm{E}$ focuses), it may be helpful to refer to Jackendoff's (1996) decomposition of a situation. Jackendoff compares situations to objects such as a cylindrical tube and an $\mathrm{H}$-beam, which are analyzed as being created by moving a cross-section along an axis. The drawings in (37) below illustrate that a representative slice of a tube is an 
annulus; of an H-beam, an $\mathrm{H}$ shape, and that this cross-section is projected onto a linear (one-dimensional) axis to form the shape of the object as a whole.

(37) a. Tube

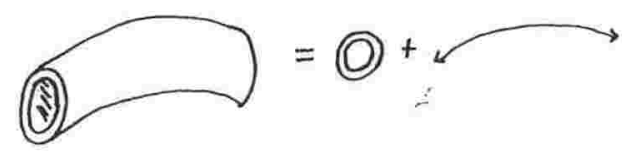

b. H-beam

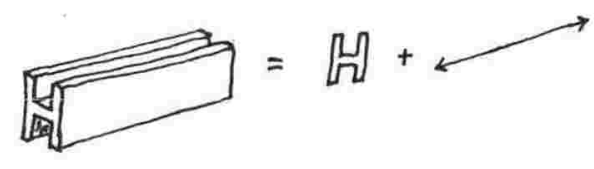

(Jackendoff 1996: 319)

Analogically, Jackendoff decomposes a situation into axis plus cross-section so that if we take a slice of a situation at any point of the axis, we get a representative crosssection of the situation.

In these terms, an $\mathrm{R}$ aligned with $\mathrm{S}$ points to a single point on the time axis and cuts out a cross-section of a situation intersecting at that point. Thus, $R=S$ focuses a cross-section of a situation or part of a situation manifested at a precise temporal point. On the other hand, an $\mathrm{R}$ aligned with $\mathrm{E}$ spans the whole length of the time axis and therefore leaves the situation undecomposed. Thus, $\mathrm{R}=\mathrm{E}$ focuses all of a situation without decomposing it.

I call a viewpoint signified by $\mathrm{R}=\mathrm{S}$ which focuses part of a situation $\mathrm{View}_{\text {part }}$ and a viewpoint signified by $\mathrm{R}=\mathrm{E}$ which focuses all of a situation $\mathrm{View}_{\text {all }}$.

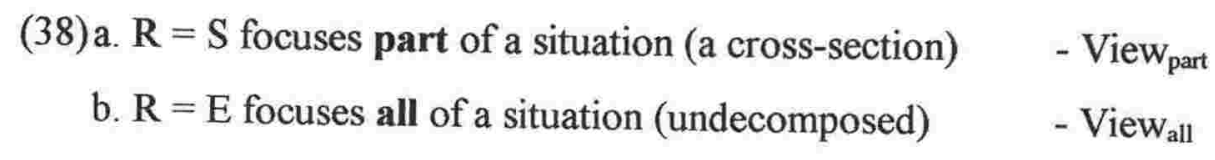

As every clause has an evaluation time, $t$ or $t^{\prime}$, every clause has a viewpoint, View $_{\text {part }}$ or View all, with View part corresponding to $t$, and View all corresponding to $t^{\prime}$. 


\subsubsection{View all $_{\text {vs. }}$ View part $_{\text {and }}$ perfective vs. imperfective}

In order to elucidate the status of the viewpoint aspects, View all and View $_{\text {part, }}$ I compare them with the so-called perfective and imperfective aspects.

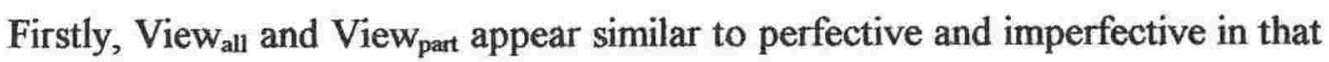
they are both characterized by the distinction between all and part in the domain of situations (cf. Forsyth 1970, Comrie 1976, Smith 1991, Filip 1993). For example, Comrie (1976) states:

'perfectivity indicates the view of a situation as a single whole, without distinction of the various separate phases that make up that situation; while the imperfective pays essential attention to the internal structure of the situation' (p. 16).

In other words,

'the perfective looks at the situation from outside, without necessarily distinguishing any of the internal structure of the situation, whereas the imperfective looks at the situation from inside, and as such is crucially concerned with the internal structure of the situation' (p. 4).

The perfective-imperfective distinction defined as above fits well with the distinction between View all and View $w_{\text {part. }}$

However, there are other characterizations of perfective and imperfective. For example, Smith (1991) distinguishes the perfective and imperfective viewpoints in terms of whether they include the initial and final endpoints of a situation. Perfective viewpoints which present a situation as a unit are characterized as including both initial and final endpoints of a situation, as illustrated in (39a) below. (They are closed informationally.) Imperfective viewpoints, on the other hand, are characterized as focusing on intervals that are neither initial nor final and thus excluding endpoints, as 
illustrated in (39b) below. (They are open to additional information and inference.) ${ }^{35}$

a. Perfective I..............F

\section{|IIIIIIIIIIIIIIIIIIIII}

b. Imperfective I.............F

\section{IIIIIII}

(I and F represent the initial and final endpoints of a situation, and the slashes indicate the possible span of the viewpoints.)

Smith's characterization of viewpoint aspects in terms of exclusion/inclusion of endpoints seems appropriate, for example, for the imperfective and perfective in English, which are illustrated in (40) and (41) below. The situation presented by the progressive is compatible with assertions that the situation is incomplete (40a), or continues (40b). This shows that the viewpoint expressed by the progressive in English, i.e., the imperfective, presents an open situation, excluding the endpoints. By contrast, the situation presented by the perfective in (41) is incompatible with such assertions, as indicated by the hashes. The impossibility of the conjunctions shows that the perfective presents a closed situation, including the endpoints.

(40) a. Mary was walking to school (but she didn't actually get there).

b. Mary was walking to school (and she is still walking).

${ }^{35}$ In addition, in accounting for aspectually vague sentences, which allow both open and closed readings, Smith (1991) counts the neutral viewpoint as another viewpoint category which arises by default. Its span includes the initial endpoint and at least one internal stage of a situation.

The Chinese example in (i) below is used to illustrate aspectually vague sentences (Smith 1991: 123).

(i) Zhangsan dao jia de shihou, Mali xie gongzuo baogao. Zhangsan arrive home DE time Mali writework report

a. When Zhangsan arrived at home, Mali wrote the work report.

b. When Zhangsan arrived at home, Mali was writing the work report.

(Smith 1991: 123)

Note, however, that the interpretations (ia) and (ib) above can be rendered unambiguous if aspectual markers are included as in (iia) and (iib) respectively (p.c. with Dianyu Li).

(ii) a. Zhangsan dao jia de shihou, Mali xie wan le gongzuo baogao.

b. Zhangsan dao jia de shihou, Mali zai xie gongzuo baogao. 
(41) a. \#Mary walked to school (but she didn't actually get there).

b. \#Mary walked to school (and she is still walking).

(Smith 1991: 101)

Notice here that in English (and in fact many other languages) the imperfective is generally equated to the progressive. This marks an important difference between the imperfective and View part that I am proposing. I conceive of View part as a viewpoint which simply focuses 'part' of a situation, that is, essentially any 'part' of a situation. Therefore, the progressive is only one of the possible presentations of View $_{\text {part. }}$ Observe that the situations described in (42) below are all taken as partial temporal manifestations perceived from a precise temporal point. I.e., they are all View $_{\text {part }}$ presentations. (Actually, I take it that the $g a$-marking of the subjects signals View $_{\text {part }}$ (see 2.4.4. below).) However, the parts of a situation in focus are all different; in (42a) the final part, in (42b) the initial part, and in (42c) an internal part of a situation. What part of a situation is in focus depends on the tense/aspect marker attached to the verb, $-t a,-r u$ or -teiru (and also the aspectual class of the verb, which will be discussed in Chapter 3).
a. John-ga en-o kai-ta. circle-Acc draw-Past
'John has just drawn a circle.'
b. John-ga en-o kak-u. circle-Acc draw-Pres

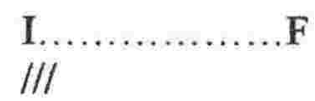
'John is about to draw a circle/John is drawing a circle.'
c. John-ga en-o kai-tei-ru. circle-Acc draw-Prog-Pres 'John is drawing a circle.'

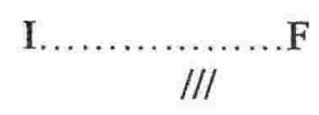

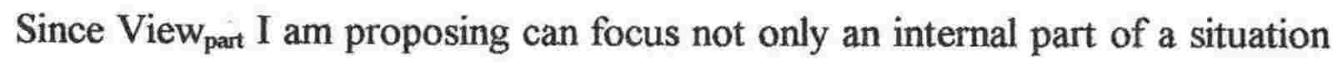
which excludes endpoints, but also the initial and final part of a situation which includes an endpoint, it is not appropriate to characterize View part $_{\text {by }}$ exclusion of endpoints.

Turning to View all, it also appears different from the perfective characterized by inclusion of endpoints. Being characterized as including both initial and final 
endpoints, perfective is said to be (canonically) incompatible with situations which have no endpoints, i.e., states. Smith (1991) shows that the perfective is not available to statives in Russian, Chinese, and Navajo, for example. ${ }^{36}$ By contrast, View all that I conceive of is more than compatible with states. In fact, many states are necessarily presented by Viewall, as will be shown and discussed in detail in 3.3. below. Roughly, this is due to the stative nature of states that forces the situation to be taken as a single whole. In other words, states are often unable to be decomposed into successive stages or 'parts' because of their very nature.

Observe, for example, that a state of John's being handsome is necessarily presented by View all, which I assume to be signaled by wa-marking of the subject in Japanese. (In 2.3.4. below, I argue that View all and View $w_{\text {part }}$ are respectively signaled by $w a$-marking and $g a$-marking of subjects in Japanese.) As shown in (43) below, the subject of a state of being handsome is most naturally marked by $-w a$, and if marked by - $g a$, it can only yield a focus reading, as indicated by the hash. On the assumption that $w a$-marking and $g a$-marking of subjects in Japanese signal Viewall and View respectively, I take the unavailability of neutral ga-marking of the subject in (43b) as suggesting the unavailability of View part to the described situation of John's being

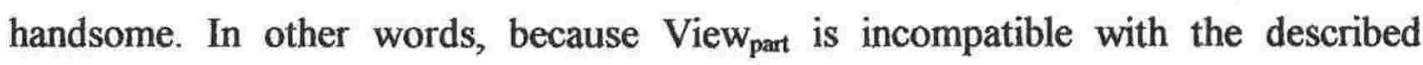
situation, the ga-marking of the subject in (43b) cannot be taken as signalling View part. It is instead taken as indicating that the subject is in focus. Crucially, the situation of John's being handsome is necessarily taken as a single whole (even in the focus reading). ${ }^{37}$ That is, if the situation holds at all, its entire schema holds. ${ }^{38}$

${ }^{36}$ Smith also observes that the perfective applies 'non-canonically' to the stative situation type in French, as seen in (i) below, and that the perfective may depart from the 'canonical' structure by presenting open stative situations, as seen in the English examples in (ii).

(i) Marie a vécu à Paris.

'Marie lived in Paris.'

(Smith 1991: 109)

(ii) a. Jennifer knew Turkish.

b. ...but she has forgotten it all (closed)

c. .... and she still knows it (open)

(Smith 1991: 109-110)

${ }^{37}$ Note that the focus reading of a $g a$-marked subject corresponds to the (neutral) thematic reading of a wa-marked subject in that it gives rise to the View all interpretation. (cf. footnote 22 in Chapter 4 below) 
(43)
a. John-wa hansamu da.
'John is handsome.'
handsome Cop
b. \#John-ga hansamu da. handsome Cop
'It is John who is handsome.'

Thus, while perfective characterized by inclusion of endpoints is canonically incompatible with states, Viewall is a most natural viewpoint for states. Assuming that states have no endpoints, it is not appropriate to characterize View all, which most naturally occurs with states, by inclusion of endpoints. ${ }^{39}$ Rather, View all is simply

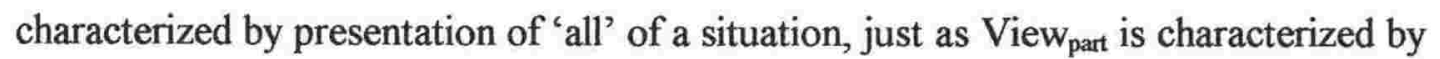
presentation of 'part' of a situation.

In addition, there seems a difference in the size of 'part' presented by the

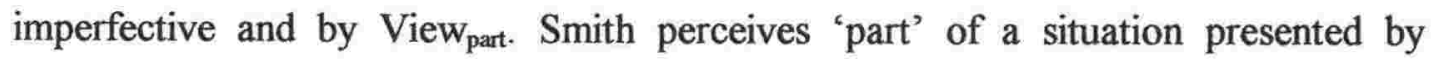
imperfective as an interval or stages of a situation. The use of such terms as an

${ }^{38}$ However, there are also 'states' which allow (neutral) ga-marking of the subjects. For example, a state of John's being sick can take either a wa-marked subject or a ga-marked subject, as shown in (i) below. See the discussion in 3.3 below.

(i) a. John-wa byoki da. sick Cop

'John is sick. (= John has been sick.)'

b. John-ga byoki da. sick Cop

'John is sick (at this very moment).'

${ }^{39}$ However, for a situation to be presented as a single whole, it must be conceived of as an individual entity which has boundaries (cf. Filip 1993: 16). That is, even a state must have endpoints somewhere, if it is presented by View all. I assume that a state has endpoints somewhere but that the endpoints are not clearly marked in the temporal schema of a state so that we cannot refer to them specifically. Just having endpoints somewhere is enough for a state to be taken as a unit and presented by View all. 
interval or stages suggests that 'part' presented by imperfective is durative. ${ }^{40} \mathrm{By}$ contrast, I conceive of 'part' of a situation presented by View a situation intersecting at a punctual point on the time axis, borrowing Jackendoff's (1996) terms. Corresponding to a cross-section of a situation, 'part' presented by View $_{\text {part }}$ is not perceived as durative but as punctual. It is important that View part necessarily presents a situation 'right now', irrespective of whether the situation actually continues 'for five mimutes' or 'from $5 \mathrm{pm}$ to $6 \mathrm{pm}$ '. 41

Thus, on the one hand, Viewall and View part are similar to perfective and imperfective in that they are both characterized by the distinction between all and part in the domain of situations. On the other hand, Viewall behaves differently from perfective, and View part from imperfective. Unlike perfective and imperfective, View all

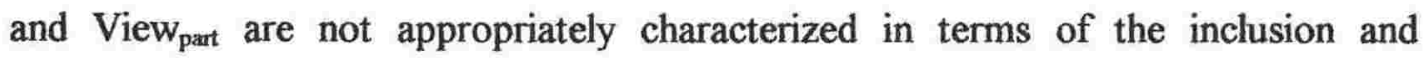
exclusion of endpoint(s). In addition, 'part' presented by imperfective and that

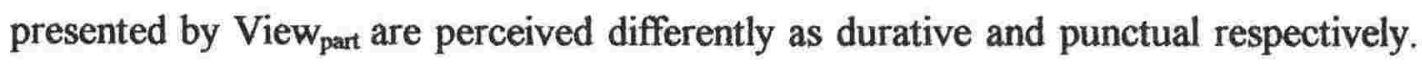
There are two logical possibilities in considering the status of View all and View part.

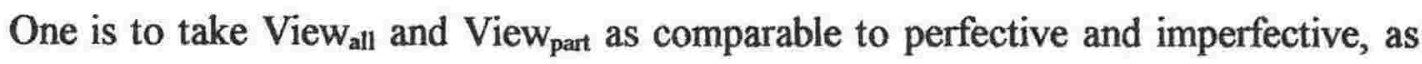
suggested by their similarities. In the view that the former operate in Japanese, and the later in English and many other languages, the difference between them are considered as cross-linguistic variations. The other possibility is to take View all and

${ }^{40}$ The duration of 'part' suggested by the use of such terms as an interval or stages is supported if overt temporal adverbials of duration such as 'for five minutes' and 'from $5 \mathrm{pm}$ to $6 \mathrm{pm}$ ' are shown to be compatible with imperfective, for example, the progressive expressed by the be + -ing form in English. (I am indebted to an examiner for pointing this out for me.) However, it is not particularly clear whether it is the case, as shown in (i) and (ii) below.

(i) a. *John is writing a book for five minutes.

b. ?John has been writing a book for five minutes

(ii) a. ${ }^{*} \mathrm{John}$ is writing a book from $5 \mathrm{pm}$ to $6 \mathrm{pm}$.

b. ?John has been writing a book from $5 \mathrm{pm}$ to $6 \mathrm{pm}$.

${ }^{41}$ Observe in (i) below that durative adverbials cannot cooccur with neutral ga-marking of the subject, which I assume to signal View part in Japanese (cf. also (5) above). (An adverbial like 'from 5 o'clock to 6 o'clock' seems incompatible with the -teiru form.)

(i) John-wa/\#ga go-hun-kan hon-o kai-tei-ru.

five-minutes-for book-Acc write-Pres-Prog

'John has been writing a book for five minutes.' 
View $_{\text {part }}$ as totally distinct entities from perfective and imperfective, as their differences suggest. This view renders their similarities coincidental.

\subsubsection{Wa/ga-marking of subjects signalling $\mathrm{View}_{\text {all }} / \mathrm{View}_{\text {part }}$}

Let us now compare the grammatical expressions of View all and View part with those of perfective and imperfective. It is generally believed that the perfective and imperfective aspects are expressed by distinct verb forms, i.e., by the presence or absence of grammatical morphemes on verbs, in many languages. In the examples in (44) below, each sentence displays imperfective aspect expressed on the main clause verb and perfective aspect on the subordinate clause verb. ${ }^{42}$

$\begin{array}{ll}\text { English: } & \text { John was reading when I entered. } \\ \text { Russian: } & \text { Ivan cital, kogda ja visel. } \\ \text { French: } & \text { Jean lisait } \text { quand j'entrai. } \\ \text { Spanish: } & \text { Juan leía cuando entré. } \\ \text { Italian: } & \text { Gianni leggeva } \text { quando entrai. }\end{array}$

(Comrie 1976: 3)

The same is observed in the Japanese equivalent for (44):

$\begin{array}{llllr}\text { Japanese: } & \text { Watashi-ga } & \text { hait-ta } & \text { toki, } & \text { John-wa yon-deita. } \\ \text { I } & \text { enter-Past } & \text { when } & \text { read-ProgPast }\end{array}$

That is, the affixes -ta and -teita attached to the verbs in (45) are seen as conveying the perfective (i.e., the past) and the imperfective (i.e., the progressive) respectively.

In contrast, Viewall and View $w_{\text {part }}$ are not expressed by verbal morphology. Rather, they are correlated with the subject marking morphemes, $-w a$ and $-g a$. Observe in the familiar examples repeated in (46)-(48) below that the described

${ }^{42}$ Comrie (1976) notes that "in English, the relation between the Progressive (e.g., was reading) and non-Progressive (e.g., entered) is rather more complex, but provided we restrict ourselves to nonstative verbs and exclude habitual meaning, then the difference between the two forms is one of imperfectivity versus perfectivity" (p. 3). 
situation is taken as either a single whole or a cross-section depending on whether the subject is marked with -wa or -ga.

(46)a. John-wa ki-ta.

John come-Past

'John came.' <the whole event in the past>

b. John-ga ki-ta.

John come-Past

'John has just come/arrived.' <the final cross-section>

(47)a. John-wa ku-ru.

come-Pres

'John will come.'

<the whole event in the future $>$

b. John-ga ku-ru.

come-Pres

'John is coming/arriving. (Here comes John.)'

$<$ a preliminary cross-section $>$

$\begin{aligned} \text { (48)a. John-wa hon-o } & \text { kai-tei-ru. } \\ \text { book-Acc } & \text { write-Prog-Pres }\end{aligned}$

'John is writing a book.' <the whole event in continuity>

b. John-ga hon-o kai-tei-ru.

book-Acc write-Prog-Pres

'John is writing a book (right now).' <an internal cross-section>

In (46), - $t a$ attached to the verb yields the past tense interpretation when the subject is marked with -wa and the described situation is taken as a single whole, and the (present) perfect interpretation when the subject is marked with -ga and the described situation being taken as a cross-section, or more specifically the final crosssection of the situation. In (47), $-r u$ yields the future tense interpretation when the subject is marked with - $w a$ and the described situation is taken as a single whole, and the proximate future interpretation when the subject is marked with $-g a$ and the described situation being taken as a cross-section, or more specifically a preliminary cross-section of the situation. And in (48), -teiru yields the static present interpretation when the subject is marked with $-w a$ and the described situation is taken as a single whole, and the dynamic progressive interpretation when the subject is marked with -ga and the described situation being taken as a cross-section, or more 
specifically an internal cross-section of the situation. These suggest that View all and View $_{\text {part }}$ are signalled by wa- and ga-markings of subjects in Japanese.

(49) Subject marker

$-w a$

$-g a$

\section{Viewpoint aspect}

Viewall

View $_{\text {part }}$

\subsubsection{Case marking and viewpoint aspects}

That Viewall and View $w_{\text {part }}$ are grammatically conveyed by subject marking morphology, $-w a$ and $-g a$, in Japanese appears as a striking contrast to the perfective and imperfective that are generally conveyed by verbal morphology. Interestingly enough, however, it has been observed in Finnish (and some Slavic languages) that the perfective and imperfective are distinguished by object marking morphology (e.g., Hainämäkki 1974, 1984, Filip 1993, Kiparsky 1995b). The examples in (50) and (51) below illustrate that when the (direct) object has the partitive case marker, the sentences receive imperfective readings, whereas when the (direct) object has the accusative case marker, the sentences receive perfective readings.
a. Join kahvia.
drank-1Sg coffee-Part
'I was drinking coffee.'
b. Join kahvin. drank-1Sg coffee-Acc 'I drank up (all) the coffee.'
(51) a. Luin kirjoja.
read-1Sg books-Pl-Part
'I was reading books.'
b. Luin kirjat.
read-1Sg books-Pl-Acc
'I read (all) the books.'

(Filip 1993: 245)

Filip (1993) and Kiparsky (1995b) independently argue that the Finnish partitive and accusative cases of direct objects have two functions, one as quantifiers over individuals and the other as markers of viewpoint aspects. The partitive case 
indicates a partial quantity of the direct object, i.e., 'part' of coffee and 'part' of books, as a quantifier, and at the same time functions as a marker of the imperfective aspect. The accusative case indicates the total quantity of the direct object, i.e., 'all' of coffee and 'all' of books, as a quantifier, and at the same time signals the perfective aspect. ${ }^{43}$ That is, the partitive and accusative markings distinguish between part and whole of individuals (as quantifiers) and also between part and whole of situations (as markers of viewpoint aspects). ${ }^{44}$ Since they are markers of noun phrases (or DPs), it seems reasonable to assume that they are primarily quantifiers to distinguish between part and whole of individuals. Then, the part-whole distinction of situations can be seen as an extension of the part-whole distinction of individuals. That is, because the part-whole distinction of individuals extends over the domain of situations, part of an individual is linked with part of a situation and the whole of an individual is linked with the whole of a situation.

Analogously, wa- and $g a$-markings of subjects in Japanese can be seen as signalling two functions, one as quantifiers over individuals (to distinguish between part and whole of individuals) and the other as markers of viewpoint aspects (to distinguish between part and whole of situations). Just as the part-whole distinction of direct objects is linked with that of situations in Finnish, in Japanese the part-whole distinction of subjects is linked with that of situations. Let me illustrate this with reference to the examples in (4) above, which are repeated in (52) below.
a. John-wahon-o kai-tei-ru. book-Acc write-Prog-Pres
'John is writing a book.'
b. John-ga hon-o kai-tei-ru. book-Acc read-Prog-Pres
'John is writing a book (right now).'

\footnotetext{
${ }^{43}$ Another thing to notice is the definite/indefinite distinction. The notion of partial quantity accompanies the notion of indefiniteness, and the notion of total quantity goes with the notion of definiteness (cf. Filip 1994, Lee 1995). I will discuss this point later in 2.4 .
}

\footnotetext{
${ }^{44}$ Mourelatos (1978), Bennett and Partee (1972), and Bach (1986) discuss the notion of partitivity involved in the semantics of situations.
} 
Recall that (52b), whose subject is marked with $-g a$, can only be uttered on the spot where the speaker perceives the actual situation in which John is writing a book, while (52a), whose subject is marked with $-w a$, can be uttered even in a speech situation, for example, where you are introducing John, who is standing next to you and hence not writing a book at the time of speech, as in "This is John. John is writing $a$ book". This indicates that the wa-marked John in (52a) refers to a rather conceptual holistic individual, which transcends and subsists beyond the spatiotemporal location in which it is perceived, whereas the ga-marked John in (52b) strictly refers to the actual manifestation of John at the time and place of speech. Crucially, when the subject is taken conceptually and holistically, the described situation is also taken conceptually and holistically as transcending and subsisting beyond the spatiotemporal location of perception. On the other hand, when the subject is seen physically as a spatiotemporally bounded manifestation, the described situation is also taken as being strictly bounded at the spatiotemporal location of perception. That is, spatiotemporally bounded subjects are necessarily predicated by spatiotemporally bounded situations, whereas spatiotemporally unbounded subjects are predicated by spatiotemporally unbounded situations.

Thus, part of an individual is linked with part of a situation and the whole of an individual is linked with the whole of a situation, presumably because the part-whole distinction of individuals extends over the domain of situations. If we assume that waand $g a$-markings of subjects are primarily quantifiers to distinguish between whole and part of individuals, since they are markers of noun phrases (or DPs), just like the Finnish accusative and partitive markings, then it can be seen as a natural consequence that they signal View all and $\mathrm{View}_{\text {part }}$ to distinguish between whole and part of situations.

However, in Finnish the part-whole distinction of situations is linked with that of direct objects, whereas in Japanese the part-whole distinction of situations is linked 
with that of subjects. ${ }^{45}$ The link between direct objects and situations is in line with recent studies such as Krifka (1989, 1992), Levin and Rappaport (1995), and Tenny $(1987,1992)$ which indicate a close interrelation between events and direct objects, that is, how internal arguments, when combined with the interpretation of the verb, can affect the interpretation of the VP so formed. On the other hand, the link between subjects and situations appears rather peculiar, since subjects have been seen as rather extraneous to events. For example, Marantz (1984) proposes that while internal arguments are arguments of the verb, external arguments are not arguments of the verb (but arguments of VP, which is a composition of the verb with its internal arguments). Pursuing Marantz's view, Kratzer (1994) proposes a syntactic theory which detaches the external argument from its verb. Bresnan (1982) and Grimshaw (1990) take a less radical view that the subject has 'a distinguished role as final argument in the semantic composition of sentence' (Bresnan 1982: 350). From these perspectives, it is not expected that markings on subjects affect the interpretation of events or situations.

${ }^{45}$ Although direct objects are marked with either $-o$ or $-g a$ in Japanese (except for the possibility of contrastive $w a$-marking), unlike the Finnish accusative and partitive objects, the alternation between $-o$ and -ga does not correlate with the whole-part distinction. The examples in (i)-(iii) below show that the alternation between $o$ - and $g a$-markings of objects depends on the predicate type: roughly activities take $o$-marked objects (the (a) sentences), whereas static states take $g a$-marked objects (the (b) sentences) (cf. Kuno 1973, II.4).

(i) a. Taro-wa eigo-0 narat-tei-ru.

English study-Prog-Pres

'Taro is studying English.'

b. Taro-wa eigo-ga deki-ru.

English be good at-Pres

'Taro is good at English.'

(ii) a. Taro-wa Hanako-o aishi-tei-ru.

'Taro loves Hanako.'

love-Prog-Pres

b. Taro-wa Hanako-ga suki-da.

'Taro likes Hanako.'

like-Cop(Pres)

(iii) a. Mary-wa piano-o hi-ku. piano play-Pres 'Mary plays the piano.'

b. Mary-wa piano-ga hik-e-ru piano play-can-Pres

'Mary can play the piano.' 
A notable exception to this is Verkuyl (1972), which discusses the role of the subject in the composition of the aspects. With Dutch examples, Verkuyl shows that the subject-NP and the verb are involved in the composition of the aspects in the same way as the direct object-NP and the verb are.

Even more crucial to my analysis is Carlson (1977), which has pointed out an important relation between subjects and predicates. He claims that 'stages' are predicated by 'stage-level predicates', while 'individuals' are predicated by 'individuallevel predicates', where a stage is defined roughly as 'a spatially and temporally bounded manifestation of something', and an individual as 'that whatever-it-is that ties a series of stages together to make them stages of the same thing' (Carlson 1977: 68). Predicating stages, which are spatiotemporally bounded manifestations of something, stage-level predicates seem to represent spatiotemporally bounded situations. So, that stages are predicated by stage-level predicates essentially means that spatiotemporally bounded subjects are predicated by spatiotemporally bounded situations. On the other hand, individual-level predicates, predicating individuals, which are spatiotemporally unbounded or transcending beings, seem to represent spatiotemporally unbounded or transcending situations. Therefore, that individuals are predicated by individual-level predicates essentially means that spatiotemporally unbounded subjects are predicated by spatiotemporally unbounded situations.

It is important to note that Carlson thus originally defines stage-level and individuallevel predicates as predicates of stages and predicates of individuals respectively, because subsequently stage-level and individual-level predicates have been taken rather independently from their subjects and often the distinction is understood mainly in terms of whether they represent transient states such as my sitting on a chair now (stage-level predicates) or more or less permanent situations such as my having brown eyes (individual-level predicates) (e.g., Kratzer 1989).

Crucially, I take Carlson's insight into the necessary agreement between the semantic type of subjects and that of predicates as indicating that the partitivity and the totality of individuals extend over the domain of situations. A stage can be considered as a part of an individual, while an individual can be considered as a whole individual in its entirety. Carlson's claim that a stage is necessarily predicated by a stage-level predicate can be taken as indicating that the partitivity of the subject noun phrase in the 
domain of individuals extends over the domain of situations. Similarly, the claim that an individual is necessarily predicated by an individual-level predicate can be taken as indicating that the totality of the subject noun phrase in the domain of individuals extends over the domain of situations.

In this light, $w a$ - and $g a$-markings of subjects in Japanese grammatically distinguish between individuals and stages. And $w a$ - and $g a$-markings of subjects are correlated with the two types of predicates, just in accordance with the claim that individuals and stages are necessarily predicated by individual-level and stage-level predicates respectively. That is, $w a$ - and $g a$-markings of subjects are correlated with the View ail and View part $_{\text {interpretations of predicates. This implies that the View }}$ and View $_{\text {part }}$ interpretations correlated with $w a$ - and ga-markings of subjects in my analysis correspond respectively to individual-level and stage-level predicates in Carlson's terms.

Note, however, the distinction between individual-level and stage-level predicates correlated with $w a$ - and $g a$-markings of subjects in Japanese appears more subtle than it is generally understood. For example, in my analysis a single predicate in the same tense/aspect form, (hon-o) kai-teiru 'is writing (a book)', is taken as either an individuallevel or a stage-level predicate, depending on whether it predicates of a wa-marked individual subject or of a ga-marked stage subject, as seen in (52) above. Thus, the dividing line between stage- and individual-level predicates runs even through a seemingly identical predicate. Still, such a division between stage- and individual-level predicates fits with the general understanding that individual-level predicates represent more or less permanent situations such as somebody's writing a book as an occupation, whereas stagelevel predicates represent transient states such as somebody's writing a book right now.

To avoid a confusion, we might call them individual-level and stage-level predications (to be distinguished from individual-level and stage-level predicates), which in principle correspond to but may not necessarily coincide with what are generally considered as individual-level and stage-level predicates. ${ }^{46}$ Rather, individual-level and stage-level predications closely correspond to what are originally distinguished as individual-level and stage-level predicates, i.e., predicates that predicate of individuals and those that predicate of stages.

\footnotetext{
${ }^{46}$ I am indebted to Elizabeth Pearce (p.c.) for this idea.
} 
Another point to note is that although ga-marking of subjects in Japanese and the partitive marking in Finnish are both seen as designating partial quantity, their distributions seem to differ. Essentially, the grammatical encoding of partitivity can apply even to a single individual subject in Japanese, while it only applies to a collective group or quantity in Finnish. In (52b) above, for example, -ga marks John, a single individual, to designate one of its stages. Notice that the notion of stages obtains when the notion of partitivity applies to a single individual. By contrast, Kiparsky (1995b: 29) shows that in Finnish partitive subjects are possible only with bare indefinite plurals and mass nouns but not with a singular bear, for example, as seen in (53) below. Since the partitive marking does not apply to a single individual, it does not have a global function of distinguishing stages from individuals (like ga-marking in Japanese). (Note that the Finnish partitive case can thus attach to subjects as well as direct objects, but that partitive subjects show only the NP-related function of partitive case as a quantifier, never the aspectual function. ${ }^{47}$ )

${ }^{47}$ Moreover, according to Kiparsky (1995b), partitive subjects only occur with intransitive verbs (hence the ungrammaticality of (ia) below), and only with the subclass of so-called PRESENTATIONAL VERBS (EXISTENTIAL VERBS, in the traditional terminology of Finnish grammarians). They can be either preverbal or post verbal, as seen in (ib) and (ic).

(i) a. \#Karhu-j-a so-I hunaja-a bear-PI-Part eat-Past-3Sg honey-SgPart

'There were bears eating honey' (transitive verb)

b. Piha-lla leikki-I laps-I-a courtyard-Adess play-3Sg child-Pl-Part 'There are children playing in the courtyard'

c. Laps-i-a leikki-I piha-lla child-PI-Part play-3Sg courtyard-Adess 'There are children playing in the courtyard'

d. \#Piha-lla hymyile-e laps-I-a courtyard-Adess smile-3Sg child-P1-Part 'There are children smiling in the courtyard'

e. \#Laps-i-a hymyile-e piha-lla child-PI-Part smile-3Sg courtyard-Adess

'There are children smiling in the courtyard'

(Kiparsky 1995b: 30)

The Japanese partitive equivalent, -ga, does not have such restriction and can occur with most of verbs, except intrinsically stative verbs such as copula (cf. 2.3 .3 above and 3.3 below).

Nevertheless, it is interesting to note that the Japanese - $g a$ also occurs in presentational or existential sentences. 
(53)a. Karhu kuol-i.

Bear-SgNomdie-Pst-3Sg

'The bear died.'

b. \#Karhu-a kuol-i.

Bear-SgPart die-Pst-3Sg

c. Karhu-t kuol-i-vat.

Bear-PINom die-Pst-3Sg

'The bears died.'

d. Karhu-j-a kuol-i.

Bear-PIPart die-Pst-3Sg

'Bears died.'

(Kiparsky 1995b: 29)

To sum up, wa- and $g a$-markings of subjects in Japanese are comparable with the accusative and partitive markings of direct objects in Finnish in that the affixes to noun phrases (or DPs), rather than to verbs, convey viewpoint aspects, View all and View $_{\text {part, }}$ or perfective and imperfective. In both cases, we can assume that the markers primarily distinguish between part and whole of individuals as quantifiers and that because the part-whole distinction of individuals extends over the domain of situations, they also distinguish between part and whole of situations as a natural consequence. A crucial difference is, however, that in Finnish, situations are grammatically identified with direct objects in the part-whole distinction, whereas in Japanese they are grammatically identified with subjects.

In that situations are linked with subjects in the part-whole distinction, the observed phenomenon in Japanese corresponds to the relation between stages/individuals and stage-level/individual-level predicates as originally claimed by Carlson (1977). Waand $g a$-markings of subjects grammatically distinguish between individuals and stages, which are necessarily predicated by individual-level and stage-level predicates

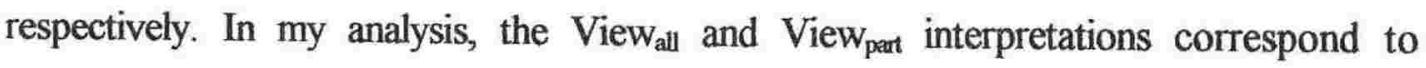
individual-level and stage-level interpretations respectively.

\subsubsection{Summary}

Separating $\mathrm{R}$ from $\mathrm{S}$ and $\mathrm{E}$ in our tense formula, $\mathrm{I}$ have argued that $\mathrm{R}$ operates as a viewpoint aspect. An $R$ which is aligned with $S$ is a viewpoint aspect which 
presents 'part' of a situation manifested at a precise temporal point (i.e., a crosssection of a situation), and I call it View part. An $\mathrm{R}$ which is aligned with $\mathrm{E}$ is a viewpoint aspect which presents 'all' of a situation without decomposing it, and I call it Viewall.

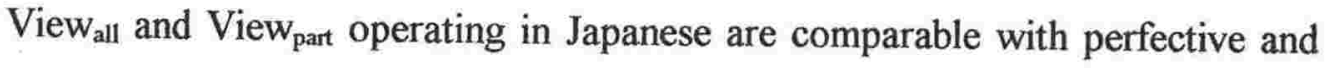
imperfective observed in many other languages in that they distinguish between all

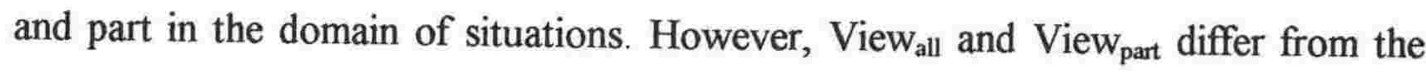
perfective and imperfective characterized by Smith (1991) in that they are not to be distinguished by inclusion and exclusion of endpoint(s). In addition, while Smith conceives of 'part' presented by the imperfective as an interval or stages of a situation which suggest duration, I conceive of 'part' presented by View cross-section of a situation intersecting at a precise temporal point and hence very punctual.

Moreover, while perfective and imperfective are expressed by verbal morphology in many languages, View all and View part in Japanese are grammatically conveyed by subject marking morphemes, $-w a$ and $-g a$, respectively. In that the affixes to noun phrases (or DPs) convey viewpoint aspects, wa- and ga-markings of subjects in Japanese are comparable with the accusative and partitive markings of direct objects in Finnish, which have been claimed to convey perfective and imperfective aspects respectively (Filip 1993, Kiparsky 1995b). In that situations are linked with subjects in the part-whole distinction, the observed phenomenon in Japanese corresponds to the relation between stages/individuals and stage-level/individual-level predicates as originally claimed by Carlson (1977).

\section{4. $W a$ - and $g a$-markings of subjects and the English articles the and $a(n)$}

Having said that $w a$ - and $g a$-markings of subjects in Japanese distinguish between whole and part of individuals, in this section I discuss that the English articles, the and $a / a n$, also have a function of making the part-whole distinction of 
individuals to some extent. ${ }^{48}$

Return to Kuroda's famous examples repeated in (54) below and observe (once again) how they are translated into English. The subject neko 'cat' is translated into the cat in (54a) and the or a cat in (54b). That is, the wa-marked cat is necessarily taken as definite, whereas the ga-marked cat is either definite or indefinite.

(54) a. Neko-wa asoko-de nemut-tei-ru. cat there-at sleep-Prog-Pres

'The cat is sleeping over there.' <individual-level>

b. Neko-ga asoko-de nemut-tei-ru. cat there-at sleep-Prog-Pres 'The/A cat is sleeping over there.' <stage -level>

The same is observed in (55) and (56) below. That is, the wa-marked subjects are translated with the, whereas the $g a$-marked subjects are translated with either the or $a$.

${ }^{48}$ Cf. Filip (1994), which shows that the semantic differences expressed by articles in English (particularly on direct objects) are conveyed by verb modifiers (which convey viewpoint aspects) in Slavic languages. Observe in the Czech examples in (i) and (ii) below that with the perfectivizing prefixes on the verbs in (ib) and (iib), the noun phrases (with mass and plural noun heads) must be translated with the definite article the in English. On the other hand, in the absence of perfectivizing prefixes in (ia) and (iia), the noun phrases most closely correspond to English noun phrases with no articles (or perhaps with the unstressed some).

(i) a. Pil kavu.

drank-Sg-Masc coffee-Acc

'He was drinking (some) coffee.'

b. Vypil kavu.

Pref-drank-Sg-Masc coffee-Acc

'He drank up (all) the coffee.'

(ii) a. Pletla svetry.

knitted-Sg-Femsweaters-Pl-Acc

'She was knitting sweaters.'

b. Upletla svetry.

Pref-knitted-Sg-Fem sweaters-Pl.Acc

'She knitted (all) the sweaters.'

[i.e., she finished knitting all the sweaters.]

(Filip 1994: 229)

Crucially, the presence and absence of the perfectivizing prefixes provide the only formal clue as to how the mass and plural noun phrases (which are the direct objects of the verbs) are to be interpreted. 
(55)a. Sensei-wa ki-ta.

teacher come-Past

'The teacher came.'

b. Sensei-ga ki-ta.

teacher come-Past

'The/A teacher has come/arrived.'

(56)a. Sensei-wa ku-ru.

teacher come-Pres

'The teacher will come.'

b. Sensei-ga ku-ru.

teacher come-Pres

'The/A teacher is coming. (Here comes a/the teacher.)'

This shows certain correspondence between $w a$ - and $g a$-markings of subjects in Japanese and the uses of the definite and indefinite articles, the and $a(n)$, in English (when the subject phrase is a common noun).

\subsubsection{Familiar vs. novel}

Firstly, both wa- and ga-markings of subjects in Japanese and the definite and indefinite articles, the and $a(n)$, in English are seen as distinguishing between familiar and novel referents in the discourse. As for wa/ga-subjects, it has been claimed that $w a$-marked subjects refer to familiar referents, whereas $g a$-marked subjects refer to novel referents in the current discourse (e.g., Chafe 1976, Halliday 1967-1968, Haviland and Clark 1974, Inoue 1980, Kuno, 1972, 1973, Prince 1981). (Roughly, the first mention in the discourse is taken as novel, and a subsequent reference to it is taken as familiar.) Similarly, as for the English definite and indefinite articles, it is generally believed that the indicates the familiarity of a referent, whereas $a(n)$ indicates the novelty of a referent in the current discourse.

This provides an explanation for the fact that $w a$-marked subjects in Japanese are translated with the definite article the in English, as seen in (54a), (55a) and (56a) above. That is, a familiar referent is marked with -wa in Japanese (if it is a 'subject') and the in English.

As for $g a$-marked subjects, however, while the above predicts that they are translated with the indefinite article $a(n)$ in English, as they refer to novel referents in 
the discourse, it is shown in (54b), (55b) and (56b) above that ga-marked subjects can be translated not only with $a(n)$ but also with the. Since the indicates that the referent is known to the interlocutors, while $a(n)$ indicates basically that it is the first mention in the discourse, this suggests that the referents of ga-marked subjects may or may not be novel. Here, we need to distinguish distinct levels of novelty. That is, although the indicates that the referent of a noun phrase is known to the interlocutors, a noun phrase with the can be presented and taken as novel to the current discourse. For example, in (57a) and (57b) below, both a teacher and the teacher are taken as novel in the sense that they have just been brought into the current discourse. The difference between the two sentences is that the interlocutors are assumed to have no knowledge about the teacher in (57a), but to have some previous knowledge about the teacher in (57b).

(57)a. Here comes a teacher.

b. Here comes the teacher.

It is exactly in this sense that the referents of $g a$-marked subjects are novel to the current discourse. That is, a novel referent in the current discourse may have been known to the interlocutors (because of their previous knowledge), in which case it takes the in English, while it may well be totally unknown, in which case it takes $a(n)$. Therefore, ga-marked subjects whose referents are novel to the current discourse are translated with either the or alan, depending on whether the referents are known or unknown to the interlocutors, as shown diagrammatically in (58b) below. On the other hand, familiar referents of wa-subjects are necessarily known to the interlocutors, as in (58a). ${ }^{49}$

\footnotetext{
${ }^{49}$ This in fact represents only one dimension of the uses of the and $a(n)$. Other uses of the and $a(n)$ include 'kind'-referring the and $a(n)$ in generic sentences (corresponding to the use of bare plurals), as shown in (i).

(i) The/A whale is a mammal. (=Whales are mammals.)

There is also a restriction on the uses of the and $a(n)$ such that they are normally not allowed with pronouns and proper names designating unique referents.
} 
(58)

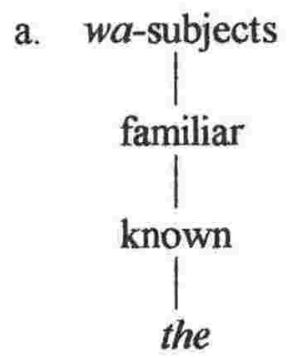

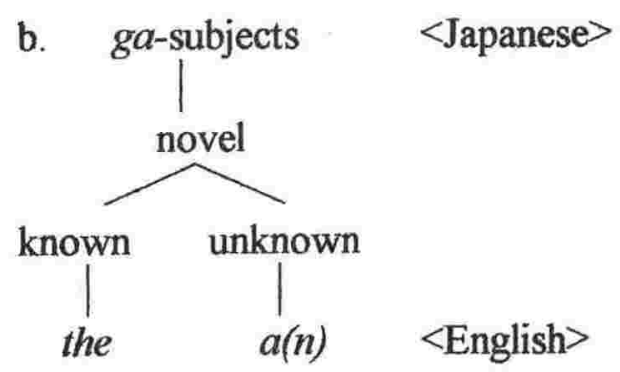

\subsubsection{Whole vs. part}

While it is a commonly held view that wa- and ga-markings of subjects distinguish between familiar and novel referents in the discourse, I have argued in 2.3.5 above that they distinguish between whole and part of individuals. Essentially, familiar referents correspond to total individuals, and novel referents correspond to partial manifestations of individuals. Such correspondence between the referential familiarity/novelty and the whole/part distinction of individuals can be explained as follows. The interpretation of familiar referents depends on linking to the antecedents in the discourse ${ }^{50}$ This linking establishes the totality or the continuity in which the referents are perceived. Therefore, familiar referents linked to the antecedents are necessarily interpreted as whole 'individuals'. On the other hand, novel referents, which lack antecedents to be linked to, are interpreted solely on the basis of their actual manifestations at the time of utterance. Without being linked to other manifestations, novel referents are not perceived in their totality or continuity beyond the spatiotemporal location of one particular manifestation. Therefore, novel referents are taken as 'stages' of individuals manifested at punctual spatiotemporal locations.

Thus, in my view the familiarity of a referent in the discourse is interrelated with the totality of a referent in our cognition, i.e., the total 'individual' interpretation, whereas the novelty of a referent is interrelated with the temporality of a referent, i.e., the transient 'stage' interpretation. Adding another level representing the part-whole distinction of individuals, the diagrams in (58) above are revised as in (59).

${ }^{50}$ The physical tokens in the actual speech situation can also serve as the antecedents to which the referents (particularly of ' $\mathrm{I}$ ' and 'you') are linked to be appropriately interpreted. This point is discussed more in detail in 4.5 .3 below. 

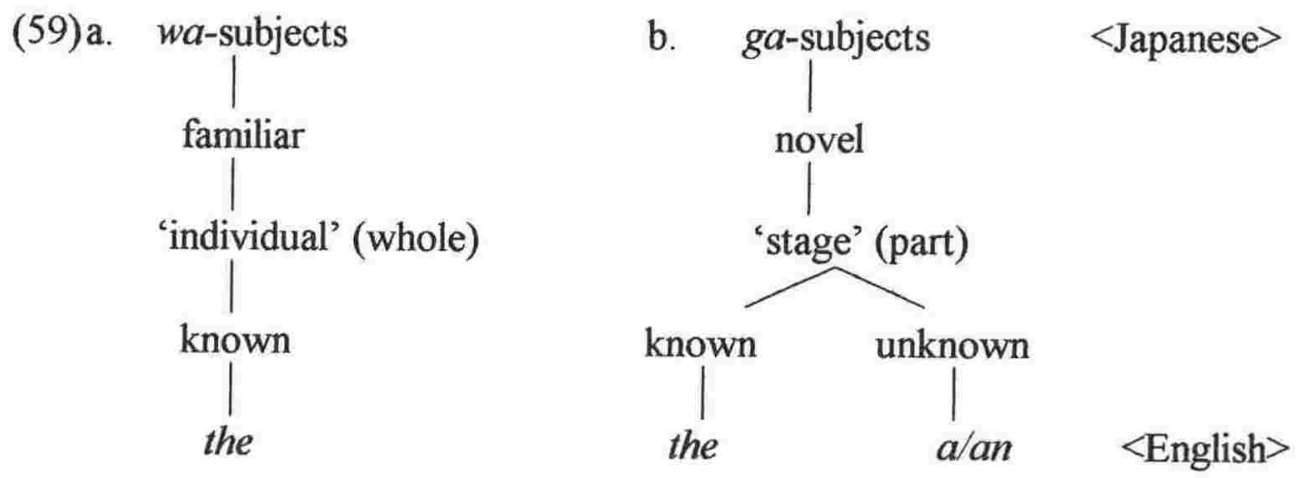

Notice in (59) that while $w a$ - and ga-markings of subjects in Japanese are straightforwardly connected to 'individuals' and 'stages' (through familiar and novel referents) respectively, the and $a(n)$ in English do not directly correspond to 'individuals' and 'stages' due to the known/unknown distinction intervening between them. However, although indirectly, the and $a(n)$ are connected to 'individuals' and 'stages' in the same way in which they are connected to familiar and novel referents respectively. This means that to the extent that the and alan designate the familiarity and novelty of referents in the discourse, they also designate the whole and part of individuals in our cognition, i.e., 'individuals' and 'stages'.

It has been pointed out that the notion of total quantity is connected with the notion of definiteness because total quantity necessarily has an exact and discernible limit (Filip 1994, Lee 1995). Moreover, the existence of total quantity is absolute and "omnitemporal". 51 Therefore, it is reasonable that the definite article the implies the exact and discernible limit and/or the absolute, omnitemporal existence of total quantity.

On the other hand, the existence of partial quantity is contingent and relative to time. It is probably in such indeterminacy that the notion of partial quantity is connected with the notion of indefiniteness. Just like the definite article the implies the absolute existence of total quantity, the indefinite article $a(n)$ implies the temporary existence of partial quantity. (The fact that sentences with indefinite subjects are taken as describing temporary existence and often identified as 'existential' supports that the indefinite article $a(n)$ indicates the temporary existence of a referent.)

\footnotetext{
51 The term 'omnitemporal' is used in Bahloul (1994).
} 
Thus, the and $a(n)$ seem to have a function of distinguishing between whole and part of individuals or between 'individuals' and 'stages' in our cognition, corresponding to their function of distinguishing between familiar and novel referents in the discourse. It follows that the part-whole distinction designated by $w a$ - and $g a-$ markings of subjects in Japanese is partly expressed by the and $a(n)$ in English.

Finally, note that while I point to a certain semantic correspondence between $w a$ and -ga in Japanese and the and $a(n)$ in English, it goes without saying that there are many apparent differences between them. To begin with, the use of $a(n)$ in English is restricted only to count nouns, whereas the mass-count distinction is irrelevant to the uses of - $w a$ and $-g a$ in Japanese. While 'kind' subjects of generic sentences are necessarily marked by -wa in Japanese, they are expressed by either the or $a(n)$ plus singular or bare plurals in English. While $-w a$ and $-g a$ are generally available to any noun phrases (which are the subjects of sentences), the and $a(n)$ are not available to some noun phrases including pronouns and proper names. ${ }^{52,53}$ For instance, while he as an 'individual' subject and as a 'stage' subject, or John as an 'individual' subject and as a 'stage' subject are distinguished by -wa and -ga in Japanese, they are not grammatically distinguished in English. In any case, the discussions above are not meant to suggest syntactic correspondence between the Japanese $w a$ - and $g a$-particles and the English articles themselves.

Nevertheless, in 4.6 .2 below I will discuss some compatibility between $w a$-marked subjects in Japanese and the-subjects in English and between ga-marked subjects in Japanese and $a(n)$-subjects in English in terms of their structural positions.

\subsection{Conclusion}

In this chapter, I have argued that $w a$ - and $g a$-markings of subjects correlate with (i) two different types of evaluation time, which are distinguished as 'original' and 'new', (ii) two types of $R$; one that coincides with $S$ but not with $E(R=S / \neq E)$

\footnotetext{
${ }^{52}$ It is however possible for a proper name to take an article as in 'the Mary that we met yesterday' and 'the Marys that I know'.

${ }^{53}$ When it comes to pronouns, wa- and $g a$-markings apply differently to the first and second person pronouns on the one hand and the third person pronouns on the other (see Section 4.5 below.)
} 
and the other that coincides with $\mathrm{E}$ but not with $\mathrm{S}(\mathrm{R}=\mathrm{E} / \neq \mathrm{S})$, and (iii) two types of viewpoint aspect, one that focuses 'part' of a situation manifested at a precise temporal point $\left(\mathrm{View}_{\mathrm{par}}\right)$ and the other that focuses 'all' of a situation without decomposing it (Viewall).

$\begin{array}{llll} & & -g a & -w a \\ \text { i. Evaluation Time } & \text { original }(t) & \text { new }\left(t^{\prime}\right) \\ \text { ii. } & \mathrm{S}, \mathrm{E}, \mathrm{R} & \mathrm{R}=\mathrm{S} / \neq \mathrm{E} & \mathrm{R}=\mathrm{E} / \neq \mathrm{S} \\ \text { iii. } & \text { Viewpoint Aspect } & \text { View }_{\text {part }} & \text { View }_{\text {all }}\end{array}$

Due to the availability of two types of evaluation time, two types of $R$, or two types of viewpoint aspect conveyed by $w a$ - and $g a$-marking of subjects, a single predicate with the same tense/aspect marker can yield two distinct temporal and aspectual interpretations in a perfect correlation to $w a$ - and $g a$-marking of the subject.

Defining a correlation between wa/ga-marking of subjects and tense/aspect interpretations, this analysis suggests an interrelation between subject marking and tense/aspect in the syntax. In particular, it points to the need to encode the distinction between the two types of evaluation time, $\mathrm{R}$, or viewpoint aspect in our syntactic representation, if we assume some syntactic mechanisms to account for wa/gamarking of subjects. I shall pursue this line of investigation in Chapter 4. 


\section{Appendix to Chapter 2}

\section{Present tense}

\section{Overlap relation}

Although Reichenbach (1947) represented the present tense with S,R,E, which signifies that all three points, $\mathrm{S}, \mathrm{R}$, and $\mathrm{E}$, coincide with one another, I have proposed the representation to be modified to the following two representations.

(1) a. $\mathrm{S}(\mathrm{R}), \mathrm{E}$

b. $S, E(R)$

It is important that I use the notation ',' in these representations to represent a relation of overlap rather than a relation of coincidence. It has been pointed out by Comrie (1985) and others that the literal coincidence between $\mathrm{S}$ and $\mathrm{E}$ is hardly observed in the semantics of the present tense. Rather than coincidence of $S$ and $E$, inclusion of $S$ in $E$ or overlap between $S$ and $\mathrm{E}$ seems to characterize various uses of present tense. ${ }^{1}$ For example, the state or the process described with the present tense in (2a) and (2b) below are taken as holding at the present moment, but having began before the present moment and may well be continuing beyond the present moment. When the present tense is used with habitual aspectual meaning as in (2c) below, it refers to a habit, or a characteristic situation, which holds at the present moment but which is not restricted only to the present moment.

(2) a. The Eiffel Tower stands in Paris.

b. The author is working on chapter two.

1 Demirdache and Uribe-Etxebarria $(1998 \mathrm{a}, \mathrm{b}, \mathrm{c})$ also argue that Present Tense (as well as Progressive Aspect) should be analyzed as a relation of inclusion. 
c. John goes to work at eight o'clock every day.

(from Comrie 1985)

Thus, the present tense is characteristically used to refer to a situation holding at the present moment but occupying a much longer period of time than the present moment (cf. Comrie 1985). In these cases, E includes S, as illustrated in (3).

(3)

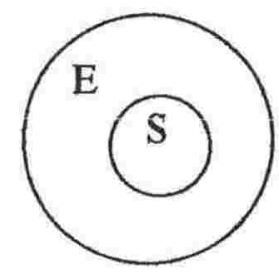

On the other hand, a relation in which $\mathrm{S}$ includes $\mathrm{E}$ seems less common but can also be observed with the present tense, for example, used in a horseracing commentary, as in (4). ${ }^{2}$

(4) Red Rover crosses the finishing line.

Although we normally take a commentator's utterance of this sentence as simultaneous with the situation being described, i.e., the event of Red Rover's crossing the finishing line, the event of crossing in fact takes place so instantaneously that it should not take as long as what it takes to utter the sentence. In such a case, $\mathrm{S}$ includes $\mathrm{E}$, as illustrated in (5).

(5)

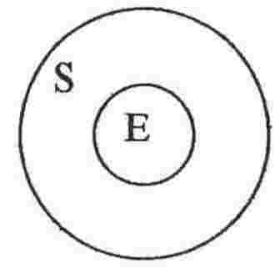

Another use of the present tense is found in performative sentences, as in (6) below. The performative use of the present tense expresses a literal 
coincidence between $\mathrm{S}$ and $\mathrm{E}$, as illustrated in (7) below. Utterance of (6a) constitutes the promise to pay ten pounds, and utterance of $(6 \mathrm{~b})$, under appropriate circumstances, constitutes the act of naming the ship.

a. I promise to pay you ten pounds.

b. I name this ship the 'Titanic'.

(from Comrie 1985)

(7)

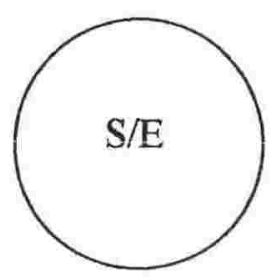

Another logical possibility of an overlap relation is a case illustrated in (8) below. However, I do not find any instances of such a case.

(8)

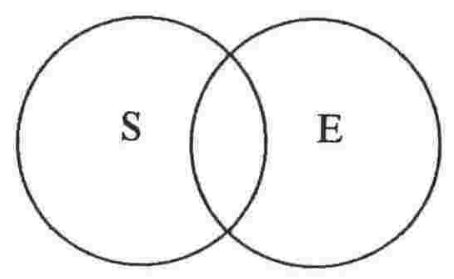

Therefore, I take the overlap relation of S,E in the representations $\mathrm{S}(\mathrm{R}), \mathrm{E}$ and $\mathrm{S}, \mathrm{E}(\mathrm{R})$ for the present tense as including the three distinct relations between $\mathrm{S}$ and $\mathrm{E}$ as illustrated in (3), (5) and (7) above.

\section{Two types of present}

While the two representations for the present tense in (1) above commonly denote an overlap relation between $\mathrm{S}$ and $\mathrm{E}$, by having $\mathrm{R}$ either attached to $\mathrm{S}$ or attached to $\mathrm{E}$, they divide the semantics of the present tense into two. With $\mathrm{R}$ attached to $\mathrm{S}$, signifying that the speech time is the reference time, ' $\mathrm{S}(\mathrm{R}), \mathrm{E}$ ' represents a dynamic present interpretation that at the moment of speech, there is a situation actively occurring. On the other hand, with $\mathrm{R}$ 
attached to $\mathrm{E}$, signifying that the event time is the reference time, 'S, E(R)' represents a static present interpretation that the situation described in the sentence temporally overlaps with the utterance of the sentence and continues throughout in space and time beyond the speech time.

Among the examples we have seen above, the ' $S(R), E$ ' interpretation of present is illustrated by one reading of (2b) and (4). The relevant reading of (2b) is that the situation of John's writing a book is actually occurring and progressing at the present moment. Rather similarly, (4) conveys that the described situation of Red Rover's crossing the finishing line is actually occurring at the present moment (though it occurs instantaneously).

On the other hand, the 'S, E(R)' interpretation of present is illustrated by (2a), the other reading of ( $2 b)$, and (2c) above. The so-called generic, habitual or characterizing sentences such as (2a) and (2c) are typical examples of the ' $\mathrm{S}, \mathrm{E}(\mathrm{R})$ ' interpretation. They convey that the described situation temporally overlaps with the utterance of the sentence and continues throughout well beyond the speech time. The ' $S, E(R)$ ' interpretation of $(2 b)$ is that the situation of John's writing a book is statically continuing beyond the spatiotemporal confine of speech. In any of these cases, the described situation does not have to be manifested at the time of speech.

In performative sentences as in (6a) and (6b) above, since $\mathrm{S}$ and $\mathrm{E}$ literally coincide, the difference between ' $S(R), E$ ' and ' $S, E(R)$ ' is expected to be rather minimal. Nevertheless, the typical interpretation of a performative sentence would be represented with ' $S, E(R)$ ' (rather than ' $S(R), E^{\prime}$ ) because in my opinion the described situation is not taken as being strictly confined to the speech situation. Although the utterance of a performative sentence constitutes the situation described in the sentence, it is also typical of a performative sentence that the performer of the described situation, i.e., the subject of the sentence, is taken as an 'individual' in Carlson's (1977) terminology, which transcends the confine of speech situation. Crucially, when the subject is taken as transcending the confine of speech situation, the situation is also taken as transcending the confine of speech situation. That is, spatiotemporally transcending subjects are necessarily predicated by spatiotemporally transcending situations (cf. 2.3.5). (In Carlson's terms, 
'individuals' are necessarily predicated by individual-level predicates.) Since the described situation is not taken as being spatiotemporally bounded at the time of utterance, a performative sentence is typically represented with ' $\mathrm{S}$, $E(R)$ ', in which ' $E(R)$ ' signifies that the situation is spatiotemporally transcending or 'omnitemporal'.

However, the ' $\mathrm{S}(\mathrm{R}), \mathrm{E}$ ' interpretation is also obtainable when a potentially performative predicate is used in a commentary, just like the example in (4) above. Consider, for example, 'The prime minister promises to reduce tax'. When it is uttered as a commentary, the sentence is rather synonymous with 'The prime minister is making a promise to reduce tax

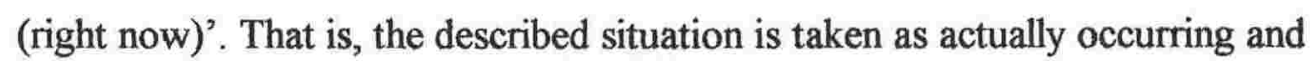
being bounded at the time of utterance.

Note that the subject of a performative sentence has to be a first person, i.e., the speaker is the performer. As I will discuss in 4.4 .2 below, rather mysteriously the first person subjects (as well as second person subjects) necessarily refer to whole 'individuals' (as opposed to 'stages'), which transcend the confine of speech situation and stand behind all of their tokens (i.e., 'stages') to connect them. When the subject is the first person and hence interpreted as an 'individual', a performative sentence is necessarily represented with 'S, E(R)' (as spatiotemporally transcending subjects are necessarily predicated by spatiotemporally transcending situations). The ' $S(R), E$ ' interpretation is only available with a third person subject, which can refer to a 'stage' (as well as to an 'individual').

\section{Present tense in Japanese}

Let us now turn to the present tense in Japanese. Firstly, observe in (9) below the Japanese equivalents to the English examples of present tense uses in (2), (4) and (6) above.

(9) a. Efferu-tou-wa pari-ni tat-tei-ru.

Paris-in stand-Prog-Pres

'The Eiffel Tower stands in Paris.'

b. Chosha-wa/ga dainishou-ni torikun-dei-ru. 
author chapter two-on work-Prog-Pres

'The author is working on chapter two.'

c. John-wa mainichi hachi-ji-ni shigoto-ni ik-u.

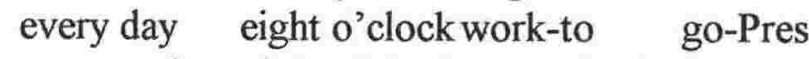

'John goes to work at eight o'clock every day.'

d. Red Rover-ga gooru-o koe-ru. goal-Acc cross-Pres

'Red Rover crosses the finishing line.'

e. Watashi-wa anata-ni jup-ponndo harau-koto-o

I you-to ten-pounds pay-Nomz-Acc yakusokusu-ru. promise-Pres

'I promise to pay you ten pounds.'

f. Watashi-wa kono-hune-o Titanic-to meimeisu-ru. I this-ship-Acc name-Pres 'I name this ship the 'Titanic'.'

We have teiru-forms in (9a-b) and ru-forms in (9c-f) to correspond to the present tense forms in English. These observations suggest that ' $\mathrm{S}, \mathrm{E}$ ' is conveyed by -teiru and -ru in Japanese. (In fact, the English present tense forms conveying ' $\mathrm{S}, \mathrm{E}$ ' also have two forms, i.e., the simple present tense form and the progressive $b e+-$ ing form.)

In the body of this thesis, I simplistically take -teiru as conveying ' $\mathrm{S}, \mathrm{E}$ ' and $-r u$ as conveying ' $\mathrm{S}<\mathrm{E}$ ', so that the correspondence between form and meaning is one to one. However, while it is true that -teiru necessarily conveys ' $\mathrm{S}, \mathrm{E}$ ', $-r u$ is in fact rather ambiguous between ' $\mathrm{S}<\mathrm{E}$ ' and ' $\mathrm{S}, \mathrm{E}$ ', as I note in footnotes at appropriate places. This is a problem that I leave outside the scope of this thesis for the sake of simplicity but that certainly needs to be properly investigated in the future.

Another point to note is $w a / g a$-marking of subjects. Subjects are marked with -wa when the ' $\mathrm{S}, \mathrm{E}(\mathrm{R})$ ' interpretation obtains and with -ga when the ' $S(R), E$ ' interpretation obtains. In (9) above, (a), (c), (e), and (f) receive the ' $\mathrm{S}, \mathrm{E}(\mathrm{R})$ ' interpretation and they necessarily have $w a$-marked subjects, whereas (d) receives the ' $\mathrm{S}(\mathrm{R}), \mathrm{E}$ ' interpretation and has a $g a$-marked subject. The subject in $(9 \mathrm{~b})$ can be marked by either $-w a$ or $-g a$, depending on whether 
the sentence receives the ' $S(R), E$ ' interpretation or the ' $S, E(R)$ ' interpretation. 


\section{Chapter 3}

\section{Three-component analysis of aspect}

In Chapter 2, I have focused on the role of tense in relation to the wa/gamarking of subjects in Japanese. In this chapter, I shift the focus to aspect in order to get a balanced view as well as to provide a thorough analysis, because tense and aspect are so closely related that they are hardly separable. In fact, I show that it is often a matter of terminology that the same concepts can be attached different labels of tense or aspect. This is important to my thesis which ultimately accounts for both tense and aspect as a unified system in the syntax, as will be developed in Chapter 4 .

Mainly, the aspect oriented analyses in this chapter confirm the main findings from the tense oriented analyses in Chapter 2. That is, the same predicate with the same tense/aspect marker(s) can yield two distinct temporal and aspectual interpretations due to the availability of two types of evaluation time, $R$, or viewpoint aspect, which are signalled by $w a$ - and ga-markings of subjects. At the same time, however, they also show that the nice contrast between $w a$ - and ga-sentences as observed in Chapter 2 does not always show up due to the other interacting factors.

In 3.1, I begin by reviewing the denotations of the markers, $-t a,-r u$, and -teiru from the aspect perspective. Although they were assumed to convey temporal relations between $\mathrm{S}$ and $\mathrm{E}$ in Chapter 2, a certain $\mathrm{S}-\mathrm{E}$ relation corresponds to a certain aspectual meaning and therefore those markers can also be considered to denote aspects.

Section 3.2 is devoted to clarifying the ambiguity of the term 'aspect'. I show that the term 'aspect' can be used to refer to (i) S-E aspect, which is conveyed by the tense/aspect markers in Japanese, (ii) viewpoint (or grammatical) aspect, which is signalled by $w a$ - and $g a$-markings of subjects in Japanese, (iii) situation types (or lexical aspect), which is largely determined by the predicates, and (iv) the fourth kind of aspect, which results from the interaction of the first three aspects.

In 3.3 , I turn to situation types and investigate what features of situations the Japanese viewpoints, Viewall and View part, interact with. Essentially, Viewall and 
View $_{\text {part }}$ interact with situation types which determine whether the situations can be decomposed into stages or not. While View all is generally available, View part is restricted to situations which can be decomposed into stages. To the extent that it determines the decomposability of situations, the distinction between states and nonstates or the feature [ $+/-$ Stage] has an important bearing on the availability of

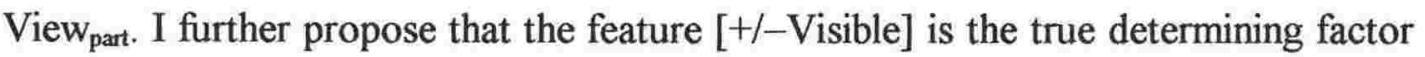
for the availability of $\mathrm{View}_{\text {part. }}$

Section 3.4 examines how S-E aspects conveyed by tense/aspect markers interact with situation types as well as viewpoints. Firstly, I show that the interpretation of -teiru depends on the [+/-Durative] feature of situations. Secondly, the presence or absence of a clear final endpoint, i.e., $[+/-$ Telic $]$, bears on the

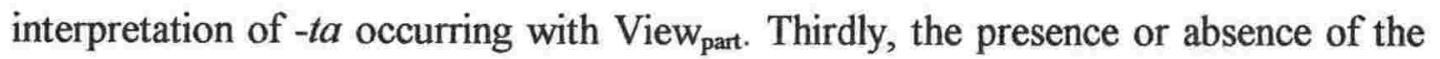
preliminary stages, i.e., [+/-Preliminary], bears on the interpretation of $-r u$ occurring with View

Having shown how situation types, viewpoint aspects, and tense/aspect markers interact with one another, I conclude in 3.5 that temporal and aspectual interpretation is compositional of those three 'aspects' expressed at different parts of a sentence. The three-component analysis enables us to account for a variety of semantic interpretations yielded by one and the same tense/aspect marker (or by one and the same string of tense/aspect markers) in Japanese, without having to assume that they are just homophonous (i.e., maintaining the assumption broadly motivated by a principle of economy that bits of language which are identical in form are also identical in meaning).

\subsection{Denotations of $-t a,-r u$, and -teiru}

In Chapter 2, we have worked with the assumption that the markers $-t a,-r u$, and -teiru designate the relations ' $>$ ', ' $<$, and ', to connect $\mathrm{S}$ and $\mathrm{E}$. These markers can also be considered to denote aspectual meanings, which will be examined one by one in this section. The discussion shows that it is only a matter of terminology whether we call it tense or aspect. 


\subsection{1. $\mathrm{S}>\mathbf{E}=$ Completed aspect}

The marker - $t a$ has been considered to carry the relation ' $>$ ' to connect $\mathrm{S}$ and $E$, i.e., ' $S>E^{\prime}$. That the time of the event is located before the time of speech suggests that the event has been completed at the time of speech. Indeed, the marker $-t a$ can also be considered to denote a completed aspect.

Recall that the marker -ta yields either the 'hot news' perfect interpretation or the simple past reading, depending on whether $\mathrm{R}$ is attached to $\mathrm{S}$ or $\mathrm{E}$ in the temporal relation ' $\mathrm{S}>\mathrm{E}$ ' (see 2.2.6 above). If we take $-\mathrm{ta}$ as conveying the aspectual meaning 'completed', the two distinct interpretations it yields can be explained as due to the

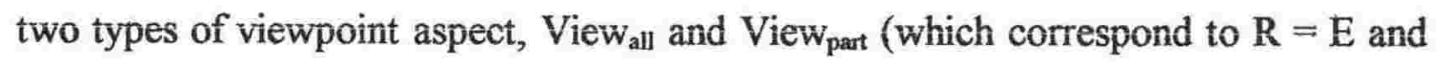
$\mathrm{R}=\mathrm{S}$ respectively). With $\mathrm{VieW}_{\text {all }}$ (corresponding to $\mathrm{R}=\mathrm{E}$ ), the completed aspect modifies an event as a whole. Since the whole event is taken as having been completed, it results in the past tense reading. On the other hand, with View part (corresponding to $\mathrm{R}=\mathrm{S}$ ), the completed aspect modifies a cross-section of an event intersecting at the present moment. Since the immediate cross-section is modified by the completed aspect, it yields an interpretation that what we have got here is the final cross-section of an event, and therefore the event has just been completed. This results in the 'hot news' perfect interpretation.

\subsection{2. $\mathrm{S}<\mathbf{E}=$ Prospective aspect}

The marker $-r u$ has been considered to convey the relation ' $<$ ' to connect $S$ and E, i.e., ' $S<E$ '. That the time of the event is located after the time of speech suggests that the event has not yet taken place at the time of speech. Indeed, the temporal relation ' $\mathrm{S}<\mathrm{E}$ ' corresponds to the aspectual meaning that the event has not yet taken place but is somehow expected to occur. I take it as an aspectual meaning because it is concerned with a stage of a situation before it occurs, which can be considered as the substructure of a situation. Let us call such an aspectual meaning 'prospective" Then, the marker $-r u$ denote an prospective aspect (which corresponds to ' $\mathrm{S}<\mathrm{E}$ ').

Recall that the temporal relation ' $\mathrm{S}<\mathrm{E}$ ' yields either the 'on-the-verge' or proximate future interpretation or the simple future reading, depending on whether $\mathbf{R}$ is attached to $\mathrm{S}$ or $\mathrm{E}$ and (see 2.2 .6 above). With the aspectual meaning 'prospective', the two distinct interpretations it yields can be explained as due to the 
two types of viewpoint aspect, Viewall and $\mathrm{View}_{\text {part }}$ (which correspond to $\mathrm{R}=\mathrm{E}$ and $\mathrm{R}=\mathrm{S}$ respectively). With $\mathrm{View}_{\text {all }}$ (corresponding to $\mathrm{R}=\mathrm{E}$ ), the prospective aspect modifies an event as a whole. Since the whole event is taken as not having taken place but will be taking place, this results in the future tense reading. On the other hand, with $V_{i e w_{p a r t}}$ (corresponding to $\mathrm{R}=\mathrm{S}$ ), the prospective aspect modifies a cross-section of an event intersecting at the present moment. Since the immediate cross-section is modified by the prospective aspect, it yields an interpretation that what we have got here is a preliminary stage of the event, and therefore the event is visibly on the verge of taking place. This results in the proximate future or 'on the verge' interpretation.

\subsection{3. $\mathrm{S}, \mathrm{E}=$ Ongoing aspect}

The string of markers -teiru has been considered to convey the relation ', to connect $S$ and $E$, i.e., 'S , E'. That the time of the event overlaps with the time of speech suggests that the event is going on at the time of speech. Indeed, the temporal relation ' $\mathrm{S}, \mathrm{E}$ ', corresponds to the aspectual meaning 'ongoing'.

Recall that -teiru yields either the dynamic progressive interpretation or the static present interpretation, depending on whether $\mathrm{R}$ is attached to $\mathrm{S}$ or $\mathrm{E}$ in the temporal relation ' $\mathrm{S}, \mathrm{E}$ ' it designates (see 2.2 .6 above). With the aspectual meaning 'ongoing', the two distinct interpretations -teiru yields can be explained as due to the two types of viewpoint aspect, View all and $\mathrm{View}_{\text {part }}$ (which correspond to $\mathrm{R}=\mathrm{E}$ and $\mathrm{R}=\mathrm{S}$ respectively). With $\mathrm{View}_{\text {all }}$ (corresponding to $\mathrm{R}=\mathrm{E}$ ), the ongoing aspect modifies an event as a whole. Since the whole event is taken as ongoing (throughout in space and time), this results in the static present interpretation. On the other hand,

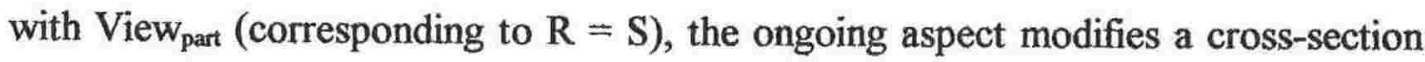
of an event intersecting at the present moment. Since the immediate cross-section is modified by the ongoing aspect, it yields an interpretation that what we have got here is one of the internal cross-sections of the event, and therefore the event is visibly going on and progressing at the present moment. This results in the dynamic progressive interpretation. 


\subsubsection{Conclusion}

I have shown above that each S-E relation has a corresponding aspectual meaning and therefore those affixes which have been assumed to convey S-E relations can also be considered to denote aspectual meanings. The two corresponding denotations of -ta, $-r u$ and -teiru are summarised in (1).

(1) Denotations of -ta, -ru and -teiru

$\begin{array}{lcc} & \text { temporal relation (S-E) } & \text { aspectual meaning } \\ -t a & > & \text { completed } \\ -r u & < & \text { prospective } \\ - \text { teiru } & , & \text { ongoing }\end{array}$

Since the S-E relations define the location of the time of the event in relation to the time of speech, they are most likely regarded as tenses. On the other hand, completed, prospective and ongoing are considered as being concerned with 'the internal temporal constituency of a situation' (Comrie 1976, 1985), and hence most likely regarded as aspects. According to such views, the S-E relation and the aspectual meaning conveyed by the same marker are differentiated as tenses and aspects respectively.

Crucially, however, my analysis suggests that S-E relations and aspectual meanings which correspond to each other are in fact two different sides of one thing. That is, those markers carry inseparable tense/aspect meanings, which denote S-E relations on the one hand and aspectual meanings on the other. If they carry inseparable tense/aspect meanings, those markers should be regarded as both tense and aspect markers, rather than either tense or aspect markers.

This stands in between the two opposing views; one that regards $-r u$ and -ta as tense markers expressing present (or non-past) and past tenses respectively (e.g., Suzuki 1977, Nakamura 1994) and the other that regards them as markers of aspects indicating the incompletion and completion of an event, or the imperfective and the 
perfective aspects (e.g., Kunihiro 1967, McGloin 1989). ${ }^{1}$ These two views are taken as conflicting because it is assumed that tense and aspect are two separate things and that it has to be either one of them that those markers express. However, my analysis suggests that those markers can be considered to express either tense or aspect, or indeed both tense and aspect. This reconciles the two opposing views, taking them both as correct, because those markers express tense and/or aspect. ${ }^{2}$

Due to the availability of two types of evaluation time, $\mathrm{R}$ or viewpoint aspect (as discussed in Chapter 2), the same S-E relation and/or the same aspectual meaning conveyed by the same marker can yield two distinct interpretations. The two distinct interpretations yielded by each of $-t a,-r u$, and -teiru are summarised in (2). ${ }^{3}$

(2) Interpretations of -ta, -ru and -teiru

$\begin{array}{llcl} & & t ' / \mathrm{R}=\mathrm{E} / \mathrm{View}_{\text {all }} & t / \mathrm{R}=\mathrm{S} / \mathrm{View}_{\text {part }} \\ \text {-ta } & \mathrm{S}>\mathrm{E} / \text { completed } & \text { Past } & \text { 'Hot news' perfect } \\ \text {-ru } & \mathrm{S}<\mathrm{E} / \text { prospective } & \text { Future } & \text { Proximate future } \\ \text {-teiru } & \mathrm{S}, \mathrm{E} / \text { ongoing } & \text { Present } & \text { Progressive }\end{array}$

Those two distinct interpretations may also be differentiated as tense and aspect. The past, future, and present interpretations yielded with a new evaluation time $\left(t^{\prime}\right), \mathrm{R}=\mathrm{E}$, or View all, are normally regarded as tenses. On the other hands, the perfect, proximate future, and progressive interpretations yielded with the original evaluation time $(t), \mathrm{R}=\mathrm{S}$, or $\mathrm{View}_{\text {part }}$ are generally regarded as aspects.

\footnotetext{
${ }^{1}$ While $-r u$ and $-t a$ are recognized as the key tense or aspect markers in Japanese, -teiru/ta seems to have been seen at a different level. For one thing, while -ru and -ta are simple markers, -teiru/ta is seemingly complex (compounded) markers (containing -ru and -ta). Another thing is that because $-r u$ and $-t a$ make a nice set of semantic opposites, -teiru/ta appears odd among them. In my analysis, however, I treat -teiru/ta on a par with -ru and -ta as major tense/aspect markers in Japanese.

${ }^{2}$ For the issue of tense-aspect controversy concerning $-t a$ and $-r u$ in Japanese, I refer the readers to Hasegawa (1999), which compares and evaluates competing analyses of $-t a$ and $-r u$. Hasegawa's discussion suggests that the crucial difference between the approach of the tense-advocates and the approach of the aspect-advocates is the direction of semantic extension, i.e., which one (of tense and aspect) is derived from the other. (Hasegawa supports the view that tense interpretation is derived from the aspectual meaning.)

${ }^{3}$ Strictly speaking, it is the -tei part of -teiru that should be regarded as conveying S,E/ongoing, since -teita is used to convey the same if the reference point, i.e., S, is recognized as "at that time" rather than "now".
} 
Thus, in both denotations and interpretations of $-t a,-r u$ and -teiru, tense and aspect are operating as two different sides of one thing. This analysis of tense and aspect as a unified system suggests that tense and aspect are unified in the syntax as well. (I will pursue this in Chapter 4.)

\subsection{Four kinds of aspects}

In the previous section, we have seen 'aspects' such as completed, prospective and ongoing, which I claim are denoted by $-t a$, $-r u$ and -teiru, and other 'aspects' such as perfect, proximate future, and progressive, which I claim are yielded by the combination of the denotations of those markers and the original evaluation time $(t)$, $\mathrm{R}=\mathrm{S}$, or View $_{\text {part }}$.

To make the term 'aspect' even more obscure, we have also been calling Viewall and View $_{\text {part }}$ 'viewpoint aspects', which generally refer to perfective and imperfective aspects in other languages. Whether $\mathrm{View}_{\text {all }}$ and View $\mathrm{w}_{\mathrm{part}}$ or perfective and imperfective, viewpoint aspects grammaticize differences in perspective that a speaker can take with respect to the event. Since viewpoint aspects are expressed by inflectional morphology (usually verbal morphology), they are also referred to as 'grammatical aspects'.

Moreover, the term 'aspect' is also used to refer to contrasts between different classes of verbs, for example, Vendler's (1967) well-known four classes of verbs, namely states, activities, accomplishments, and achievements. This kind of 'aspect' is also referred to by other terms such as 'situation type' (Smith 1991), 'aktionsart', and 'eventuality type' (Bach 1981, 1986, Parsons 1990), among which I use Smith's term in this thesis. Since aspectual classes of verbs are largely lexically determined (though it is the properties of an entire predicate, rather than of just verbs, that counts), they are also referred to as 'lexical aspects' (as opposed to 'grammatical aspects').

As for the relation between 'grammatical' and 'lexical' aspect, there are two different views. Filip and Carlson (1997) summarize as follows: 
A 'two-component theory of aspect' (the term was coined by Smith 1991) assumes that the 'grammatical' and 'lexical' aspects are separate categories whose members interact in systematic and predictable ways (cf. Comrie 1976, 1985, Dowty, 1979, Dahl 1985, Smith 1991, Filip 1993, Depraetere 1995). In contrast, what may be dubbed a 'one-component theory of aspect' assumes that there need be drawn no, or no strict line, between the 'grammatical' and 'lexical' aspects (cf. Bennett 1981, Vlach 1981, Kamp and Rohrer 1983, Hinrichs 1985, Krifka 1992, Parsons 1990).

I follow the two-component theory. In fact, I am going to extend it to a "threecomponent theory', because in addition to grammatical and lexical aspects, "aspects' such as completed, prospective and ongoing (corresponding to S-E relations) denoted by $-t a,-r u$ and -teiru in Japanese join the interaction. Furthermore, as a result of the interaction of the three aspects, the fourth kind of aspect such as perfect, proximate future, and progressive arises.

Having thus clarified the ambiguity of the term 'aspect', in the following sections I examine how the three 'aspects', namely viewpoint (or grammatical) aspects, situation types (or lexical aspects), and S-E aspects, interact with one another.

\subsection{Interaction between viewpoints and situation types}

Situation types (or lexical aspects) divide situations into different classes according to their features that determine their temporal schemata. Since viewpoints operate on the temporal schemata of situations, they necessarily interact with situation types determining the temporal schemata of situations. In this section, I investigate what features of situations the Japanese viewpoints, View an and View part,

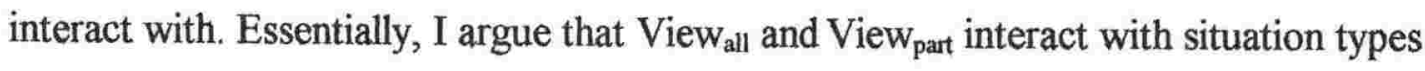
which determine the decomposability of situations, examining in particular the distinction between states and non-states, the feature $[+1-$ Stage $]$, the stagelevel/individual-level distinction, and the visibility of situations. 


\subsubsection{States vs. non-states}

Since View all and View part $_{\text {in }}$ Japanese are comparable with perfective and imperfective in other languages, let us begin by considering the features of situations that have been observed to interact with the perfective and imperfective aspects.

In terms of Vendler's (1967) four-way distinction, as illustrated in (3) below, the English imperfective, which is often equated with the progressive, is grammatical with activities, accomplishments and achievements but not with states, as shown in (4) below.

(3) a. States: e.g., know, believe, love

b. Activities: e.g., run, walk, swim, play the piano

c. Accomplishments: e.g., bake a cake, draw a circle, sing a song

d. Achievements: e.g., recognize, spot, reach, lose, find, die

(4) a. *John is liking the guitar. <state>

b. John is playing the guitar. <activity>

c. John is building a guitar. <accomplishment>

d. John is reaching the guitar. <achievement>

Note that the grammaticality of the progressive with achievements, as in (4d) above, is rather doubtful. Since achievements are distinguished from accomplishments in that they are more or less instantaneous events, they are logically incompatible with the progressive. That is, we cannot "progressivize" the actual moment of reaching the guitar. As Parson (1990; 285 n.2) suggests, there is a shift in meaning when we "progressivize" achievements. When we say John is reaching the guitar, we mean John is stretching out for the guitar or trying to touch the guitar, which is an accomplishment rather than an achievement. ${ }^{4}$ That is, (4d) is in effect no different from (4c) above in that both describe a process which has some duration and leads to a goal (i.e., an accomplishment). Since the imperfective is a viewpoint which presents 'part' of a situation, it is expected to be essential that a situation has some duration

${ }^{4}$ I will explain this kind of shift in meaning with respect to the Japanese progressive -teiru in 3.4.1 below. 
and consists of parts (or stages). The ungrammaticality of the progressive with states is ascribed to the fact that states are not conceived of as being made up of parts (or stages), though they are durative.

On the other hand, the perfective, which is roughly equated with the past tense in English, is indiscriminately available to all the four classes, as shown in (5).

(5)
a. John loved the guitar.
$<$ state $>$
b. John played the guitar.
$<$ activity>
c. John built a guitar.
$<$ accomplishment>
d. John reached the guitar.
$<$ achievement $>$

Since View $\mathrm{wall}_{\text {ll }}$ and $\mathrm{View}_{\text {part }}$ correspond to respectively perfective and imperfective in that they present 'all' and 'part' of a situation, we can reasonably

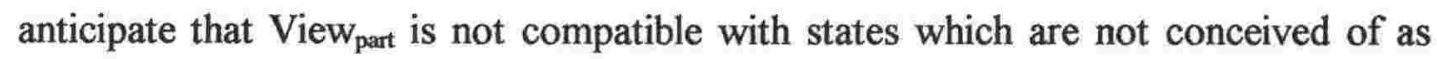
being made up of parts (or stages), while Viewall is generally available to all types of situation. Firstly, observe in (6) below the Japanese sentences equivalent to the English sentences in (4) above. They show that ga-marking of the subject, which I

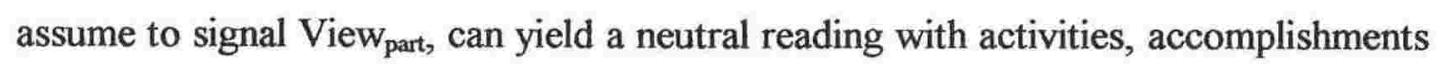
and achievements but not with states. ${ }^{5}$ The hash on (6a) indicates that the sentence is grammatical only with a focus reading that it is John who likes the guitar. ${ }^{6}$

$\begin{array}{lll}\text { (6) a. \#John-ga } & \text { gitaa-o } & \text { konon-dei-ru. } \\ & \text { guitar-Acc } & \text { like-Prog-Pres }\end{array}$

'John likes the guitar.'

b. John-ga gitaa-o hii-tei-ru.

guitar-Acc play-Prog-Pres

'John is playing the guitar.'

${ }^{5}$ In fact, te o nobasu in (6d), which literally means 'stretch one's hand (arm)', is not an achievement but an accomplishment. With a real achievement, for example, sinu 'die', -teiru yields a distinct interpretation (see 3.4.1 below).

${ }^{6}$ Kuroda (1965) calls the focus reading of a ga-marked subject "characterization", as it functions to characterize the subject by the property described by the predicate. In this respect, the focus reading of a ga-marked subject is akin to the topic/thematic reading of a $w a$-marked subject.

In fact, when a $g a$-marked subject cannot yield a neutral reading and is forced to be construed as being in focus, the sentence receives the $\mathrm{R}=\mathrm{E}$ or View all interpretation just like a sentence with a $w a$-marked subject. 
$\begin{aligned} \text { c. John-ga gitaa-o } & \text { tsukut-tei-ru. } \\ \text { guitar-Acc } & \text { make-Prog-Pres }\end{aligned}$

'John is building a guitar.'

d. John-ga gitaa-ni te-o nobashi-tei-ru.

guitar-to hand-Acc stretch-Prog-Pres

'John is reaching the guitar.'

In contrast, wa-marking of the subject, which I assume to signal View all, is good with all the four classes, as shown in (7).

(7) a. John-wa gitaa-o konon-dei-ru.

guitar-Acc like-Prog-Pres

'John likes the guitar.'

b. John-wa gitaa-o hii-tei-ru. guitar-Acc play-Prog-Pres

'John is playing the guitar.'

c. John-wa gitaa-o tsukut-tei-ru. guitar-Acc make-Prog-Pres

'John is building a guitar.'

d. John-wa gitaa-ni te-o nobashi-tei-ru. guitar-to hand-Acc stretch-Prog-Pres

'John is reaching the guitar.'

Thus, as we expect, View part has limited distribution, while View all is generally available. Essentially, the distribution of View part is restricted by the fact that some situations are not conceived of as being made up of parts.

\subsection{2. [+Stage] vs. [-Stage] situations}

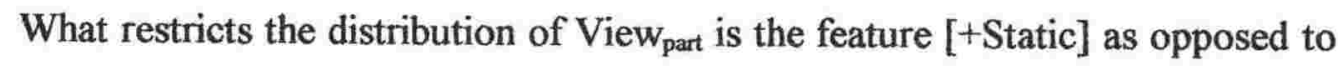
the feature [+Stage] in Smith's (1991) terminology. Smith (1991: 30) defines that a [+Stage] situation has an internal structure with successive stages of the situation, whereas a [+Static] situation is in effect a single, undifferentiated period of states, without an internal structure.

Thus defined, the features [+Stage $]$ and $[+$ Static $]$ seem totally antagonistic to each other so that $[+$ Stage $]$ suggests $[-$ Static $]$ and that $[+$ Static $]$ suggests $[-$ Stage $]$. This means that the two-term contrast is not necessary, as we can take one term and 
assign + and - values to it. While this raises the issue of why Smith does not collapse them into a single feature, ${ }^{7}$ I simply choose to use the feature [Stage] with the specification of + and - values for economical reasons.

The [-Stage] feature forces a situation to be taken as a whole. That is, if a [Stage] situation holds at all, its entire schema holds. Since it is not conceived of being made up of stages, it is simply not possible for us to assert that one or some of the stages of a [-Stage] situation hold at any given moment in time. Therefore, a [Stage] situation necessarily selects Viewall.

In contrast, the [+Stage] feature allows us to go into the stages of a situation and assert that a particular stage of a situation holds at a particular spatiotemporal location. At the same time, a [+Stage] situation can also be seen from outside as a single whole. That is, we can also assert that the entire schema of a [+Stage] situation holds at a certain time, without going into its stages. Thus, with a [+Stage $]$ situation, we have an option as to whether we take it as a whole and claim that its entire schema holds or to focus a part of it and assert that one stage of the situation holds at any given moment in time. Therefore, a [+Stage] situation is compatible with both View $_{\text {part }}$ and View all. .

\subsubsection{1. [+Stage] situations}

The examples discussed in Chapter 2 have all exhibited a good contrast in the temporal and aspectual interpretation in correlation with wa-marking (which signals $V_{\text {iew }}$ all) and $g a$-marking (which signals $V_{i e w_{p a r t}}$ ) of the subjects. This means that those situations such as (John's) coming/arriving, (John's) writing a book, and (a/the cat's) sleeping are considered to have successive stages in their temporal structure, i.e., [+Stage]. In terms of Vendler's four-way distinction, come/arrive is an achievement, write a book is an accomplishment, and sleep is an activity.

Since accomplishments and activities have durations, it is easy to conceive of them as having successive internal stages, as illustrated in (8) below.

\footnotetext{
${ }^{7}$ I appreciate an examiner's comment pointing this out for me.
} 
(8) $[+$ Durative] situations

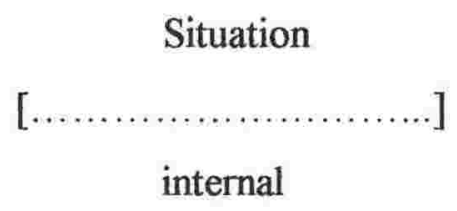

On the other hand, achievements are considered as instantaneous situations, whose temporal structure is said to consist of a single point, at which they occur instantaneously. However, if they are made up of a single temporal point, how are they conceived of having successive stages? Although it is true that instantaneous situations (such as arriving) take place at a punctual temporal point, we in fact talk about the stages leading to the occurrence of the instantaneous situation and the stages following it. Therefore, I take it that the temporal structure of instantaneous situations is made up of stages before and after the actual occurrence of the situation described by verbs, as illustrated in (9) below.

(9) [-Durative] situations

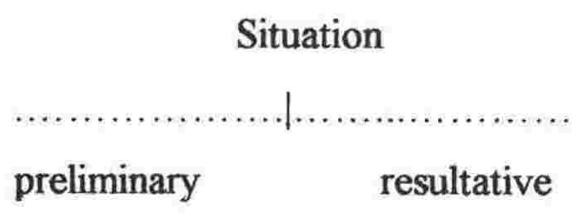

Notice that the [+Stage] feature is insensitive to the telicity of situations, i.e., whether a situation has an intrinsic goal or not. Activities are atelic, whereas accomplishments and achievements are telic. Since activities are atelic and lack an intrinsic endpoint, their stages are all homogeneous without a direction (e.g., an event of sleeping). In contrast, the stages of an accomplishment (e.g., an event of writing a book) are directed towards a goal and therefore each stage is theoretically distinct. And the stages of an achievement (e.g., an event of arriving) are combination of both. The preliminary stages are directed towards a goal, whereas the resultative stages are homogeneous without a direction. Thus, it does not matter to the [+Stage] feature whether stages are directional or homogeneous. All that matters is that there are successive stages. 
Another group of situations (pointed out by an examiner) is atelic instantaneous situations, or Smith's (1991) semelfactives, such as coughing and flapping a wing. ${ }^{8}$ With these situations, we do not conceive of successive stages, but rather just one stage. However, these situations can take either $w a$-marked or ga-marked subjects in Japanese and in correlation exhibit a contrast in the temporal and aspectual interpretation. Observe in (10) and (11) below that with wa-marked subjects, the described situations are interpreted as having taken place at a certain time in the past, whereas with $g a$-marked subjects, the described situations are interpreted as having taken place just now.

(10)a. John-wa seki-o si-ta. cough-Acc do-Past 'John coughed.'

b. John-ga seki-o si-ta. cough-Acc do-Past 'John has just coughed.'
(11)a. Hakuchou-wa
swan
tubasa-o habatai-ta. 'The swan flapped its wings.'
b. Hakuchou-ga tubasa-o habatai-ta. swan wing-Acc flap-Past 'The/A swan has just flapped its wings.'

This suggests that View part signalled by $g a$-marking of subjects does not require that a situation has successive stages. Rather, it seems to only require that a situation has a stage or stages, where it does not matter whether it has just one stage or many stages. This sounds very reasonable because View $_{\text {part }}$ presents a stage of a situation manifesting at a precise temporal point (rather than stages). In other words, it focuses just one stage of a situation. All it requires is therefore a stage, whether it is preceded and/or followed by successive stages or not.

\footnotetext{
${ }^{8} \mathrm{I}$ am indebted to an examiner for pointing this out for me.
} 


\subsubsection{2. [-Stage] situations}

Let us now turn to [-Stage]. By definition, [-Stage] situations cannot be conceived of as being made up of successive stages (or just a stage). Therefore, they are incompatible with View part, which means that they cannot receive the $\mathrm{R}=\mathrm{S}$ or $V_{\text {iew }}$ interpretation (even when the subject is marked with -ga). However, how do we know that the [-Stage] feature of a situation forces the situation to be taken as a whole, rather than that a situation is [-Stage] because it is always taken as a whole? There seems circularity here. We need to clarify what makes a situation [-Stage] and incompatible with View part. In other words, why can't some situations be conceived of as being made up of successive stages (or a single stage)?

As a first approximation, we can consider that the feature [-Stage] is inherent in 'states'. That is, 'states' do not have an internal structure with successive stages (or a stage), in contrast with 'events', which have an internal structure (cf. Smith 1991: 30).

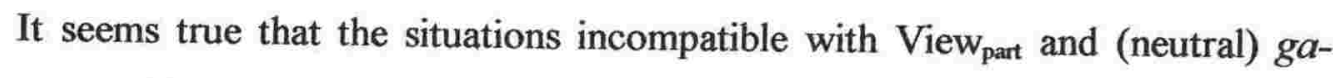
marking of subjects are typically states. In addition to the example in (6a) above, (12) shows some more examples which are incompatible with View part $_{\text {and (neutral) } g a-}$ marking of the subjects.

(12)a. John-\#ga/wa hansamu/shinsetsu/dokushin da

'John is handsome/kind/single.' handsome/kind/single Cop(Pres)

b. John-\#ga/wa nihon-ni sun-dei-ru. 'John lives in Japan.' Japan-in live-Prog-Pres

c. John-\#ga/wa Toyota-ni tsutome-tei-n.

Toyota-at be employed-Prog-Pres

'John is employed at Toyota.'

The unavailability of the neutral interpretation of $g a$-marked subjects (indicated by the hashes) and the $\operatorname{View}_{\text {part }}(\mathrm{R}=\mathrm{S})$ interpretation in these examples can be ascribed to the [-Stage] feature of those states. For example, we might explain that because a state of John's being handsome cannot be conceived of as being made up of successive stages, we cannot talk about John's being handsome manifested at a 
particular spatiotemporal location. That is, if John is handsome at all, he is (supposedly) always handsome.

However, there are also 'states' which allow (neutral) ga-marking of the subjects and can receive the $\operatorname{View}_{\text {part }}(\mathrm{R}=\mathrm{S})$ interpretation. For example, a state of John's being sick can take either a wa-marked subject or a ga-marked subject, as shown in (13) below. With a wa-marked subject, the situation of John's being sick is taken as a whole and the entire schema is said to hold. Thus, (13a) yields the Viewall interpretation (corresponding to the representation ' $\mathrm{S}, \mathrm{E}(\mathrm{R})$ '). With a $g a$-marked subject in (13b), on the other hand, the described situation (of John's being sick) is taken as a temporal manifestation, i.e., the View $w_{\text {par }}$ interpretation (corresponding to the representation ' $\left.S(R), E^{\prime}\right){ }^{9}$. Note that the distinction between the Viewall

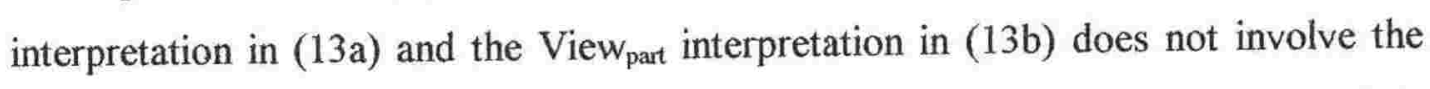
distinction between perennial and temporary sickness. Irrespective of whether John's sickness is perennial and temporary, it can be captured and presented either in its entirety or precisely at a certain temporal point where its manifestation is observed. The availability of the View $w_{\text {part }}(\mathrm{R}=\mathrm{S}$ ) interpretation with a (neutral) ga-subject shows that a state of John's being sick can be taken as having successive stages, i.e., [+Stage].

(13) a. John-wabyooki da. sick Cop(Pres)

'John is sick. (= John has been sick.)'

b. John-ga byooki da. sick $\operatorname{Cop}($ Pres)

'John is sick (at this very moment).'

Such an interpretive difference may be more clearly observed with examples such as (14) below. With a wa-marked subject, (14a) conveys that the sky is blue in the sense that it is essentially/characteristically blue, whereas with a ga-marked subject, (14b) conveys that the sky is blue in the sense that it is looking blue or it happens to be blue right now. The former describes a spatiotemporally transcending characteristic of the sky and that of ice, whereas the latter describes a

${ }^{9}$ Note that (13b) can also get the View ${ }_{\text {all }}$ interpretation (i.e., $S, E(R)$ ) with the subject construed as being in focus. 
spatiotemporally bounded manifestation of the sky. The two distinct interpretations observed in the (a) and (b) sentences correspond to the View all interpretation (' $\mathrm{S}$, $\left.E(R)^{\prime}\right)$ and the $V_{i e w_{p a r t}}$ interpretation ('S(R), E').

a. Sora-wa aoi.

sky blue(Pres)

'The sky is blue (essentially, characteristically).'

b. Sora-ga aoi.

sky blue(Pres)

'The sky is blue (= is looking blue at this very moment).'

It is perhaps worth noting here that it is well known that in Spanish such a difference is distinguished by the use of ser and estar, as shown in (15) below. ${ }^{10} \mathrm{Da}$ Silva (1978: 77) explains that "estar indicates a state, a condition, or a semblance of being (what the subject feels like, looks like, happens to be like at a certain time)", while ser "indicates essential qualities, basic characteristics".
a. El cielo
es azul.
(= Sora-wa aoi.)
the sky
blue
'The sky is blue (essentially, characteristically).'
b. El cielo está azul.
the sky blue
(= Sora-ga aoi.)
'The sky is blue (at this very moment).'

\begin{abstract}
${ }^{10}$ Although the examples in (15) demonstrate a correspondence between ser in Spanish and -wa in Japanese and that between estar in Spanish and -ga in Japanese, it is not necessarily the case that they correspond exactly to each other. In particular, the characterising interpretation associated with the use of ser in Spanish is only one of the $\operatorname{View}_{\text {all }}(\mathrm{R}=\mathrm{E})$ interpretations which I associate with wamarking of subjects in Japanese. Therefore, when a wa-sentence does not yield a characterising reading, for example, as seen in (13a) above, there seems no corresponding ser sentence in Spanish. (Compare (13a) above and (ia) below.) Also, the transient interpretation associated with the use of estar in Spanish does not seem as sharp and punctual as that 1 associate with $g a$-marking of subjects in Japanese. (Compare (13b) above and (ib) below.)
\end{abstract}

(i) a. Juan es malo.

'John is a bad man (csscntially, charactcristically).'

b. Juan está malo.

bad

'John is bad (in his illness).' 
The availability of the View part $_{(R}=S$ ) interpretation with a (neutral) ga-subject in Japanese (and also with estar in Spanish) in the (b) examples above shows that not all 'states' are [-Stage]. While some states such as John's being handsome are not compatible with a (neutral) $g a$-subject and the View part interpretation (as seen in 3.3.3.1 above), other states such as John's being sick and the sky's being blue are. (In Spanish, while some states such as joven (young), viejo (old), rico (rich) and pobre (poor) normally take ser, others such as pálido (pale), malo (bad), frí (cold), and verde (green) freely take either estar or ser (cf. Da Silva 1978: 77).) Since 'states' can be either [-Stage] (in which case they are only compatible with Viewall) or [+Stage] (in which case they are compatible with both Viewail and View $w_{\text {part }}$ ), we need to look further into what makes some states [-Stage] and others [+Stage]?

\subsubsection{Stage-level vs. individual-level predicates}

We might consider the distinction between $[+$ Stage $]$ and $[-$ Stage $]$ situations in terms of the distinction between stage-level and individual-level predicates. As discussed in 2.3 .5 above, stage-level and individual-level predicates are originally distinguished as predicates of stages and those of individuals (Carlson 1977), where a stage is defined roughly as 'a spatially and temporally bounded manifestation of something', and an individual as 'that whatever-it-is that ties a series of stages together to make them stages of the same thing' (p. 68). Subsequently, however, the distinction between the two types of predicates has been taken rather independently from the distinction between the two types of subjects. Often, the stage-level and individual-level distinction is understood mainly in terms of whether they represent transient states such as my sitting on a chair now (stage-level predicates) or more or less permanent situations such as my having brown eyes (individual-level predicates) (e.g., Kratzer 1989). The distinction is thus rather loosely captured.

Nevertheless, the distinction has been proved useful in analyzing a number of grammatical phenomena. For example, observe in (16) below that while (16a) can mean 'If John stands on a chair, he can touch the ceiling', (16b) cannot mean 'If John has unusually long arms, he can touch the ceiling' (Stump 1985 cited in Kratzer 1989). Such a contrast in interpretation is ascribed to the assumption that standing on 
a chair is a stage-level predicate, while having unusually long arms is an individuallevel predicate.

(16)a. Standing on a chair, John can touch the ceiling.

b. Having unusually long arms, John can touch the ceiling.

(Stump 1985: 41-43, cited in Kratzer 1989: 1)

The stage-level and individual-level distinction is also used to account for a contrast in grammaticality. Observe in (17) below that there-insertion is grammatical with available but not with alinistic, where the assumption is that available is a stagelevel predicate, while altruistic is an individual-level predicate.

(17)a. There are firemen available.

b. *There are firemen altruistic.

(Kratzer 1989: 1, based on Milsark 1974)

However, although the stage-level and individual-level distinction can provide an account for these contrasts, it is not that these contrasts can provide definitions of what stage-level and individual-level predicates are. Apparently, there are multiple factors interacting in each case and the predicates are not the only key to those contrasts.

Without being able to precisely define what stage-level and individual-level predicates are, it is probably pointless to consider the distinction between [+Stage] and [-Stage] situations in terms of the distinction between stage-level and individuallevel predicates. Nevertheless, we intuitively notice that (John's) 'being sick' and 'being handsome' seem to semantically correspond respectively to (John's) 'standing on a chair' and 'having unusually long arms', or (firemen's) 'being available' and 'being altruistic'. Since 'standing on a chair' and 'being available' are assumed to be stagelevel, to the extent that 'being sick' seems to semantically correspond to 'standing on a chair' and 'being available', it seems plausible that 'being sick' is stage-level. On the other hand, to the extent that 'being handsome' seems to semantically correspond to 
'having unusually long arms' and 'being altruistic', which are assumed to be individuallevel, it seems plausible that 'being handsome' is individual-level.

This seems to suggest that the distinction is somehow connected to the lexical semantics of the predicate (whether it is a verb, an adjective, or a verb phrase). That is, [+Stage] situations are lexically and inherently stage-level, while [-Stage] situations are lexically and inherently individual-level. Accordingly, the differing compatibility of 'being sick' and 'being handsome' with the View part $_{\text {interpretation and }}$ with a (neutrally) $g a$-marked subject in Japanese might be ascribed to the stage-level and individual-level distinction. That is, stage-level predicates (which include being sick') are compatible with the View part interpretation and with a (neutrally) ga-marked subject in Japanese, while individual-level predicates (which include 'being handsome') are not. In other words, individual-level predicates are necessarily presented by Viewall, whereas stage-level predicates can be presented by either Viewall or View part.

It is noticeable however that to the extent that stage-level and individual-level predicates correspond to [+Stage] and [-Stage] situations, they are only different terms for the same things. Thus, the stage-level and individual-level distinction does not help us identify what distinguishes between [-Stage] and [+Stage] situations.

Besides, espousing the original view that stage-level and individual-level predicates are distinguished as predicates of stages and those of individuals respectively, I do not conceive of the stage-/individual-level distinction as lexically determined (at least not entirely). In my view, even the same predicate can be either stage-level or individual-level, depending on whether it predicates of a stage (which I claim to be marked by $-g a$ in Japanese) or of an individual (which I claim to be marked by -wa in Japanese) in the context of use. In other words, the situations presented by Viewall (signalled by $w a$-marking of the subject in Japanese) are taken as individual-level and those presented by Viewpart (signalled by wa-marking of the 
subject in Japanese) are taken as stage-level. (See (13) and (14) above, for example.) ${ }^{11}$ Particularly with this view, the stage-level and individual-level distinction does not come before the $[+$ Stage $]$ and $[-$ Stage $]$ distinction.

\subsubsection{Visible vs. invisible situations}

Return to the $\operatorname{View}_{\text {part }}(\mathrm{R}=\mathrm{S})$ interpretation in (13b) above. The View $w_{\text {part }}(\mathrm{R}=$ S) interpretation is possible, for example, when the speaker sees a scene in which John is lying in bed with a thermometer in his mouth. The scene can be taken as a temporal manifestation of John's sickness and an assertion can be made just for that. Importantly, the View $w_{\text {part }}(\mathrm{R}=\mathrm{S})$ interpretation is obtainable only when the situation is "visible". Here, being "visible" means not only that a situation is physically manifested in front of our eyes so that we can "see" it but also more broadly that the physical manifestation of a situation can be perceived or ascertained by any of our senses. For example, one might perceive that John is sick through John's voice she/he hears on the phone. The sentence (13b) can also be uttered in such a case to yield the View $_{\text {part }}(\mathrm{R}=\mathrm{S})$ interpretation. $^{12}$

In contrast, for the Viewall $(\mathrm{R}=\mathrm{E})$ interpretation, it is not required that a situation is physically perceivable. For example, we can utter (13a) above when John is absent in a class (which he is expected to attend). In such a case, that John is sick is not physically perceivable (to the interlocutors who are in the class). Since (13a) asserts that the situation of John's being sick holds in its entirety, it does not require that its stage is visibly manifested. In fact, the entirety of a situation can only be understood conceptually.

${ }^{11}$ Individual-level and stage-level predicates thus associated with View all and View ${ }_{\text {part }}$ and hence with waand $g a$-markings of subjects in Japanese may not necessarily coincide with what are generally considered as individual-level and stage-level predicates. To avoid a confusion, we might call them individual-level and stage-level predications (to be distinguished from individual-level and stage-level predicates) (cf. 2.3.5 above). Although individual-level and stage-level predications in principle correspond to what are generally considered as individual-level and stage-level predicates, i.e., predicates representing more or less permanent situations and those representing transient states respectively, they correspond more strictly to what are originally distinguished as individual-level and stage-level predicates, i.e., predicates that predicate of individuals and those that predicate of stages.

${ }^{12}$ Related to this, Makino (1987: 300 ) points out that with a ga-marked subject, the speaker focuses on an action, existence, or temporary state of the ga-marked object (which may be animate or inanimate) primarily through visual or auditory sense. Crucially, the description with a ga-marked subject depends on the speaker's direct perception. It often indicates an exclamatory expression of the speaker. 
Similarly, (14b) above is uttered to yield the $\operatorname{View}_{\text {part }}(R=S)$ interpretation only when the speaker actually perceives the colour of the sky as blue, while (14a) can be uttered when and where the sky cannot be looked up and therefore rather irrespective of whether it is actually blue or grey at the time of utterance.

Essentially, stages of a situation are manifestations of a situation. As manifestations, stages are inherently "visible". The feature $[+$ Stage $]$ thus seems to entail [+Visible]. States such as being sick, being blue, and being cold are [ + Stage] and therefore intrinsically [+Visible]. An intrinsically [+Visible] situation can be presented either as an actually "visible" situation with a physical manifestation (as in (13b) and (14b) above) or as an "invisible" situation holding in its entirety (as in (13a) and (14a) above), depending on whether it is presented by Viewall or View

Conversely, does the feature [-Stage] entail [-Visible]? Consider a [-Stage] state of (John's) being handsome, for example. Is it [-Visible]? We can see the physical manifestations of John's being handsome. Does it mean that the feature [Stage] does not entail [-Visible]? Notice, however, that John's being handsome is very different from John's looking handsome. The former is considered a more or less permanent characteristic of John, whereas the latter is a temporary state of John. Although we may think that we can see the physical manifestations of John's being handsome, as a characteristic ascribed to an individual called John the state of being handsome is more or less permanent and taken as holding in its entirety. Crucially, the entirety of a state is not something that can be physically observed but rather something that is understood conceptually. In this sense, [-Stage] situations are [Visible]. We cannot assert (or deny) John's being handsome restrictively only at a particular spatiotemporal location (while we can assert (or deny) John's looking handsome restrictively only at a particular spatiotemporal location). What we can assert (or deny) is that the entire state of John's being handsome holds.

But if [ + Stage $]$ and [-Stage] situations correspond precisely to [+Visible] and [-Visible] situations respectively, visibility is not a helpful criterion for determining

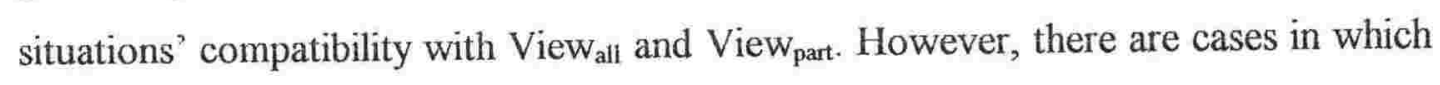
two situations are hard to distinguish in terms of the opposition between [ + Stage] and [-Stage] but can be differentiated as [+Visible] and [-Visible], and crucially exhibit a difference in their compatibility with Viewall and View $w_{\text {part }}$ Consider, for 
example, a situation of someone's being here as a result of his/her having come here and a situation of someone's being somewhere out there as a result of his/her having gone there. In terms of [+Stage] and [-Stage], it is hard to differentiate these two situations. However, the data in (18) and (19) below suggest that a situation of someone's being here as a result of his/her having come here is compatible with both Viewall (which is signalled by wa-marking of the subject) and View part $_{\text {(which is }}$ signalled by ga-marking of the subject), whereas a situation of someone's being somewhere out there as a result of his/her having gone there is only compatible with Viewall (but not with View $\left._{\text {part }}\right)^{13}$ The hash on -ga in (19) indicates that the ga-marked subject cannot be interpreted neutrally (and therefore the focus interpretation is forced).

\section{(18)John-wa/ga ki-tei-ru. come-Prog-Pres}

'John has come and is here.'

(19) John-wa/\#ga Amerika-ni it-tei-ru.
America-to go-Prog-Pres
'John has gone to America and is in America.'

Although these two situations are hard to differentiate in terms of [+Stage] and [-Stage], they are clearly distinguished in terms of visibility to the speaker. A situation of someone's being here is visible to the speaker, who is also here. On the other hand, a situation of someone's being somewhere out there is invisible to the speaker, who is here. (Note that deictics here and there are used to refer to respectively a place where the speaker is and a place where the speaker is not.) A [+Visible] situation of someone's being here can be presented either as an actually visible situation with a physical manifestation (by $V_{\text {iew }}$ part) or as an invisible situation

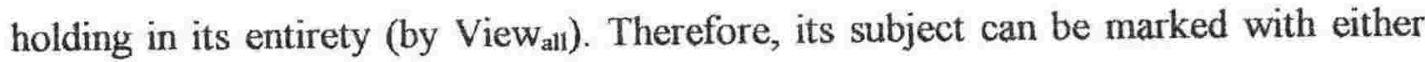
-wa or $-g a$, as shown in (18) above. On the other hand, with a [-Visible] situation of someone's being somewhere out there, we have no option of talking about a visible

${ }^{13}$ The teiru-forms in (18) and (19) express result states, due to the [-Durative] feature of the verb. I will discuss the interaction between the denotation of the marker -teiru and the [+Durative] and LDurative] features of situations in 3.4.1 below. 
manifestation of the situation. Without being able to see the physical manifestations, we can only assert (or deny) that the situation as a whole holds. ${ }^{14}$ That is, a [-Visible] situation cannot be presented by View part $_{\text {but only by View }}$. The incompatibility with View $_{\text {part }}$ is indicated by the absence of neutral ga-marking of the subject in (21) above.

The examples in (20) and (21) below show similar contrasts. Situations described in (20) and (21) are hard to distinguish in terms of [+Stage] and [-Stage]. However, in terms of visibility to the speaker, a/the mole's being dead and a/the door's being open described in (20) are inherently [+Visible] (as they have physical manifestations), whereas John's knowing and John's being married described in (21) are inherently [-Visible] (as they lack physical manifestations). And [+Visible] situations can have either wa-marked or ga-marked subjects, whereas [-Visible] situations can only have wa-marked subjects (except for ga-marked subjects construed as being in focus, as indicated by the hashes).

(20)a. Mogura-ga/wa sin-deiru.

mole die-Prog-Pres

'There is a dead mole./ The mole is dead."

b. Doa-ga/wa ai-tei-ru.

door open-Prog-Pres

'A/The door is open.'

(21)a. John-\#ga/wa sit-tei-ru.

'John knows (that).'

know-Prog-Pres

b. John-\#ga/wa kekkon-si-tei-ru.

'John is married.'

marriage-do-Prog-Pres

Thus, where the opposition between [+Visible] and [-Visible] does not correspond to that between [ + Stage] and [-Stage], Viewall and View part $_{\text {interact with }}$ $[+$ Visible $]$ and [-Visible] rather than $[+$ Stage $]$ and [-Stage]. While Viewall is available to both [+Visible] and [-Visible] situations, View part $_{\text {has }}$ limited distribution

${ }^{14}$ Exceptional cases are when a situation somewhere out there is made possible to be perceived by the speaker here by the use of a telephone, a TV, etc. 
only with $[+$ Visible $]$ situations. Since [ + Visible] situations can be presented by either View all or View $w_{\text {part }}$, they can yield two distinct temporal and aspectual interpretations in correlation with wa- and ga-markings of the subjects. On the other hand, [Visible] situations can yield only one temporal and aspectual interpretation, i.e., the Viewall interpretation. This asymmetric pattern of interaction between viewpoints and situation types is illustrated in (22) below. ${ }^{15}$

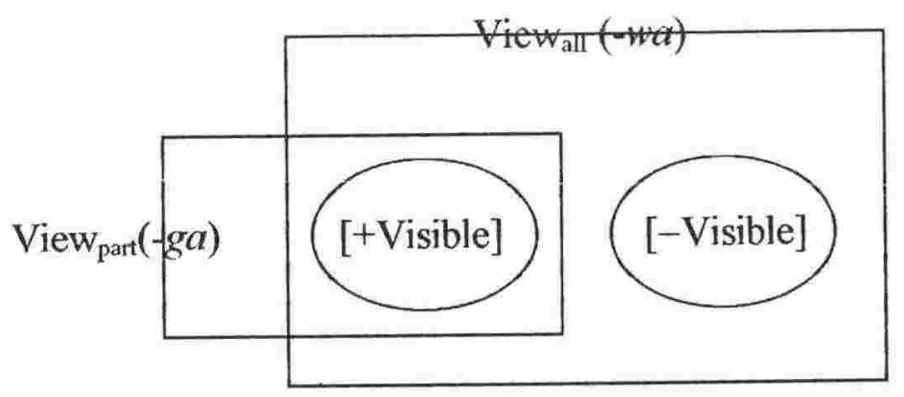

This leads us to conclude that what makes a situation incompatible with View $_{\text {part }}$ is the invisibility of a situation. That is, the invisibility is at least one of the reasons why some situations cannot be conceived of as being made up of successive stages (or a stage), i.e., [-Stage].

Some situations such as a situation of knowing are inherently [-Visible] and in these cases the visibility seems lexically determined. However, there are many nonlexical factors that determine the visibility of a situation. For one thing, the visibility of a situation is relative to where the speaker is (in relation to the situation talked about). That is, one and the same situation can be either visible or invisible to the speaker, depending on where he/she is. The visibility of a situation is also affected by the use of a telephone, a TV, and so on. Moreover, the visibility of a situation may differ according to the intended meaning. For example, the situation described in the sentence John is teaching linglish is visible with the intended meaning that John is

${ }^{15}$ Smith (1991: 94) claims that when a language exhibits an asymmetric pattern of interaction between viewpoints and situation types, i.e., one viewpoint has limited distribution, and the other(s) appear(s) generally, the generally available viewpoint is dominant. Applying this to the above case, Viewall which is generally available (as opposed to View $w_{\text {part }}$ which has limited distribution) is a dominant viewpoint in Japanese. Although it is not clear exactly what Smith means by the word dominant, let us simply take it that the dominant viewpoint is used more frequently than the other

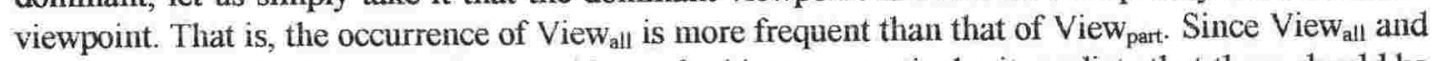
$V_{\text {iew }}$ art are signaled by $w a$ - and ga-markings of subjects respectively, it predicts that there should be more wa-marked subjects than (neutral) ga-marked subjects in total. 
actually teaching English right now but invisible with the intended meaning that John teaches English as an occupation. In addition, some grammatical items such as negation, potential, and past and future tenses have an effect of making situations invisible. Importantly, however, only lexically and potentially [+Visible] situations can be affected by these other factors to be actually visible or invisible. Lexically and inherently [-Visible] situations can never be visibly manifested. Without visible manifestations, these situations are not conceived of as being made up of successive stages (or a stage). Therefore, $[-$ Visible $]$ situations are incompatible with View $\mathrm{w}_{\text {part }}$.

Let me note in addition that unlike the situation of knowing, some situations such as memorizing something, solving a problem, and falling in love are potentially $\left[+\right.$ Visible], though we may consider them rather invisible. ${ }^{16}$ Crucially, we can readily imagine some visible scenes of memorizing something, solving a problem, and falling in love (but not a visible scene of knowing). These scenes can be taken as the visible manifestations of the stages of these situations, and therefore can be presented by View $_{\text {part }}$.

As far as the visibility is seen as a lexically determined semantic feature rather than a pragmatic notion, it can probably supersede the [Stage] feature as a feature that interact with Viewall and View $w_{\text {part }}$.

\subsubsection{Summary}

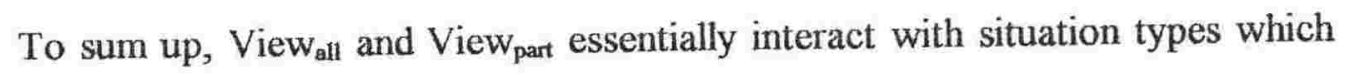
determine whether the situations can be decomposed into stages or not. While View all is generally available, View part $_{\text {is }}$ restricted to situations which can be decomposed into stages (or a stage). To the extent that it determines the decomposability of situations, the distinction between states and non-states or the feature [+/-Stage] has an important bearing on the availability of View part.

However, it is not clear whether the [-Stage] feature of a situation forces the situation to be taken as a whole or the fact that a situation is always taken as a whole makes the situation [-Stage]. What seems to make a situation incompatible with View $_{\text {part }}$ more fundamentally is the invisibility of a situation. Some situations (such as knowing) are lexically and inherently [-Visible] and can never be visibly manifested.

${ }^{16} \mathrm{I}$ appreciatc an cxamincr's comment on this point. 
Without visible manifestations, these situations are not conceived of as being made up of successive stages (or a stage). Therefore, [-Visible] situations are incompatible with View part. $_{\text {. }}$

Although in many cases [+Visible] and [-Visible] situations correspond to [+Stage] and [-Stage] situations, where they do not, View all and View $w_{\text {part }}$ interact with [+Visible] and [-Visible] rather than with [+Stage] and [-Stage]. This leads us to conclude that while Viewall is generally available, View part has limited distribution only with [+Visible] situations. Thus, the feature [Visible], as a lexically determined semantic feature rather than a pragmatic notion, seems to supersede [Stage] as a feature that interacts with View all and View part.

\subsection{Interaction between situations types and denotations of -ta, -ru, and -teiru}

In addition to the interaction between viewpoints and situation types, which we have just seen in the previous section, the S-E aspects conveyed by tense/aspect markers join the interaction. In this section, I will examine how the S-E aspects interact with situation types as well as viewpoints.

\subsubsection{Interpretations of -teiru}

\subsubsection{1. [+/-Durative]}

In 3.3.2 above, we have seen that the distinction between durative and instantaneous situations does not matter to the availability of Viewall and View part. However, that distinction has an important bearing on the interpretation of teiruforms of verbs. I take the [+Durative] and [+Instantaneous] features as totally antagonistic to each other so that [ + Durative] suggests [-Instantaneous] and that [+Instantaneous] suggests [-Durative]. 1 only use the feature [Durative] with the specification of + and - values. 
The teiru-forms have been recognised as diagnoses for [+Durative] and [Durative] situations (Kindaichi 1950, 1955, 1976), as summarized in (23) below: ${ }^{17}$

(23)a. If the -leiru form of a verb is interpreted as expressing an ongoing process, the verb is [+Durative].

b. If the -teiru form of a verb is interpreted as expressing a result state, the verb is [-Durative].

The examples in (24) below illustrate the diagnosis (23a). The -leiru forms are interpreted as expressing ongoing processes, and the verbs indeed describe processes which have durations.

(24)a. John-wa/ga (ima) Chomsky-o yon-dei-ru. now Chomsky-Acc read-Prog-Pres 'John is reading Chomsky (now).' <present/progressive>

b. John-wa/ga (ima) oyoi-deiru. now swim-Prog-Pres 'John is swimming (now).' <present/progressive>

c. John-wa/ga (ima) nihongo-o benkyoo-si-tei-ru. now Japanese-Acc study-do-Prog-Pres 'John is studying Japanese (now).' <present/progressive>

With a wa-marked subject which signals Viewall, the -teiru form presents an ongoing situation as a whole. This yields a static present interpretation. With a $g a$ marked subject which signals Viewpart, the -teiru form presents an arbitrary internal cross-section of an ongoing situation, which gives rise to a dynamic progressive interpretation. Notice that with the static present interpretation, the situations described in the sentences are not necessarily visible to the speaker, while with the dynamic progressive interpretation they are necessarily visible.

${ }^{17}$ The diagnoses also apply to -teita. Strictly speaking, it is the -tei part of -teiru that should be regarded as expressing an ongoing process or a result state, as -teita also expresses them. (The difference between -teiru and-teita is whether the reference point is recognized as "now" or "at that time".) 
The diagnosis (23b) above is illustrated by the examples in (25) below. The -leiru forms receive result state interpretations, and the verbs indeed describe discrete changes which happen instantaneously. ${ }^{18}$

(25)a. John-wa/ga

ki-tei-ru.

come-Prog-Pres

'John has come and is here."

$<$ result(invisible/visible) $>$

b. Mado-wa/ga ai-tei-ru.

window open-Prog-Pres

'The/A window is open.'

$<$ result(invisible/visible) $>$

c. Mogura-wa/ga sin-dei-ru.

mole die-Prog-Pres

'The mole is dead./There is a dead mole.' <result(invisible/visible)>

With a wa-marked subject which signals Viewall, the described result state is taken as a whole. With a ga-marked subject which signals View $w_{\text {part, }}$ the described result state is taken as an arbitrary internal cross-section of a result state. Again, the sentences with $g a$-marked subjects require that the described situations be visible to the speaker, while those with wa-marked subjects do not have such requirement.

Such an interpretive difference between ongoing processes and result states yielded by -teiru can be ascribed to the structural difference between [+Durative] and [-Durative] situations, while we maintain the assumption that -teiru uniformly denotes the ongoing aspect (or the topological relation ", to connect $\mathrm{S}$ and $\mathrm{E}$ ) (cf. 3.1 .3 above). [+Durative] situations have a temporal schema with only internal stages, as illustrated in (8) above, which is reproduced in (26) below. In such a schema, if something is said to be ongoing, it can only be the internal stages that are ongoing. That the internal stages are continuing means that the process is in progress.

${ }^{18}$ Notice that te o nobasu in (6d) and (7d) above, which literally means 'stretch one's hand (arm)', is not a [-Durative] achievement, since the teiru-form does not express an ongoing result state but rather an ongoing process. 
(26) $[+$ Durative $]$ situations

Situation

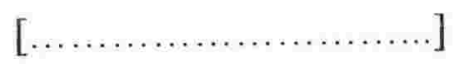

internal

On the other hand, [-Durative] situations have a temporal schema with a single temporal point which is preceded by preliminary stages and followed by resultative stages, as illustrated in (9) above, which is reproduced in (27) below. In such a schema, if something is said to be ongoing, it is either the preliminary stages or the resultative stages that can be ongoing. It goes without saying that the resultative interpretation obtains when the resultative stages are taken as ongoing.

(27) [-Durative] situations

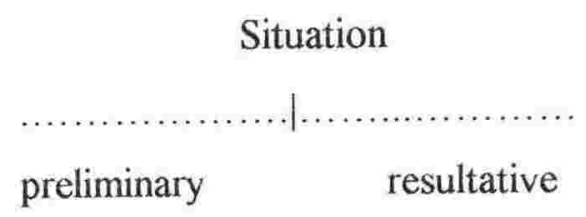

If the preliminary stages are taken as ongoing, it should yield an interpretation that what is going on now is leading to the occurrence of the instantaneous situation described by the verb in the (near) future. Logically, such an anticipative interpretation should also be available with the teiru-forms of [-Durative] verbs. The fact that it is not seems rather idiosyncratic.

Interestingly enough, the English progressive shows the opposite case. That is, when [-Durative] situations are "progressivized", it is the preliminary stages but not the resultative stages that are taken as ongoing. Observe in (28) below that the English equivalents for the [-Durative] verbs in (25) above in the progressive form yield the interpretation that the preliminary stages that lead to the occurrence of the actual situation described by the verb are ongoing. Thus, in English [-Durative] situations in the progressive form yield the anticipative interpretation but not the resultative interpretation. 
(28)a. John is coming.

b. The window is opening.

c. The mole is dying.

Thus, the progressive form of a [-Durative] situation necessarily yields the resultative interpretation in Japanese and the impending prospective interpretation in English. For this difference, I have no explanation to offer. Crucially, however, the choice between the ongoing process interpretation and the resultative interpretation both yielded by -teiru in Japanese is explained by the structural difference between [+Durative] and [-Durative] situations. Since [+Durative] situations only have internal stages, the ongoing aspect denoted by -teiru has no choice but to modify the internal stages. ${ }^{10}$ This results in the ongoing process interpretation (as seen in (24) above). On the other hand, with [-Durative] situations, which have preliminary and resultative stages, the ongoing aspect denoted by -leiru selectively modifies the resultative stages to yield the resultative interpretation (as seen in (25) above). Thus, we can ascribe the distinct semantic interpretations yielded by -leiru to the distinct temporal structures of the predicates. This allows us to maintain the assumption broadly motivated by a principle of economy that bits of language (i.e., -ieiru) which are identical in form are also identical in meaning (i.e., ongoing) and yet to account for the distinct interpretations obtained.

To summarize, -teiru expresses an ongoing process with a [+Durative] situation, which yields the static present interpretation with Viewall $(-w a)$ and the dynamic progressive interpretation with $\operatorname{View}_{\text {part }}(-g a)$. With a [-Durative] situation, on the other hand, -ieiru expresses an resultant state, which is taken as invisible with Viewall $_{(-w a)}$ and visible with View part $(-g a)$.

${ }^{19}$ When we take the possibility of the experiential interpretation of -teim into consideration, this is in fact an overstatement. As will be discussed in the following section (3.4.1.2 below), the teiruform of a [+Durative] situation can be ambiguous between the ongoing process interpretation and the experiential interpretation. 
(29) The interpretations of -teiru

$\begin{array}{lll} & {[+ \text { Durative }]} & {[- \text { Durative }]} \\ & \text { Ongoing process } & \text { Ongoing resultant state } \\ \text { Viewall }_{\text {a }}(-w a) & \text { Static present (Invisible) } & \text { Invisible } \\ \text { View }_{\text {part }}(-g a) & \text { Progressive (Visible) } & \text { Visible }\end{array}$

\subsubsection{Experiential interpretation of -teiru}

However, the interpretations of -teiru in (29) above are not exhaustive. Another interpretation of -teiru is past experience. The experiential interpretation can obtain with both [+Durative] and [-Durative] situations, as shown in (30) and (31) below. Although the experiential interpretation often and most naturally obtains with overt adverbials which denote a past time or the number of times such as 'beforehand' and 'once', it is not that the occurrence of the experiential interpretation requires the presence of such adverbials. ${ }^{20}$ (Note that the experiential interpretation of the verb 'die' in (3lc) pragmatically requires an imaginary setting such as a fairy-tale.)

(30)a. John-\#ga/wa (mae-ni) Chomsky-o yon-dei-ru.

before Chomsky-Acc read-Prog-Pres

'John has read Chomsky (before).'

b. John-\#ga/wa (izen) intaahai-de oyoi-dei-ru.

before inter high-at swim-Prog-Pres

'John has swum at an inter-high (before).'

c. John-\#ga/wa kookoosei-no-toki nihongo-o

high school student-of-when Japanese-Acc

benkyoo-si-tei-ru.

study-do-Prog-Pres

'John has studied Japanese when he was a high school student.'

(31)a. John-\#ga/wa mae-ni ki-tei-ru.

before come-Prog-Pres

'John has come before.'

b. Mado-\#ga/wa ichi-do ai-tei-ru.

window once open-Prog-Pres

'The window has been open once.'

${ }^{20} \mathrm{I}$ appreciate an examiner's comment on this point. 

c. Mogura-\#ga/wa ni-do sin-deiru.
mole two-times die-Prog-Pres
'The mole has died two times.'

Past experiences are a special kind of result states. Every time a situation ends, the subject of the situation is left with a result state that he/she has done it. In this sense, a past experience is an indirect result state of every situation, which is permanently ascribed to the subject. For example, if John read Chomsky, it is true forever that he has read Chomsky (even after he has totally forgotten what he read). Importantly, experiences ascribed to individuals are necessarily [-Visible]. Therefore, they are only compatible with Viewall (and hence wa-marking of subjects) but not

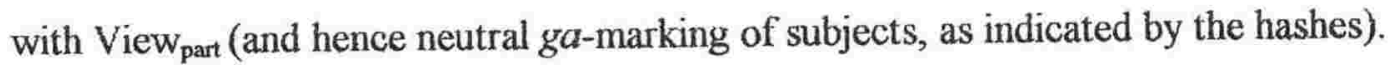

To account for the possibility of the experiential interpretation with both [ + Durative] and [-Durative] situations, we might add the indirect result state necessarily following in every temporal schema of situation, as illustrated in (32) and (33) below. A dotted line indicates a series of potentially visible stages of a situation, which therefore can be presented by either Viewall (with $-w a$ ) or View part (with $-g a$ ), whereas a solid line indicates a necessarily invisible state, which therefore can only be presented by Viewall (with $-w a)^{21}$ (The boundary between the direct resultative stages and the indirect result state of a [-Durative] situation is arbitrary.)

(32) [+Durative] situations

Situation Result state

$\begin{array}{ll}\Uparrow & \Uparrow \\ \text {-teiru } & \Uparrow \\ (\text { wa/ga }) & \text {-teiru } \\ \end{array}$

${ }^{21}$ Note that while potentially visible situations can be presented as either visible or invisible, inherently invisible situations have no choice but to be presented as invisible (See the discussions in 3.3.3.3 above). 
(33) [-Durative] situations

Situation

$\Uparrow$

-teiru

(wa/ga)
Result state

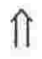

-teiru

(wa)

With the possibility of the experiential interpretation, -leiru can be ambiguous (out of context) particularly with wa-marked subjects. With [+Durative] situations, -teiru can be taken as either modifying the internal stages to express an ongoing process or modifying the result state to express a past experience, as illustrated in (32) above and exemplified in (34) below. With [-Durative] situations, -teiru can be taken as either modifying the direct resultative stages to express an ongoing resultant state or modifying the indirect result state to express a past experience, as illustrated in (33) above and exemplified in (35) below. (The situations presented with wamarked subjects, which signal View all, are all taken as invisible.)

(34) [+Durative]

John-wa Chomsky-o yon-dei-ru.

Chomsky-Acc read-Prog-Pres

a. 'John is reading Chomsky." <Ongoing process (static present)>

b. 'John has read Chomsky." <Experience>

(35) [-Durative]

John-wa ki-tei-ru.

come-Prog-Pres

a. 'John has come and is here.' <Ongoing resultant state (invisible)>

b. 'John has come here (before).' <Experience>

On the other hand, when the subject is marked with $-g a$, the experiential interpretation of -leiru is not available (except with the focus interpretation of the gamarked subject). Therefore, -teiru is unambiguously interpreted as expressing an ongoing process if it is modifying a [+Durative] situation, as shown in (36) below, and an ongoing resultant state if it is modifying a [-Durative] situation, as shown in (37) below. (The situations presented with ga-marked subjects, which signal View part, are necessarily visible.) 
(36) $[+$ Durative $]$

John-ga Chomsky-o yon-deiru.

Chomsky-Acc read-Prog-Pres

'John is reading Chomsky.' <Ongoing process (progressive)>

(37) [-Durative]

John-ga ki-tei-ru.

come-Prog-Pres

'John has come and is here.'

$<$ Ongoing resultant state (visible) $>$

\subsubsection{Summary}

In this section, I have elucidated that the interpretation of -teiru depends on whether the situation described by the verb is [ + Durative] or [-Durative]. With a [+Durative] situation, which only has internal stages, the ongoing aspect denoted by teiru is taken as modifying the internal stages. This results in the ongoing process interpretation. On the other hand, with a [-Durative] situation, which has preliminary and resultative stages, the ongoing aspect denoted by -leiru is taken as modifying the resultative stages. This results in the resultative interpretation.

In addition, -teiru can also yield the experiential interpretation, irrespective of the $[+$ Durative $]$ and [-Durative] features of situations. With the possibility of the experiential interpretation, -leiru can be ambiguous (particularly with wa-marked subjects) between the ongoing process interpretation and the experiential interpretation with [+Durative] situations and between the resultative and the experiential interpretations with [-Durative] situations.

Crucially, as a result of interaction with situation types, [+Durative] and [Durative], as well as with viewpoint aspects, Viewall and View part, the marker -teiru, which is maintained as having a constant denotation, yields various semantic interpretations.

\subsection{2. $[+/-$ Telic $]$ and the interpretation of $-t a$}

In 3.3 .2 above, 1 have mentioned the telicity of situations as something irrelevant to the $[+/-$ Stage $]$ feature. However, when it comes to the interpretation of -ta (particularly occurring with a ga-marked subject), it is an important factor whether a situation has a clear final endpoint or not, i.e., $[+$ Telic $]$ or $[-$ Telic $]$. 
Recall the two distinct interpretations yielded by $-t a$. When it occurs with a wamarked subject, -la yields the past tense interpretation (38a), whereas with a $g a$ marked subject, it yields the "hot news" perfect interpretation (38b).

\section{(38)a. John-wa ki-ta. \\ come-Past}

'John came.'

b. John-ga ki-ta.

come-Past

'John has just come.'
$<$ Past $>$

$<$ <Hot news' perfect $>$

On the assumption that $-t a$ constantly conveys the completed aspectual meaning (corresponding to the relational meaning '> to connect $\mathrm{S}$ and $\mathrm{E}$ ) (cf. 3.1.1 above), the two distinct interpretations it yields are explained as follows. The past tense reading obtains when the completed aspect denoted by -ta is taken as modifying the situation (described by the verb) as a whole, with a wa-marked subject signalling Viewall. That is, the situation as a whole has been completed some time in the past. On the other hand, the 'hot news' perfect interpretation obtains when the completed aspect is taken as modifying a cross-section of the situation intersecting at the present moment. That is, what we have got here is the final cross-section of a situation, and therefore the situation has just been completed.

Notice that it is essential for the 'hot news' perfect interpretation that the final cross-section of a situation is visibly manifested at the moment of speech. (Recall that View $w_{\text {part }}$ is only compatible with [+Visible] situations.) For a situation to be able to visibly manifest its final cross-section, it must have a clear final endpoint, i.e., $[+$ Telic]. If the 'hot news' perfect interpretation of $-t a$ requires a visible manifestation of the final cross-section of a situation, it means that the 'hot news' perfect interpretation is only available with [+Telic] situations.

In terms of Vendler's four-way classification, achievements and accomplishments are [+Telic], whereas states and activities are [-Telic]. Accordingly, we predict that the 'hot news' perfect interpretation of $-l a$ is restricted to achievements and accomplishments and unavailable with states and activities. The situation of coming/arriving in (38) above is an example of achievements, and it has been shown that $-t a$ can yield the 'hot news' perfect interpretation with a ga-marked 
subject. In (39) below, a situation of drawing a circle is demonstrated as an example of accomplishments, with which -la can yield either the past interpretation or the 'hot news' perfect interpretation, depending on whether the subject is marked with -wa or $-g a^{22}$

$\begin{array}{cl}\text { (39)a. John-wa en-o } & \text { kai-ta. } \\ \text { circle-Acc } & \text { draw-Past }\end{array}$

'John drew a circle.'

$\begin{array}{cl}\text { b. John-ga en-o } & \text { kai-ta. } \\ \text { circle-Acc } & \text { draw-Past }\end{array}$

'John has just drawn a circle.' <'Hot news' perfect>

$<$ Past $>$
In (40) below, a situation of John's being sick is demonstrated as an example of states, which are [-Telic] (without a clear final endpoint). As predicted, the $t a$-form of a state fails to get the 'hot news' perfect reading with a ga-marked subject. With states, $-t a$ can only yield the past tense interpretation, even with a ga-marked subject, which then has to be interpreted as being in focus, as indicated by the hash on (40b).
(40)a. John-wa
byooki dat-ta.
sick Cop-Past
'John was sick.'
$<$ Past $>$
b. \#John-ga byooki dat-ta.
sick Cop-Past
'It is John who was sick.'

Recall that the state of being sick is $[+$ Stage $]$ and hence compatible with View $_{\text {part, }}$ when it does not occur with -ta (see (13) above). Therefore, it is not the incompatibility between the situation type and the viewpoint that makes the "hot news' perfect interpretation unavailable. It is the incompatibility between the situation type (i.e., $[-$ Telic $]$ ) and the combination of $-t a$ and View part $_{\text {. }}$

${ }^{22}$ In English, draw a circle and draw circles are distinguished as [+Telic] and [-Telic] respectively. Similarly, draw the circles and draw circles are distinguished as [+Telic] and [-Telic] respectively. In Japanese, however, such distinctions between singular and plural and between definite and indefinite are not grammatically expressed. Therefore, the telicity of en o kaku may well alter depending on the context of use. 
In (41) below, a situation of swimming is demonstrated as an example of activities, which are also [-Telic]. ${ }^{23}$ Without a clear final endpoint, a situation of swimming is not expected to allow a 'hot news' perfect reading of -ta. However, the 'hot news' perfect interpretation of $-t a$ is marginally available with a ga-marked subject, as indicated by the question mark on (41b).

(41)a. John-wa

$$
\begin{aligned}
& \text { oyoi-da. } \\
& \text { swim-Past }
\end{aligned}
$$

'John swam.'

$<$ Past $>$

b. ?John-ga oyoi-da.

swim-Past

'John has just swum.'

$<$ 'Hot news' perfect>

When the $t a$-form of a typically activity verb receives the 'hot news' perfect interpretation (with a $g a$-marked subject), the clear final endpoint of the situation is actually perceived. For example, if we are watching a swimming competition, John has just swum is taken as John has just swum his race or John has just swum $100 \mathrm{~m}$ and so on. (Note that such a commentary flavour is always a characteristics of the 'not news' reading.) Although the linguistically described situation itself is classified as [-Telic] without a clear endpoint, the context of speech can supply a final endpoint, which is understood by the interlocutors. Thus, what is typically a [-Telic] activity can also be taken as a [+Telic] accomplishment, depending on the context of use.

To conclude, the above bears out our prediction that $-t a$ can yield the chot news' perfect interpretation (with a ga-marked subject signalling View ${ }_{\text {part }}$ ) only with [+Telic] situations. However, it seems not only that the availability of the 'hot news' perfect interpretation depends on the [+Telic] feature of a situation but also that the 'hot news' perfect interpretation forces the described situation to be interpreted as [+Telic], where it is possible. As suggested by the possible 'hot news' perfect interpretation with an activity verb, the telicity of a situation is not so rigid that it may well alter depending on the context of use. ${ }^{24}$

\footnotetext{
${ }^{23}$ The marker $-d a$ is a phonological variant of $-t a$.

${ }^{24}$ The telicity of a situation appears even more fluid in Japanese, considering the fact noted in footnote 22 above.
} 


\subsection{3. $[+/-$ Preliminary $]$ and the interpretation of -ru}

Just as the telicity of situations, i.e., the presence or absence of a clear final endpoint, bears on the interpretation of $-t a$, the presence or absence of the preliminary stages bears on the interpretation of -ru (occurring with a ga-marked subject signalling View $w_{\text {part }}$ ).

As shown in (42) below, $-r u$ yields a future tense reading with a wa-marked subject and the 'on the verge' interpretation with a ga-marked subject. ${ }^{25}$ On the assumption that $-r u$ conveys the prospective aspectual meaning (corresponding to the relational meaning ' $<$ ' to connect $\mathrm{S}$ and E) (cf. 3.1 .2 above), the two distinct interpretations it yields are explained as follows. The future reading obtains when the prospective aspect denoted by $-r u$ is taken as modifying the situation (described by the verb) as a whole, with a $w a$-marked subject signalling Viewall. That is, the situation as a whole is going to take place some time in the future. On the other hand, the 'on the verge' reading obtains when the prospective aspect is taken as modifying a cross-section of the situation intersecting at the present moment, with a ga-marked

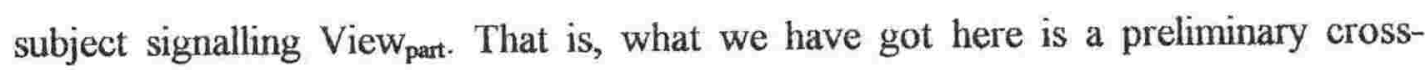
section of a situation, and therefore the situation described by the verb is visibly on the verge of taking place.

\section{(42)a. John-wa ku-ru. \\ come-Pres}

'John will come.'

<Future>

b. John-ga ku-ru.

come-Pres

'John is arriving/ just about to arrive.' $<$ On the verge $>$

Notice that it is essential for the 'on the verge' interpretation that one of the preliminary stages of a situation is visibly manifested at the moment of speech.

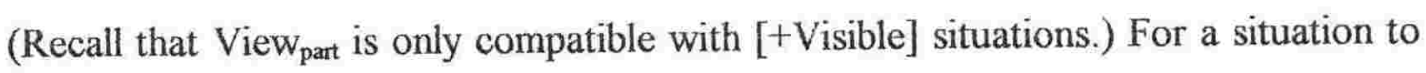
be able to visibly manifest one of its preliminary stages, it must have the preliminary

${ }^{25}$ Another possible interpretation of (42a) is habitual, i.e., 'John comes'. As briefly discussed in Appendix to Chapter 2, the denotation of $-r u$ is actually ambiguous between 'S $\angle E$ '/prospective and 'S,E'/ongoing. While I leave this problem outside the scope of this thesis for the sake of simplicity, it certainly needs to be properly investigated in the future. 
stages. If the 'on the verge' interpretation of $-r u$ requires a visible manifestation of a preliminary cross-section of a situation, it means that the 'on the verge' interpretation is only available with those situations which have the preliminary stages.

In 3.3.2 above, I have assumed the presence of the preliminary stages with [Durative] situations but not with [+Durative] situations, as illustrated in the representations in (8) and (9) above, which are reproduced in (43) and (44) below. This predicts that the on-the-verge interpretation of $-r u$ is only available with achievements, which are [-Durative], but not with states, activities, and accomplishments, which are $[+ \text { Durative }]^{26}$

(43) [+Durative] situations

Situation

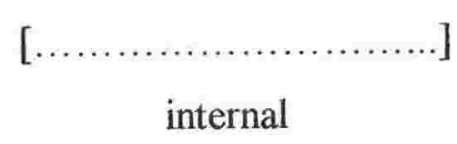

(44) [-Durative] situations

Situation

$\ldots \ldots \ldots \ldots \ldots \ldots . \ldots \ldots \ldots \ldots \ldots$
preliminary

However, the - $r u$ forms of activities and accomplishments can yield the on-theverge interpretation with a ga-marked subject, as seen in (45b) and (46b) below, though only in some special contexts such as a running commentary, where it is essential that the described situation is visible, as indicated by the question marks. ${ }^{27}$
(45)a. John-wa
oyog-u.
swim-Pres

'John will swim.'

$<$ Future $>$

\footnotetext{
${ }^{26}$ I classify accomplishments as durative because they have a durative activity subpart. However, the overall event of accomplishments is not durative in the same way that activities and states are, as pointed out by an examiner.

${ }^{27}$ The sentences (45a) and (46a) can also receive a habitual reading, i.e., 'John swims' and 'John draws a circle' respectively. See footnote 25 above.
} 
b. ?John-ga oyog-u. swim-Pres

'John is swimming/ just about to swim.'

$<$ On the verge $>$

(46)a. John-wa en-o kak-u.

circle-Acc draw-Pres

'John will draw a circle.'

$<$ Future $>$

b. ?John-ga en-o kak-u.

circle-Acc draw-Past

'John is drawing a circle/ just about to draw a circle.' <On the verge>

When the ru-form of a [ + Durative] verb occurring with a ga-marked subject yields the on-the-verge interpretation, the [+Durative] situation is conceived of as having the preliminary stages, as illustrated in (47) below. The on-the-verge interpretation obtains when $-r u$ is interpreted as modifying one of the preliminary 
$\begin{array}{lll}\text { (48)a. John-wa byooki da. } & \begin{array}{l}\text { dack } \\ \text { sick }\end{array}\end{array}$

'John is sick. (= John has been sick)'

b. John-ga byooki da.

sick Cop(Pres)

'John is sick (at this very moment).'
$<$ Static present $>$

$<$ Dynamic present $>$

The unavailability of the prospective (or ' $S<E$ ') interpretation may be due to the assertiveness of the copula $d a$, with which states are necessarily asserted either to hold or not to hold (or either to have held or not to have held). But the unavailability of the 'on the verge' interpretation in particular can also be explained as due to the absence of preliminary stages in the temporal schema of states.

In any case, the presence of preliminary stages is required for the availability of

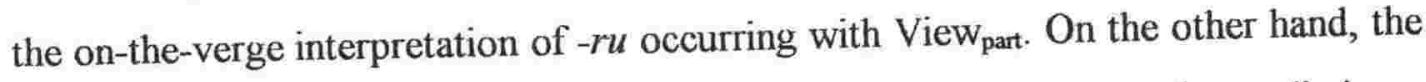
on-the-verge interpretation forces a situation to be conceived of as having preliminary stages, where it is possible.

\subsubsection{Summary}

In this section, we have observed the interaction between situation types (i.e., aspectual classes of verbs) and the S-E aspect conveyed by -teiru, -ta and $-r u$ in Japanese. Firstly, I have shown that the interpretation of -teiru differs, depending on the $[+/$-Durative] feature of situations (though the experiential interpretation of -leiru obtains irrespectively of the [+/-Durative] feature). Secondly, the telicity of situations, i.e., the presence or absence of a clear final endpoint, bears on the interpretation of $-1 a$ occurring with View $w_{\text {part }}$ Thirdly, the presence or absence of the preliminary stages bears on the interpretation of $-r u$ occurring with $V_{i e w_{p a r t}}$.

\subsection{Conclusion: Three-component analysis of aspect}

In 3.1, we have seen the aspectual meanings of tense markers. In 3.3, we have observed the interaction between viewpoint aspects and situation types. And in 3.4, we have observed the interaction between situation types and the denotations of tense/aspect markers. The discussions in these sections have shown that the temporal 
and aspectual interpretation is compositional of the three different things, which are possibly all called 'aspects'.

As illustrated in (49) below, those three 'aspects' are expressed at different parts of a sentence. Firstly, the subject markers, -wa and -ga, convey viewpoint aspects, Viewall and $V_{\text {View }}$ part. Secondly, situation types such as [+/-Stage], [+/-Durative], [+/-Telic] and [+/Preliminary] are conveyed by (lexical) predicates. Thirdly, verbal affixes such as $-t a,-r u$ and -teiru convey what 1 call 'S-E aspects' expressing such meanings as completed, prospective and ongoing. Those properties conveyed by three 'aspects' are originally independent of one another, but as an outcome of interacting with one another, they yield a certain temporal and aspectual interpretation. (Note that the distinct temporal and aspectual interpretations of (a) and (b) in (49) are due to the distinct viewpoint aspects conveyed by the subject markers, $-w a$ and $-g a$.)

(49) Three components of 'aspect'
i. Viewpoint aspect (Grammatical aspect)
ii. Situation type (Lexical aspect)
iii. S-E Aspect

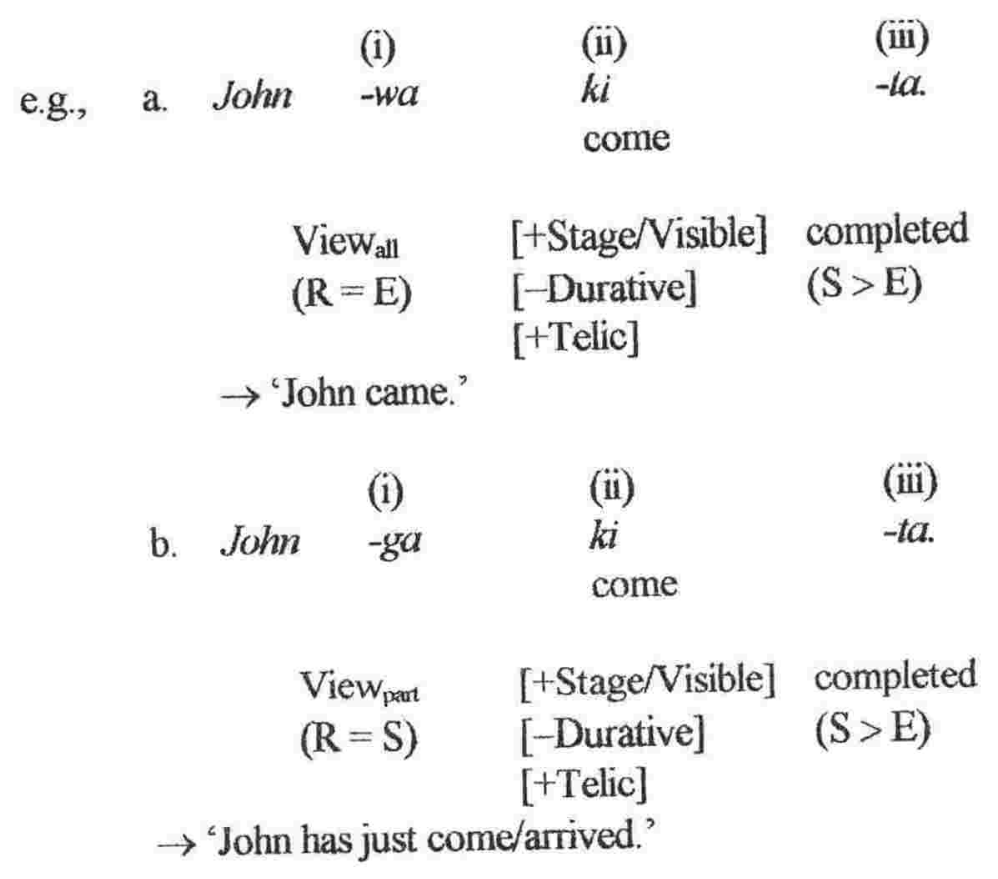

This three-component analysis is an extension to Smith's (1991) twocomponent theory. While Smith has viewpoint aspects and situation types, I have S-E 
aspects in addition to the two. In effect, I have decomposed Smith's viewpoint aspects into two parts; viewpoint aspects 'proper' and S-E aspects. Notice that Smith's viewpoint aspects do two jobs; one is to distinguish 'all' and 'part' of a situation and the other is to specify which 'part' of a situation is in focus (if 'part' rather than 'all' is in focus). In my analysis, viewpoint aspects do just one job, i.e., the job of distinguishing 'all' and 'part' of a situation. The other job, i.e., the job of designating which 'part' of a situation, is allocated to the S-E aspects conveyed by the verbal affixes. Recall the discussions in Chapter $2(2.4 .3)$ that while the imperfective is almost equated to the progressive in Smith's characterization, the progressive is only one of the possible presentations of View part in Japanese. View part can focus a preliminary stage of a situation and the final stage of a situation as well as an internal stage of a situation, depending on the marker attached to the verb (i.e., $r u,-t a$, or -teiru).

Furthermore, as a result of introducing S-E aspects, which interact with two different viewpoint aspects, tense and aspect are merged into one system. With Viewall, $S-E$ aspects express tenses such as past, future, and present, whereas with View $_{\text {part }}$ they express aspects such as perfect, proximate future, and progressive.

The three-component analysis enables us to maintain the assumption broadly motivated by a principle of economy that bits of language which are identical in form are also identical in meaning and yet to account for a variety of temporal and aspectual interpretations yielded by one and the same tense/aspect marker (or one and the same string of tense/aspect markers) in terms of the interaction with situation types and viewpoint aspects.

More crucially to our purpose, we confirm that due to the availability of two types of viewpoint aspect conveyed by $w a$ - and ga-markings of subjects, the same predicate with the same tense/aspect marker(s) can yield two distinct temporal and aspectual interpretations in correlation with wa- and ga-marking of the subject. However, due to the incompatibility between a viewpoint and a situation type (i.e., View $_{\text {part }}$ and [-Stage] or [-Visible]) and/or the incompatibility between a situation type and the combination of a tense/aspect marker and a viewpoint (i.e., [-Telic] and the combination of $-t a$ and $V_{\text {iew }}$ part), wa/ga-pairs of sentences do not necessarily exhibit the nice Viewall-View part contrast as illustrated in Chapter 2. 


\section{Chapter 4}

\section{The phrase structure of tense}

I have shown in the previous chapters that wa- and ga-markings of subjects in Japanese correlate with two types of evaluation time/R/ viewpoint aspect. If we assume some syntactic mechanisms to account for wa/gamarking of subjects, it suggests that we need to encode the distinction between the two types of evaluation time/R/viewpoint aspect in our syntactic representation. In this chapter, I propose a phrase structure which enables us to see the interrelation between the two types of evaluation time/R/viewpoint aspect and wa/ga-marking of subjects in Japanese. To the extent that the $w a / g a$-phenomena are concerned with the notions of both tense and aspect as shown in Chapters 2 and 3, the system I propose to account for them in this chapter is a unified system of tense and aspect in the syntax.

In 4.1 , I start with the task of representing our tense formulae with the $\mathrm{S}-\mathrm{E}$ relation at one level and $\mathrm{R}$ aligned with either $\mathrm{S}$ or $\mathrm{E}$ at another level in the phrase structure. To syntactically represent the S-E relation, I follow the spirit of Zagona (1990) and Stowell (1994a,b) in analyzing that a tense phrase (i.e., TP) denotes a relation between two times, one of which is given and serves as a reference point, with respect to which the other is located. To represent $\mathrm{R}$ aligned with either $\mathrm{S}$ or $\mathrm{E}$, I propose that $\mathrm{R}=\mathrm{E}$ and $\mathrm{R}=\mathrm{S}$ project their own syntactic phrases, which are both tense phrases defining the relation between $\mathrm{S}$ and $\mathrm{E}$. I call them $\mathrm{T}_{\mathrm{R}=\mathrm{E}} \mathrm{P}$ and $\mathrm{T}_{\mathrm{R}=\mathrm{S}} \mathrm{P}$ respectively.

In 4.2 , I scrutinise the semantic contents of the two functional heads, $T_{R=E}$ and $T_{R=S}$. The essential semantic content of $T_{R=S}$ is identified as an anchor to a spatiotemporal location, while that of $\mathrm{T}_{\mathrm{R}=\mathrm{E}}$ is identified as an anchor to a world. An anchor to a spatiotemporal location is represented by a event variable $e$, which may or may not occur in the event-place $E$. On the other hand, an anchor to a world is represented by a world variable $\omega$, which may or may not occur in the world-place $W$. Assuming that the event-place $E$ and the 
world-place $W$ project their own phrases, which correspond to $\mathrm{T}_{\mathrm{R}=\mathrm{S}} \mathrm{P}$ and $\mathrm{T}_{\mathrm{R}=\mathrm{E}} \mathrm{P}$ respectively, $\mathrm{I}$ rename them as $E \mathrm{P}$ and $W \mathrm{P}$.

In 4.3, I investigate the syntactic mechanisms operating in the temporal structure made up of WP and EP. In particular, I argue for the syntactic and semantic association between $W \mathrm{P}$ and $w a$-marked subjects and that between $E \mathrm{P}$ and ga-marked subjects. As temporal categories, $W$ and $E$ are assumed to have T-features (to be checked by the relevant features of predicates) and Dfeatures (to be checked by the relevant features of DPs). However, their Tand D-features need to be checked only when $W$ and $E$ are activated by the occurrence of $\omega$ and $e$ respectively. That is, activated $W$ and $E$ attract predicates in order to have their T-features checked by their features and subject DPs to their Spec positions in order to have their D-features checked by their features through Spec-head agreement.

While the T- and D-features of $W$ and $E$ syntactically function as triggers of movement and licensers of relevant items (due to their need to be checked by appropriate items), due to the distinct semantic contents of $W$ and $E$, their T-features checked by the relevant features of predicates affect the temporal/aspectual interpretations of the predicates, whereas their D-features checked by the relevant features of DPs affect the semantic interpretations of the subject DPs. The T-features of $W$ and $E$ checked by the features of predicates give rise to the $\mathrm{R}=\mathrm{E}$ and the $\mathrm{R}=\mathrm{S}$ interpretations respectively. The D-features of $W$ and $E$ checked by the features of DPs make the subject DPs taken as referring to spatiotemporally transcending whole individuals (i.e., 'individuals') and spatiotemporally bounded manifestations of individuals (i.e., 'stages') respectively. Assuming that those subjects appearing in [Spec, $W \mathrm{P}]$ and taken as referring to 'individuals' are $w a$-marked and those appearing in [Spec, EP] and taken as referring to 'stages' are $g a$-marked in Japanese, wamarked and $g a$-marked subjects are licensed by the D-features of $W$ and $E$ respectively. The correlation between $w a / g a$-subjects and the two types of temporal and aspectual interpretations obtained for the clauses is explained by the $\mathrm{T}$ - and $\mathrm{D}$-features of $W$ and $E$, which are respectively responsible for the two types of temporal and aspectual interpretations and for licensing of wa- 
marked and ga-marked subjects. Crucially, the T- and D-features of $W$ and $E$ assure that subjects and predicates of the same semantic type are properly paired and, as an interesting consequence of my analysis, the distinction between stage- and individual-level predicates is encoded in the phrase structure of tense.

In 4.4, I compare my analysis as a system to syntactically account for the stage-/individual-level distinction with the previous analyses of Kratzer (1989) and Diesing (1992). I show that while maintaining the spirit of the previous analyses, my proposal exhibits both empirical and theoretical advantages .

In 4.5, I compare my analysis with Davis' (1998) proposal which also considers subject licensing to depend on a temporal structure. While I associate $w a$ - and $g a$-marked subjects in Japanese with the two temporal heads ( $W$ and $E)$, Davis associates the $\phi$-features of the first and second person subjects and those of the third person subjects with the two temporal heads ( $T$ and Asp). Investigating the commonality between the split between $1 \& 2$ subjects and 3 subjects and the $w a / g a$-split of subjects in Japanese, I argue that the exact properties that distinguish between the two classes of subjects associated with the two temporal categories are the referential familiarity vs. novelty in the discourse and the totality vs. temporality of the referent in our perception, which are closely interrelated. I propose that those properties are encoded in the D-features of $W$ and $E$ and checked by subject DPs raised to their Spec positions.

In 4.6, I show that the two subject positions proposed for $w a-$ and $g a-$ subjects in Japanese are tenable across languages, even where there is little overt differentiation of two kinds of subjects as in English.

Lastly in 4.7, I discuss an implication of my analysis for first language acquisition. 


\subsection{Syntactic representations for the $S-E$ relation and $R$ as a viewpoint} aspect

The summary table from Chapter 2 is reproduced in (1) below as a quick reminder of the correlation between $w a$ - and ga-marking of subjects and (i) two types of evaluation time, (ii) two types of R, and (iii) two types of viewpoint aspect.

(1)

$\begin{array}{llll} & & -g a & -w a \\ \text { i. Evaluation Time } & \text { original }(t) & \text { new }\left(t^{\prime}\right) \\ \text { ii. } & \mathrm{S}, \mathrm{E}, \mathrm{R} & \mathrm{R}=\mathrm{S} / \neq \mathrm{E} & \mathrm{R}=\mathrm{E} / \neq \mathrm{S} \\ \text { iii. } & \text { Viewpoint Aspect } & \text { View }_{\text {part }} & \text { View }_{\text {all }}\end{array}$

While the two types of evaluation time, $R$, and viewpoint aspect correspond to one another, the two types of $\mathrm{R}$ in particular provide a good starting point for investigating the syntactic representations.

Recall that the two types of $\mathrm{R}$ are represented in our tense formulae, where a temporal relation is specified between $\mathrm{S}$ and $\mathrm{E}$ at one level and $\mathrm{R}$ is aligned with either $\mathrm{S}$ or $\mathrm{E}$ at another level. The formulae are reproduced in (2) below. I take it as my first task to represent the formulae in (2) in the syntax.

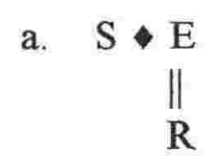
b. $\mathrm{S} \bullet \mathrm{E}$<smiles>C1=CC=C1</smiles> $\mathrm{R}$

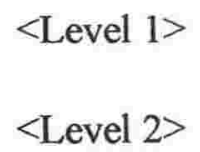

\subsubsection{Representation for the S-E relation}

Let me begin by reviewing the analysis of tense as a dyadic predicate, as in Stowell (1994a,b) based on Zagona (1990), which seems highly pertinent to our task of representing the S-E relation in the syntax. To syntactically express that tense is a relation between two times, one of which is given and serves as a reference point, with respect to which the other is located, Zagona (1990) proposes that tense takes two time-denoting phrases as arguments and defines the temporal relation between them. The time denoting arguments, 
which Stowell (1994a,b) calls ZPs ("Zeit-Phrase"), thus appear in both external and internal argument positions of Tense, as shown in (3).

(3)

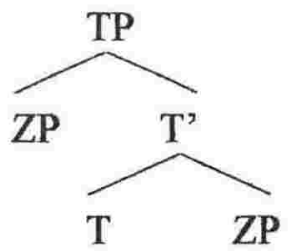

Stowell maintains that the internal ZP argument denotes the Event Time, the time at which the event instantiated by the predicate of the clause is interpreted to take place, and that the external ZP argument refers to a time relative to which the internal $\mathrm{ZP}$ argument is (temporally) ordered. The external ZP argument typically denotes the utterance time, though theoretically it has no fixed indexical denotation. (I will return to this point shortly.) Tense temporally locates the denotation of its internal argument in relation to the denotation of its external argument, i.e., the event time (E) in relation to the utterance time (S) most typically. For example, if Tense contains Past, or the relation 'after' (' $>$ '), the Tense Phrase (TP) denotes that the utterance time is after the event time, as shown in (4) below. This yields the past tense interpretation.

(4)

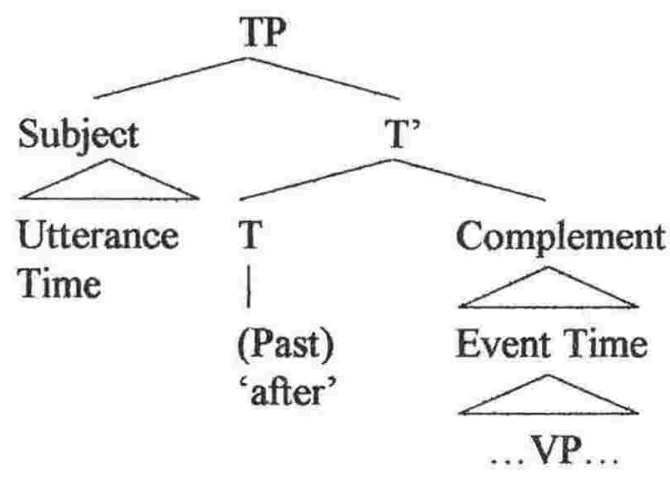

(Stowell 1994a: 8)

Let us now take a closer look at the denotation of the external argument. Although it is typically the utterance time which serves as a reference point, with respect to which the event time is temporally located, other temporal moments can also serve as a reference point when they are 
recognized as the "now" point in the speech situation, as discussed in 2.2.3.1 above. To capture this fact, Stowell compares the external argument of $\mathrm{T}$ to PRO. The denotation of the external argument, a PRO-ZP, is controlled by a c-commanding ZP. As the external argument of a main clause Tense, PRO-ZP has no c-commanding syntactic antecedent. It is therefore analogous to

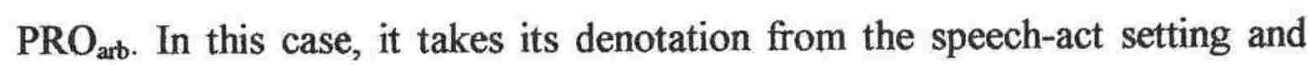
denotes the time of utterance or refers to a time recognized as "now" as specified by other sentences in the discourse. In subordinate clauses, PRO-ZP is obligatorily bound by the event time ZP in the immediately higher clause, and therefore it refers to the event time of the immediately higher clause. Thus, the external ZP argument essentially denotes the "now" time, which serves as the reference point for the temporal location of the event time. And presumably because it is the time which serves as the reference point, Stowell refers to the denotation of the external $\mathrm{ZP}$ argument as the Reference Time.

It is important to note here that Stowell's use of the term Reference Time or $\mathbf{R}$ is quite different from Reichenbach's and also from mine. Recall that Reichenbach used $\mathrm{R}$ to primarily represent a "point of view" for the semantic interpretation of perfect (and in other cases, just bundled it up with $\mathrm{E})$, whereas I have been taking $\mathrm{R}$ as representing the viewpoint aspect of a clause by attaching to either S or E (of the S-E relation) (cf. Chapter 2). Stowell uses $R$ to refer to the time in relation to which the event time is located. In effect, Stowell's $\mathbf{R}$ corresponds to my $\mathbf{S}$ defined as a deictic element which refers to a time recognized as the "now" point in the discourse, with respect to which the event time is located. Accordingly, a temporal relation between $\mathrm{R}$ and $\mathrm{E}$ Stowell claims to be expressed in his TP corresponds to a relation between $\mathrm{S}$ and $\mathrm{E}$ in my definitions. Therefore, $\mathrm{I}$ assume that by adopting the spirit of Zagona-Stowell analysis of tense, the $\mathrm{S}$ $\mathrm{E}$ relation in our tense formulae is syntactically represented in the phrase structure of Tense.

From the analysis that Tense defines the relation between $\mathrm{S}$ (the denotation of its external argument) and $\mathrm{E}$ (the denotation of its internal argument), it follows that what carries the information about the relation between $\mathrm{S}$ and $\mathrm{E}$ should appear in $\mathrm{T}$ at some stage of derivation (whether 
overtly or covertly). Recall that we have been working with the assumption that in Japanese the relations to connect $\mathrm{S}$ and $\mathrm{E}$ are carried by verbal affixes such as $-t a,-r u$, and -teiru (cf. Chapter 2). If this assumption is correct, we expect that those affixes, $-t a,-r u$, and -teiru, appear in $\mathrm{T}$ to connect $\mathrm{S}$ and $\mathrm{E}$.

However, let me note here that alternatively we can assume that $-t a$, $r u$, and -teiru carry the whole S-E relations rather than just the (topological) relations to connect two things. That is, we can assume that not just '>', ' $<$ ', and ',' but ' $\mathrm{S}>\mathrm{E}$ ', 'S $<\mathrm{E}$ ', and ' $\mathrm{S}, \mathrm{E}$ ' are conveyed as a whole pack by $-t a$, $-r u$, and -teiru respectively. With this alternative view, we can maintain that Tense is a relation between $S$ and $E$ without having $S$ and $E$ represented as its arguments in the phrase structure. In fact, despite the beauty of the analysis, it is hard to find concrete evidence for the existence of ZPs denoting $\mathrm{S}$ and $\mathrm{E}$ as the arguments of Tense because they cannot be overtly realized. ${ }^{1}$ It therefore seems equally conceivable that $\mathrm{S}$ and $\mathrm{E}$ are not syntactically represented as arguments in the phrase structure. As I advance my analysis in the following, I will come to adopt this alternative view.

\subsubsection{Representation for $R$ as a viewpoint aspect}

I now turn to the syntactic representation of $\mathrm{R}$ which is aligned with either $\mathrm{S}$ or $\mathrm{E}$. I propose that these two kinds of $\mathrm{R}$ project their own syntactic phrases in an articulated temporal structure. Let us call those phrases $T_{R=E} P$ and $\mathrm{T}_{\mathrm{R}=\mathrm{S}} \mathrm{P}$ for the present. Building on the analysis that a tense phrase primarily defines the relation between $\mathrm{S}$ and $\mathrm{E}$, as discussed in 4.1.1 above, I assume that both $T_{R=E} P$ and $T_{R=S} P$ define the relation between $S$ and $E$. Then, $T_{R=E} P$ represents the tense formula in (2a), and $T_{R=S} P$ represents that in (2b) above.

As illustrated in (5) below, I assume that the sequence (dominance relation) of $T_{R=E} P$ and $T_{R=S} P$ is such that $T_{R=E} P$ dominates $T_{R=S} P$. One reason

\footnotetext{
${ }^{1}$ In Stowell's analysis, the syntactic projection of the external argument of $\mathrm{T}$ is required for a PRO argument, which accounts for the shifting of the denotation of his reference time in embedded contexts, as pointed out by an examiner. However, with the new notion of 'S' I propose as a deictic element which refers to a time recognized as the "now" point in the discourse, the control analysis for the shifting of its denotation is not necessary, as will be discussed in the following section 4.1.2.
} 
to assume such a hierarchical relation between the two tense phrases is that semantically $\mathrm{R}=\mathrm{S}$ comes under the scope of $\mathrm{R}=\mathrm{E}$. Recall that as a viewpoint aspect $R=S$ focuses part of a situation, while $R=E$ focuses all of a situation. Since all of a situation contains part of a situation, I conceive that $\mathrm{R}=\mathrm{E}$ (which focuses all of a situation) has wide scope over $\mathrm{R}=\mathrm{S}$ (which focuses part of a situation) in the syntactic structure.

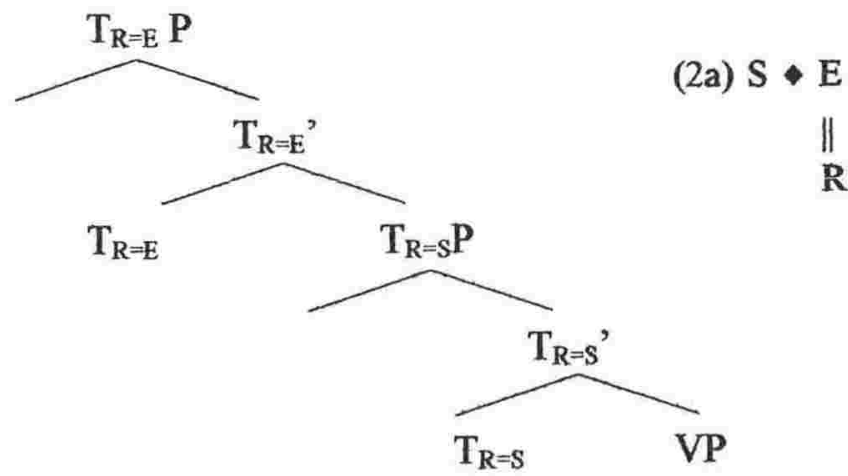

$(2 \mathrm{~b}) \mathrm{S} \bullet \mathrm{E}$<smiles>C=[Hg]</smiles>
$\mathbf{R}$

Another reason is the anticipation that $\mathrm{T}_{\mathrm{R}=\mathrm{E}} \mathrm{P}$ and $\mathrm{T}_{\mathrm{R}=\mathrm{S}} \mathrm{P}$ are somehow associated with $w a$ - and $g a$-marked subjects respectively. Recall the correlation between $\mathrm{R}=\mathrm{E}$ and $w a$-marked subjects and that between $\mathrm{R}=\mathrm{S}$ and ga-marked subjects observed in Chapter 2. Based on the well-observed structural hierarchy between $w a$ - and $g a$-marked subjects such that $w a$ marked subjects occupy a higher syntactic position than ga-marked subjects (cf. 1.3 above), it seems reasonable to assume that $\mathrm{T}_{\mathrm{R}=\mathrm{E}} \mathrm{P}$ associated with wamarked subjects are structurally higher than $\mathrm{T}_{\mathrm{R}=\mathrm{S}} \mathrm{P}$ associated with ga-marked subjects.

Let us consider here the issue of whether to assume that a tense phrase is a dyadic predicate of two time-denoting arguments, as Zagona and Stowell do. If we adopt the analysis of tense as a dyadic predicate as it is, we need to postulate time denoting phrases, i.e., ZPs, in both external and internal argument positions of $T_{R=E} P$ and $T_{R=S} P$, as shown in (6) below. 
(6)

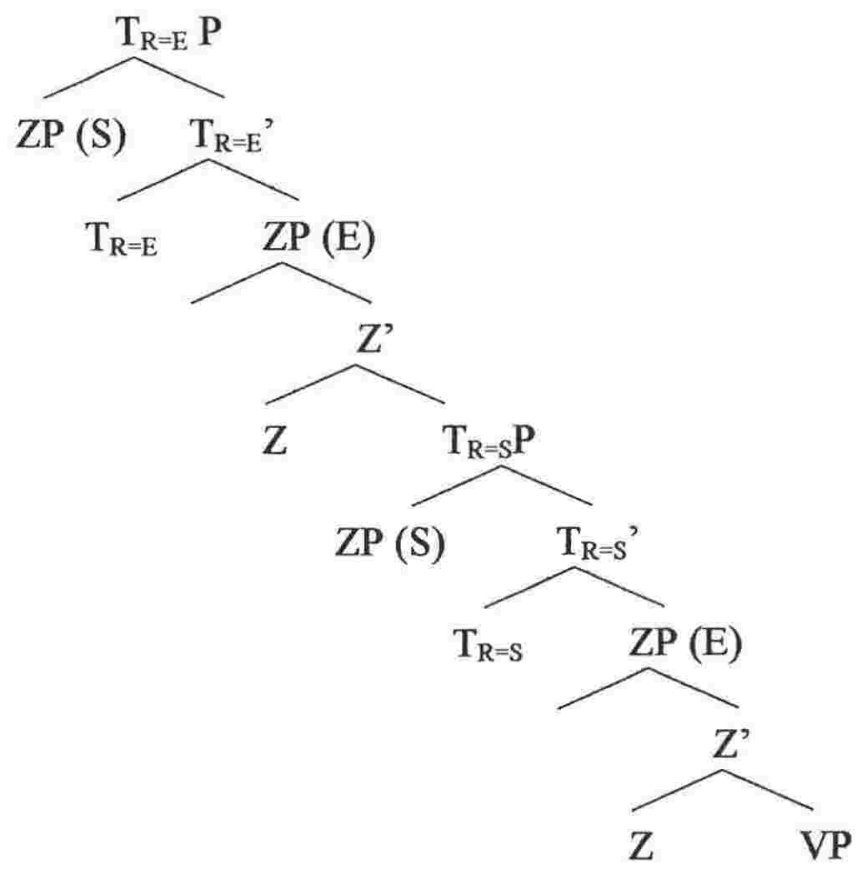

In Stowell's analysis, the syntactic projection of the external argument of $\mathrm{T}$ is required for a PRO argument, which accounts for the shifting of the denotation of his reference time in embedded contexts. However, with the new notion of 'S' I propose as a deictic element which refers to a time recognized as the "now" point in the discourse, the control analysis for the shifting of its denotation is not necessary. It simply picks a time recognized as "now" in each context, which is in an embedded context the time of the event described in the higher clause. In my view, such a phenomenon does not need to be captured and represented in the syntax. As for the syntactic projection of the internal argument, its repetitive occurrence in (6) above appears rather redundant. In the interest of economy and on the basis of lack of evidence for the existence of those time denoting phrases, I rather assume simply that each tense phrase defines the relation between $\mathrm{S}$ and $\mathrm{E}$, without having $\mathrm{S}$ and $\mathrm{E}$ syntactically represented as arguments. That is, I assume that an articulated temporal structure looks like (5) above rather than (6).

Since $T_{R=E} P$ and $T_{R=S} P$ are both tense phrases that define the relation between $\mathrm{S}$ and $\mathrm{E}$, those affixes which are assumed to carry the information about the relation between $\mathrm{S}$ and $\mathrm{E}$, i.e., $-t a,-r u$, and -teiru in Japanese, should be able to appear in both $T_{R=E}$ and $T_{R=s}$. More precisely, in a given clause, those affixes should appear in either $T_{R=E}$ or $T_{R=S}$ at some stage of 
derivation either overtly or covertly. Crucially, although $-t a,-r u$, and -teiru constantly convey ' $\mathrm{S}>\mathrm{E}$ ', ' $\mathrm{S}<\mathrm{E}$ ', and ' $\mathrm{S}, \mathrm{E}$ ' respectively, depending on whether they appear in $T_{R=E}$ or $T_{R=S}$, the same $S-E$ relations yield distinct temporal and aspectual interpretations, due to the semantic contents, $\mathrm{R}=\mathrm{E}$ and $\mathrm{R}=\mathrm{S}^{2}$

\subsubsection{Comparison with Demirdache and Uribe-Etxebarria (1998a,b,c)}

The temporal structure with a couple of functional projections, $\mathrm{T}_{\mathrm{R}=\mathrm{E}} \mathrm{P}$ and $\mathrm{T}_{\mathrm{R}=\mathrm{S}} \mathrm{P}$, that $\mathrm{I}$ am proposing is strikingly similar to that with $\mathrm{TP}$ and AspP proposed by Demirdache and Uribe-Etxebarria (1998a,b,c) (henceforth D \& UE). Extending Zagona (1990) and Stowell (1993), D \& U-E assume that not only Tense but also Asp is a dyadic predicate of spatiotemporal ordering, establishing a topological relation between two time denoting arguments. However, while they say both Tense and Asp are dyadic predicates, D \& U-E do not assume a time denoting phrase in the internal argument position, unlike Stowell. Rather, as seen in (7) below, their time denoting arguments are all in the specifier positions, i.e., the external argument positions. Without a time denoting phrase occurring in the internal argument position of each temporal projection, D \& U-E's temporal structure is made up of just the two functional projections which both define spatiotemporal ordering.

${ }^{2}$ Travis (1991) has also proposed an analysis that a single tense morpheme can appear in two distinct syntactic postitions to yield two distinct interpretations. The data from Oweré Igbo presented by Déchaine (1991) shows that the morpheme ga appears in two different positions and yields two different interpretations, as seen as in (i).

(i) a. O rí- ga ri à. 3sg eat prog food this

'S/he is eating this food.'

b. O ga e-rí- ri à. 3 sg fut ?-eat food this 'S/he will eat this food.'

(Travis 1991: 9)

Travis analyzes that the progressive and future interpretations derive from the same morpheme, $g a$, with the same meaning, irrealis. Mapping onto the phrase structure she argues for, Travis explains that when ga appears in the upper tense position, the whole event is unrealized and it has the interpretation of future tense and when it appears in the lower tense position, only the resulting state is unrealized and it has the interpretation of uncompleted aspect, or progressive. 
(7)

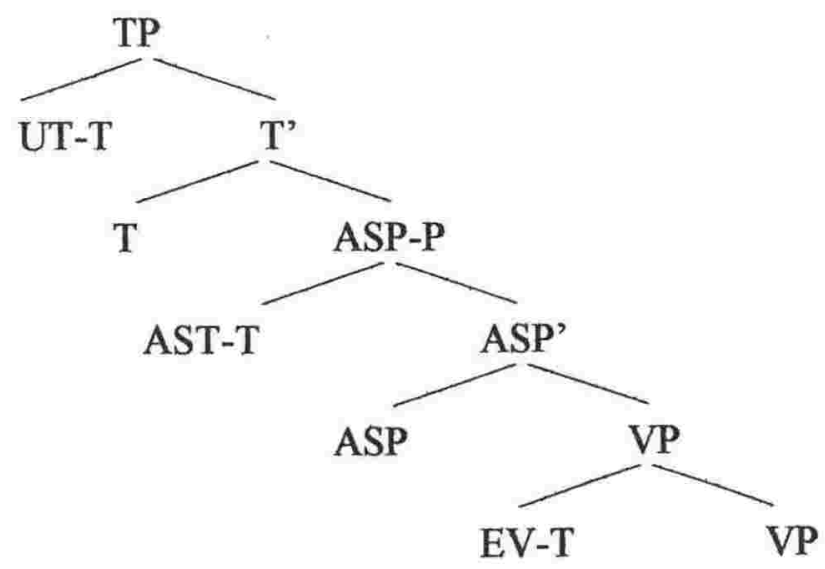

Both Asp and T have the meaning of AFTER, BEFORE, or (WITH)IN. Crucially, however, the same import, AFTER, BEFORE, or (WITH)IN, gives rise to two distinct interpretations depending on whether it appears in Asp or T. Aspect establishes a topological relation between the assertion time (AST-T), the time for which an assertion is made or to which the assertion is confined (Klein 1995), and the event time (EV-T). On the other hand, Tense orders the assertion time (AST-T) with respect to the utterance time (UT-T). Therefore, AFTER, BEFORE, and (WITH)IN respectively yield Perfect, Prospective, and Progressive interpretations in Aspect, and Past, Future, and Present interpretations in Tense.

$\begin{array}{lll} & \text { Aspect } & \text { Tense } \\ \text { AFTER } & \text { Perfect } & \text { Past } \\ & \text { (AST-T } \text { after } \text { EV-T) } & \text { (UT-T after AST-T) } \\ \text { BEFORE } & \text { Prospective } & \text { Future } \\ & \text { (AST-T } \text { before } \text { EV-T) } & \text { (UT-T before AST-T) } \\ \text { (WITH)IN } & \text { Progressive } & \text { Present }\end{array}$

(AST-T within EV-T)

(UT-T within AST-T)

According to D \& U-E, Past Progressives (e.g., Mary was reading $L I$ ), for example, derive from the compositional interaction of Tense and Aspect, as illustrated in (9) below. Asp orders the time to which the assertion of the sentence is confined (AST-T) (with)in the EV-T, and T orders the UT-T after the AST-T (which refers to a proper subpart of the EV-T). 
(9) Past Progressive (e.g., Mary was reading $L I$.)

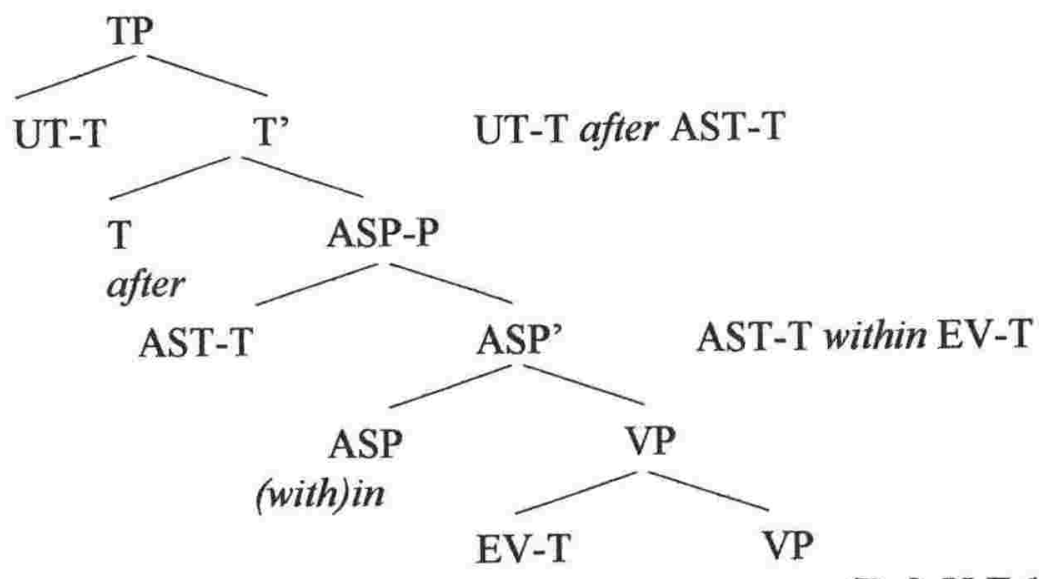

(D \& U-E 1998a: 29)

For the cases without morphological Tense or without morphological Aspect, D \& U-E assume that although TP and AspP are always projected, when $\mathrm{T}$ or Asp lacks morphological content, its external argument is syntactically equated with its internal argument (via binding or movement). For example, a sentence with Prospective Aspect and no morphological Tense (supposedly in Salish) has the phrase structure (10a) below, in which the UT$\mathrm{T}$ binds the AST-T which is ordered before the EV-T. On the other hand, the simple Future Tense with no morphological Aspect has the phrase structure (10b) below, in which the UT-T is ordered before the AST-T which itself binds the EV-T (since Asp is empty).

(10) a. Prospective Aspect without Morphological Tense

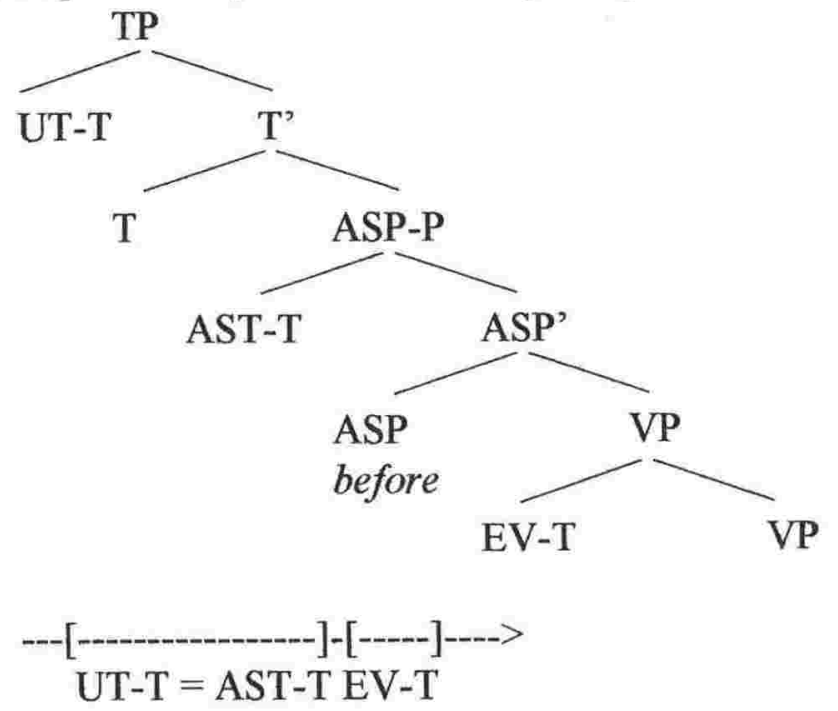


b. Future Tense without Morphological Aspect

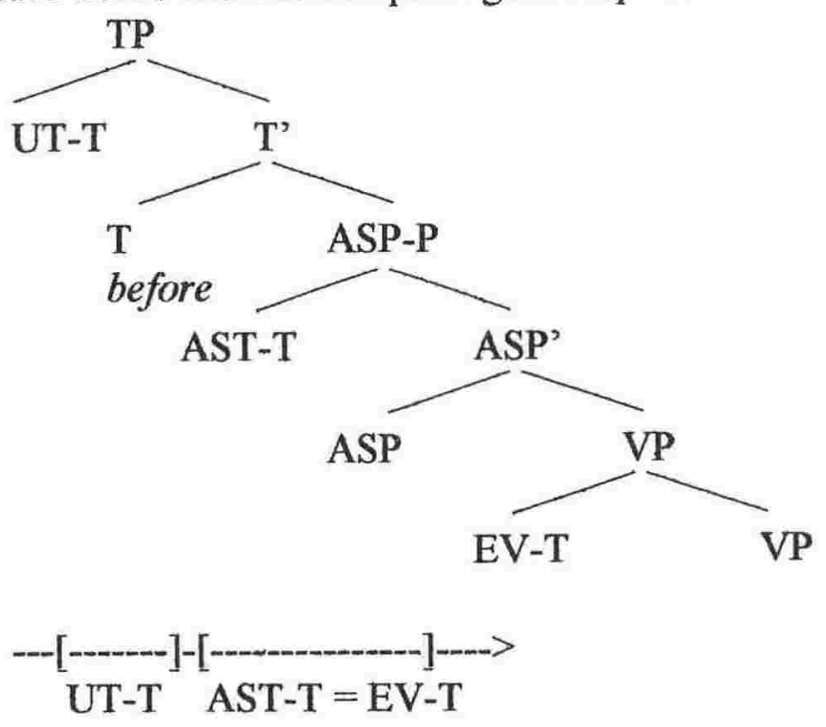

(D \& U-E 1998a: 29)

Notice that Prospective Aspect and Future Tense share a single topological relation BEFORE but are distinguished by whether BEFORE appears in Asp or T. Having BEFORE in Asp, Prospective Aspect has a deactivated $\mathrm{T}$ without content. Having BEFORE in $\mathrm{T}$, Future Tense has a deactivated Asp without content. Deactivated $\mathrm{T}$ in Prospective Aspect conveys that its external argument UT-T (i.e., S) is equated with its internal argument AST-T (i.e., R), that essentially means $\mathrm{R}=\mathrm{S}$. On the other hand, deactivated Asp in Future Tense conveys that its external argument AST-T (i.e., R) is equated with its internal argument EV-T (i.e., E), that essentially means $\mathrm{R}=\mathrm{E}$.

Importantly, both D \& U-E and I propose two functional projections of temporal ordering. Moreover, we both encode the information about whether R (AST-T) coincides with S (UT-T) or E (EV-T) in one way or another. In D \& U-E's proposal, deactivated T conveys UT-T = AST-T (corresponding to $\mathrm{R}=\mathrm{S}$ ) and deactivated Asp conveys AST-T $=\mathrm{EV}-\mathrm{T}$ (corresponding to $\mathrm{R}=$ $\mathrm{E})$. That is, $\mathrm{R}$ is equated with $\mathrm{S}$ or $\mathrm{E}$ only when $\mathrm{T}$ or Asp is deactivated. When both $\mathrm{T}$ and Asp are activated, $\mathrm{R}$ is not equated with $\mathrm{S}$ nor $\mathrm{E}^{3}$ In my proposal, on the other hand, the higher temporal phrase (corresponding to D

\footnotetext{
${ }^{3}$ The other logical possibility in D \& U-E's analysis is that both T and Asp are deactivated to convey that $R$ is equated with both $S$ and $E$, i.e., $R=S=E$. However, $D$ \& U-E do not seem to allow for such a case.
} 
\& U-E's T) directly encodes $\mathrm{R}=\mathrm{E}$ and the lower temporal phrase (corresponding to D \& U-E's Asp) encodes $\mathrm{R}=\mathrm{S}$. Therefore, $\mathrm{R}$ is necessarily equated with $\mathrm{E}$ or $\mathrm{S}$. There is no possibility of $\mathrm{R}$ being distinct from both $\mathrm{E}$ and $\mathrm{S}$.

Thus, an important difference between D \& U-E's and my analyses is that $\mathrm{I}$ only allow for two types of $\mathrm{R}$, that is, $\mathrm{R}$ has to be equated with either $\mathrm{E}$ or $\mathrm{S}$ (i.e., $\mathrm{R}=\mathrm{E}$ or $\mathrm{R}=\mathrm{S}$ ), while $\mathrm{D} \& \mathrm{U}-\mathrm{E}$ allow for the possibility of $\mathrm{R}$ being distinct from both $\mathrm{E}$ and $\mathrm{S}$ as well as the possibility of $\mathrm{R}$ being equated with $\mathrm{E}$ or S. On first sight, the two analyses also differ in that while in my analysis the two temporal phrases define the relation between $S$ and $E$, in $D$ and U-E's analysis the higher phrase defines the relation between UT-T and AST-T (corresponding to $\mathrm{S}$ and $\mathrm{R}$ ) and the lower phrase defines the relation between AST-T and EV-T (corresponding to R and E). However, this difference is in fact reducible to the issue of whether we only allow for two types of $\mathrm{R}$ or not. Although D \& U-E's TP denotes the relation between UT-T and AST-T (i.e., the S-R relation), when Asp is empty and AST-T is equated with EV-T (i.e., $\mathrm{R}=\mathrm{E}$ ), the relation between UT-T and AST-T specified in TP is essentially the relation between UT-T and EV-T, i.e., the S-E relation. Similarly, although D \& U-E's AspP denotes the relation between AST-T and EV-T (i.e., the R-E relation), when T is empty and UT-T is equated with AST-T (i.e., $\mathrm{R}=\mathrm{S}$ ), the relation between AST-T and EV-T specified in AspP is essentially the relation between UT-T and EV-T, i.e., once again the S-E relation. That is, if $\mathrm{R}$ (or AST-T) is necessarily equated with $\mathrm{E}$ (EV-T) or $\mathrm{S}$ (UT-T), the two sets of relation, the relation between UT-T and AST-T and that between AST-T and EV-T, are essentially reduced to the relation between UT-T and EV-T, i.e., the S-E relation. The issue of whether we should only allow for two types of $\mathrm{R}$ or not hinges on the discussions in Chapter 2, where I suggest some modifications of Reichenbach's tense theory.

For the present purpose, however, let us rather converge on the similarities between D \& U-E's and my analyses. That is, D \& U-E's and my analyses support each other in that an articulated temporal structure is made up of two functional projections of temporal ordering and encodes the 
information about two types of $\mathrm{R}$, i.e., $\mathrm{R}=\mathrm{E}$ (or $\mathrm{AST}-\mathrm{T}=\mathrm{EV}-\mathrm{T}$ ) and $\mathrm{R}=\mathrm{S}$ (or AST-T $=$ UT-T). ${ }^{4}$

\subsubsection{Summary}

To sum up, in order to represent our tense formulae in (2) above, I have proposed a series of functional projections, $\mathrm{T}_{\mathrm{R}=\mathrm{E}} \mathrm{P}$ and $\mathrm{T}_{\mathrm{R}=\mathrm{S}} \mathrm{P}$, as an articulated TP structure. The higher temporal phrase, $T_{R=E} P$, represents the tense formula in (2a), whereas the lower phrase, $T_{R=S} P$, represents that in (2b) above.

Since both $T_{R=E} P$ and $T_{R=S} P$ define the relation between $S$ and $E$, verbal affixes such as $-t a,-r u$, and -teiru in Japanese, which I assume to carry the information about the relation between $S$ and $E$, can appear in both $T_{R=E}$ and $T_{R=S}$, or in a given clause either in $T_{R=E}$ or in $T_{R=S}$ at some stage of derivation either overtly or covertly. While those morphemes constantly convey the S-E relations (' $\mathrm{S}>\mathrm{E}$ ', ' $\mathrm{S}<\mathrm{E}$ ', and ' $\mathrm{S}, \mathrm{E}$ '), depending on whether they appear in $\mathrm{T}_{\mathrm{R}=\mathrm{E}}$ and $\mathrm{T}_{\mathrm{R}=\mathrm{S}}$, the same $\mathrm{S}-\mathrm{E}$ relations yield distinct temporal and aspectual interpretations.

\subsection{More on the semantics of the two tense phrases}

Having postulated the two functional projections making up the phrase structure of tense, in this section I further examine the semantic content of those functional heads.

\subsubsection{The lower tense phrase and a spatiotemporal location}

The lower temporal projection postulated as $T_{R=S} P$ is to be compared with Cowper's (1997) AspP and Stowell's (1994a,b) ZP (as the internal argument of T) not only in terms of the location in the phrase structure (as seen in (11) below) but also in terms of the semantic content.

\footnotetext{
${ }^{4}$ However, on the basis of lack of evidence for the presence of time denoting arguments, I do not particularly espouse the idea that those 'times' are syntactically represented as arguments occupying the Spec positions of those FPs. Later in 4.3, I will propose that waand $g a$-marked subjects in Japanese appear in the Spec positions of those FPs.
} 

a. Torii
b. Cowper (1997)
c. Stowell $(1994 a, b)$
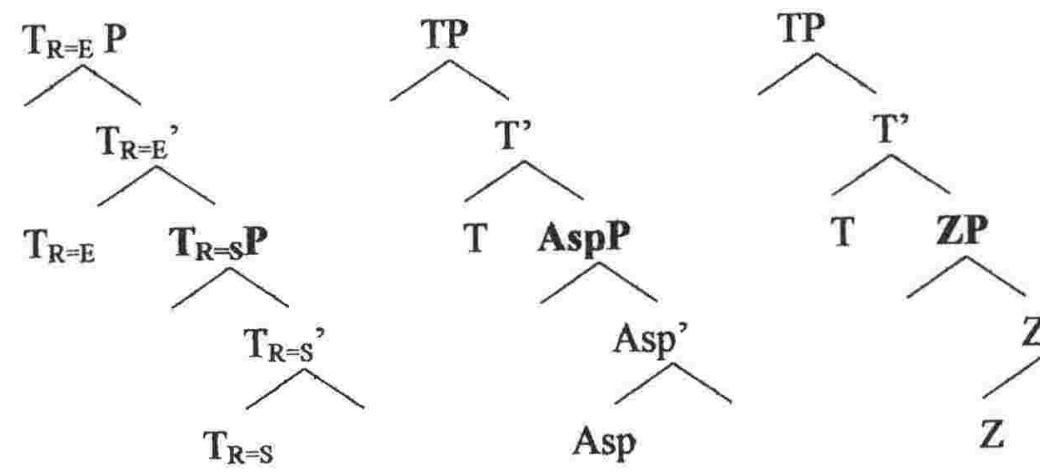

Cowper (1997) argues for an $e$ projection, which she calls AspP after the aspectual nature of $e$. Cowper's AspP is not to be confused with aspectual projections that have been proposed by Travis (1991) or with the aspectual phenomena discussed by Tenny $(1987,1992)$. Travis and Tenny among others (e.g., McClure 1994, Diesing 1997) are concerned with lexical aspects or situation types such as transitivity and telicity, which are conveyed by (lexical) predicates and are to be syntactically represented within the verb phrase(s). In contrast, Cowper's AspP is concerned with the VP-external aspectual structure particularly for viewpoint/grammatical aspects and is therefore situated outside of VP, between TP and VP.

Cowper argues that the Davidsonian event element $e$ is not a lexical property of verbs but rather a property of a clause. Essentially, clauses may or may not have $e$, depending on whether they describe events or states. For example, in Kelly is eating junk food describing an event, $e$ is present, whereas in Kelly eats junk food describing a characteristic of Kelly, i.e., a state, there is no $e$. That is, the distinction between eventive and stative clauses is accounted for by the presence or absence of $e$, which is independent of the choice of verb.

Cowper proposes that $e$ projects its own syntactic category as part of the inflectional superstructure of a clause. Eventive clauses have $e$ and hence an $e$ projection (AspP), whereas stative clauses lack $e$ and hence an $e$ projection (AspP) altogether. Note that while $e$ is originally a (non-nominal) argument of predicates (Davidson 1967), Cowper treats it not as an argument but as the head of a syntactic category in the phrase structure of a clause. 
I agree with Cowper in assuming that $e$ projects its own syntactic category and that $e$ may be present or absent in a given clause. However, while Cowper takes it that the absence of $e$ means the absence of the syntactic category in the phrase structure, I rather assume that the functional category is always present in the phrase structure of a clause, irrespective of the presence or absence of $e$, following the spirit of Cinque (1999). This means that the functional head is not $e$ itself but the event-place, in which $e$ may or may not occur. To distinguish between the event-place and an actual token of event, I use $E$ for the former and $e$ for the latter. ${ }^{5} E$ as the event-place is always present but it may or may not have the content, i.e., an actual token of $e$, depending on whether a clause describes an event or a state. Thus, I take it that it is $E$ rather than $e$ that projects its own projection in the phrase structure of a clause.

The occurrence of $e$ in $E$ signifies that there exists an event at some spatiotemporal location. I take $e$ as a variable standing for a spatiotemporal location, and the actual occurrence of $e$ in $E$ as an anchor to a spatiotemporal location. ${ }^{6}$ A clause anchored to a spatiotemporal location is interpreted as being strictly bounded at that spatiotemporal location. The situation described in such a clause is therefore taken as spatiotemporally bounded, eventive, or stage-level. Thus, the occurrence of $e$ in $E$ gives rise to the $\mathrm{R}=\mathrm{S}$ interpretation (or the View part $_{\text {interpretation). }}$

This suggests that the semantic content of the lower temporal head $\mathrm{T}_{\mathrm{R}=\mathrm{S}}$ is comparable to $e$ in $E$ as an anchor to a spatiotemporal location. Notice that as a functional head $T_{R=S}$ is expected to be always present in the phrase structure of a clause, but that the semantic interpretation of $\mathrm{R}=\mathrm{S}$ is present at some time and absent at another. This is appropriately characterised by the presence or absence of $e$ in $E$. As the event-place $E$ is always present, I take $E$

\footnotetext{
${ }^{5}$ Note that the italicised $E$ is to be clearly distinguished from the non-italicised $\mathrm{E}$. The former $(E)$ represents the event-place and is a functional category (as I introduce so), while the latter $(\mathrm{E})$ is Reichenbachian "event time".

${ }^{6} \mathrm{I}$ am using the notion of anchoring in a broad sense so that a spatiotemporal location anchors the intension of a clause as well as a world does, although a spatiotemporal location certainly does not anchor in the same way as a world does.
} 
as the functional head, which corresponds to $T_{R=S}$, and call the phrase it projects $E \mathrm{P}$, which corresponds to $\mathrm{T}_{\mathrm{R}=\mathrm{S}} \mathrm{P}$. (The main reasons for this renaming are typographical convenience and the ease of pronunciation. I rather do not adopt Cowper's label, AspP, to avoid the confusion with the other kind of AspP as in Travis (1991) and Tenny $(1987,1992)$.)

Turning to Stowell (1994a,b), he also assumes the presence of an event element in the lower functional phrase of a temporal structure, which he calls ZP (see (11c) above). He says that 'some element at the ZP-level (either Z itself or an operator residing in the Spec of ZP) binds a temporal variable within VP corresponding to Kratzer's (1989) “external" event argument' (Stowell 1994a: 6). (Note that Kratzer (1989) postulates an event argument as the external argument of (stage-level) VPs.) Drawing an analogy between DP and ZP, Stowell (1994b) suggests that Z binds the external argument of its VP complement, just as D binds the external argument of its NP complement, as shown in (12) below.'
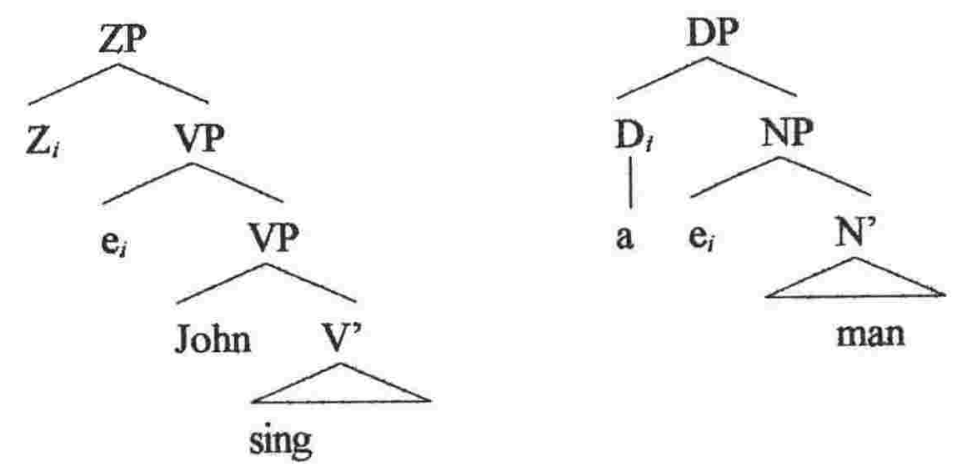

(Stowell 1994b: 10)

Such binding of a temporal variable seems to correspond to what $e$ in $E$ does as an anchor to a spatiotemporal location. If we assume the presence of a temporal variable to be bound within VP, we could say that $e$ in $E$ anchors the intension of a clause to a spatiotemporal location by virtue of binding this variable.

${ }^{7}$ This analysis 'implies that the true external argument of VP is the time-denoting argument bound by $Z$, rather than the traditional DP subject that figures in most small clause theory and in the VP-internal subject hypothesis' (Stowell 1994b: 10). 
Moreover, as Kratzer (1989) originally postulates an event argument, $e$, only for stage-level (or eventive) VPs (or predicates), Stowell's binding of $e$ by $\mathrm{Z}$ is naturally concerned with the distinction between stative and eventive predicates. Stowell conceives that the distinction between stative and eventive predicates is encoded in the semantics of $\mathrm{ZP}$, which is again comparable to that of DP. Like DP, ZP is semantically either definite or indefinite, according to Stowell.

With a stative predicate, the event time ZP is generally understood to have a definite reference; in other words, it is typically understood as referring to a time already mentioned. With an eventive predicate, the event time ZP can have either definite or indefinite reference: it can either refer to a time already mentioned, or it can introduce a new time. (Stowell 1994a: 8).

Thus, Stowell relates the distinction between eventive and stative predicates to the distinction between definite and indefinite event times somehow encoded in $\mathrm{Z}$ (or $\mathrm{ZP}$ ), though it is not a simple one-to-one relation. Recall that in my analysis the distinction between eventive and stative predicates is determined by the presence or absence of $e$ in $E$. An interesting commonality is that the lower functional head (or projection) of the articulated tense structure is given a function of distinguishing between eventive and stative predicates.

Furthermore, with a little speculation, the similarity between the semantic content of $\mathrm{Z}$ and that of $E$ can become more significant. Assume that each functional head intrinsically contains a unique semantic feature. Then, $\mathrm{Z}$ should have only one of the two values, definite or indefinite, as its intrinsic semantic content. The two logical possibilities are (i) $\mathrm{Z}$ is intrinsically definite, and (ii) $\mathrm{Z}$ is intrinsically indefinite. Interestingly, if we opt for the second possibility and take indefinite (rather than definite) as the intrinsic semantic content of $Z$, the similarity between the semantic content of $\mathrm{Z}$ and that of $E$ becomes striking. The interpretation of "an indefinite time", i.e., a time newly introduced to the discourse $^{8}$ solely relies on and directly derives from the actual spatiotemporal location of the speech situation (most typically). An indefinite event time therefore

\footnotetext{
${ }^{8}$ A time is indefinite in the sense that it has no antecedent.
} 
yields an interpretation that the described situation is new to the discourse and bounded at that particular spatiotemporal location in the discourse. Thus, indefinite $Z$ signifies eventive or stage-level situations. ${ }^{9}$

So, there are some similarities among the lower functional phrase of a temporal structure, which I originally postulated as $\mathrm{T}_{\mathrm{R}=\mathrm{S}} \mathrm{P}$ and now call $E \mathrm{P}$, Cowper's (1997) AspP, and Stowell's (1994a,b) ZP (as the internal argument of T) not only in terms of the location in the phrase structure but also in terms of the semantic content (at least to some extent). I assume that the intrinsic semantic content of the lower temporal head is an anchor to a spatiotemporal location, which is responsible for the eventive or stage-level interpretation of a clause, that is, the $\mathrm{R}=\mathrm{S}$ (or View part $_{\text {) interpretation. }}$

\subsubsection{The upper tense phrase and a world}

Having argued that the semantic content of the lower temporal head is analogous to Stowell's $(1994 a, b)$ indefinite $Z$, I conjecture the semantic content of the upper temporal head to be analogous to Stowell's definite Z. That is, $I$ in effect split Stowell's $Z$ and shift the definite one to the upper temporal head, so that each functional head contains an absolutely unique semantic property.

Stowell's definite $\mathrm{Z}$ indicates that the event time (ZP) refers to a definite time, which is a time already talked about or somehow established as the topic time in the discourse. (The specification of a definite event time is provided by a non-linguistic or linguistic antecedent.) The semantic interpretation of a definite event time is dependent on the link to an antecedent time in the discourse. With a definite event time, the described situation is interpreted to take place at the understood topic time. The topic time designated by a definite event time in fact fixes a context, in which the described situation is interpreted to take place. In contrast to an indefinite event time, which typically refers to the punctual moment of speech as a brand new time in the discourse, a definite event time refers to an old time in the discourse, which is not a punctual time and rather fixes a context.

\footnotetext{
${ }^{9}$ In contrast, definite $\mathrm{Z}$ signifies stative or individual-level situations. But I defer discussing this to the next section.
} 
Imagine a speech situation where we have been talking about the party which was held last Friday. A sentence, for example, John came (John-wa ki-ta) uttered in such a discourse is understood to mean that John came to the party. In the interpretation of this sentence, the exact time at which the event of John's coming took place is irrelevant. That is, John came simply sometime when the party was being held. This suggests that the sentence is anchored to the context fixed by the definite event time "last Friday when the party was held" but not to a punctual spatiotemporal location at which the event of John's coming actually took place. ${ }^{10,11}$

Following this, I assume that the semantic content of the higher temporal head is an anchor to a context, which is fixed in the discourse. A context is made up of a set of spatiotemporal locations. A particular set of spatiotemporal locations is a particular world. A world may be, for example, one in which a party was held last Friday, or one in which John has blue eyes. An important characteristic of a world is that it transcends and subsists beyond spatiotemporal locations.

Adopting Svenonius' (1994) notation, I represent an anchor to a world with $\omega$, which stands for world. Analogising with $e$ in $E, I$ assume that $\omega$, a particular world, appears in $W$, the world-place. ${ }^{12}$ As $I$ have renamed the lower temporal projection $\mathrm{T}_{\mathrm{R}=\mathrm{S}} \mathrm{P}$ as $E \mathrm{P}, \mathrm{I}$ also rename the upper temporal projection $\mathrm{T}_{\mathrm{R}=\mathrm{E}} \mathrm{P}$ as $W \mathrm{P}$ mainly for typographical convenience and the ease of pronunciation. As $E \mathrm{P}$ is projected by the event-place $E, W \mathrm{P}$ is projected by the world-place $W$. As the occurrence of $e$ in $E$ functions as anchor to a spatiotemporal location, the occurrence of $\omega$ in $W$ functions an anchor to a world.

\footnotetext{
${ }^{10}$ Recall the discussion in 2.1 .2 above that a new evaluation time $t^{\prime}$ refers to a more loosely defined time, while the original evaluation time $t$ refers to a precise temporal point. Note that a new evaluation time is a topic time in the discourse and therefore often an old (understood) time.

${ }^{11}$ This essentially agrees with Partee's (1973) claim that the past tense in a sentence like John went to a private school refers to whenever it was that John went to school. For such vagueness of the referent of the past tense, Partee draws a parallelism to the use of the pronoun they as in They haven't installed my telephone yet, which refers to whoever it is that's supposed to install the telephone.

${ }^{12}$ I am indebted to Harry Leder (p.c.) for this idea.
} 
Just like $e$ may or may not appear in $E$, $\omega$ may or may not appear in $W$. While the presence or absence of $e$ in $E$ depends on whether a clause describes an eventive or stative situation, the presence or absence of $\omega$ in $W$ depends on whether a clause is to be evaluated in terms of its truth or not. The truth can be evaluated only in a certain context with a certain set of background assumptions of the speaker and hearer regarding the relevant domain of discourse, and so on. Therefore, an anchor to a context, $\omega$, is essential for any clause which is to be evaluated for its truth. Basically, I assume that a main clause is necessarily to be evaluated for its truth and therefore that $\omega$ is always present in root $W^{13}$ However, a non-root or subordinate clauses may or may not be evaluated for its truth, and accordingly $\omega$ may or may not be present in subordinate $W$. (I will take up this issue in Chapter 5, which examines subordinate clauses.)

\subsubsection{A world and a spatiotemporal location}

Although $\mathrm{R}=\mathrm{S}$ and $\mathrm{R}=\mathrm{E}$ (or $\mathrm{View}_{\text {part }}$ and $\mathrm{View}_{\text {all }}$ ) are unable to both exist at the same time (cf. Chapter 2), $e$ in $E$ and $\omega$ in $W$ are not mutually exclusive. A world and a spatiotemporal location stand in the part-whole relation in that the former contains the latter, or the latter is part of the former. Therefore, an anchor to a world, $\omega$, and an anchor to a spatiotemporal location, $e$, also stand in the part-whole relation.

To reiterate, $W$ and $E$, which respectively represent the world-place and the event-place, are constantly present in the functional structure of a clause, whereas $\omega$ and $e$, which are respectively variables for the actual tokens of world and spatiotemporal location, may or may not occur in $W$ and $E$. The occurrence of $\omega$ in $W$ depends on whether a clause is to be evaluated for the truth, whereas the occurrence of $e$ in $E$ depends on whether a clause describes an eventive or stative situation. Since what is said in root clauses is necessarily evaluated for its truth, $\omega$ is always present in root $W$. Therefore,

\footnotetext{
${ }^{13} \mathrm{I}$ assume that interrogative sentences as well as in affirmative sentences are anchored to a particular world, in which what is asked is understood and evaluated. I conceive that the distinction between interrogative and affirmative sentences is made somewhere higher in the structure above WP (presumably in a C-related position).
} 
depending on whether $e$ is present or absent in $E$, we have two different configurations of root temporal structure, as shown in (13).
a. $[W P[W \omega[E P[E-]]]]$
$\mathrm{R}=\mathrm{E} / \mathrm{View}_{\text {all }}$
b. $[W P[W \omega[E P[E \quad e \quad]]]]$
$\mathrm{R}=\mathrm{S} /$ View $_{\text {part }}$

The configuration (13a) with $\omega$ but without $e$ characterizes stative or individual-level sentences, which are anchored to a world but not to a spatiotemporal location. It is responsible for the $\mathrm{R}=\mathrm{E}\left(\mathrm{View}_{\mathrm{all}}\right)$ interpretation. On the other hand, the configuration (13b) with both $\omega$ and $e$ characterizes eventive or stage-level sentences, which are anchored to a spatiotemporal location and also to a world (since they are to be evaluated for the truth too). It is responsible for the $\mathrm{R}=\mathrm{S}$ (View $\mathrm{wart}_{\text {p }}$ ) interpretation.

Note that there is a twist from the earlier discussions in 4.1 above, where I assumed that the two Tenses I postulated conveyed the information of $\mathbf{R}=\mathrm{E}$ and that of $\mathrm{R}=\mathrm{S}$ in each head separately. With this assumption, we would not expect that both heads be activated at the same time in a single clause. However, with the elaboration that the two heads represent the worldplace and the event-place in which a world and a spatiotemporal location may occur, the semantic interpretations of $\mathrm{R}=\mathrm{E}$ and $\mathrm{R}=\mathrm{S}$ do not derive directly from the respective heads. Rather, it is the configuration of the temporal structure as a whole that determines the semantic interpretation. That is, the $\mathrm{R}=\mathrm{E}$ interpretation is due to the configuration (13a), and the $\mathrm{R}=\mathrm{S}$ interpretation is due to the configuration (13b) above.

Another important point is that $\omega$ and $e$ are not occupants of syntactic positions, $W$ and $E$. The presence or absence of $\omega$ and $e$ makes $W$ and $E$ syntactically active or inactive. Therefore, the configurations in (13) above are more appropriately represented with + and - values specified for $W$ and $E$, as in (14) below. 

(14)
a. $[W P[W[+][E P[E[-]]]]]$
$\mathrm{R}=\mathrm{E} /$ View $_{\text {all }}$
b. $\left.\left[W_{P}\left[m^{+}\right]\left[\begin{array}{lll}E P & {[E[+]}\end{array}\right]\right]\right]$
$\mathrm{R}=\mathrm{S} / \mathrm{View}_{\text {part }}$

\subsubsection{Conclusion}

I have examined the semantic contents of two functional heads, which I have postulated as $T_{R=S} P$ and $T_{R=E} P$ to syntactically represent our tense formulae. The semantic content of $\mathrm{T}_{\mathrm{R}=\mathrm{S}}$ has been identified as an anchor to a spatiotemporal location, which is represented by an event variable $e$, which may or may not occur in the event-place $E$. On the other hand, the semantic content of $T_{R=E}$ has been identified as an anchor to a world, which is represented by a world variable $\omega$, which may or may not occur in the worldplace $W$. Assuming that the event-place $E$ and the world-place $W$ project their own phrases, which correspond to $T_{R=S} P$ and $T_{R=E} P$ respectively, $I$ have renamed them as $E \mathrm{P}$ and $W \mathrm{P}$.

Whether we call them $\mathrm{T}_{\mathrm{R}=\mathrm{S}} \mathrm{P}$ and $\mathrm{T}_{\mathrm{R}=\mathrm{E}} \mathrm{P}$ or $E \mathrm{P}$ and $W \mathrm{P}$, they are functional projections making up the temporal structure of a clause. In other words, they are essentially temporal projections. However, as the new labels indicate, they are concerned not only with temporal matters but also with spatial matters. This points to a somewhat inseparable relation between time and space.

\subsection{Syntactic mechanisms in the temporal structure}

I now turn to the syntactic mechanisms operating in the temporal structure made up of WP and EP, particularly to argue for the syntactic and semantic association between WP and wa-marked subjects and that between $E \mathrm{P}$ and $g a$-marked subjects.

\subsubsection{T-features and D-features}

As functional categories, $W$ and $E$ are assumed to be always present in the phrase structure of a clause, but they may be active or inactive both 
semantically and syntactically in a given clause. As temporal categories, $W$ and $I ;$ are assumed to have T-features (to be checked by the relevant features of predicates) and D-features (to be checked by the relevant features of DPs). Crucially, however, their T- and D-features need to be checked only when $W$ and $E$ are activated by the occurrence of $\omega$ and $e$ respectively. In other words, only when they are specified with $[+], W$ and $E$ attract predicates to have their T-features checked by them and DPs to have their D-features checked by them. ${ }^{14}$

\subsubsection{Movement}

Now, recall the two distinct configurations of root temporal structure, (14a) and (14b) above. Firstly, in the configuration (14a), $W$ is syntactically active and has a $\mathrm{T}$-feature and a D-feature to be checked but $E$ is syntactically inactive and does not have a T-feature nor a D-feature to be checked. In a clause with this configuration of the temporal structure, $W$ attracts a predicate, which is assumed to have some features that need to check $\mathrm{T}$. We might assume at least tentatively that the constellation of a predicate with a tense/aspect marker (such as $-l a,-r u$, and -leiru) attached to it raises from the predicate head (such as V) to $W$ via $E$, i.e., a head-to-head movement. In such an analysis, the movement may be assumed covert in order to account for the V-final surface word order in Japanese. Nevertheless, I do not exclude the possibility of overt movement. I rather leave it open as to the details and specifics of the movement involved for the checking of a $\mathrm{T}$-feature, which at least in part depends on the movement possibilities applying to other clauseinternal constituents.

${ }^{14}$ Note that the requirement that the D-features of $W$ and $E$ be checked (when they are active) constitutes the EPP (extended projection principle) which requires that sentences have subjects. While this analysis suggests that [Spec, WP] and [Spec, EP] are two EPP positions in Japanese, it appears rather questionable to treat [Spec, WP] as an EPP position when we take non-subject $w a$-marked topics into account. If we were to allow non-subject wa-marked topics to appear in $[\mathrm{Spec}, W \mathrm{P}]$ as well, we need to conceive of $[\mathrm{Spec}, W \mathrm{P}]$ not simply as one of the EPP positions to which subject arguments may raise but as a more versatile position, in which non-argument "pure topic" phrases (without a theta-role) may be base generated and PPs and other forms of adjunct may be moved to from their base positions (or possibly base generated as a "pure topic"). Importantly, in my view those nonsubject wa-marked topics show the same semantic effects as wa-marked subjects under consideration. 
Activated $W$ also attracts a subject DP presumably to its Spec position in order to have its D-feature checked through Spec-head agreement. Assuming that subjects are all base-generated within VP (or the maximal projection of the predicate) (see, e.g., Kitagawa 1986, Koopman and Sportiche 1991, Harley 1995), 1 propose that a subject DP raises from the VP- or predicate-internal position directly to [Spec, WP] to check the Dfeature of $W$ through Spec-head relation, as illustrated in (15) below. 1 assume that this movement is overt.

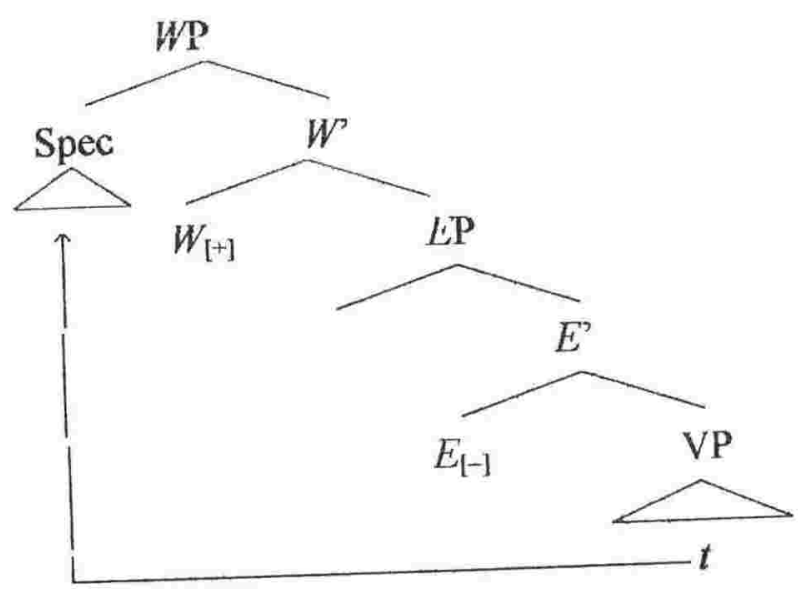

The direct movement from a VP-internal position to [Spec, WP] might be seen as a violation of one of the economy principles, namely Shortest Movement (see Chomsky 1993: 15), as spelled out in (16) below, if we see [Spec, EP] as the first possible landing site. However, by hypothesis, a potential specifier position is present only when the semantic content is present in its head. That is, [Spec, EP] is present only when $e$ is present in $E$. A subject raises to [Spec, $W \mathrm{P}]$, precisely when $e$ is not present in $E$, and therefore when $[\mathrm{Spec}, E \mathrm{P}]$ is not present. In this configuration, [Spec, WP] is the first appropriate landing site for the movement.

\section{(16) Shortest Movement (Economy)}

The target of movement must be no farther than the first appropriate landing site, where appropriate includes the following: 

a. a head position for head movement.
b. an A-position for A-movement
c. an $\mathrm{A}^{\prime}$-position for $\mathrm{A}^{\prime}$-movement

(spelled out in Bobaljik and Jonas 1996: 198-199)

Secondly, in the configuration (14b) above, both $W$ and $E$ are syntactically active and have $\mathrm{T}$ - and $\mathrm{D}$-features to be checked. In a clause with this configuration of the temporal structure, a predicate raises to $E$ to check the T-feature, and a subject DP to $[\mathrm{Spec}, E \mathrm{P}]$ to check the D-feature. They do not move further up to $W$ and [Spec, WP] because Shortest Movement requires that the target of movement be no farther than the first appropriate landing site. Again, I assume that the movement of a subject DP is overt, while the movement of a predicate may not be.

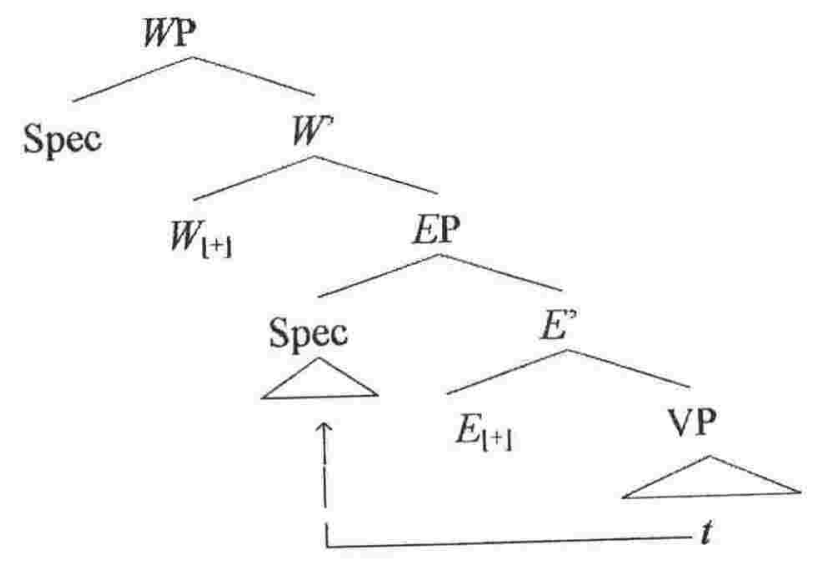

Here, a question arises as to what happens to the T- and D-features of $W$ which remain unchecked in this configuration. Although this is not a trivial problem, I simply leave it open except to mention a possibility that the D- 
feature of $W$ may be checked by an expletive such as there in English. ${ }^{15}$ (1 will discuss this later in 4.6.2.) However, not all languages have overt expletives and Japanese is one of the languages that lack overt expletives.

Note that the requirement that the D-features of $W$ and $E$ be checked (when they are active) constitutes the EPP (extended projection principle) which requires that sentences have subjects. This means that [Spec, WP] and [Spec, EP] are two EPP positions. In the case of (17) above, the EPP is satisfied when a subject DP raises to [Spec, LP]. Therefore, no further movement is required.

Thus, the choice between [Spec, WP] and [Spec, LP] as the destination of subject raising depends on the configuration of temporal structure. Since $W$ and $E$ need their D-features to be checked only when they are active, the target of subject raising is basically the one which is active and whose Dfeature needs to be checked. However, when both $W$ and $E$ are active, the target of movement is the first appropriate landing site, i.e., $E$, as Shortest Movement requires.

\subsubsection{Semantic interpretations}

So far, $\mathrm{I}$ have argued that $W$ and $E$ have both $\mathrm{T}$-features and $\mathrm{D}$-features, which are checked respectively by the relevant features of predicates and subject DPs when they are active. Syntactically, the T-features and D-features of $W$ and $E$ function as triggers of movement and licensers of relevant items (due to their need to be checked by appropriate items). Crucially, however, as the functional categories, $W$ and $E$, have distinct semantic contents, the Tand D-features of $W$ and $E$ also bear distinct semantic features.

15 While an argument is assumed to raise (from its base position) to [Spec, WP], an expletive is assumed to be base-generated in [Spec, WTP].

The possibility of base generation in [Spec, $W \mathrm{P}]$ will provide an account for wa-marked non-argument subjects, i.e., without theta-roles, which are often called "pure topics". Pure topics are often observed in the multiple subject construction, as in (i) below. Sakana 'fish' is a pure topic without a theta-role. (Note that the ga-marked tai "snapper' yields the focus interpretation, but not the neutral interpretation, as indictaed by the hash.)

(i) Sakana-wa tai-\#ga ii.

fish snapper good

'As for fish, smapper is good.'

(= It is snapper and not any other fish that it is good.) 
Recall that we have identified the semantic content of $W$ as an anchor to a world, which is represented by a world variable $\omega$, and that of $E$ as an anchor to a spatiotemporal location, which is represented by an event variable $e$ (cf. 4.2 above). Due to these distinct semantic contents of $W$ and $E$, their Tfeatures checked by the relevant features of predicates affect the temporal/aspectual interpretations of the predicates, whereas their D-features checked by the relevant features of DPs affect the semantic interpretations of the subject DPs.

The T-feature of $E$ checked by the relevant feature of a predicate gives rise to the $\mathrm{R}=\mathrm{S}$ interpretation. It means that the predicate is taken as describing a situation bounded at a punctual spatiotemporal location. This is because the predicate is anchored to a punctual spatiotemporal location by checking the T-feature of $E$. On the other hand, the T-feature of $W$ checked by the relevant feature of a predicate gives rise to the $\mathrm{R}=\mathrm{E}$ interpretation. It means that the predicate is taken as describing a situation transcending beyond spatiotemporal locations. This is because the predicate is anchored to a world (beyond spatiotemporal locations) by checking the T-feature of $W$.

Recall that in Japanese the verbal affixes, $-t a,-r u$, and -teiru, yield distinct temporal and aspectual interpretations, even though they are assumed to have constant denotations, i.e., certain S-E relations and/or corresponding aspectual meanings (cf. 3.1 above). This is explained as due to the semantic contents of the temporal heads whose T-features they check. When they check the T-feature of $W$, these affixes are taken as tense markers (i.e., past, future, and present) and give rise to the $\mathrm{R}=\mathrm{E} / \mathrm{View}_{\text {all }}$ interpretations. When they check the $\mathrm{T}$-feature of $E$, they are taken as aspect markers (i.e., perfect, proximate future, and progressive) and give rise to the $\mathrm{R}=\mathrm{S} / \mathrm{View}_{\mathrm{part}}$ interpretations. Essentially, the interpretation of a tense/aspect marker is affected by the intrinsic semantic content of the temporal head whose $\mathrm{T}$ - 
feature it checks. ${ }^{16}$

Just as the T-features of $W$ and $E$ checked by the relevant features of predicates give rise to distinct temporal and aspectual interpretations of the predicates, the D-features of $W$ and $L$ checked by the relevant features of DPs give rise to distinct semantic interpretations of the subject DPs. Since the semantic content of $E$ is an anchor to a punctual spatiotemporal location, by checking the D-feature of $E$, a DP is anchored to a punctual spatiotemporal location. As a result, the subject DP is taken as being bounded at a punctual spatiotemporal location. In other words, it is taken as referring to a spatiotemporally bounded manifestation of an individual. On the other hand, the semantic content of $W$ is an anchor to a world beyond spatiotemporal locations. Therefore, by checking the D-feature of $W$, a DP is anchored to a world beyond spatiotemporal locations. As a result, the subject DP is taken as being transcending beyond spatiotemporal locations, or referring to a whole individual which transcends and connects all its spatiotemporal manifestations.

Notice that the T- and D-features of $E$ and $W$ ensure that subjects and predicates are necessarily of the same semantic type. While the T-feature of $E$ checked by the relevant feature of a predicate makes the described situation taken as being spatiotemporally bounded, the D-feature of $E$ checked by the relevant feature of a subject (raised to $[\mathrm{Spec}, \mathrm{LP}]$ ) makes the subject taken as being spatiotemporally bounded. In this case, the predicate and the subject share the semantic property of spatiotemporal boundedness. On the other hand, while the T-feature of $W$ checked by the relevant feature of a predicate makes the described situation taken as being spatiotemporally transcending, the Dfeature of $W$ checked by the relevant feature of a subject (raised to [Spec, WP]) makes the subject taken as being spatiotemporally transcending. In this case, the predicate and the subject share the semantic property of continuity beyond spatiotemporal locations. (Recall that 1 have claimed in 2.3 .5 above

${ }^{16}$ As tense/aspect markers are attached to $\mathrm{V}$ or predicate on the surface, we might assume that the whole constellation raises from $\mathrm{V}$ or predicate head to $E$ or further to $W$ to check their T-features (cf. 4.3.2 above). In such an analysis, $V$-movement may be assumed covert in order to account for the V-final surface word order in Japanese, though 1 do not exclude the possibility of overt movement. The details and specifics of how the T-features are actually checked need to be worked out for the analysis to be complete. 
that spatiotemporally bounded situations necessarily have spatiotemporally bounded subjects, whereas spatiotemporally transcending situations necessarily have spatiotemporally transcending subjects.)

This correlation between the semantic type of predicate and that of subject has been pointed out by Carlson (1997). It is said in Carlson's terminology that stage-level predicates necessarily predicate of stages, while individual-level predicates necessarily predicate of individuals. It is an interesting consequence of my analysis that stages and stage-level predicates are necessarily paired by the intrinsic semantic content of $E$, which have both $\mathrm{T}$-features and D-features, while individuals and individual-level predicates are necessarily paired by the intrinsic semantic content of $W$, which also have both $\mathrm{T}$-features and $\mathrm{D}$ features. While the T-features of $E$ and $W$ checked by the relevant features of predicates are responsible for the semantic interpretations of stage- and individual-level predicates respectively, the $\mathrm{D}$-features of $E$ and $W$ checked by the relevant features of subjects are responsible for the semantic interpretations of stage and individual subjects respectively.

Recall, however, that individual-level and stage-level predicates associated with the T-features of $W$ and $E$ and hence with $w a$-and $g a$-markings of subjects in Japanese may not necessarily coincide with what are generally considered as individual-level and stage-level predicates (cf. 2.3.5 above). To avoid a confusion, we might call them individual-level and stage-level predications (to be distinguished from individual-level and stage-level predicates). Although individual-level and stage-level predications in principle correspond to what are generally considered as individual-level and stage-level predicates, i.e., predicates representing more or less permanent situations and those representing transient states respectively, they correspond more strictly to what are originally distinguished as individual-level and stage-level predicates, i.e., predicates that predicate of individuals and those that predicate of stages.

\subsubsection{Wa- and ga-markings of subjects}

Let us now turn to $w a$ - and ga-marked subjects in Japanese. Essentially, I have been aiming to syntactically account for the correlation between the $\mathrm{R}$ $=\mathrm{E}\left(\right.$ or View $\left.\mathrm{w}_{\text {all }}\right)$ interpretation and wa-marked subjects and that between the 
$\mathrm{R}=\mathrm{S}$ (or View $\mathrm{w}_{\text {part }}$ ) interpretation and $g a$-marked subjects, which have been observed in Chapter 2. In the first place, I have postulated the two functional projections, originally $\mathrm{T}_{\mathrm{R}=\mathrm{E}} \mathrm{P}$ and $\mathrm{T}_{\mathrm{R}=\mathrm{S}} \mathrm{P}$, subsequently renamed as $W \mathrm{P}$ and $E \mathrm{P}$, with anticipation that they are syntactically associated with wa- and gamarked subjects.

Recall that the two configurations (14a) and (14b) above are responsible for the $\mathrm{R}=\mathrm{E}$ and the $\mathrm{R}=\mathrm{S}$ interpretations, which are correlated with $w a$ - and $g a$-marked subjects respectively. In the configuration (14a) with $W_{[+]}$and $E_{[-]}$, subjects necessarily appear in [Spec, WP], as shown in (15) above. Therefore, I assume that those subjects appearing in [Spec, WP] and taken as individual subjects are $w a$-marked in Japanese. On the other hand, in the configuration (14b) with $W_{[+]}$and $L_{[+]}$, subjects appear in [Spec, $L \mathrm{P}$ ], as shown in (17) above. Therefore, 1 assume that those subjects appearing in $[\mathrm{Spec}, L \mathrm{P}]$ and taken as stage subjects are $g a$-marked in Japanese.

A question is where -wa and -ga come from. It is indeed a matter of controversy when $-w a$ and $-g a$ get attached to subjects. For example, according to the lexicalist view (Chomsky 1970), which is adopted in the minimalist framework, $-w a$ and $-g a$ (among all the other inflectional affixes) are assumed to be attached to their hosts before syntactic derivation. An alternative view suggested by Kayne (1994: 143) briefly in a footnote is that ga heads the projection housing a ga-marked subject (whether it is TP, AgrP, or whatever we call it), on a par with the nominative Case heading the projection housing a subject in English, as illustrated in (18) below. Analogising to this, we can also conceive that $-w a$ heads the projection housing a $w a$-marked subject. 


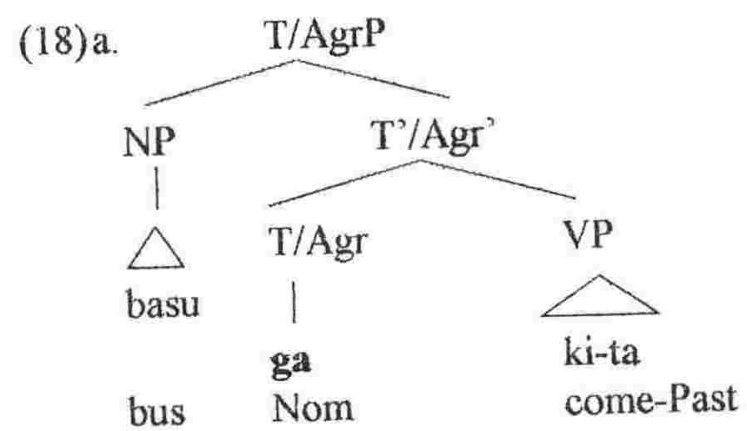

'The bus has come.'

b.

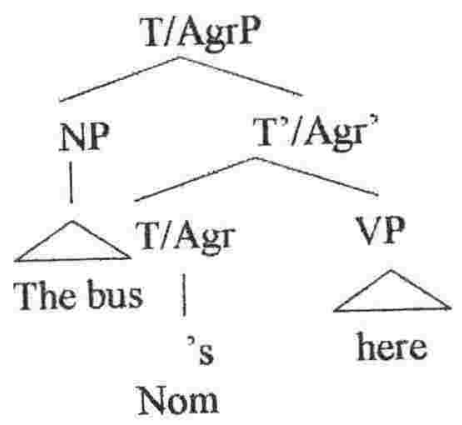

'The bus is here.'

(from Whitman 1997)

If we apply Kayne's view to the syntactic system I am proposing, it suggests that $-w a$ and -ga reside in $W$ and $E$ respectively and that they get attached to subjects appearing in their Spec positions as a result of raising. Since I have been assuming that subject phrases check the semantic features of $W$ or $E$ to be taken as individuals or stages, it seems reasonable to also assume that the markers of individual and stage subjects, i.e., $-w a$ and $-g a$, originate in $W$ and $E$ and get attached to those phrases when they check the semantic features of $W$ and $E$ respectively.

However, a problem with this assumption is that it is hard to account for the fact about scrambling that $-w a$ and $-g a$ necessarily move together with the phrases they are attached to. Considering the possibility of scrambling, it is desirable that $-w a$ and $-g a$ and the phrases they are attached to form a constituent. As one way of doing this, we might assume a constituent of a DP plus -ga (or -wa) as a KP (Kase Phrase) which is headed by a morpheme such as -ga and -wa and has a DP in its Spec. Then, a subject KP appears in the 
Spec of $W$ or $E$ (which may correspond to T, Agr, or whatever), as shown in (19).

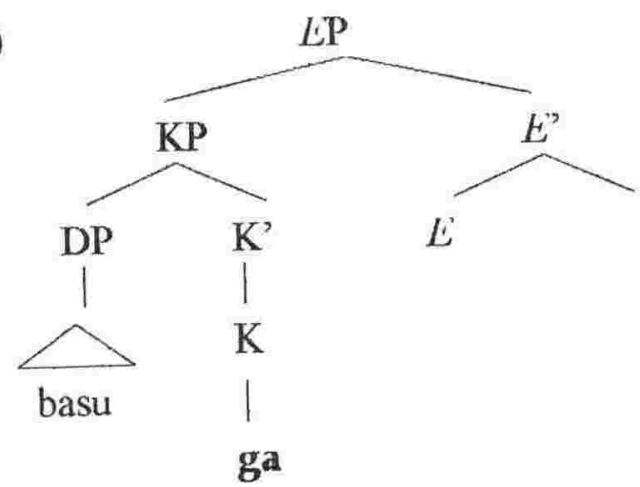

In this scenario, we can further assume that the stage and individual features reside in those affixes, $-w a$ and $-g a$, and that those semantic features of KPs match with the semantic features of the functional heads, $W$ and $E$. Here, it is the matching of semantic features rather than the matching of Case features that seems required for licensing of subjects. This may mean that when the semantic feature is checked, the Case feature is also checked as a free rider. That is, the mechanisms of Case checking correspond to interpretive material. The functional categories containing semantic interpretation also encode Case. ${ }^{17}$

\subsubsection{Evidence for the structural hierarchy between wa- and ga-subjects}

A piece of evidence that $w a$-marked subjects and ga-marked subjects appear in $[\mathrm{Spec}, W \mathrm{P}]$ and $[\mathrm{Spec}, \mathrm{LP}]$ respectively is found in the interaction with negation.

I have shown in 1.3.2 above that $w a$-marked subjects are compatible with negation, whereas ga-marked subjects are not. The examples are repeated in (20) and (21) below. ${ }^{18}$ The sentence (20a) with a wa-marked subject can be negated without affecting the interpretation of the subject, i.e.,

${ }^{17}$ Rosen (1999) points this out with regard to the syntactic representations of events in the clausal functional projections as in Borer $(1994,1996)$, Travis $(1994,1997$, to appear) and Ritter and Rosen (1998, to appear).

${ }^{18} \mathrm{ki}$ - and $\mathrm{ko}$ - in (20) and (21) are phonological variants of a verb 'to come'. 
the same topic interpretation, as shown in (20b). On the other hand, (21a) with a ga-marked subject cannot be negated without affecting the interpretation of the subject. As indicated by the hash on (21b), with negation a $g a$-marked subject cannot yield the neutral interpretation and the focus interpretation is forced. Moreover, in the focus reading, the punctual interpretation of $\mathrm{R}=\mathrm{S}$ is unobtainable and the $\mathrm{R}=\mathrm{E}$ interpretation is forced. This suggests that the $\mathrm{R}=\mathrm{S}$ interpretation can only obtain with affirmation (i.e., not with negation), while the $\mathrm{R}=\mathrm{E}$ interpretation can obtain with both affirmation and negation.
a. John-wa ki-ta.
John come-Past
'John came.'
b. John-wa ko-nakat-ta.
John come-Neg-Past
'John did not come.'
a. John-ga ki-ta.
John come-Past
'John has just come/arrived.'
b. John-\#ga ko-nakat-ta.
John come-Neg-Past
'It is John who did not come.'

Notice that 'John came' in (20a) and 'John did not come' in (20b) illustrate the $\mathrm{R}=\mathrm{E}$ interpretation with affirmation and negation respectively. That is, John's having come is seen as a whole, and it is said to have taken place at a certain time in the past in (20a) and not to have taken place at a certain time in the past in $(20 \mathrm{~b}) .^{19}$ On the other hand, 'John has just arrived' in (21a) above illustrates the $\mathrm{R}=\mathrm{S}$ interpretation with affirmation. That is, at the

19 It has been pointed out by an examiner that this hinges on Partee's (1973) famous example, I didn't turn off the stove. To quote Partee, '[w] hen uttered, for instance, halfway down the turnpike, such a sentence clearly does not mean either that there exists some time in the past at which I did not turn off the stove or that there exists no time in the past at which I turned off the stove. The sentence clearly refers to a particular time - not a particular instant, most likely, but a definite interval whose identity is generally clear from the extra-linguistic context' (p. 602-603). I agree with Partee on this view. That is, time reference is made only to a definite time interval in the past, which is understood in the discourse, but not to an indefinite time within that interval at which I did not turn off the stove or at which 1 turned off the stove and which does not exist. 
spatiotemporal location of speech there is a punctual manifestation of John's having come. Interestingly, the $\mathrm{R}=\mathrm{S}$ interpretation is only possible when there is a spatiotemporal manifestation of some situation. In the absence of a spatiotemporal manifestation, we cannot say a sentence that will yield the $\mathrm{R}=$ $\mathrm{S}$ interpretation. That is, in the absence of a spatiotemporal manifestation of John's having come, it is not possible to say 'John has just not arrived' to yield the 'hot news' perfect interpretation that at the spatiotemporal location of speech there is a punctual manifestation of John's not having arrived. Plainly, the situation of John's not having arrived is inherently invisible and hence not compatible with View part (corresponding to $\mathrm{R}=\mathrm{S}$ ) which presents a visible manifestation of a situation at a punctual spatiotemporal location. ${ }^{20}$

To confirm this, observe in (22) and (23) below that while the static present interpretation of John's writing a book (i.e., the $\mathrm{R}=\mathrm{E}$ interpretation) can obtain with both affirmation (22a) and negation (22b), the dynamic progressive interpretation of John's writing a book at a punctual spatiotemporal location (i.e., the $\mathrm{R}=\mathrm{S}$ interpretation) obtains with affirmation (23a) but not with negation (23b).
a. John-wa hon-o kai-tei-ru.
book-Acc write-Prog-Pres
'John is writing a book.'
b. John-wa hon-o kai-tei-nai.
book-Acc write-Prog-Neg(Pres)
'John is not writing a book.'
a. John-ga hon-o kai-tei-ru.
book-Acc write-Prog-Pres
'John is writing a book (right in front of us).'
b. John-\#ga hon-o kai-tei-nai,
book-Acc write-Prog-Neg(Pres)
"It is John who is not writing a book."

${ }^{20}$ It seems possible to say 'John has not just arrived', as opposed to 'John has just not arrived'. However, even the former does not yield the 'hot news' perfect interpretation. Essentially, the 'hot news' perfect is not available with negation. 
Let us assume that NegP is situated between $W \mathrm{P}$ and $E \mathrm{P}$, as illustrated in (24) below. ${ }^{21}$ If NegP is below $W \mathrm{P}$, wa-subjects in [Spec, WP] and the semantic feature responsible for the $\mathrm{R}=\mathrm{E}$ interpretation in $W$ are structurally higher than Neg. Therefore, wa-marked subjects and the $\mathrm{R}=\mathrm{E}$ interpretation necessarily take wide scope over what may or may not be negated, i.e., the occurrence or non-occurrence of a situation. On the other hand, if $\mathrm{NegP}$ is above $E \mathrm{P}, \mathrm{ga}$-subjects in [Sped, EP] and the semantic feature responsible for the $\mathrm{R}=\mathrm{S}$ interpretation in $E$ are structurally lower than Neg. Since gamarked subjects and the $\mathrm{R}=\mathrm{S}$ interpretation do not have wide scope over Neg, if negation should take place, the ga-marked subject and the $\mathrm{R}=\mathrm{S}$ interpretation are also in the scope of negation. That is, the whole sentence is negated to yield an interpretation such that it is not the case that .... Unlike the cases with wa-marked subjects, with ga-marked subjects it is not possible to negate the lower part of the sentence, i.e., the predicate, only.

${ }^{21}$ The phrase structure needs to be altered to right-headed to derive the surface word order in Japanese, unless we assume Kayne (1994).

(i)

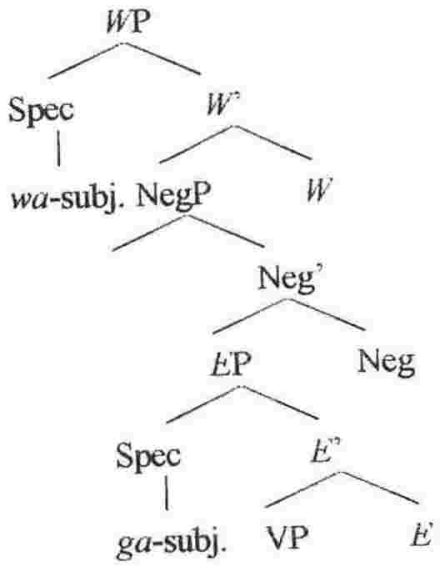


(24)

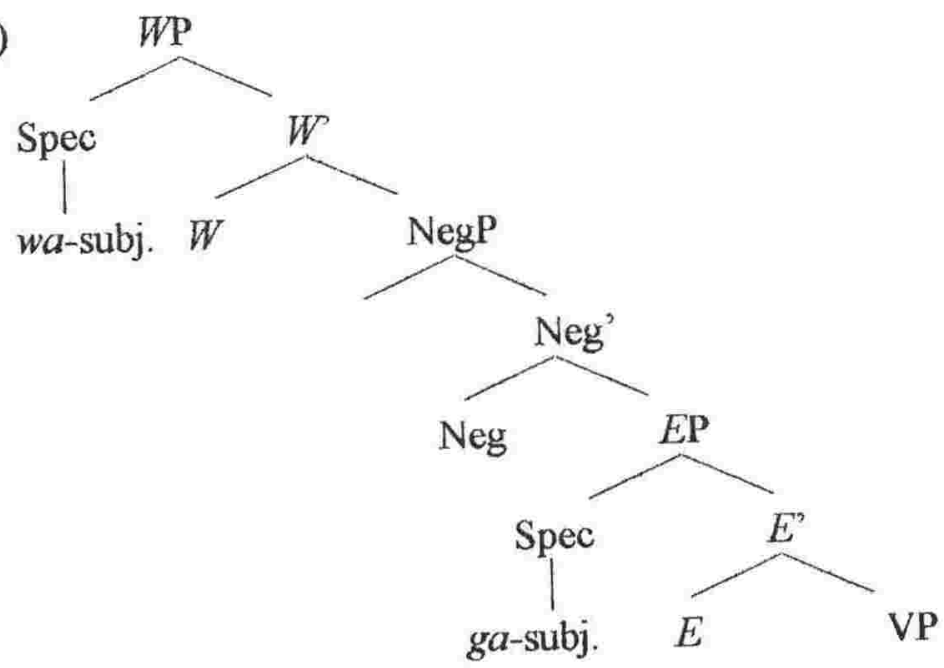

Thus, the interaction with negation provides support for the structural hierarchy between $w a$-marked and ga-marked subjects and for the structural hierarchy between the semantic features responsible for the $R=E$ interpretation and the $\mathrm{R}=\mathrm{S}$ interpretation. By assuming the position of $\mathrm{NegP}$ below WP and above $E \mathrm{P}$, we can justify that wa-marked subjects and $g a$ marked subjects appear in $[\mathrm{Spec}, W \mathrm{P}]$ and $[\mathrm{Spec}, L \mathrm{P}]$ respectively and that the semantic features responsible for the $\mathrm{R}=\mathrm{E}$ interpretation and the $\mathrm{R}=\mathrm{S}$ interpretation are encoded in $W$ and $E$ respectively. ${ }^{22}$

Incidentally, let us consider the positions of point adverbials in relation to the position of Neg. Recall that I have shown in 2.1.2 above that it is more natural for a point adverbial such as ichi-ji juugo-hun ni 'at one fifteen' to appear after the wa-marked subject (than before that), as shown in (25a)

${ }^{22}$ Considering the focus interpretations of the ga-marked subjects in (21b) and (23b), I envisage that they possibly appear in [Spec, WP]. Note that when a ga-marked subject receives the focus interpretation but not the neutral interpretation, the sentence necessarily receives the $\mathrm{R}=\mathrm{E} / \mathrm{Vicw}_{\text {all }}$ intcrpretation, just like a sentence with a wa-markcd subjcct. Morcover, the focus -ga is akin to the topic/thematic -wa in the sensc that it has a function of characterization. For example, the focused subject, John in (ia) below, is characterized by the property described by the predicatc, i.c., being a student, rather similarly to the way in which a topicalized subject, John in (ib) below, is characterized by the property described by the predicatc.

(i) a. John-ga gakusei da. student Cop

'It is John who is a student.'

b.John-wa gakusei da. student Cop

'As for John, he is a student.' 
below, whereas it has to be inserted before the ga-marked subject to get the neutral reading, as shown in (26a). (If inserted after the ga-marked subject, the $g a$-marked subject is interpreted as being in focus.) As this suggests (if the scopal relation is mirrored in the syntax), (25a) yields a reading such that as for John, it is the case that he came/arrived at $1: 15$, whereas (26a) yields a reading such that at $1: 15$ it was the case that John has just come/arrived. That is, a point adverbial takes wide scope over a ga-marked subject, but a wamarked subject is outside its scope.

(25)a. John-wa

$$
\begin{array}{llll}
\text { ichi-ji } & \text { juugo-hun ni ki-ta. } \\
\text { one o'clock fifteen-min. at come-Past }
\end{array}
$$

'John came at $1: 15$.'

$\begin{array}{lll}\text { b. John-wa } & \begin{array}{l}\text { ichi-ji } \\ \text { one o'clock fifteen-min. at come-Neg-Past }\end{array}\end{array}$ 'John did not come at $1: 15$.'
(26)a. Ichi-ji juugo-hun ni John-ga ki-ta. one $o^{\prime}$ clock fifteen-min. at come-Past 'At 1:15, John has just arrived.'
b. \#Ichi-ji juugo-hun ni John-ga ko-nakat-ta. one o'clock fifteen-min. at come-Neg-Past 'At 1:15, John (and only John) did not come.'

Now, compare (25b) and (26b). In interpreting (25b), the point adverbial, ichi-ji juugo-hun ni 'at one fifteen', is taken as being under the scope of negation (as well as that of the wa-marked subject). That is, (25b) yields a reading such that as for John, he did not come/arrive at 1:15. In this interpretation, the point adverbial is considered to modify the "event time" (as opposed to the "reference time" or the "evaluation time") under the scope of negation (as well as that of the wa-marked subject). ${ }^{23}$ On the other hand, in (26b), with a reading that the point adverbial takes wide scope over the gamarked subject (which is to yield a neutral interpretation), negation is not possible. That is, such a reading that at 1:15 John has just not come/arrived (or even that at 1:15 it was not the case that John has just come/arrived) 
cannot obtain. Essentially, with negation, the $\mathrm{R}=\mathrm{S}$ interpretation (i.e., the 'hot news' perfect interpretation in this case) becomes unavailable. ${ }^{24}$ It seems impossible for a point adverbial modifying the $\mathrm{R}=\mathrm{S}$ interpretation (occurring with a neutral ga-marked subject) to take wide scope over negation. This suggests that the structural position of a point adverbial is below NegP so that it is necessarily under the scope of negation (as well as that of a wa-marked subject), and above EP so that it takes wide scope over a ga-marked subject (see (24) above).

\subsubsection{Summary}

In this section, I have investigated the syntactic mechanisms operating in the temporal structure made up of $W P$ and $L P$. In particular, I have argued for the syntactic and semantic association between $W \mathrm{P}$ and wa-marked subjects and that between $L \mathrm{P}$ and $g \alpha$-marked subjects. As temporal categories, $W$ and $E$ are assumed to have T-features (to be checked by the relevant features of predicates) and D-features (to be checked by the relevant features of DPs). However, their T- and D-features need to be checked only when $W$ and $E$ are activated by the occurrence of $\omega$ and $e$ respectively. That is, activated $W$ and $E$ attract predicates in order to have their T-features checked by their features and subject DPs to their Spec positions in order to have their D-features checked by their features through Spec-head agreement.

While the T- and D-features of $W$ and $E$ syntactically function as triggers of movement and licensers of relevant items (due to their need to be checked by appropriate items), due to the distinct semantic contents of $W$ and $E$, their $T$-features checked by the relevant features of predicates affect the temporal/aspectual interpretations of the predicates, whereas their D-features

${ }^{23}$ Alternatively, the point adverbial can be taken as a topic. In this case, the adverbial takes wide scope over everything else in the sentence.

${ }^{24}$ Note that (26b) is interpreted, in a sense by default, as that at 1:15, John (and only John) did not come. Since it is an $\mathrm{R}=\mathrm{E}$ interpretation (with the subject in focus), in this reading the point adverbial is not considered to modify the "reference time" (or the "evaluation time") and to take wide scope over the subject and/or the negation, but to modify the "event time" under the scope of subject and/or negation. An exception to this is when the adverbial is taken as a topic, in which case it seems to have scope over everything else in the sentence. 
checked by the relevant features of DPs affect the semantic interpretations of the subject DPs. The T-features of $W$ and $E$ checked by the relevant features of predicates give rise to the $\mathrm{R}=\mathrm{E}$ and the $\mathrm{R}=\mathrm{S}$ interpretations respectively. The D-features of $W$ and $E$ checked by the relevant features of DPs make the subject DPs taken as referring to spatiotemporally transcending whole individuals (i.e., 'individuals') and spatiotemporally bounded manifestations of individuals (i.e., 'stages') respectively. Assuming that those subjects appearing in [Spec, WP] and taken as referring to 'individuals' are wa-marked and those appearing in [Spec, EP] and taken as referring to 'stages' are ga-marked in Japanese, wa-marked and $g a$-marked subjects are licensed by the D-features of $W$ and $E$ respectively. The correlation between $w a / g a$-subjects and the two types of temporal and aspectual interpretations obtained for the clauses is explained by the T- and D-features of $W$ and $E$, which are respectively responsible for the two types of temporal and aspectual interpretations and for licensing of wa-marked and ga-marked subjects. Crucially, the T- and Dfeatures of $W$ and $E$ assure that subjects and predicates of the same semantic type are properly paired and, as an interesting consequence of my analysis, the distinction between stage- and individual-level predicates is encoded in the phrase structure of tense.

Another point to note is that the D-features of $W$ and $E$ include the EPP features (which are parametrically varying) and the semantic properties (which are perhaps invariant) (cf. Chomsky 1995: 284). While the EPP features trigger subject raising, the semantic properties license subjects (as subjects of particular semantic types). Although the Case checking theory assumes that NP movement is triggered by the need to check a Case feature and that a subject is licensed by the matching Case feature, my analysis suggests that what is required for licensing of subjects is the matching of semantic features rather than the matching of Case features. This may mean that the mechanisms of Case checking correspond to interpretive material.

Lastly, in the light of the three-component analysis of tense/aspect interpretations proposed in Chapter 3, "viewpoint aspects" are syntactically encoded in the functional categories, $W$ and $E$, and interact with "situations types" and "S-E aspects" which are assumed to be conveyed lexically by 
predicates and tense/aspect markers respectively. How this compositional semantics works in the full syntactic structure needs to be explicated in the future.

\subsection{Stage- and individual-level predicates in the temporal structure}

It is an interesting consequence of my analysis that the distinction between individual-level and stage-level predicates is encoded in the phrase structure of tense. As a system to account for the stage-/individual-level distinction in the syntax, my analysis is to be compared with Kratzer (1989) and Diesing (1992). In this section, I review those two previous proposals and show that my proposal exhibits both empirical and theoretical advantages over Kratzer's and Diesing's, while maintaining their spirit.

\subsubsection{Kratzer (1989)}

Kratzer (1989) argues that stage-level predicates and individual-level predicates have different argument structures, which generate distinct D-structure representations. The essential difference is that stage-level predicates, such as dance, fall, and hit, have a 'Davidsonian' argument for spatiotemporal location as their highest argument, whereas individual-level predicates, such as becutiful and know, lack this argument, as illustrated in (27) below. (The abbreviation "dargument" stands for "Davidsonian argument".)

(27) stage-level predicates

$\begin{array}{ll}\text { dance } & <\text { d-argument, agent, theme }> \\ \text { fall } & <\text { d-argument, theme }> \\ \text { hit } & <\text { d-argument, agent, theme }>\end{array}$

individual-level predicates

beautiful <theme $>$

know <experiencer, theme $>$

(Kratzer 1989: 11) 
Following the argument-linking analysis of Williams (1981), Kratzer assumes that all but the highest argument are realized within the lexical projection of the predicate, i.e., only the highest argument is realised externally to the predicate. In the case of stage-level predicates, the highest argument to occupy the external argument position is an event argument. Since all the other arguments are realized internally to the predicate, subjects of stage-level predicates are also generated internally. On the other hand, in the case of individual-level predicates, which do not have an event argument, the highest argument to occupy the external argument position is a lexical argument. This highest lexical argument mapped to the external argument position is the subject of an individual-level predicate. Thus, while subjects of stage-level predicates are generated in a VPinternal position, subjects of individual-level predicates are generated in the VPexternal subject position.

Notice that the relative height between VP-internal and external positions for subjects of stage-level and individual-level predicates matches with that between LP and WP in which I claim that subjects of stage-level and individuallevel predicates appear respectively.

\subsubsection{Diesing (1992)}

Diesing (1992) maintains Kratzer's (1989) syntactic characterization of the two types of predicates, that is, stage-level predicates have their subjects generated in a VP-internal position, whereas individual-level predicates have their subjects generated in the VP-external subject position. Diesing however proposes that the distinct D-structure subject positions for stage-level and individual-level predicates are due to there being two types of Infl associated with the two predicate types. She argues that stage-level predicates have an Infl that does not assign a theta-role to its $\mathrm{Spec}$, while individual-level predicates have an Infl that assigns a theta-role to [Spec, IP]. (A theta-role assigned to [Spec, IP] by an Infl of individual-level predicates has roughly the meaning 'has the property $\mathrm{x}$,' where $\mathrm{x}$ is the property expressed by the predicate.) With an Infl that does not assign a theta-role, stage-level predicates generate their subjects in [Spec, VP] (assuming that [Spec, VP] is always assigned a theta-role by V.) With an Infl that does assign a theta-role, individual-level predicates generate their subjects in [Spec, IP] 
(In this case, [Spec, VP] which receives a theta-role from V has a PRO subject, which is controlled by the lexical subject in [Spec, IP]. $)^{25}$ The representations in (28) and (29) illustrate the D-structure representations for stage-level and individual-level predicates respectively.

(28) D-structure representation for stage-level predicate

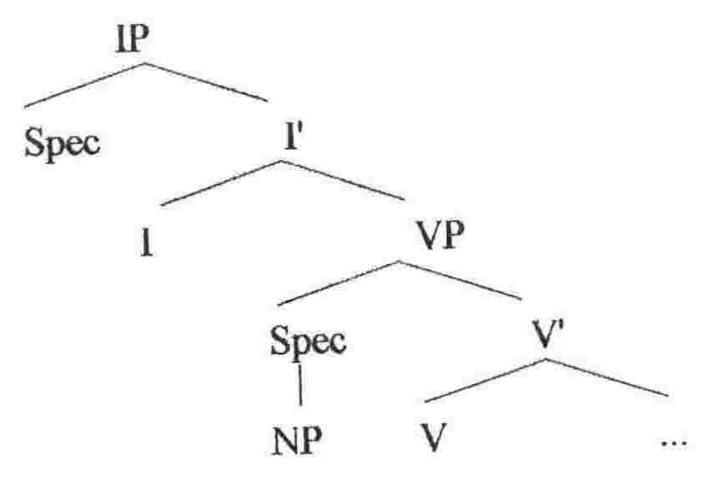

(Diesing 1992: 361)

(29) D-structure representation for individual-level predicate

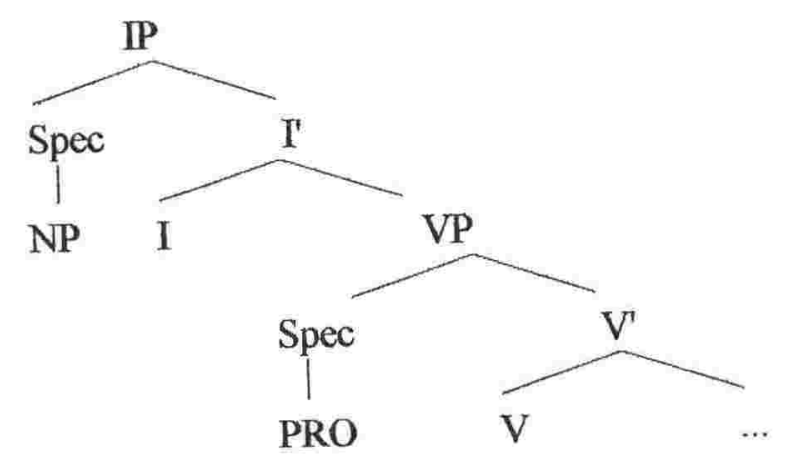

(Diesing 1992: 363)

\subsubsection{Comparisons}

I shall now compare these two analyses reviewed above with the analysis I am proposing in this chapter in terms of (i) the origin of the distinction: lexicon vs. syntax, (ii) the link between syntax and semantics, (iii) the level of syntactic representation, (iv) the "aboutness" relation, and (v) stage- and individual-level predicates in the temporal structure.

${ }^{25}$ As a result, individual-level predicates are analyzed as parallel to control structures, while stage-level predicates are given an analysis parallel to raising verbs. 


\subsubsection{Origin of the distinction: lexicon vs. syntax}

The first point of comparison is the origin of the distinction between the two types of predicates. Kratzer assumes that each predicate is specified as either stage-level or individual-level in the lexicon, by having or not having a Davidsonian argument for spatiotemporal location in its argument structure.

It is however problematic to treat the stage-/individual-level distinction as a lexical property of predicates. In fact, predicates normally thought of as stagelevel can be interpreted as individual-level as well, while normally individual-level predicates can also be interpreted as stage-level as well. Cowper (1977), for example, shows that any verb that canonically describes an event (i.e., stagelevel) can appear in the simple present tense with the habitual/generic reading (i.e., individual-level), as in (30) below. ${ }^{26}$ In addition, verbs which typically appear in stative sentences (i.e., individual-level) can, under certain circumstances, appear in a clause describing an event (i.e., stage-level), as shown in (31) below. These examples show that the distinction between the two types of predicates is not lexically determined (at least not entirely). ${ }^{27}$

(30)a. Kate drives a Mercedes.

(Cowper 1997: 9)

b. Kelly eats junk food.

(Cowper 1997: 10)

(31)a. Sue was polite three times this morning. The first time it happened, the teacher fell off her chair.

b. What Sue is doing is being polite.

c. What is happening is that Sue is being polite.

(Cowper 1997: 13)

\footnotetext{
${ }^{26}$ It has been pointed out by an examiner that a generic/habitual reading is due to the fact that there is a quantification over events and times, as captured by analyses incorporating some generic operator.

${ }^{27}$ However, there are some verbs which do not seem alterable between stage- and individual-level interpretations. For example, know in English seems to be never taken as stage-level. This suggests that even if the stage-/individual-level distinction is mainly encoded in the syntax, it is not entirely disconnected from the lexical semantics of the verb. It is possible that some form of restriction is encoded within the lexicon of the verb. (Rosen (1999) discusses the event representations in three different components of the grammar, i.e., the lexicon, the syntax, and the semantics.)
} 
If we assume that what distinguishes between the two types of predicates is the presence or absence of a Davidsonian event element and that it is part of a verb's lexical entry, then virtually every verb must have two lexical entries, one with a Davidsonian event element and one without. ${ }^{28} \mathrm{Or}$, virtually every verb contains a Davidsonian event element in its lexical entry and it must be always optional.

Ramchand (1996) in analyzing data from modern Scottish Gaelic also argues that the distinction between stage-level and individual-level predicates must be reconceived as a non-lexical, constructional one.

Moreover, as I have pointed out in 2.3 .5 above, the distinction between individual-level and stage-level predicates which correlates with wa- and gasubjects in Japanese draws a line even to divide a single predicate in the same tense/aspect form. For example, a predicate, (hon-o) kai-tei-ru is writing (a book)', can be interpreted as either individual-level (with a wa-marked individual subject) or stage-level (with a ga-marked stage subject).

The above strongly suggests a departure from the assumption that stagelevel and individual-level predicates are pre-syntactically distinguished in the lexicon. In the system I am proposing, the stage-/individual-level distinction only appears in the syntax, since the Davidsonian event element whose presence or absence distinguishes the two types of predicates is turned into the semantic content of a functional head $(E)$ in the phrase structure of a clause. The presence or absence of $e$, the semantic content of $E$, depends on the type of a clause but not on the choice of a lexical predicate. ${ }^{29}$ The same predicate can appear either in a clause with $e$ in $E$ (i.e., $E_{\mathrm{l}^{+}+}$) or in a clause without $e$ in $E$ (i.e., $E_{\mathrm{t}-1}$ ). Accordingly, it can be interpreted as either stage-level or individual-level.

In terms of a departure from the assumption that stage-level and individuallevel predicates are pre-syntactically distinguished in the lexicon, Diesing has made a significant move. By associating the two types of predicates with the two types of Infl, Diesing has shifted the source of the distinction from the lexicon to

${ }^{28}$ This claim may be too strong. There are some verbs which do not seem alterable between stage- and individual-level. See footnote 27 above.

${ }^{29}$ Again, see footnote 27 above. 
the syntax. However, there seems a jump of logic in simply linking the two type of predicates with the two types of Infl, which results in failing to capture the semantic characteristics of the two types of predicates. This leads us to the second point of comparison; the link between syntax and semantics.

\subsubsection{Link between syntax and semantics}

Stage-level and individual-level predicates are essentially distinguished in terms of their semantic characteristics, or more specifically in terms of their 'spatiotemporal boundedness'. In Kratzer's analysis, this semantic distinction between the two types of predicates is represented by presence and absence of an event argument in the argument structures of predicates. Roughly, stage-level predicates describe spatially and temporally bounded situations, as they have an event argument which locates situations at a punctual spatiotemporal location. On the other hand, individual-level predicates describe spatially and temporally unbounded situations, as they lack an event argument which locates situations at a punctual spatiotemporal location. This semantic distinction characterized by presence and absence of an event argument in the argument structures specified in the lexicon is linked to the syntactic distinction characterized by distinct Dstructure subject positions as a result of mapping of arguments. Although it is problematic to assume that the stage-/individual-level distinction is made entirely in the lexicon (as discussed in 4.4.3.1 above), the presence and absence of an event argument capture the essential semantic characteristics of the two types of predicates.

In contrast, Diesing links the two types of semantically distinguished predicates directly with the two types of syntactically distinguished Infl, i.e., one that assigns a theta-role to its Spec and that does not. Unlike the presence and absence of an event argument in Kratzer's analysis, Infl's ability and inability of assigning a theta-role to its Spec in Diesing's analysis do not explain the semantic characteristics of stage-level and individual-level predicates. Although Diesing stipulates that a theta-role assigned to [Spec, IP] by an Infl of individual-level predicates has roughly the meaning 'has the property $x$,' where $x$ is the property expressed by the predicate, it does not really account for the essential semantic characteristic of spatiotemporal unbounded situations described by individual-level 
predicates. As for the spatiotemporal boundedness of stage-level predicates, there is nothing to account for it.

Diesing connects syntax and semantics by her mapping hypothesis that the IP area of a clause maps onto a restrictive clause (and therefore subjects occurring in that area receive the strong reading) and the VP maps onto the nuclear scope (and therefore subjects occurring in that area receive the weak reading). While the mapping hypothesis provides an account for the scopal difference between the subjects of stage- and individual-level predicates, what I think is the essential semantic distinction between individuals and stages or that between individuallevel and stage-level predicates particularly in terms of 'spatiotemporal boundedness' is left unexplained in Diesing's system.

In this respect, Kratzer's analysis with an event argument, whose presence and absence in the external argument position capture the semantic characteristics of the two types of predicates, links the syntax and the semantics of stagefindividual-level predicates more transparently. Similarly, my analysis with $e$, whose presence and absence in the functional head $E$ capture the semantic characteristics of the two types of predicates, transparently links the syntax and the semantics of stage-/individual-level predicates. I believe this is desirable in that it clearly shows why and how the two semantically distinct types of predicates exhibit distinct syntactic characteristics (i.e., two distinct subject positions in the syntax).

\subsubsection{Level of syntactic representation}

Let us now consider the level of syntactic representation at which stage-and individual-level predicates are distinguished. Both Kratzer and Diesing represent the syntactic characteristics of stage-level and individual-level predicates at the level of D-structure by assuming their subjects are generated in two distinct positions.

Although $I$ also maintain that the stage-level/individual-level distinction is syntactically characterized by two distinct positions in which their subjects appear, $I$ assume that the subjects appear in the two distinct positions not before but after syntactic derivation. Before syntactic derivation or at the level of D-structure, subjects of both stage-level and individual-level predicates are assumed to be 
inside VP (or the maximal projection of the predicate), where they are generated and theta-roles are assigned. The structural hierarchy between the subjects of stage-level and individual-level predicates shows up only as a result of syntactic derivation or movement. That is, subjects move out of VP to either [Spec, LP] or [Spec, WP] (see (15) and (17) above).

It is desirable to generate subjects inside VP in accordance with the VPinternal subject hypothesis (Koopman and Sportiche 1988), especially when we consider phenomena such as floated quantifiers. Diesing points out that a problem in Kratzer's analysis is that it rules out a possibility of some kind of relationship holding between the VP-internal and VP-external subject positions in individuallevel predicates (by generating subjects of individual-level predicates in [Spec, IP]). If there is no connection to a VP-internal position with individual-level predicates, then floated quantifiers should not be possible with subjects of individual-level predicates (Bonet 1989). Whether or not we adopt Sportiche's (1988) analysis that floated quantifiers originate from the VP-internal subject position and are derived by NP-movement, there must be a possibility of some kind of relationship holding between the VP-internal and VP-external subject positions in (32).

[IP The pigs are [vp all_ stout]].

(Diesing, 1992: 360)

Diesing's solution to this problem is to establish a control relation between the VP-external and VP-internal subject positions by assuming a PRO subject in [Spec, VP]. My solution is not to cause the problem from the beginning simply by generating subjects all inside VP (and raising them to two distinct positions, according to the feature-checking system proposed in 4.3 above.)

\subsubsection{The "Aboutness" relation}

Another point of comparison is the "aboutness" relation. A significant aspect of Kratzer's analysis is that spatiotemporal location is taken as a syntactic argument and mapped to the external subject position in the syntax. It has been subsequently argued that the external subject position is the position for an entity which the predicate is about and that an event argument realized in the external 
subject position is a "real" subject of stage-level predicates (e.g., Calabrese 1993, Raposo and Uriagereka 1993). This means that stage-level predicates which have an event argument in the external subject position are about an event, while individual-level predicates are about an individual which is realized in the external subject position.

It is intuitively clear that individual-level predicates are about an individual. For example, the sentence (33a) below is a statement about an individual cat, as for which it says that it is sleeping over there. On the other hand, it is far less clear that stage-level predicates are about an event. For example, although the sentence (33b) is certainly different from (33a) in that the/a cat is not taken as the topic which the sentence is about, what then is the topic of the sentence is not clear. It is even unclear if there is a topic in a sentence like (33b).

Neko-wa asoko-de nemut-tei-ru.
the cat there at sleeping-is

'The cat is sleeping over there.'

b. Neko-ga asoko-de nemut-tei-ru. the/a cat there at sleeping-is 'The/A cat is sleeping over there.'

While it is possible to conceive that the topic of (33b) is an event, i.e., the sentence is about an event (as an abstract topic), it is also possible to conceive of (33b) as a sentence without a topic. Especially because an event as a topic is such an abstract notion that we are hardly aware of, the absence of a topic rather seems to match our cognition.

Kuroda $(1965,1972,1976,1992 b)$ claims that a sentence with a ga-marked subject expresses a thetic judgement, which lacks the cognitive act of recognition of a Subject (cf. 1.3.1 above). Remember that Kuroda uses the term 'Subject' (with a capital S) to refer to the logical subject of a logical predicate, which is to be distinguished from the syntactic subject of a clause. Essentially, a Subject is a topic about which a Predicate predicates. Due to the absence of recognition of a Subject, a sentence with a ga-marked subject does not have a Subject-Predicate structure (in the logical representation). Where there is no Subject-Predicate structure, there is no predication. Therefore, according to 
Kuroda, a sentence with a ga-marked subject (expressing a thetic judgement) does not constitute a predication. Rather, it constitutes a (non-predicational) description.

My analysis is congenial to such a view. If we take the position in which subjects of individual-level predicates appear as a special position for an entity which the predicate is about since it is intuitively clear that individual-level predicates are about individuals, the corresponding position in my system is [Spec, WP]. Crucially, because I treat a spatiotemporal location not as an argument but as the semantic content of a functional head, $E$, it never appears in [Spec, WP] as the subject of a predicate. When a spatiotemporal location $e$ is present in $E$, the subject of a clause appears in [Spec, EP] and [Spec, WP] is left unfilled (except for the possible occurrence of expletives in some languages). Since [Spec, WP] is the special position for an entity which the predicate is about, that it is empty means the predicate does not predicate of anything particular. Unfilled [Spec, WP] indicates the absence of a topic, and hence the absence of an "aboutness" relation or a Subject-Predicate structure. Thus, in my analysis stage-level predicates do not predicate of an event or anything. Supposedly, without predication, they merely describe. ${ }^{30,31}$

In contrast, when a spatiotemporal location $e$ is absent in $E$, the subject of a clause is raised to [Spec, WP]. This represents individuals and individual-level predicates forming the Subject-Predicate structure, where individual-level predicates predicate of individuals.

\subsubsection{Stage- and individual-level predicates in the temporal structure}

Finally, notice that in my analysis, the stage-/individual-level distinction is represented in the phrase structure of tense. Semantically, a stage-level predicate is characterized by the presence of the semantic content of a temporal head $E$, which signifies $\mathrm{R}=\mathrm{S}$, whereas an individual-level predicate is characterized by the

${ }^{30}$ Strictly speaking, it is not stage-level predicates but rather stages and stage-level predicates as a set that describe (non-predicationally).

${ }^{31}$ Since $\omega$ is present in all root clauses, when [Spec, WP] is not filled by the subject, it may be filled by an expletive type content in some languages. 1 will discuss this possibility with reference to English in 4.6.2 below. 
absence of the semantic content of $E$, which essentially signifies $\mathrm{R}=\mathrm{E}$. Syntactically, a stage-level predicate is characterized by having a subject in [Spec, $E \mathrm{P}]$, where it is licensed as the subject of a stage-level predicate, whereas an individual-level predicate is characterized by having a subject in [Spec, WP], where it is licensed as the subject of a individual-level predicate.

It is significant that the syntax and semantics of stage- and individual-level predicates fall under the syntax and semantics of tense. It takes no extra machinery and mechanisms to represent stage- and individual-level predicates, besides those which are independently required to account for tense/aspect phenomena. This suggests that while the notions of stage-level and individuallevel predicates (and those of stages and individuals) provide us with a useful frame of reference, they are essentially reducible to the system of tense, which constitutes the central functional architecture in the phrase structure of languages. ${ }^{32}$

\subsubsection{Conclusion}

In this section, 1 have evaluated my analysis as a system to account for the stage- and individual-level distinction in the syntax in comparison with the previous analyses of Kratzer (1989) and Diesing (1992). While my analysis maintains the spirit of those previous analyses, it exhibits both empirical and theoretical advantages in terms of (i) the origin of the distinction: lexicon vs. syntax, (ii) the link between syntax and semantics, (iii) the level of representation, (iv) the "aboutness" relation, and (v) the stage- and individual-level predicates in the temporal structure.

It should be noted here (once again) that my analysis of the syntax and semantics of stage-and individual-level predicates espouses Carlson's (1977) original view that stage-level and individual-level predicates are distinguished as predicates of stages and those of individuals respectively. This is an important point especially if there is a gap between what are originally

${ }^{32}$ Raposo and Uriagereka (1995) also claim that there are no such things as individuallevel and stage-level predicates. For them, what is at stake are differences in information (theme/rheme) structure. 
distinguished as stage-level and individual-level predicates and what are generally thought of as stage-level and individual-level predicates.

\subsection{Subjects and the temporal structure}

1 have proposed in 4.3 above that wa- and ga-marked subjects in Japanese are associated with the functional projections making up a temporal structure (i.e., WP and EP). Such an analysis is very much akin to Davis' (1998) proposal which also considers subject licensing to depend on a temporal structure. In this section, I compare Davis' and my analyses to deliberate on the relation between subjects and a temporal structure.

\subsubsection{Davis (1998)}

Davis (1998) observes a structural asymmetry between the first and second person subjects on the one hand (henceforth $1 \& 2$ subjects) and the third person subjects on the other (henceforth 3 subjects) in all types of agreement system, which is characterized by the two central generalizations given in (34).

(34)a. If a language shows a person split, $1 \& 2$ subjects occupy a structurally superior position than 3 subjects.

b. If a language shows a person split, it will have expletive subjects in sentences containing 3 subjects.

(Davis 1998: 83)

Davis assumes that this structural asymmetry is characterized by differential raising of subjects from a lower into a higher subject position, that is, $1 \& 2$ subjects raise but 3 subjects do not.

In order to account for this differential raising of subjects, Davis argues that $\phi$-features of $1 \& 2$ subjects and 3 subjects are associated with two different functional heads. As he assumes that functional projections encode 
temporal structure, he claims that $\phi$-features are parasitically attached to temporal heads, whose existence is independently motivated. ${ }^{33}$ Since $1 \& 2$ subjects are structurally higher than 3 subjects, the $\phi$-features of $1 \& 2$ subjects are related to the higher temporal head, whereas 3 subjects are related to the lower temporal head. Adopting D \&U-E's (1998a,b,c) temporal architecture with TP and AspP, as discussed in 4.1.2 above, Davis associates the $\phi$-features of $1 \& 2$ subjects with T and (non-deictic) 3 subjects with Asp.

The association of $1 \& 2$ subjects with $T$ is also justified by the semantics of $1 \& 2$ pronouns. Although the referents of $1 \& 2$ are variable being defined by the speech situation - they always refer directly to the speech participants at the time of utterance. Davis takes this to reflect the generalization that the $\phi$-features of $1 \& 2$ subjects are associated with $T$, which encodes UT-T. In contrast, 3 subjects may relate either (deictically) to UT-T or (anaphorically) to AST-T. Accordingly, 3 subjects are associated with either T, which encodes UT-T, or Asp, which encodes AST-T.

\subsubsection{Person split and wa/ga-split}

Needless to remind the readers, I have associated $w a$-marked and $g a$ marked subjects with the temporal heads, $W$ and $E$, which essentially correspond to D/U-E's T and Asp respectively. It is striking that both Davis and $I$ divide subjects into two groups and associate them with two temporal heads. The higher temporal head (whether we call it $\mathrm{T}$ or $W$ ) is associated with $1 \& 2$ subjects in Davis' analysis and with wa-subjects in my analysis, whereas the lower temporal head (whether we call it Asp or $E^{\prime}$ ) is associated with 3 subjects in Davis' and with ga-subjects in mine. This naturally raises a question as to whether the person split between $1 \& 2$ and 3 subjects corresponds to the split between wa- and $g a$-marked subjects in Japanese.

Examining $w a$ - and $g a$-marking of subjects in the light of $1 \& 2$ and 3 persons, we find that $1 \& 2$ subjects are typically marked with $-w a$ and that only 3 subjects have the genuine option of wa/ga-marking. The examples in

33 An important consequence of this assumption is that there are no AGReement projections. 
(35) and (36) below show that while 3 subjects can be marked by either -wa or -ga to yield the neutral interpretations, depending on whether they refer to individuals or stages, $1 \& 2$ subjects cannot be neutrally marked by $-g a$, as indicated by the hashes.

(35)a. John-wa/ga nai-tei-ru.

John cry-Prog-Pres

'John is erying.'

b. Boku-wa/\#ga nai-tei-ru.

l cry-Prog-Pres

'I am crying.'

c. Kimi-wa/\#ga nai-tei-ru.

you cry-Prog-Pres

'You are crying.'

(36)a. Sensei-wa/ga ki-ta.

teacher come-Past

'The teacher came./A/The teacher has come.'

b. Watashi-wa/\#ga ki-ta.

I come-Past

'1 have come.'

c. Anata-wa/\#ga ki-ta.

you come-Past

'You have come.'

Note that the above suggests that stage-level predicates cannot occur with $1 \& 2$ subjects. This is true with the view that stage-level predicates are predicates of stages (and that individual-level predicates are predicates of individuals), as discussed in 2.3 .5 above. Thus defined, individual-level and stage-level predicates correspond to the View all and View $w_{\text {part }}$ interpretations in my analysis obtained respectively with $w a$ - and ga-marked subjects in Japanese (since wa- and $g a$-marked subjects correspond to individuals and stages respectively). Importantly, this distinction between stage- and individual-level predicates can be much more subtle than it is generally understood. Recall that it distinguishes between the 'static present' interpretation and the 'dynamic progressive' interpretation of the same 
predicate, for example, nai-teiru 'be crying', depending on whether it predicates of a $w a$-marked individual subject or of a ga-marked stage subject. Essentially, with wa-marked individual subjects (which 1 \& 2 subjects necessarily are), the 'not news' flavour of stage-level/View part $_{\text {interpretation (as }}$ in the 'dynamic progressive' interpretation) is simply unobtainable.

Kuno (1973: 55) has pointed out that it is next to impossible to interpret sentences with the first person subject as sentences of neutral description'. Kuno speculates that it is because 'the speaker is not allowed to look at his own action or existence objectively and to describe it as if it were a new event'. Since it is in fact similarly impossible to interpret sentences with the second person subject as sentences of neutral description, we might extend Kuno's theory to say that the speech participants are not allowed to look at their own or each others' action/existence objectively and to describe it as if it were a new event. In the light of the stage/individual distinction, this means that we cannot talk about the stages of speech participants. Rather mysteriously, 1 \& 2 subjects necessarily refer to whole individuals, which transcend the confine of speech situation and in fact stand behind all of their tokens (or stages) to connect them.

This is perhaps related to the fact that the referents of $1 \& 2$ subjects are necessarily "familiar" in the speech situation. The status of "familiarity" is typically obtained after the first mention in the discourse. However, with 1 \& 2 pronouns which refer to the speech participants, the "familiar" status is given even before the first mention, since we know who ' $\mathrm{I}$ ' and 'you' refer to even from the first time they are mentioned in the current discourse. Thus, the interpretation of 1 \& 2 subjects necessarily involves linking to a familiar referent in the discourse. I assume that this linking to a familiar referent establishes the totality or the continuity in which 1 \& 2 subjects are necessarily interpreted and their referents are perceived. This may provide an explaination why $1 \& 2$ subjects necessarily refer to whole individuals.

On the other hand, the referents of 3 subjects may be "known/familiar" or "novel" to the common ground of the discourse. Return to the examples (35a) and (36a) above. Proper names such as John and common nouns such as sensei 'teacher' may refer to familiar referents, i.e., they have been already 
established in the discourse, or to novel referents, i.e., they are newly introduced to the discourse. Let me remind the readers that there are two levels of novelty to be distinguished, as discussed in 2.4 above. A DP may refer to a referent that is known to the interlocutors (because of their previous knowledge) but presented and taken as novel to the current discourse. While the in English indicates that the referent of a noun phrase is known to the interlocutors, a noun phrase with the can be presented and taken as novel to the current discourse. In Japanese, ga-marked subjects necessarily refer to novel referents to the current discourse, though they may be known to the interlocutors (because of their previous knowledge), or may well be totally unknown. Therefore, when marked with $-g a$, sensei in (36a) above can be translated as either 'a teacher' or 'the teacher'. On the other hand, wa-marked subjects necessarily refer to familiar referents in the current discourse. Therefore, when marked with -wa sensei is necessarily translated as 'the teacher'. See the diagrams reproduced in (37).
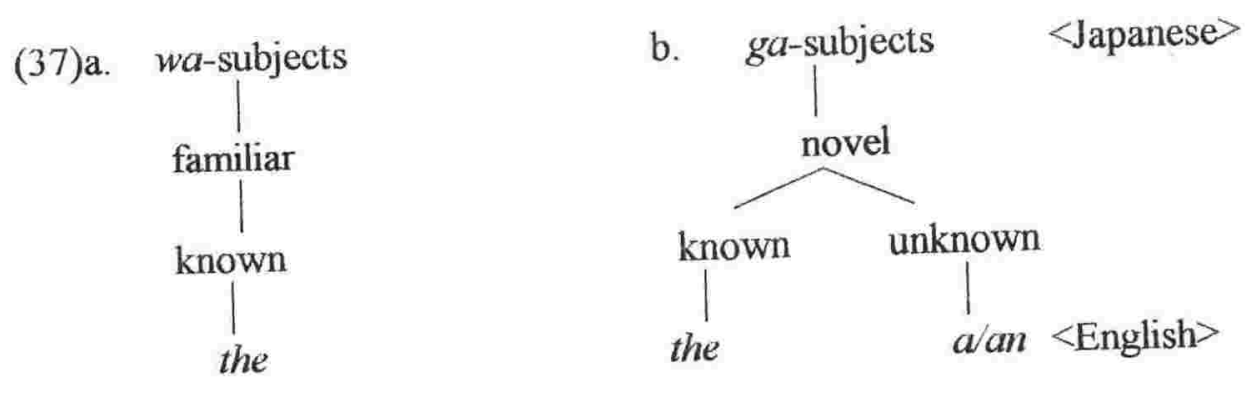

The third person pronouns such as kare 'he', kanojo 'she', kore 'this', sore 'it', and are 'that' basically refer to known referents. Therefore, they can be interpreted by virtue of being linked to already established referents in the discourse. However, they can also be used deictically to refer to novel referents to the discourse. Therefore, 3 pronoun subjects can be marked by either $-w a$ or $-g a$, as shown in (38) and (39) below, depending on whether they refer to familiar or novel referents.

(38) Kanojo-wa/ganai-tei-ru. she cry-Prog-Pres

'She is crying.' 
(39) Sore-wa/ga ki-ta.

it come-Past

'It came./It has just come.'

On the other hand, some 3 pronouns such as dareka 'someone' and nanika 'something' necessarily refer to unknown referents in the discourse. ${ }^{31}$ Unknown referents are never taken as familiar but necessarily taken as novel, as shown in (37) above. Those 3 subjects are necessarily marked by -ga to yield the neutral interpretation. As indicated by the asterisks in (40) and (41) below, wa-marking of those subjects is ungrammatical.

(40) Dareka-*wa/ga nai-tei-ru. someone cry-Prog-Pres

'Someone is crying.'

(41) Nanika-*wa/ga ki-ta.

something come-Past

'Something has come.'

Note that Kuno (1973) also observes that wa-marking of subjects is ungrammatical with some noun phrases such as oozei no hito 'many people' and omosiroi hito 'interesting people' as well as dareka 'somebody', as shown in (42) below. Kuno explains that because 'their referents have not been

${ }^{34}$ The referents of wh-pronouns such as dare 'who' and nani 'what' are also unknown (at least to the speaker), and those $w h$-subjects are necessarily marked with -ga in Japanese, as shown in (i), (ii), and (iii) below. However, this ga-marking does not seem to yield the neutral interpretation but the focus interpretation, as indicated by the hashes. For example, to ask who is crying, there is an assumption that somebody is crying. While Somebody is crying is an existential sentence meaning that there is somebody crying, Who is crying is a question over this existential sentence asking who is that somebody who is crying? This suggests that $w h$-subjects are marked with - $g a$ because they are necessarily in focus (rather than because their referents are unknown).

(i) Darc-*wal\#ga nai-ici-ru no.

who cry-Prog-Pres Q

'Who is crying?'

(ii) Nani-*wa/\#ga ki-ta no.

what come-PastQ

"What came?'

(iii) Darc-*wal\#ga kirci?

who pretty

'Who is prelly'? 
entered into the registry of the present discourse' (p. 45) they do not qualify as topics. That is, in my terminology, their referents are not familiar but novel to the current discourse.

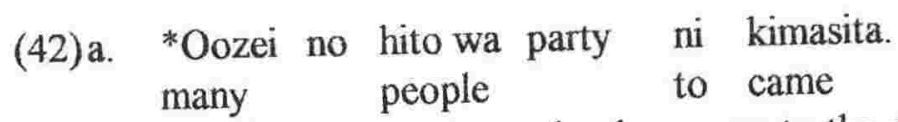

'Speaking of many people, they came to the party.'

b. *Omosiroi hito wa party ni kimasita. interesting people to came 'Speaking of interesting people, they came to the party.'

c. *Darekawa byooki desu.

somebody sick is

'Speaking of somebody, he is sick.'

(Kuno 1973: 45)

Thus, the option of $w a / g a$-marking exists only when the subject phrase could refer to either a familiar referent or a novel referent in the discourse. Since $1 \& 2$ subjects necessarily refer to familiar referents, they are neutrally marked by $-w a$. (If marked by - ga, the neutral interpretation is not available.) On the other hand, some 3 subjects such as dareka 'someone' and nanika 'something' necessarily refer to unknown novel referents and are therefore necessarily marked by $-g a$. Only those 3 subjects that can refer to either familiar or novel referents have the genuine option of wa/ga-marking.

The above shows that there certainly exist some parallelisms between the person split and the $w a / g a$-split of subjects in Japanese. Although the wa/ga-split does not draw a clear line between $1 \& 2$ subjects on the one hand and 3 subjects on the other, Davis also allows some fluidity of 3 subjects by distinguishing between deictic and non-deictic 3 subjects.

To the extent that the person split and the $w a / g a$-split of subjects correspond to each other, Davis' and my analyses support each other especially in our claim that there are two different classes of subjects, which are related to the two functional projections making up the temporal structure of a clause. 


\subsection{3. $1 \& 2$ vs. 3 person subjects, familiar vs. novel subjects, and} individual vs. stage subjects

A question now is exactly what distinguishes the two classes of subjects. Davis claims that it is the distinct $\phi$-features of subjects, drawing a line between $1 \& 2$ subjects on the one hand and 3 subjects on the other to be associated with $\mathrm{T}$ and Asp respectively. However, the structural asymmetry Davis attempts to account for is actually observed between $1 \& 2$ subjects and deictic 3 subjects on the one hand and non-deictic 3 subjects on the other (rather than simply between $1 \& 2$ subjects and 3 subjects). As deictic and non-deictic 3 subjects share the same $\phi$-features, the asymmetry between the two cannot be accounted for by distinct $\phi$-features. This casts a doubt on the view that $\phi$-features really distinguish the two classes of subjects which exhibit the structural asymmetry.

The comparison between the person split and the $w a / g a$-split of subjects in Japanese in 4.5 .2 above suggests that the two classes of subjects are distinguished in terms of the distinction between familiar vs. novel in the discourse. The first \& second person subjects and definite 3 subjects refer to known referents in the discourse and they are typically marked neutrally with $-w a$. On the other hand, indefinite 3 subjects refer to new referents and they are marked neutrally with -ga.

Furthermore, familiar referents of $w a$-marked subjects are necessarily taken as (total) individuals, whereas novel referents of $g a$-marked subjects are taken as (transient) stages (cf. 2.4 above). This correlation between familiarity and individuals and that between novelty and stages can be explained as follows. The interpretation of familiar referents depends on linking to the antecedents in the discourse, or to the physical tokens in the actual speech situation particularly in the cases of the referents of ' 1 ' and 'you'. This linking establishes the totality or the continuity in which the referents are perceived. Therefore, familiar referents linked to the antecedents or the physical tokens are necessarily interpreted as whole individuals. On the other hand, novel referents are interpreted solely on the basis of actual manifestations of individuals at the time of utterance, i.e., without being linked to the 
individuals of which they are manifestations. The interpretation of novelty obtains when they are perceived as punctual manifestations,. Therefore, novel referents are taken as stages, and conversely stages are taken as novel to the discourse.

Notice that while $\phi$-features are presumably inherent in subject noun phrases, the distinction between familiar and novel referents and that between (total) individuals and (transient) stages are not properties of noun phrases but rather properties of their referents. Therefore, I do not assume that those properties inhere in the noun phrases. Rather, 1 conceive that those properties are encoded in the functional heads, $E$ and $W$, as their D-features and checked by subject noun phrases appearing in their Spec positions (as proposed in 4.3.1 above). That is, the $\mathrm{D}$-feature of $W$ encodes the referential familiarity and the totality of an individual. Recall that the semantic content of $W$ is $\omega$, an anchor to a world, or a particular context which is fixed in the discourse. The context to which $\omega$ anchors a clause and in which the truth of a clause is evaluated is necessarily understood by interlocutors. It is part of the common ground of the discourse. Due to such semantic content of $W$, a subject checking the D-feature is interpreted as referring to a familiar referent in the discourse. Also, a subject anchored to a world must stand in the world transcending and subsisting beyond each punctual spatiotemporal location which makes up the world. This gives rise to the 'individual' interpretation of subject (as opposed to the 'stage' interpretation).

On the other hand, the D-feature of $E$ encodes the referential novelty and the temporality of a stage. Recall that the semantic content of $E$ is $e$, an anchor to a punctual spatiotemporal location. A punctual spatiotemporal location to which $e$ anchors a clause and strictly on which the truth of a clause is dependent is always seen as new and vivid in the dynamics of the discourse. Due to such semantic content of $E$, a subject checking its D-feature is interpreted as referring to a novel referent to the discourse, as well as a punctual manifestation of an individual at that particular spatiotemporal location, i.e., a 'stage'.

Thus, I assume that the two classes of subjects are distinguished by the referential familiarity vs. novelty in the discourse and the totality vs. 
temporality of the referent in our perception, which are closely interrelated. In my analysis, those properties are encoded in $W$ and $E$ as their D-features and are checked by the matching features present in $\mathrm{K}$ or $\mathrm{D}$ of subject $\mathrm{KP} / \mathrm{DPs}$ raised to their Spec positions.

\subsubsection{Conclusions}

In this section, I have reviewed Davis' (1998) proposal that $\phi$-features of subjects are related to a temporal structure, which is very much akin to my analysis that $w a$ - and $g a$-subjects are associated with the two functional projections making up a temporal structure. Davis associates the $\phi$-features of $1 \& 2$ subjects (and deictic 3 subjects) with the higher temporal head (T) and (non-deictic) 3 subjects with the lower temporal head (Asp), while I associates wa-marked with the higher temporal head $(W)$ and $g a$-marked subjects with the lower temporal head $(L)$. Since Davis and I assume the same kind of temporal structure based on Stowell (1994a,b) and D \& U-E (1998) despite the different labels we use, it has led us to examine whether the person split between $1 / 2$ and 3 subjects corresponds to the split between wa- and $g a$ marked subjects in Japanese. The findings suggest that there are some parallelisms between the person split and the $w a / g a$-split of subjects. Davis? and my analyses support each other in that there are two classes of subjects which are related to the two functional projections making up the temporal structure of a clause.

While $\phi$-features of subjects certainly have a bearing on the distinction between the two classes of subjects, I have suggested that the properties that really distinguish between the two classes of subjects are the referential familiarity vs. novelty in the discourse and the totality vs. temporality of the referent in our perception, which are closely interrelated. I assume that those properties are encoded in $W$ and $E$ as their $\mathrm{D}$-features and are checked by the matching features present in $\mathrm{K}$ or $\mathrm{D}$ of subject $\mathrm{KP} / \mathrm{DPs}$ raised to their Spec positions. That is, subjects raised to $[\mathrm{Spec}, W \mathrm{P}]$ check the referential familiarity and the totality of an individual, whereas subjects raised to [Spec, $L P]$ check the referential novelty and the temporality of a stage. 


\subsection{Two subject positions across languages}

I have argued for two syntactic positions for subjects, [Spec, WP] and [Spec, EP], particularly to account for the phenomena in Japanese, where subjects are marked with either $-w a$ or $-g a$ and $w a$-marked and ga-marked subjects exhibit a structural hierarchy (i.e., wa-marked ones are structurally superior to ga-marked ones). Nevertheless, I envisage that the proposed two positions for subjects in the temporal structure are tenable across languages, even if with some parametric variations.

\subsubsection{German, Icelandic, Italian, and Scottish Gaelic}

Firstly, in some languages such as German, Icelandic, Italian, and Scottish Gaelic, two structurally distinct subject positions have been observed even more clearly, though they do not exhibit distinct subject markings. For example, with the German examples in (43) below, Diesing (1992) shows that subjects appearing in the higher subject position are interpreted generically, while those appearing in the lower subject position are interpreted existentially.

(43) German

a. ... weil (Linguisten) ja doch (Linguisten) Kammermusik spielen. since (linguists) PRT PRT (linguists) chamber music play GENERIC EXISTENTIAL

Generic reading: ' ... since linguists play chamber music.'

Existential reading: ' ... since linguists are playing chamber music.'

(Diesing 1992: 370)

$\begin{array}{lllll}\text { b. ... weil } \begin{array}{l}\text { (Mäuse) ja doch } \\ \text { since }\end{array} & \begin{array}{l}\text { (Mäuse) Käse essen. } \\ \text { (mice) PRT PRT } \\ \text { (mice) cheese eat } \\ \text { GENERIC }\end{array} & \begin{array}{l}\text { EXISTENTIAL } \\ \end{array}\end{array}$

Generic reading: ' ... since mice eat cheese.'

Existential reading: '. .. since mice are eating cheese.'

(Bobaljik \& Jonas 1996: 216) 
With the Icelandic examples in (44) below, Bobaljik and Jonas (1996) point out that definite subjects necessarily appear in the higher subject position, while indefinite one preferentially appear in the lower position.

(44)Icelandic

a. Í gær kláuðu (pessar mýs) sennilega (*pessar mýs) ostinn. yesterday finished (these mice) probably (these mice) the cheese DEF
'The

b. Í gær kláuðu (?margar mýs) sennilega (margar mýs) ostinn. yesterday finished (many mice) probably (many mice) the cheese NDEF NDEF

'Many mice probably finished the cheese yesterday.'

(Bobaljik \& Jonas 1996: 217)

The Italian examples in (45) below show that the natural answer to (45a) takes a post verbal subject as in (45b) but not a preverbal subject as in (45c). The hash on (45c) indicates that the sentence is perfectly grammatical in other contexts with the old information interpretation but not in this context with the new information interpretation. This suggests that new information appears in the postverbal position, whereas old information appears in the preverbal position.

(45) Italian

a. Chi è partito?

who is left

'Who left?'

b. È partito Gianni.

is left Gianni

'Gianni left.'

c. \#Gianni è partito.

Gianni is left

'Gianni left.'

(Belletti 1998) 
In Scottish Gaelic, Ramchand (1996) argues that individual subjects appear in the higher subject position, whereas stage subjects appear in the lower subject position as shown in (46). ${ }^{35}$

(46) Scottish Gaelic

a. Is Cop-pres careful Calum 'Calum is a careful person (by nature).'

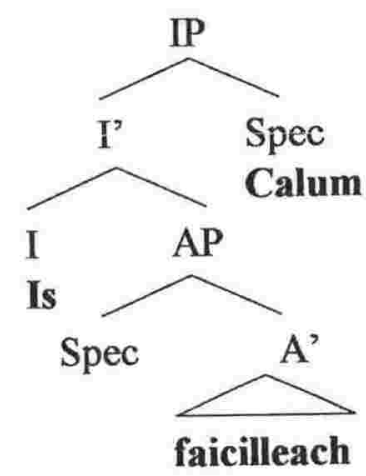

b. Tha Calum faicilleach.

Be-pres Calum careful

'Calum is (being) careful.'

${ }^{35}$ Chung and McCloskey (1987) assume that the surface word order of VSO (in Irish) is derived from raising of V to Infl, as shown in (i), where SC represents a small clause:

(i)

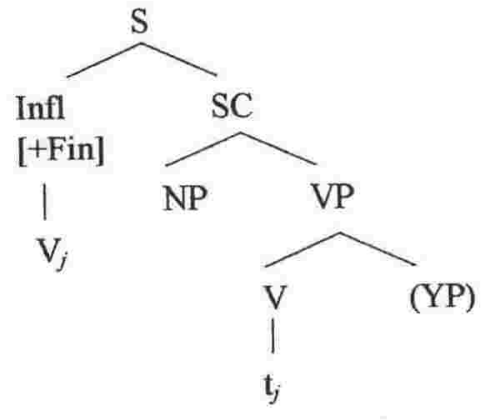

(Ramchand 1996:168)

However, Ramchand argues for a phrase structure which places the subject in the Spec position of the projection that is the complement of the tense-bearing head Infl. Furthermore, IP branches to the right, because a subject (in [Spec, IP]) appears sentence finally in the constructions which make use of the copula verb is (see (46a)). 


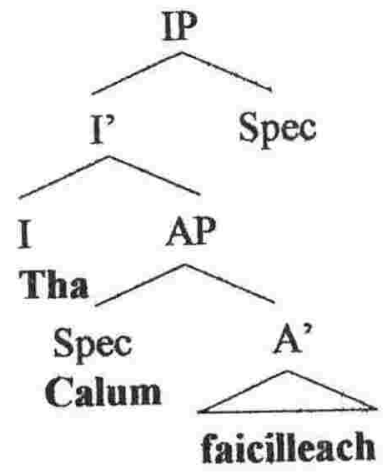

(Ramchand 1996: 173-174)

All these observations conform to my analysis that the two syntactic positions for subjects are semantically motivated and more specifically related to the definite/indefinite distinction, the stage/individual distinction, old/new information, and generic/existential interpretations. Although I do not investigate the details of each case here, the subjects appearing in two distinct positions in those languages seem semantically equivalent to $w a$ - and $g a$ marked subjects in Japanese, in the manner in which the distinctions are implemented. As I propose two distinct subject positions within the functional projections, $W \mathrm{P}$ and $E \mathrm{P}$, for $w a$ - and $g a$-marked subjects in Japanese, I anticipate that these functional projections and the essential syntactic mechanisms operating therein would provide an account for such data as (43)-(46) above from various languages, though it is likely that there are some parametric variations.

\subsubsection{English}

Just to demonstrate how WP and EP would possibly apply in other languages, I contemplate the case in English. In English, it is generally believed that there is a unique position for subjects where the nominative case is assigned or checked. Nevertheless, we can still observe two subject positions. As shown in (47) below, some subjects can appear in the preverbal position as in (47a) or in the postverbal position in the existential there construction as in (47b). 
(47) a. A cricket is on the table.

b. There is a cricket on the table.

It is well known that the there construction with a subject in the postverbal position is only possible when the subject phrase is indefinite, as first pointed out by Milsark (1974). ${ }^{36}$ With a definite subject in the postverbal position, the there construction is ungrammatical, as shown in (48b).

(48)a. The cricket is on the table.

b. *There is the cricket on the table. (* = existential interpretation)

Thus, while the preverbal subject position is generally available irrespective of the definite and indefinite distinction of subjects, as seen in (47a) and (48a) above, the postverbal subject position is reserved for indefinite subjects only, as seen in the contrast between (47b) and (48b). ${ }^{37}$

Now, observe the Japanese translations (49a) and (49b) below for $(47 a, b)$ and $(48 a)$ above respectively. (Note that the stylistic difference between (47a) and (47b) does not show in Japanese.) The subject is marked by $-g a$ in (49a) and by $-w a$ in (49b).

(49)a. Koorogi-ga teeburu-no ue-ni i-ru.
$\begin{aligned} & \text { cricket } \\ & \text { table-of top-at be(anmt)-Pres }\end{aligned}$
'A cricket is on the table/There is a cricket on the table.'

${ }^{36}$ Milsark (1974) also points out that the there construction can only occur with a particular set of verbs, which has been subsequently identified as unaccusatives/ergatives (Perlmutter 1978, Burzio 1986). While (ib) is grammatical, (iib) is not.

(i)
a. A teacher arrived.
<unaccusative>

b. There arrived a teacher.

(ii) a. A teacher shouted.

<unergative>

b. *There shouted a teacher.

${ }^{37}$ Note that a wh-question like (ia) below indicates a wh-word such as what as indefinite (cf. footnote 34 above).

(i) What did you say that there is $t$ on the table? 
b. (Sono) koorogi-wa teeburu-no ue-ni i-ru.
the cricket table-of top-at be(anmt)-Pres
'The cricket is on the table.

Since I analyse that $g a$-marked and wa-marked subjects appear in $[\mathrm{Spec}, E \mathrm{P}]$ and $[\mathrm{Spec}, W \mathrm{P}]$ respectively, one logical possibility is to apply this directly to English and assume that the English subjects which correspond to ga-marked equivalents in Japanese appear in [Spec, EP] and those which correspond to wa-marked equivalents in Japanese appear in [Spec, WP]. That is, a cricket in $(47 \mathrm{a}, \mathrm{b})$ is in [Spec, EP], while the cricket in $(48 \mathrm{a})$ is in [Spec, WP], as illustrated in (50).

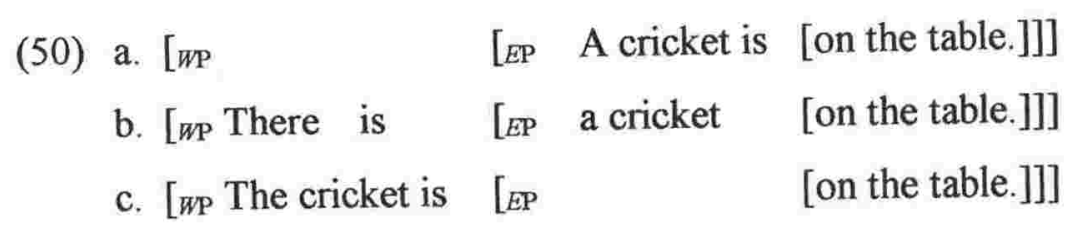

As a strong hypothesis, we can posit that an indefinite subject appears in [Spec, EP], while a definite subject appears in [Spec, WP]. Recall that I have mentioned in 4.3 .2 above the possibility of having an expletive type content in [Spec, WP] when the subject of a clause appears in [Spec, EP] in the configuration with $W_{[+]}$and $E_{\left[^{+}+\right.}$. With an indefinite subject occupying [Spec, $E \mathrm{P}$ ], [Spec, WP] can be filled by there as in (50b), or left empty as in (50a). ${ }^{38}$ On the other hand, the appearance of a definite subject in [Spec, WP] justifies that the insertion of there is prohibited with a definite subject. This analysis suggests that the insertion of there is optional. However, the differing

${ }^{38}$ The insertion of there can be seen as optional, as one has a choice between the paraphrases with and without there as in (47a) and (47b) above.

Even when the occurrence of there seems more obligatory, it is still possible to paraphrase the sentences in the there-construction such as (ia) and (iia) without there, for example (ic) and (iic), though (ib) and (iib) are ungrammatical.

(i) a. There is a lot of water.

b. *A lot of water is.

c. A lot of water is filling the lake.

(ii) a. There will be quite a few people.

b. \#Quite a few people will be.

c. Quite a few people will be at the party. 
positions of $i s$ in (50) above, suggesting two $\mathrm{I}^{\circ}$ head-like positions (i.e., $W$ and $E)$ in English are problematic. ${ }^{39}$

An alternative weak hypothesis is that while a definite subject necessarily appears in [Spec, WP], an indefinite subject may appear in [Spec, $E \mathrm{P}]$ but can also appear in [Spec, WP] under certain conditions, as shown in (51) below. The advantage of (51) over (50) is that we can fix the position of is consistently above EP. In this analysis, we assume that all preverbal subjects in English are in a uniform position perhaps due to a language specific requirement that in English [Spec, WP] must be filled.

(51)a. [WP A cricket is $[E P$ [on the table.]]]
b. [WP There is
c. [EP a cricket [on the table.]]]

As noted in 4.3 .6 above, I assume that the D-features of $W$ and $E$ include the EPP features (which are parametrically varying) and the semantic properties (which are perhaps invariant) (cf. Chomsky 1995: 284). Therefore, it is possible to assume that [Spec, WP] is the only EPP position in some languages including English, while in other languages including Japanese both [Spec, EP] and [Spec, WP] are considered as EPP positions. Importantly, however, even if there is such a parametric difference in the EPP features of $W$ and $E$, I maintain that their semantic properties are invariant. That is, even if all preverbal subjects in English are in [Spec, WP] in the end, we can still distinguish between those which have raised directly from VP, skipping [Spec, EP], and those which have been through [Spec, EP] and checked the semantic properties of $E$.

Nevertheless, even the strong hypothesis can find support, for example, in the differing compatibility of definite and indefinite subjects with negation. The examples in (52) and (53) below show that while a sentence with a

${ }^{39} \mathrm{I}$ am indebted to Elizabeth Pearce (p.c.) for pointing this out for me and suggesting the following alternative analysis. 
definite subject can be negated, a sentence with an indefinite subject cannot be negated. $^{40}$

(52) a. The nurse-aide administered CPR to the patient.

b. The nurse-aide didn't administer CPR to the patient.
a. A nurse-aide administered CPR to the patient.
b. *A nurse-aide didn't administer CPR to the patient.
c. Nurse-aides administered CPR to the patient.
d. *Nurse-aides didn't administer CPR to the patient.

One possible explanation for this contrast is to assume that Neg is situated between the position in which a definite subject appears and the position in which an indefinite subject appears. If so, it is grammatical that the subject appears structurally higher than negation in (52b), because it is definite. On the other hand, it is ungrammatical in (53b) and (53d) because indefinite subjects are supposed to be lower than negation. ${ }^{41,42}$ In 4.3 .4 above, I have suggested that NegP is situated between WP and EP (see (24) above). This assumed position of NegP below WP and above EP justifies that definite subjects appear in [Spec, WP] and indefinite subjects in [Spec, EP].

Note, however, that the postverbal subject position is available not only for indefinite subjects but also for definite subjects, as shown in (54) below. ${ }^{43}$

${ }^{40}$ Heidi Quinn (p.c.) pointed this out for me. The examples (52) and (53) are hers.

${ }^{41}$ The sentences (53b) and (53d) are acceptable with contrastive stress on the subjects.

${ }^{42}$ Note that I have used the same argument for the structural hierarchy between wa-marked and $g a$-marked subjects in 4.3 .5 above.

${ }^{43}$ Elizabeth Pearce (p.c.) pointed out for me that while we can assume that $i s$, an auxiliary, raises to I (or an equivalent functional head), we cannot assume that arrived, a verb, raises. This creates a problem for the view that the post-verb argument is in [Spec, EP], which is above the VP.

Considering the contrast between unaccusatives and unergatives in the possibility of the subject being post-verbal (see footnote 36 above), it is reasonable to assume that the unaccusative subject is in the Theme position, while the unergative subject is in the highest Spec-type position within the VP, as illustrated in (i) and (ii) below.

(i) [vp

(ii) $[\mathrm{vP}$ [arrived] a/the teacher ] [shouted]] <unaccusative>

$<$ unergative> 
Although (54b) is often excluded or given a highly marked status, it is acceptable when uttered in an appropriate context. Essentially, whether marked as definite or indefinite, the postverbal subjects convey now information to the current discourse. That is, the referents of the postverbal subjects are suddenly brought into the current discourse, and therefore give rise to a vivid dynamic interpretation.
a. Here comes a teacher.
b. Here comes the teacher.

The difference between (54a) and (54b) is that the interlocutors are assumed to have no knowledge about the teacher in (54a), but to have some previous knowledge about the teacher in (54b). Importantly, even in the case of (54b), though the interlocutors should know who the teacher refers to, they should not have been talking about the teacher when the sentence is uttered. ${ }^{44}$ The occurrence of here in (54) above is explained by assuming that the subjects conveying new information appear in [Spec, EP], leaving [Spec, WP] available for here. Thus, the distinction that really counts is not that between definite and indefinite subjects but that between familiar and novel referents in the current discourse.

In that the referents of postverbal subjects are suddenly brought into the current discourse, and therefore give rise to a vivid dynamic interpretation, postverbal subjects in English correspond to ga-marked subjects in Japanese. In fact, the Japanese equivalents to the English sentences with sentence-initial there and here necessarily have ga-marked subjects, as shown in (55)-(58)

${ }^{44}$ If they were talking about the teacher, (i) instead of (54b) would be uttered.

(i) Here he comes.

Interestingly, when the subject is a pronoun, it does not appear in the postverbal position but in the preverbal position.

As a way of explaining such a contrast between (54b) and (i) above, I suggest that the pronoun subject he in (i) appears in [Spec, WP] as it conveys old information (just like wamarked subjects in Japanese), while the teacher in (54b) appears in [Spec, EP] as it conveys new information (just like ga-marked subjects in Japanese). However, in (i) above, since [Spec, WP] is occupied by he, here must be in a position higher than [Spec, WP], while in (54b) here is assumed to be in [Spec, WP] since the teacher is in [Spec, EP]. 
below. ${ }^{45,46,47}$ (The hashes on -wa simply indicate that with $-w a$ the Japanese sentence is not a correct translation for the English sentence.)

(55) There is a cricket on the table.

$$
\begin{array}{clll}
=\begin{array}{ll}
\text { Koorogi-\#wa/ga } \\
\text { cricket }
\end{array} & \begin{array}{l}
\text { teeburu-no } \\
\text { table-of }
\end{array} & \begin{array}{l}
\text { ue-ni } \\
\text { top-at }
\end{array} & \text { be(anmt)-Pres } \\
&
\end{array}
$$

(56) Here comes a/the teacher.

$=$ Sensei-\#wa/ga ku-ru.

teacher come-Pres

(57) There arose a storm.

$$
\begin{array}{ll}
=\begin{array}{ll}
\text { Arashi-\#wa/ga } \\
\text { storm }
\end{array} & \begin{array}{l}
\text { oki-ta. } \\
\text { arise-Past }
\end{array}
\end{array}
$$

(58) There goes the dinner bell!

$$
\begin{aligned}
& \text { = Shokuji-no-beru-\#wa/ga nat-tei-ru. } \\
& \text { meal-of-bell ring-Prog-Pres }
\end{aligned}
$$

The above suggests that postverbal subjects in English referring to novel referents in the discourse correspond to $g a$-marked subjects in Japanese which occupy the lower subject position, i.e., [Spec, EP]. However, it is not always the case that subjects referring to novel referents occupy a postverbal position in English. For example, in John is eating some popcorn, the referent

${ }^{45}$ Note that these sentences with sentence-initial there and here can be paraphrased without there and here, as shown in (47) above and (i)-(iii) below.

(i) a. Here comes a/the teacher.

b. A/The teacher is coming.

(ii) a. There arose a storm.

b. A storm had arisen.

(iii) a. There goes the dinner bell!

b. The dinner bell is ringing!

${ }^{46}$ While (55) is an existential sentence, (56)-(58) are not. 
of John may be either familiar or novel in the current discourse and the sentence accordingly yields either the static present interpretation or the dynamic progressive interpretation. However, regardless of the distinct interpretations, the subject John is necessarily preverbal.

(59) John is eating some popcorn.

a. = John-wa poppukoon-o tabe-tei-ru.

b. = John-ga poppukoon-o tabe-tei-ru.

According to the strong hypothesis, we can conceive of two distinct syntactic representations for the two possible readings, as shown in (60) below. The representation (60a) with the subject in [Spec, EP] is supposed to yield the dynamic progressive interpretation, because the subject in [Spec, $E \mathrm{P}]$ is taken as a temporal manifestation of an individual, i.e., a stage of John. It corresponds to the Japanese equivalent with a ga-marked subject. On the other hand, the representation $(60 \mathrm{~b})$ with the subject in [Spec, WP] is cunnosed to vield the static nresent interpretation, because the subject in

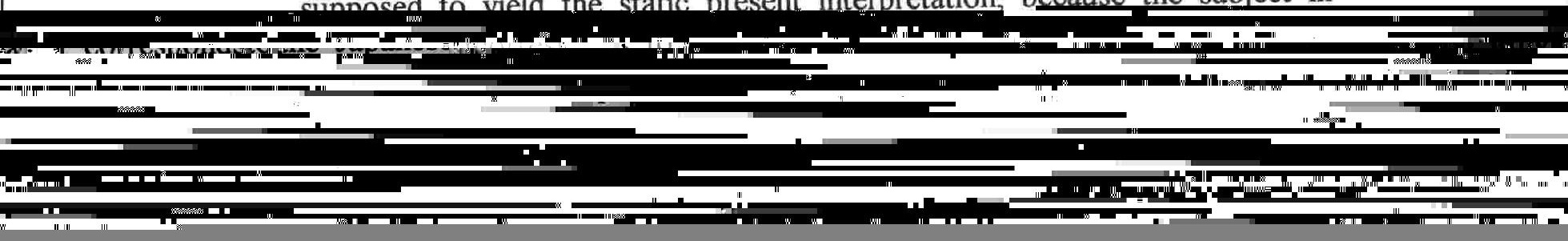


raises directly from the VP-internal (or predicate-internal) position to [Spec, $W \mathrm{P}$ ], skipping [Spec, EP]. In (61b), on the other hand, the subject raises to [Spec, WP] via [Spec, EP], checking the semantic properties of $E$.

(61) John is eating some popcorn.
a. [WP $\mathrm{John}_{\mathrm{i}}$ is $[E \mathrm{P}$
[ $t_{\mathrm{i}}$ eating some popcorn.]]]
b. [ $\mathrm{WP}_{\mathrm{P}} \mathrm{John}_{\mathrm{i}}$ is $\left[\mathrm{EP}^{\mathrm{P}}\right.$
$t_{\mathrm{i}}^{\prime} \quad\left[t_{\mathrm{i}}\right.$ eating some popcorn.]]]

Crucially, no matter whether we adopt the strong or the weak hypothesis, the two readings are associated with the two distinct configurations of temporal structure, i.e., one with $W_{[+]}$and $E_{[-]}$and one with $W_{[+]}$and $E_{[++}$, as shown in (62) below. The difference between the strong and the weak hypotheses is a possible parametric variation in the EPP features of $W$ and $E$.
(62)a. $[W P[W[+][E P[E[-]]]]]$
$\mathrm{R}=\mathrm{E} / \mathrm{View}_{\text {all }}$

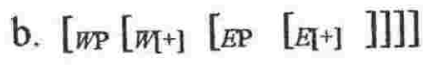
$\mathrm{R}=\mathrm{S} / \mathrm{View}_{\text {part }}$

Thus, even if with some parametric variations, the functional projections, $W \mathrm{P}$ and $E \mathrm{P}$, and the essential syntactic mechanisms operating therein seem tenable across languages.

\subsection{Implication for the first language acquisition}

Lastly, I would like to consider an implication of my analysis for the first language acquisition. Shirai (1997) points out that a young Japanese child (Aki, Miyata 1995) uses the so-called past tense marker -ta to encode completed aspect but not to encode past tense. (I also observed the same, though informally, in the earliest stages of my son's linguistic development.) There has also been a report cited in Shirai that Polish children at around age 1 and 2 cannot use past tense forms to encode pastness but to encode aspect 
such as completion, result-state, punctuality, etc. Such observations have led to the Aspect Before Tense Hypothesis (e.g., Bloom, Lifter \& Hafitz 1980), which has often been attributed to children's cognitive immaturity, i.e., the lack of the concept of temporal displacement (e.g., Antinucci and Miller 1976).

Shirai (1997) takes on board the proposal of Bybee et al. (1994) that many so called past tense markers are in the process of grammaticization (e.g., Romance, German, where the perfect forms of 'have/be + participle' are grammaticizing into past tense markers). Assuming that this grammaticization process is universal, Shirai takes the Japanese past tense form -ta as being in the process of grammaticizing into a past tense marker. This then suggests that children's language acquisition takes the same path as the grammaticization process, i.e., perfect $\rightarrow$ past.

In the system I am proposing, the denotation of -ta is consistent, i.e., 'S $>\mathrm{E}^{\prime}$ or 'completed', which is broadly motivated by a principle of economy. The interpretive difference between completed aspect and past tense derives from the presence/absence of $e$ in $E$, in the temporal structure of a clause. Early uses of the - $t a$ form for completed aspect (i.e., perfect) but not for past tense suggest that $e$ is always present in the temporal structure of a clause that young children utter. That is, young children possess $e$ in their linguistic apparatuses. This further suggests that $e$ is part of the universal grammar innate to human beings and we have it without acquiring it. Then, what we have to acquire is not to have $e$.

I have been assuming that the functional category $E$ is always present in the phrase structure of a clause, while the semantic content, $e$, may or may not be present in $E$. As suggested by young children's speech, I assume that $E$ originally contains $e$. That is, we are naturally equipped with $E$ which has $e$ in it. And as we develop, we learn to deactivate this $E$ by dropping $e$.

This also conforms to the cognitive development of children. With $e$ in $E$, a clause is anchored by $e$ to a spatiotemporal location of (typically) where the speaker is at. The situation described in such a clause is concrete and visible to the speaker. This concreteness and visibility of a situation makes it 
easy for young children to understand and generate a clause with $e$. On the other hand, in the absence of $e$ in $E$, a clause is solely anchored by $\omega$ to a world. The situation described in such a clause is conceptual and invisible to the speaker. In understanding and generating a clause without $e$, it is necessary that the child can abstract away from the spatiotemporal location where he/she is at. Precisely due to this abstractness of a situation anchored not to a spatiotemporal location but only to a world, not having $e$ is cognitively harder than having $e$ especially for young children. ${ }^{48}$

\subsection{Conclusions}

In this chapter, I have proposed the phrase structure of tense made up of a series of functional projections, WP and $E \mathrm{P}$, which encode the distinction between the two types of $\mathrm{R}$ (or viewpoint aspect) and enable us to see the mechanisms to account for $w a / g a$-marking of subjects in Japanese. Roughly, the upper temporal category $W$ contains the semantic feature responsible for the $\mathrm{R}=\mathrm{E}\left(\mathrm{View}_{\text {all }}\right)$ interpretation and the lower temporal category $E$ contains the semantic feature responsible for the $R=S\left(V_{i e w_{p a r t}}\right)$ interpretation.

As temporal categories, $W$ and $E$ have T-features (to be checked by the relevant features of predicates) and D-features (to be checked by the relevant features of DPs) but their T- and D-features need to be checked only when $W$ and $E$ are activated semantically and syntactically. Activated $W$ and $E$ attract predicates (presumably from $\mathrm{V}$ or the predicate head) in order to have their T-features checked by their features and subject DPs presumably from a VPinternal (or predicate-internal) position to their Spec positions in order to have their $\mathrm{D}$-features checked by their features through Spec-head agreement.

While the T-features of $W$ and $E$ checked by predicates give rise to the $\mathbf{R}=\mathrm{E}$ and the $\mathbf{R}=\mathrm{S}$ interpretation respectively, the $\mathrm{D}$-features of $W$ and $E$

\footnotetext{
${ }^{48}$ What may follow from this is that the first and second person subjects are similarly hard for young children. Recall the discussion in 4.5 above that the first and second person subjects necessarily refer to whole individuals which transcend the confine of speech situation and are associated with the absence of $e$.
} 
checked by subject DPs make the DPs taken as referring to spatiotemporally transcending whole individuals (i.e., 'individuals') and spatiotemporally bounded manifestations of individuals (i.e., 'stages') respectively. Assuming that those subjects appearing in [Spec, WP] and taken as referring to 'individuals' are wa-marked and those appearing in [Spec, $E \mathrm{P}$ ] and taken as referring to 'stages' are $g a$-marked in Japanese, $w a$-marked and $g a$-marked subjects are licensed by the D-features of $W$ and $E$ respectively. The correlation between wa/ga-subjects and the two types of temporal and aspectual interpretations obtained for the clauses is thus explained by the Tand $\mathrm{D}$-features of $W$ and $E$, which are respectively responsible for the two types of temporal and aspectual interpretations and for licensing of wamarked and ga-marked subjects. Importantly, the T- and D-features of $W$ and $E$ assure that subjects and predicates of the same semantic type are properly paired and, as an interesting consequence of my analysis, the distinction between stage- and individual-level predicates is encoded in the phrase structure of tense.

As a system to syntactically account for the stage-/individual-level distinction, my analysis is compared with the previous analyses of Kratzer (1989) and Diesing (1992). While maintaining the spirit of those previous analyses, my analysis exhibits both empirical and theoretical advantages in terms of (i) the origin of the distinction: lexicon vs. syntax, (ii) the link between syntax and semantics, (iii) the level of representation, (iv) the "aboutness" relation, and (v) stage- and individual-level predicates in the temporal structure.

Moreover, my analysis that $w a$ - and ga-marked subjects in Japanese are associated with the two functional projections making up a temporal structure (i.e., WP and EP) is very much akin to Davis' (1998) proposal which also considers subject licensing to depend on a temporal structure. Comparing Davis' (1998) person split between $1 \& 2$ subjects and 3 subjects and the $w a / g a$-split of subjects in Japanese, I have argued that the properties that really distinguish between the two classes of subjects associated with two temporal projections are the referential familiarity vs. novelty in the discourse and the totality vs. temporality of the referent in our perception, which are closely interrelated. 
Following this, I have shown that the proposed two syntactic positions for subjects are tenable across languages, even where there is only a limited distinction of two kinds of subjects, as observed in English. In addition, the proposed analysis has an interesting implication for the first language acquisition. 


\section{Chapter 5}

\section{$W a / g a$-subjects in subordinate clauses}

In Chapter 4, I have proposed that $w a$ - and ga-marked subjects are associated with the functional projections, $W$ and $E$, respectively. This chapter examines how my system can be applied in subordinate clauses, because $w a-$ and $g a$-markings of subjects differ in matrix and subordinate clauses. Since a comprehensive account for subordinate clauses goes well beyond the scope of this thesis, I investigate some of the clearly distinct types of subordinate clauses particularly just to provide some indications of how my system can be applied in subordinate clauses.

In 5.1, I first summarise puzzling differences between matrix and subordinate clauses in $w a$ - and $g a$-markings of subjects in Japanese, which need to be accounted for in this chapter. I also briefly outline the basic ontological distinction between "propositions" and "states of affairs" and the further distinction between "concrete (dynamic) states of affairs" and "abstract (non-dynamic) states of affairs", as discussed in Svenonius (1994), which constitute the backbone of the following discussions.

Section 5.2 examines the specifications of $W$ and the possibility of wamarking of subjects in subordinate clauses. I begin by distinguishing between factive and non-factive clauses. Factive clauses are not to be evaluated for their truth, and therefore lack their own anchor $\omega$. Their $W$ is specified as anaphoric (represented as $W_{\text {[ana] }}$ ) and controlled by the $\omega$ in the higher (i.e., main clause) $W$. On the other hand, non-factive clauses are to be evaluated for their truth independently of the main clauses, and therefore have their own anchor $\omega$, i.e., $W_{[+]}$. By contrast, subordinate clauses expressing states of affairs totally lack an anchor and therefore there $W$ is deactivated, i.e., $W_{[-]}$. $W a$-marking of subjects is only possible with $W_{[+]}$, but not with $W_{[\text {ana] }}$ and $W_{[-]}$.

Having examined the specifications of $W$ and the possibility of $w a-$ marking of subjects, Section 5.3 turns to the specifications of $E$ and the 
possibility of $g a$-marking of subjects in subordinate clauses. I begin by distinguishing between stage- and individual-level clauses. Stage-level clauses exemplified by the complement clauses of perception and contact verbs have $E_{\left[^{+}\right]}$as they have a specific spatiotemporal location $e$. On the other hand, individual-level clauses exemplified by the complement clauses of the socalled epistemic verbs have $E_{[-]}$as they totally lack a spatiotemporal location. In addition to the distinction between clauses with $E_{[+]}$and $E_{[-]}$, there are some subordinate clauses which are neither precisely stage-level nor individual-level, as exemplified by the complement clause of the so-called emotive verbs. Those subordinate clauses describe states of affairs with an unspecified spatiotemporal location, i.e., abstract states of affairs, in contrast to concrete states of affairs with a specified spatiotemporal location described by stage-level clauses. Subordinate clauses describing abstract states of affairs have $E_{[\mathrm{un}]}$ (with an $e_{\mathrm{un}}$ which stands for an unspecified spatiotemporal location). Assuming that $E_{[u n]}$ is syntactically as active as $E_{[+]}$, it provides an account for the unexpected $g a$-marking of subjects in some subordinate clauses. That is, ga-marking of subjects is possible with both $E_{[+]}$and $E_{[\text {un]. }}$.

Finally, Section 5.4 puts together the two sets of findings from 5.2 and 5.3 below, to give us four distinct configurations of subordinate tense structure. While some differences between main and subordinate clauses are noted, basically the same mechanisms operate in the same functional structure in both main and subordinate clauses. That is, wa- and ga-markings of subjects are associated with the semantic properties of the functional heads $W$ and $E$ in subordinate clauses as well.

\subsection{The subordinate puzzle}

It is well known that $w a$ - and ga-markings of subjects differ in matrix and subordinate clauses. The difference has often been addressed in terms of the interpretations of ga-marked subjects, or the availability of the neutral interpretation of ga-marked subjects (e.g., Kuno 1973, Kuroda 1987, Shirai 
1986). The sentence (1) below is ambiguous because the ga-marked subject may receive one of the two interpretations, i.e., the neutral and the focus interpretations, as I note in Chapter 1. However, this ambiguity disappears with a certain type of predicate, as in (2). (The hash indicates that the neutral interpretation is not available.)

\section{(1) John-ga ki-ta. \\ come-Past}

'John has come.' <neutral $>$

'It is John who came.' <focus $>$

(2) John-\#ga gakusei da

student Cop(Pres)

'It is John who is a student.' < focus>

Kuno (1973) states that a ga-marked subject can receive a neutral reading if the predicate represents "an objectively observable action, existence, or temporary state as a new event" (p. 50). On the other hand, if the predicate represents "a stable state", a ga-marked subject cannot receive the neutral interpretation, and therefore the focus (exhaustive-listing) interpretation is forced. Subsequently, such a division of predicates has been expressed in terms of the stage- and individual-level distinction (e.g., Shirai 1986, Heycock 1994). That is to say that with an individual-level predicate, a ga-marked subject can only receive the focus interpretation. or a [Stage/Visible] situation as discussed in 3.above

However, when the sentence is embedded, the same $g a$-marked subject of an individual-level predicate can receive the neutral interpretation most naturally, as shown in (3) and (4).

$\begin{array}{llll}\text { (3) John-ga } & \begin{array}{l}\text { gakusei dat-ta-ra, Mary-wa } \\ \text { student Cop-Past-if }\end{array} & \begin{array}{l}\text { kyoomi-o } \\ \text { interest-Acc }\end{array} & \begin{array}{l}\text { mota-nai- } \\ \text { have-Neg- }\end{array}\end{array}$ daroo. probably

'If John was a student, Mary would not be interested (in him).'

(4) Mary-wa John-ga gakusei da toyuu koto-o wasure-tei-ta. student Cop Comp fact-Acc forget-Prog-Past 'Mary forgot that John is a student.' 
The fact that in embedded clauses a ga-marked subject can receive the neutral interpretation even with an stative, individual-level predicate has been seen as a puzzle because it has been believed that the availability of the neutral interpretation of a $g a$-marked subject is conditioned by the type of the predicate and that the type of a predicate is lexically determined (e.g., Kuno 1973, Kuroda 1987, Shirai 1986). That is, in (3) and (4) above, due to the stative, individual-level predicate, gakusei da 'to be a student', the ga-marked subjects are not expected to be able to receive the neutral interpretation.

Heycock (1994) has provided an account for this contrast between main and embedded clauses in the availability of the neutral interpretation of a gamarked subject with an individual-level predicate. She takes this as a matter of focus projection. She explains why $g a$-marked subjects with individual-level predicates are forced to be construed as being in focus in main clauses, while they can receive a neutral reading in subordinate clauses, by appealing to Valluduvi's (1992) I[nformation] Structure.

However, the subordinate puzzle described in terms of the interpretations of $g a$-marked subjects above can also be described in terms of a contrast between $w a$ - and ga-markings of subjects in matrix and subordinate clauses. Observe that to express that John is a student, the matrix clause takes a wa-marked subject as shown in (5) below, while many subordinate clauses including those in (3) and (4) above take ga-marked subjects. When the wamarking of the subject in (5) is explained as due to the type of the predicate, gakusei da 'to be a student', it is perplexing that the same predicate takes a $g a$-marked subject (to yield the neutral interpretation) when embedded in subordinate clauses as in (3) and (4) above.

(5) John-wa/\#ga gakusei da

'John is a student.'

student Cop(Pres)

In my view, however, it seems that the assumption that the availability of wa- and ga-marked subjects (with the neutral interpretations) is conditioned by the lexically determined predicate type creates the subordinate 
puzzle. That is, if we overthrow this assumption, we are free from the puzzle (though the assumption contains an important generalization which holds true in most matrix clauses).

In my analysis, we do not assume that $w a$ - and $g a$-markings of subjects depend on the lexically determined types of predicates, though it is true that some predicates typically take wa-marked subjects (i.e., the so-called individual-level predicates or [-Stage/Visible] situations). Rather, wa- and $g a-$ markings of subjects are associated with the functional projections, WP and $E \mathrm{P}$, or more precisely the semantic contents of $W$ and $E$, which may be present or absent in a given clause. In this light, the availability of $w a-$ and $g a-$ marked subjects with the neutral interpretations is expected to be ascribed to the presence and absence of the semantic content of $W$ and $E$, i.e., whether $W$ and $E$ are respectively activated or deactivated in a given clause. In other words, a difference in the wa/ga-marking of subjects observed between matrix and subordinate clauses suggests a difference in the configurations of their temporal structure.

To explore differences and similarities between matrix and subordinate clauses, I investigate some of the clearly distinct types of subordinate clauses. I largely rely on the basic ontological distinction between "propositions" and "states of affairs" and the further distinction between "concrete (dynamic) states of affairs" and "abstract (non-dynamic) states of affairs", as discussed in Svenonius (1994). According to Svenonius, a proposition is translated into an information unit, which consists of a proposition plus an "anchor". An anchor specifies the context in which the proposition is to be evaluated. I take this as corresponding to $\omega$ in $W$ in my system. On the other hand, a "state of affairs" is considered as a pair consisting of a spatiotemporal location and a situationtype. A spatiotemporal location is taken as corresponding to $e$ in $E$ in my system. Importantly, a spatiotemporal location may be specified or unspecified. A state of affairs with a specified spatiotemporal location is dynamic or concrete, whereas a state of affairs with an unspecified spatiotemporal location is non-dynamic or abstract. Thus, there will be two different kinds of $e$, i.e., specified and unspecified. 


\subsection{Subordinate $\boldsymbol{W}$}

\subsubsection{Subordinate clauses expressing propositions}

I begin by examining subordinate clauses expressing propositions. To repeat, Svenonius (1994) sees a proposition as an information unit consisting of a proposition plus an anchor. Say that a sentence $\mathrm{P}$ translates into a proposition $\phi$. If uttered in the context $w_{R}$, which stands for the "real world", then the complete information unit represented by $\mathrm{P}$ in that context can be modelled as in (6a) below, where A signifies 'assert,' and the proposition is added to the anchor, $w_{R}$. According to Svenonius, there are other modes of anchoring, for example, 'presuppose' which could be represented as in (6b) when $\phi$ is presupposed in $w_{R}$.
(6) a. $A\left(w_{R}, \phi\right)$
b. $\Pi\left(w_{R}, \phi\right)$

However, I perceive a significant difference between asserted and presupposed propositions. While asserted propositions are necessarily to be evaluated for their truth, presupposed propositions are not, simply because they are presupposed to be true. In this section, I elucidate the difference, which will have an important bearing on the specification of $W$ and in turn the possibility of $w a$-marking of subjects .

\subsubsection{Factive and non-factive clauses}

Firstly, consider the interpretation of a sentence embedded in a sentential subject in (7) below. In order for the sentences in (7) to be true, it must be the case that senators actually take bribes in (7a) and that Jason has actually made cookies in (7b). In other words, the truth of the embedded sentences is a necessary condition for the truth or falsity of the sentences in (7).

(7) a. That senators take bribes disturbs me. 
b. That Jason has made cookies makes sense. (Svenonius 1994: 77)

Observe in (8) below that the negation of the embedded sentences gives rise to a contradiction for the sentences in (7). Moreover, the negation of the embedded sentences also contradicts the negation of the whole sentence in (7), as shown in (9) below.

(8) a. * That senators take bribes disturbs me, but senators do not take bribes.

b. * That Jason has made cookies makes sense, but Jason has not made cookies.

(9) a. * That senators take bribes does not disturb me, but senators do not take bribes.

b. * That Jason has made cookies does not make sense, but Jason has not made cookies.

With the notion of presupposition, which is defined as in (10) below, ${ }^{1}$ we can say that the sentences in (7) above presuppose the embedded sentences. In (7a), for example, if it is true that senators take bribes disturbs me or that senators take bribes does not disturb me, it is true that senators take bribes.

(10)A sentence A presupposes a sentence B if:

a. A entails B

b. $\sim$ A entails B

(Suzuki 1993: 14)

We can observe the same with some complement CPs. In (11) below, the truth of the complement CPs, i.e., that Mary had left, is presupposed to be true. Therefore, the negation of the embedded sentence contradicts the

${ }^{1}$ Entailment is defined as in (i):

(i) A sentence A entails a sentence B iff in all worlds in which A is true, B is true.

(Suzuki 1993: 13) 
sentences in (11), as shown in (12) below, and also with the negation of the whole sentences in (11), as shown in (13) below .

(11)a. John regretted that Mary had left.

b. John remembered that Mary had left.

c. John was glad that Mary had left.

(Kuno 1973: 213)

(12)a. *John regretted that Mary had left, but in fact Mary had not left.

b. *John remembered that Mary had left, but in fact Mary had not left.

c. *John was glad that Mary had left, but in fact Mary had not left.

(13)a. *John did not regret that Mary had left, but in fact Mary had not left.

b. *John did not remember that Mary had left, but in fact Mary had not left.

c. *John was not glad that Mary had left, but in fact Mary had not left.

By contrast, the sentences in (14) below are interpreted without any presupposition of the truth of the subject CPs. Observe in (15) and (16) below that the negation of the embedded sentences does not contradict the sentences in (14) nor the negation of the whole sentences in (14).

(14)a. That the earth is flat was widely believed until recently.

b. That Clinton will run for re-election is likely.

(Svenonius 1994: 77)

(15)a. That the earth is flat was widely believed until recently, but the earth is not flat.

b. That Clinton will run for re-election is likely, but actually he will not run for re-election. 
(16)a. That the earth is flat was not widely believed until recently, and actually the earth is not flat.

b. That Clinton will run for re-election is not likely, and actually he will not run for re-election.

Similarly, the sentences in (17) below are interpreted without any presupposition of the truth of the complement CPs. Therefore, the negation of the embedded sentences does not contradict the sentences in (17) nor the negation of the whole sentences in (17), as shown in (18) and (19) below.

(17)a. John thought that Mary had left.

b. John heard that Mary had left.

c. John asserted that Mary had left.

(Kuno 1973: 213-214)

(18)a. John thought that Mary had left, but in fact Mary had not left.

b. John heard that Mary had left, but in fact Mary had not left

c. John asserted that Mary had left, but in fact Mary had not left.

(19)a. John did not think that Mary had left, and in fact Mary had not left.

b. John heard that Mary had left, but in fact Mary had not left

c. John did not assert that Mary had left, and in fact Mary had not left.

As first noted by Kiparsky \& Kiparsky (1970), whether the truth of an embedded clause is presupposed or not depends (at least partly) on the matrix predicate. Those predicates listed in (20a) below presuppose the truth of their sentential subjects or objects and are called factive predicates. On the other 
hand, those predicates listed in (20b) below do not require the truth of their sentential subjects or objects and are called non-factive predicates. ${ }^{2,3,4}$

a.

Factive
significant
odd
tragic
exciting
relevant
matters
counts
makes sense
suffices
amuses
bothers

regret
be aware (of)
grasp
comprehend
take into account
bear in mind
ignore
make clear
mind
forget (about)
deplore
resent
care (about)

b. Non-factive

$\begin{array}{ll}\text { likely } & \text { suppose } \\ \text { sure } & \text { assert } \\ \text { possible } & \text { allege } \\ \text { true } & \text { assume } \\ \text { false } & \text { claim } \\ \text { seems } & \text { charge } \\ \text { appears } & \text { maintain } \\ \text { happens } & \text { believe } \\ \text { chances } & \text { conclude } \\ \text { turns out } & \text { conjecture } \\ & \text { intimate } \\ & \text { deem } \\ & \text { fancy } \\ & \text { figure }\end{array}$

(Kiparsky and Kiparsky 1970: 143-145)

\footnotetext{
${ }^{2}$ Kiparsky and Kiparsky (1970) also note that some verbs occur indifferently with both factive and non-factive complements, e.g., anticipate, acknowledge, suspect, report, remember, emphasize, announce, admit, deduce.

${ }^{3}$ I expect that semantically equivalent predicates in other languages (including Japanese) would be similarly classified, and I will show this in my Japanese examples, as I proceed.

${ }^{4}$ Kiparsky and Kiparsky (1970: 146) show that this semantic distinction between factive and non-factive predicates correlates with various syntactic differences in English. For example, only factive predicates allow gerundial constructions and extraposition, whereas only non-factive predicates allow subject raising and the accusative and infinitive construction.
} 


\subsubsection{Factive and non-factive clauses in Japanese}

The factive and non-factive distinction has been applied to Japanese data to explain the choice between koto and to to head subordinate clauses (Kuno 1973). Essentially, subordinate clauses are headed by koto (which means 'fact') if their truth is presupposed, and by to if their truth is not presupposed. For example, the clause 'that Japanese is difficult' is headed by koto in (21a), where it is the complement of a factive predicate manabu 'learn' and its truth is presupposed. On the other hand, in (21b), the same clause is headed by to, because it is the complement of a non-factive predicate $i u$ 'say' and its truth is not presupposed.
(21)a. John-wa nihongo-ga muzukasii koto-o/*to manan-da. Japanese difficult -Acc learn-Past
'John learned that Japanese is difficult.'

b. John-wa nihongo-ga muzukasii to/ ${ }^{*} k o t o-0$ it-ta. Japanese difficult -Acc say-Past 'John said that Japanese is difficult.'

(Kuno 1973: 213)

Some predicates can take both a koto-clause and a to-clause as their complement. Those predicates are interpreted as either factive or non-factive, depending on whether their complement clause is headed by koto or to, as illustrated in (22). ${ }^{5}$
(22)a. John-wa Mary-ga baka na koto-o nagei-ta. stupid Cop -Acc deplore-Past
'John deplored the fact that Mary was stupid (she was stupid).'

b. John-wa Mary-ga baka da to nagei-ta. stupid Cop deplore-Past

'(Lit.) John deplored that Mary was stupid (she might or might not have been stupid).'

(Kuno 1973: 216)

\footnotetext{
${ }^{5}$ In fact, even those predicates which are classified as factive or non-factive based on their typical usage can take both to-clause and koto-clause, as Suzuki (1993) points out. This suggests that Japanese predicates are not lexically specified as factive, non-factive, or indifferent. It rather seems that the choice of complementizer is determined by "the degree of the speaker's conviction" about the truth of a clause (Suzuki 1993), according to which a clause may be factive or non-factive.
} 


\subsubsection{The differing possibility of $w a$-marking of subjects}

When the choice between koto and to is under investigation, it is reasonable that not much attention is paid to wa/ga-marking of subjects. This is however our main concern. In fact, if we pay proper attention to $\mathrm{wa} / \mathrm{ga}$ marking of subjects in subordinate clauses, we can observe a correlation between $w a / g a$-marking of subjects and the factivity of the clauses.

In Kuno's examples in (21) and (22) above, the subjects of the subordinate clauses are all marked with - $g a$, no matter whether the clauses are taken as factive or non-factive. In a factive subordinate clause, it is true that it has to be $-g a$ that marks the subject (to yield the neutral interpretation). That is, wa-marking of the subject cannot be interpreted neutrally or is rather ungrammatical in a factive subordinate clause, as indicated by the hash in (23a) and the asterisk in (24a) below. In a non-factive subordinate clause, however, the subject can also be marked with $-w a$ (to yield the neutral interpretation). In fact, the ga-marked subjects of non-factive subordinate clauses in Kuno's examples are not taken neutrally but as being in focus, which I indicate with hashes in (23b) and (24b) below. (I.e., It is Japanese but not Chinese or any other language that is difficult.)

(23)a. John-wa nihongo-\#wa/ga muzukasii koto-o manan-da. Japanese difficult -Acc learn-Past 'John learned that Japanese is difficult.'

b. John-wa nihongo-wa/\#ga muzukasii to it-ta. Japanese difficult say-Past

'John said that Japanese is difficult.'

(Kuno 1973: 213)

(24)a. John-wa Mary-*wa/ga baka na koto-o nagei-ta. stupid Cop -Acc deplore-Past

'John deplored the fact that Mary was stupid (she was stupid).'

b. John-wa Mary-wa/\#ga baka da to nagei-ta. stupid Cop deplore-Past

'(Lit.) John deplored that Mary was stupid (she might or might not have been stupid).'

(Kuno 1973: 216) 
With respect to the possibility of $w a$-marking of subjects, the above data show that sentences embedded in factive koto-clauses cannot have wa-marked subjects, while sentences embedded in non-factive to-clauses can have wamarked subjects. ${ }^{6}$

\subsubsection{4. $W_{\text {[ana] }}$ in factive clauses}

That the differing possibility of wa-marking of subjects is correlated with the distinction between factive and non-factive clauses suggests that the factive and non-factive distinction has a bearing on the capability of $W$ as the licenser of $w a$-marked subjects.

Recall that while $W$ is the world-place, which is assumed to be always present as a functional head in the phrase structure of a clause, $\omega$ is an actual token of a particular world, which may or may not occur in $W$. It is assumed that $\omega$ occurs in $W$ to fix a context in which the truth is to be evaluated (cf. 4.2.2 above). Thus, $\omega$ corresponds to an anchor which specifies the context in which the truth of a proposition is to be evaluated. As an anchor, $\omega$ is necessary in every clause that is to be evaluated for its truth, since the truth can only be evaluated in a certain context (with a certain set of background assumptions of the speaker and hearer regarding the relevant domain of discourse, and so on). ${ }^{7}$ This suggests that when a clause is not to be evaluated for its truth (because it is presupposed to be true), the clause lacks $\omega$ in its $W$.

Now, return to factive clauses as seen in the examples in (11) above, which are repeated in (25) below. Those subordinate clauses occurring with factive predicates are not to be evaluated for their truth, simply because they are presupposed to be true. That is, it is presupposed to be true that Mary had left. Whether it is true or not is not to be evaluated. There is only one

\footnotetext{
${ }^{6}$ About the possibility of ga-marking of subjects, the data in (23) and (24) suggest that the sentences embedded in non-factive to-clauses cannot have neutral ga-subjects, while the sentences embedded in factive koto-clauses must have $g a$-marked subjects. I take up this point later in 5.3, where I discuss the presence and absence of $e$ in subordinate clauses.

${ }^{7} \mathrm{I}$ assume that this is not only true with affirmative sentences but also with interrogative sentences. That is, interrogatives must also be anchored to a certain context, in which what is asked is understood and evaluated. I imagine that the distinction between interrogative and affirmative sentences is made somewhere higher in the structure above WP (presumably in a C-related position).
} 
evaluation of truth for the entire sentence, i.e., whether it is true that John regretted it, remembered it, or was glad about it.

(25) John regretted/remembered/was glad that Mary had left.

If $\omega$ occurs only when the clause is to be evaluated for its truth, then that factive clauses are not to be evaluated for their truth suggests that they do not have their own anchor, $\omega$. Nevertheless, for the truth to be presupposed, there must be a context in which it is presupposed. Factive clauses are presupposed to be true in the context set in which the main clause assertion is to be evaluated. I assume that factive clauses are anchored to the context set fixed by the main clause $\omega$, lacking their own $\omega$. In this sense, factive clauses are parasitic on the main clause $\omega$. I assume that their $W$ is somehow specified as anaphoric and controlled by the $\omega$ in the higher (i.e., main clause) $W$. I represent such $W$ with $W_{\text {[ana], where 'ana' stands for }}$ 'anaphoric'.

$W_{\text {[ana] }}$ is defective because it lacks the real semantic content of $W$, i.e., $\omega$. Without a $\omega$ occurring in $W, W$ is inactive both semantically and syntactically. Therefore, I assume that $W_{\text {[ana] }}$ is incapable as the licenser of $w a$-marked subjects in Japanese. This explains the impossibility of $w a$-marking of subjects in factive clauses.

To verify this, observe in (26) below that to express that John is a student, the matrix clause takes a $w a$-marked subject (a), but that many subordinate clauses take $g a$-marked subjects (b-e) to yield the neutral interpretations. Recall that this differing possibility of $w a$-marking of subjects in matrix and subordinate clauses has been a puzzle, as discussed in 5.1 above.

(26)a. John-wa/\#ga gakusei da.

'John is a student.' student Cop(Pres) 
b. John-\#wa/ga gakusei da kara, Mary-wa

student Cop(Pres) because

hatarak-anakerebanaranai.

work-have to

'Because John is a student, Mary has to work."

c. John-\#wa/gagakusei da toyuu koto-ga bare-ta. student Cop(Pres) Comp fact reveal-Past

'The fact that John is a student has been revealed.'

d. John-\#wa/ga gakusei de yokat-ta. student good-Past

'I am glad that John is a student.'

e. John-*wa/gagakusei no uchi-ni, ryokoo ni ik-oo. student while trip to go-let's

'Let us go on a trip, while John is a student.'

In (26a), John wa gakusei da asserts that John is a student. Whether it is true or not is to be evaluated in the current discourse context set. By contrast, John ga gakusei da/de/no embedded in subordinate clauses in (26be) does not assert that John is a student. In (26b), embedded in a kara(because)-clause, it is presupposed to be true that John is a student. In other words, the sentence (26b) as a whole entails that it is true that John was a student. Therefore, (26b) and the negation of the embedded sentence contradict, as shown in (27).

$\begin{array}{lll}\text { (27)* John-ga gakusei da kara, Mary-wa } & \begin{array}{l}\text { hataraka-nakereba- } \\ \text { student Copbecause }\end{array}\end{array}$ naranaiga, John-wa gakusei ja-nai. but student Cop-Neg

'Because John is a student, Mary has to work, but John is not a student.'

The example (26c) has a koto-clause as its subject. As suggested by the head noun koto, which means 'fact', the truth of the embedded sentence is presupposed. Therefore, (26c) and the negation of the embedded sentence leads to a contradiction, as shown in (28) below. 
(28) *John-ga gakusei da toyuu koto-ga bare-ta ga, John-wa student Cop Comp fact reveal-Past but gakusei ja-nai. studentCop-Neg

'The fact that John is a student has been revealed, but John is not a student.'

Similarly, (29) and (30) below show that (26d) and (26e) are contradictions with the negation of the embedded sentence.

(29)*John-ga gakusei de yokat-ta ga, John-wa gakusei ja-nai. student good-Past but student Cop-Neg

'I'm glad that John is a student, but John is not a student.'

(30) * John-wa gakusei ja-nai ga, John-ga gakusei no uchi-ni, ryokooni ik-oo.

trip to go-let's

'Although John is not a student, let us go on a trip while John is a student.'

Thus, in all of the above cases where subordinate clauses cannot have $w a$-marked subjects to yield the neutral interpretation (though comparable 'stand alone' clauses can), the truth of the embedded sentence is presupposed and hence not to be evaluated. Those subordinate clauses lack their own $\omega$ and their $W$ is specified as anaphoric and controlled by the $\omega$ in the higher (main clause) $W$, for their truth is presupposed in the context set in which the main clause assertion is to be evaluated. Without the real semantic content (i.e., a $\omega), W_{\text {[ana] }}$ is incapable as the licenser of wa-marked subjects. This explains the absence of wa-marked subjects in those subordinate clauses. However, it still remains unexplained why then they are marked with $-g a$. I will return to this issue in 5.4.3. below.

\subsubsection{5. $W_{[+]}$in non-factive clauses}

Let us now turn to non-factive clauses as seen in the examples in (17) above, which are repeated in (31) below. Those subordinate clauses occurring with non-factive predicates are not presupposed to be true. That is, it is not presupposed to be true that Mary had left. John could have thought so, heard 
so, or asserted so even when Mary had not left, and John may not have thought so, heard so, or asserted so even when Mary had left.

(31) John thought/heard/asserted that Mary had left.

Crucially, for sentences like (31), we can have two separate truth values for the main clause and the subordinate clause. That is, it can be true or false that John thought so, heard so, or asserted so, irrespective of whether it is true or false that Mary had left. And it can be true or false that Mary had left, irrespective of whether it is true or false that John thought so, heard so, or asserted so. This suggests that there are two separate truth evaluations; one for the truth of the main clause and the other for the truth of the subordinate clause. Since the truth can be evaluated only in a certain context, each clause must have an anchor, $\omega$, which specifies the context of evaluation. That is, both the main clause $W$ and the subordinate clause $W$ have their own $\omega$ s. The main clause and the subordinate clause are anchored to respective context sets, in which their truths are evaluated. Presumably, the main clause is anchored to and evaluated in the current discourse context set, which consists of the intension of all the previous assertions in the discourse, plus various entailments of those assertions, plus various other salient propositions shared by the interlocutors. On the other hand, the complement clause is evaluated in the context set fixed by the main clause predicate, i.e., John's thought-set, heard-set, assertion-set, and so on. While these sets may be quite similar to the current discourse context set, they may have nothing in common with the current discourse context set. Importantly, the two context sets, to which the main and the subordinate clauses are anchored and in which their truths are evaluated, are independent.

Recall that in (18) and (19) above the negation of the sentence embedded in the complement clause does not contradict the whole sentence nor the negation of the whole sentence. Notice that the embedded sentence is negated not in the context set to which it is originally anchored but in the current discourse context set. That is, the embedded sentence that Mary had 
left is originally anchored to John's thought-set, heard-set, or assertion-set, but when it is negated, it is brought out of the original context and the negation is anchored to the current discourse context set. Since the sentence embedded in the complement clause is anchored to John's thought-set, heardset, or assertion-set, and the truth of the sentence is to be evaluated only in the context set to which it is anchored, negation of the sentence in another context set (namely in the current discourse context set) does not affect the truth or falsity of what is originally said. ${ }^{8}$

A point to note is that the context set to which the complement clause is anchored is fixed by the main clause predicate. In (31) above, the verb think, hear, or assert fixes a context set for the complement clause, i.e., a thoughtset, a heard-set, or an assertion-set (of John). This suggests that a $\omega$ occurring in the complement clause $W$ is related to the main clause verb. As a way of capturing this, Svenonius (1994) assumes that each of those epistemic verbs bears a $\omega$ feature specification, which in particular specifies a context of evaluation, such as John's thought-set and so on. Then, this $\omega$ feature specification of an epistemic verb is somehow copied onto and inherited by the embedded $W$. To provide a mechanism, Svenonius further assumes that Comp and $W$ embedded under an epistemic verb bear $\omega$, which are unspecified, as shown in (32a) below. Through a head-chain formed among $\mathrm{V}$, Comp, and the embedded $W$, the $\omega$ feature specification of an epistemic verb is copied onto the complementizer and then onto the embedded $W$, as shown in (32b).

(32)a. John thought ${ }_{[\omega:<\mathrm{A}, \text { wh }(j)>]}\left[\mathrm{CP}\right.$ that ${ }_{[\omega]}\left[{ }_{\mathrm{WP}}\right.$ Mary $\left[w_{[\omega]}\right]$ had left]].

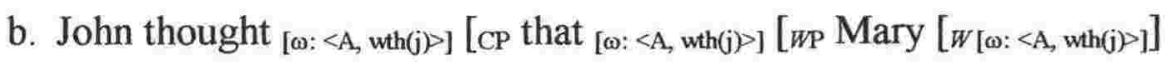
had left]].

(In " $W_{t h}(j)$ ", "w" stands for a world, "th" stands for thought(s), and (j) represents that the external argument is John. Therefore, " $W_{\text {th }}(\mathrm{j})$ " is John's thought-set.) (adapted from (110) in Svenonius 1994: 80)

\footnotetext{
${ }^{8}$ I am indebted to Harry Leder (p.c.) for pointing this out.
} 
Alternatively, we might assume that the crucial distinction between the two types of subordinate clauses is encoded in $\mathrm{C} .{ }^{9}$ In line with Grimshaw's (1979) complement selection, we can assume that the so-called factive verbs subcategorize for or select CP whose head is specified with [+fact] and that non-factive verbs select CP whose head is specified with [-fact]. Furthermore, $\mathrm{CP}$ with $\mathrm{C}[+$ fact $]$ selects $W \mathrm{P}$ with $W_{\text {[ana], }}$ whereas $\mathrm{CP}$ with $\mathrm{C}[-$ fact] selects $W P$ with $W_{[+]}$.

I leave it open as to what the precise mechanism is, the point being that there must be a connection between a $\omega$ occurring in the complement clause $W$ and the epistemic verb in the main clause. ${ }^{10}$

Crucially for our present purpose, non-factive clauses (typically embedded under the so-called epistemic verbs) have their own $\omega$, which specifies the context of evaluation of their own. Since the occurrence of $\omega$ activates their $W$ (i.e., $W_{[+1}$ ) as the licenser of $w a$-marked subjects, it provides a necessary condition for the presence of $w a$-marked subjects in those clauses (though it does not guarantee the occurrence of $w a$-marked subjects by itself).

To verify this, observe in (33) below that non-factive clauses (typically embedded under epistemic verbs) can have wa-marked subjects, with no difference from comparable 'stand alone' clauses. (In fact, ga-marked subjects cannot be interpreted neutrally (just as in root contexts), as indicated by the hashes.)

(33)a. John-wa/\#ga gakusei da.

'John is a student.' student Cop(Pres)

\footnotetext{
${ }^{9}$ Notice that those sets such as John's thought-set and heard-set are not accessible to the interlocutors, unlike the current discourse context set. Since we cannot access those private worlds, to which those subordinate clauses are anchored and in which their truth is to be evaluated, it is actually not possible for us to evaluate the truth of those subordinate clauses (p.c. with Harry Leder). Thus, irrespective of whether we actually evaluate the truth of the clause or not, wherever there is a separate truth value, a $\omega$ occurs.

${ }^{10}$ Note that a connection is between the $\omega$ in the subordinate $W$ and the main clause predicate, not between the $\omega$ s in the main clause $W$ and the subordinate $W$.
} 
b. Mary-wa [John-wa/\#ga gakusei da] to it-ta. 'Mary said that John was a student.'

c. Mary-wa [John-wa/\#ga

$$
\begin{array}{ll}
\text { gakusei da] to } & \text { omot-tei-ru. } \\
\text { student CopComp } & \text { think-Prog-Pres }
\end{array}
$$

'Mary thinks that John is a student.'

$\begin{array}{llll}\text { d. [John-wa/\#ga } & \text { gakusei da] to yuu hanashi da. } \\ \text { student } & \text { CopComp rumour Cop }\end{array}$

'It is rumoured that John is a student/They say that John is a student.'

Crucially, those subordinate clauses have their own $\omega$, which specifies the context of evaluation for their truth independent from the context of evaluation for the truth of the main clauses. While the main clause is anchored to and evaluated in the current discourse context set, the complement clause is anchored to and evaluated in a context set fixed by the main clause, for example, Mary's report-set (consisting of what Mary says) in (33b) above, Mary's belief-set (consisting of what Mary believes) in (33c), and a hearsayset (consisting of what people (generally) say) in (33d).

To support this, (34) below shows that negation of the sentence embedded in the complement clause does not contradict the whole original sentence. Notice that the sentence embedded in the complement clause is anchored to Mary's report-set, belief-set, or a hearsay-set, whereas its negation is anchored to the current discourse context set. Because they are anchored to two distinct context sets, the affirmation and the negation of the same sentence do not contradict.
(34)a. Mary-wa John-wa gakusei da to it-ta ga, John-wa gakusei ja-nai. student CopComp say-Past but student Cop-Neg
'Mary said that John was a student, but he isn't.'

b. Mary-wa John-wa gakusei da to omot-tei-ru ga, John-wa gakusei ja-nai. student CopComp think-Prog-Pres but student Cop-Neg

'Mary thinks that John is a student, but he isn't.' 
c. John-wa gakusei da to yuu hanashi da ga, student CopComp rumour Copbut jitsu-wa gakusei ja-nai. as a matter of fact student Cop-Neg 'They say that John is a student, but as a matter of fact, he isn't.'

Since those subordinate clauses have their own anchor $\omega$, which specifies the context of evaluation, their $W$ is activated, i.e., $W_{[+]}$. This justifies the wa-marking of subjects in those clauses, though it does not guarantee the $w a$-marking of subordinate subjects because if the subordinate $E$ is also activated by the occurrence of $e$, subordinate subjects would rather be gamarked (cf. 4.3 .1 above). The presence and absence of $e$ in subordinate clauses will be discussed in 5.3 below.

\subsubsection{Summary}

In this section, I have examined some of the subordinate clauses expressing propositions. In particular, I have compared factive and nonfactive clauses. Factive clauses are not to be evaluated for their truth, as they are presupposed to be true. Therefore, they lack their own $\omega$. Their $W$ is specified as anaphoric and controlled by the higher $\omega$, for their truth is presupposed in the context set in which the main clause assertion is to be evaluated. I represent it with $W_{\text {[ana] }}$. On the other hand, non-factive clauses are to be evaluated for their truth in a context independent from the matrix clause context of evaluation. Therefore, they have their own $\omega$ in the subordinate $W$ (i.e., $W_{[+]}$), which fixes a context of evaluation of their own.

Factive clauses cannot have $w a$-marked subjects, even if comparable 'stand alone' clauses have wa-marked subjects. This is explained as due to

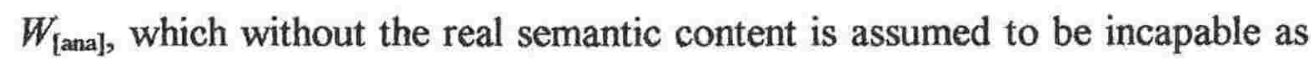
the licenser of wa-marked subjects. On the other hand, non-factive clauses (typically embedded under epistemic verbs) can have wa-marked subjects, with no difference from comparable 'stand alone' clauses. This is justified by $W_{[+]}$, though $W_{\left[^{+}\right]}$by itself does not guarantee the occurrence of $w a$-marked subjects. 


\subsubsection{Subordinate clauses expressing states of affairs}

Having discussed subordinate clauses expressing propositions, in this section I turn to subordinate clauses expressing states of affairs. Importantly, states of affairs are not anchored in the way that propositions are. Unlike propositions, states of affairs totally lack an anchor, which specifies the context in which the truth is evaluated.

\subsubsection{Complement clauses of perception verbs}

States of affairs are most typically exemplified by the complement clauses of verbs of physical perception and verbs of physical contact or approach, as seen in (33) below. ${ }^{11}$ In Japanese, the complement clauses of this class of verbs are characteristically headed (and nominalized) by no or tokoro but not by koto. Concerning the uses of no and koto, Kuno (1973), Lewis (1976), and Horie (1990) among others explain that no nominalizes clauses which describe concrete events (or direct physical perception), whereas koto nominalizes clauses which describe abstract concepts (or indirect mental perception). ${ }^{12}$ While I do not evaluate how generally such an explanation holds, the characterization of no-clauses as describing concrete events or direct physical perception captures the nature of the complement clauses of verbs of physical perception, contact and approach.

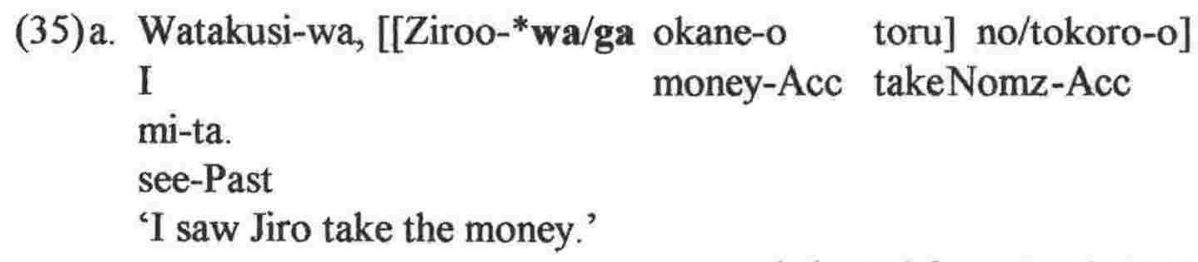

(adapted from Lewis 1976: 318)

\footnotetext{
${ }^{11}$ Note that the examples of states of affairs discussed in this section are all concrete states of affairs. Although states of affairs are distinguished between concrete and abstract states of affairs, the distinction does not seem to make any difference when it comes to the $W$ specification. Therefore, although I only discuss concrete states of affairs in this section, what I say about them, particularly with respect to the $W$ specification, is meant to hold for states of affairs in general. I defer the discussion of abstract states of affairs to 5.3 .3 below.

${ }^{12}$ Kuno (1973), Lewis (1976), and Horie (1990) set only no against koto. It seems that tokoro has not been taken into account.
} 
b. Watakusi-wa [John-*wa/ga Mary-o but-tei-ru no/tokoro -o] mi-ta.

-Acc see-Past

'I saw John hitting Mary.'

(adapted from Kuno 1973: 213)

c. Keikan-wa [[hannin-*wa/ga kuruma-o tome-ta] tokoro-o] policeman criminal car-Acc stop-Past Nomz-Acc taiho-su-ru tumori-da. arrest-do-Pres intention-Cop 'The policeman intends to seize the criminali when he $i$ has stopped the car.'

(adapted from Nakau 1976: 460)

Lewis (1976) claims that the truth of the complement clauses of this class of verbs is "implied". For example, in (35a) above, by asserting that he saw Jiro take the money, the speaker automatically implies that it is true that Jiro took the money. ${ }^{13}$ Karttunen (1970: 335) also observes that excluding the possibility of mistaken perception, see, hear, feel and other similar verbs appear to express a sufficient condition for the truth of the complement sentence. In other words, if it is true that one sees/hears/feels $\mathrm{S}, \mathrm{S}$ is normally taken as true, where $\mathrm{S}$ is the complement sentence. On the other hand, if the speaker did not see Jiro take the money, it is non-committal as to whether Jiro took the money or not. That is, while 'see/hear/feel $\mathrm{S}$ ' entails 'S', 'not see/hear/feel $\mathrm{S}$ ' does not entail ' $\mathrm{S}$ '. Recall now that according to our definition in (10) above, presupposition requires both ' $A$ ' and 'not $A$ ' entail ' $\mathrm{B}$ '. Since the cases with perception verbs do not perfectly fit in with our definition of presupposition, it makes sense to distinguish them as the cases of implication. For presupposed clauses, I have assumed that their $W$ is specified as anaphoric and controlled by the $\omega$ in the higher $W$. For implied clauses, I

\footnotetext{
${ }^{13}$ A question is whether this is due to the fact that the whole sentence is in the past tense. Consider, for example, I am going to see Jiro take the money. Although the sentence is non-committal as to whether Jiro actually takes the money or not (since it is a future event), the speaker believes that Jiro will take the money. In this sense, I take it that non-past sentences can also imply just as well as past tense sentences (cf. (35c) above).
} 
assume that they totally lack an anchor. Without the semantic content $\omega$, their $W$ is specified with - and deactivated. ${ }^{14}$

Notice in (35) above that the subjects of those complements clauses cannot be marked by $-w a$. This is explained as due to $W_{[-]}$, which is incapable as the licenser of $w a$-marked subjects.

\subsubsection{Summary}

To sum up, subordinate clauses are classified into three types according to their $W$ specifications. Subordinate clauses expressing propositions have $W_{\text {[ana] }}$ if they are factive and their truth is presupposed and $W_{[+]}$if they are non-factive and their truth is to be evaluated independently of the main clauses. Subordinate clauses expressing states of affairs have $W_{[-]}$, as they totally lack an anchor. $W a$-marked subjects are only found in clauses with $W_{[+]}$.

$$
W \text { specification licensing of } w a \text {-subjects }
$$

Propositions

factive

ana

non-factive

States of affairs

\subsection{Subordinate $E$}

In the previous section, I have distinguished three types of subordinate clauses in terms of $W$ specifications. In this section, I examine the specification of $E$ in subordinate clauses.

${ }^{14} \mathrm{Or}, W$ may not be even present in this type of subordinate clause. This is highly conceivable especially with perception verbs, which do not seem to take full subordinate clauses. However, for the present I only maintain that in subordinate clauses describing states of affairs $W$ is inactive both semantically and syntactically, leaving it open whether such vacuous $W$ is actually present or absent. 
To recapitulate, while $E$ is the event-place, which is always present as a functional head in the phrase structure of a clause, $e$ is an actual token of an event at a particular spatiotemporal location, which may or may not occur in $E$. The presence or absence of $e$ in $E$ depends on whether a clause describes an eventive or a stative situation, in other words whether a clause is stagelevel or individual-level. When a clause describes an eventive, stage-level situation, $e$ occurs in $E$ to anchor the clause to a spatiotemporal location. On the other hand, when a clause describes a stative, individual-level situation, it is not to be anchored to a spatiotemporal location and therefore $e$ is absent in its $E$ (cf. 4.2 .1 above).

\subsubsection{Stage-level and individual-level clauses}

In 5.2.1.1 above, we have observed that whether the truth of an embedded clause is presupposed or not depends (at least partly) on the matrix predicate. Rather similarly, whether an embedded clause is interpreted as stage-level or individual-level depends (at least partly) on the matrix predicate.

For example, compare the small clause interpretations in (37a) and (37b).

(37)a. I consider the sea green.

b. I saw the sea green.

(Raposo and Uriagereka 1995: 192)

In (37a), the green the speaker considers to hold of the sea is a permanent state of the sea, which characterises the sea. On the other hand, in (37b), the green with which the speaker saw the sea is a temporary state of the sea, which was manifested when he/she saw the sea. Thus, what may look like an identical small clause at first sight receives the individual-level interpretation in (37a), where it is the object of consider, and the stage-level interpretation in (37b), where it is the object of saw.

Typically, a group of verbs, including the so-called epistemic verbs such as say and believe select an individual-level complement clause, whereas 
another group of verbs, including verbs of physical perception and verbs of physical contact or approach, select a stage-level complement clause. ${ }^{15}$ In fact, the former cannot select a stage-level complement clause, and the latter cannot select an individual-level complement clause. According to my analysis, this means that $E$ in the complement clauses of epistemic verbs is deactivated by the absence of $e$, whereas $E$ in the complement clauses of perception and contact verbs is activated by the presence of $e$. In other words, epistemic verbs somehow subcategorize for a clause with $E_{[-]}$, whereas perception and contact verbs somehow subcategorize for a clause with $E_{\left.\mathrm{I}^{+}\right]}$as their complement. Recall that we have seen that epistemic verbs subcategorize for a clause with $W_{[+]}$in 5.2.1.5 above and that perception and contact verbs subcategorize for a clause with $W_{[-]}$in 5.2.2.1 above.

\subsubsection{The differing possibility of ga-marking of subjects}

In my analysis, $E$ is responsible for licensing $g a$-marked subjects in Japanese. Therefore, we can reasonably predict that subjects are marked with -ga in the complement clauses of perception and contact verbs, which have $E_{[+]}$, but not in the complement clauses of epistemic verbs, which have $E_{[-]}$. In this section, I show that this prediction is borne out.

\subsubsection{The presence of ga-subjects in stage-level clauses}

Observe once again the complement clauses of verbs of physical perception, contact and approach, as seen in (35) above, which are repeated in (38) below. They are typical stage-level subordinate clauses, which yield the eventive or punctual interpretation. A situation in which Ziroo takes the money in (38a) and a situation in which John is hitting Mary in (38b) are taken as being manifested punctually at the moment when I saw it. In (38c), the policeman intends to seize the criminal precisely at the moment when he has stopped his car.

\footnotetext{
${ }^{15}$ It has been extensively pointed out that these two different classes of verbs select different types of complement clauses (e.g., Nakau 1976, Calabrese 1993, Safir 1994, Svenonius 1994, Raposo and Uriagereka 1995).
} 


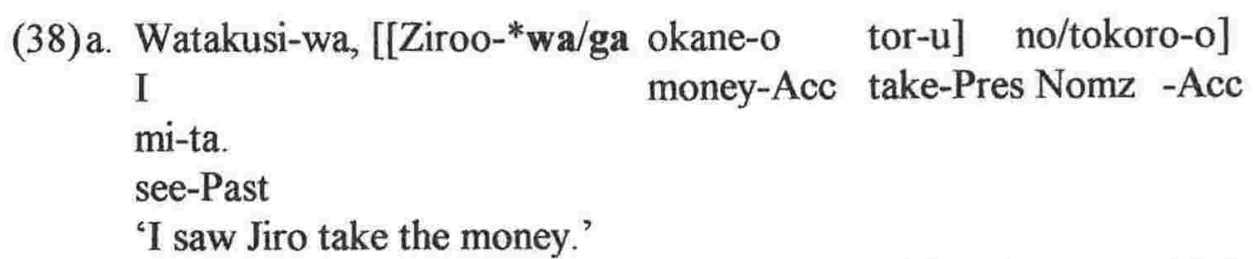

(adapted from Lewis 1976: 318)

b. Watakusi-wa [John-*wa/ga Mary-o but-tei-ru no/tokoro

\begin{tabular}{llll}
\multicolumn{1}{l}{ I } & -Acc & hit-Prog-Pres Nomz \\
-o] mi-ta. & & \\
-Acc see-Past &
\end{tabular}

(adapted from Kuno 1973: 213)

c. Keikan-wa [[hannin-*wa/ga kuruma-o tome-ta] tokoro-o] policeman criminal car-Acc stop-Past Nomz-Acc taiho-su-ru tumori-da. arrest-do-Pres intention-Cop

'The policeman intends to seize the criminal ${ }_{i}$ when he ${ }_{i}$ has stopped the car.'

(adapted from Nakau 1976: 460)

Notice further that the tense/aspect markers in those subordinate clauses yield their $\mathrm{R}=\mathrm{S} / \mathrm{View}_{\text {part }}$ interpretation rather than $\mathrm{R}=\mathrm{E} / \mathrm{View}_{\text {all }}$ interpretation. The affix $-u(-r u)$ in the subordinate clause in (38a) is certainly not taken as conveying that the situation described by the predicate is going to take place some time in the future, but rather that it is just about to occur or occurring. ${ }^{16}$ The affix -teiru in the subordinate clause in (38b) is taken as conveying that the situation described by the predicate is now actively going on, i.e., the dynamic progressive interpretation, but not the static present interpretation. The affix $-t a$ in the subordinate clause in (38c) is taken as conveying that the situation described by the predicate has just been completed, i.e., the "hot news" perfect interpretation, but not the past tense interpretation. The eventive and punctual interpretations of those complement clauses indicate that they have an $e$.

An $e$ occurring in the complement clause $E$ is necessarily specified for a particular spatiotemporal location which is fixed by the main clause verb. That

16 In this case, -ru may also be taken as conveying that the situation described by the predicate is now actively going on, i.e., the dynamic progressive interpretation, but not the static present interpretation. 
is, the event described in the complement clause is necessarily interpreted as occurring at the spatiotemporal location of the event denoted by the main clause predicate. As we have assumed in 5.2.1.5 above that an epistemic verb somehow fixes a context of evaluation for the proposition expressed in the complement clause, we can also assume that a perception or contact verb somehow specifies a particular spatiotemporal location for the event described in the complement clause. ${ }^{17}$

Now, notice that the subjects of those subordinate clauses in (38) above are all marked by -ga (and not by $-w a$ ), as we expected. This is explained as due to the occurrence of $e$ in those clauses which activates their $E$, i.e., $E_{\mathrm{f}+\text { ] }}$.

Recall that we have discussed in 3.3 above that the punctual eventive interpretation (yielded by $V_{\text {iew }}$ part) is restricted to [+Stage] or [+Visible] situations. From this, we expect that only [+Stage/Visible] situations (but not [-Stage/Visible] situations) can appear in the complement clause of a perception or contact verb. This is borne out by the grammatical (39a) and the ungrammatical (39b).

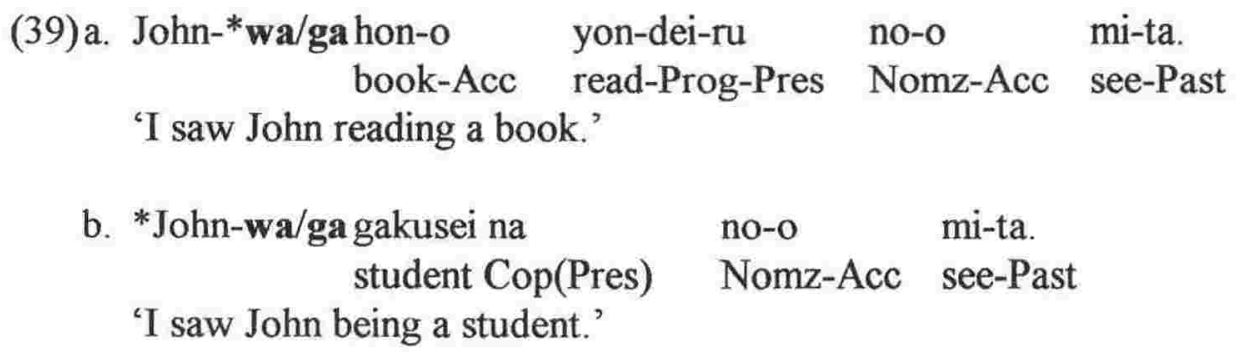

\subsubsection{The absence of $g a$-marked subjects in individual-level clauses}

Let us now turn to individual-level clauses. Typical individual-level clauses are the complement clauses of epistemic verbs, as seen in (33) above. However, the situation of John's being a student described in the complement clauses in (33) above is intrinsically stative, individual-level. That is, it is a [-

\footnotetext{
${ }^{17}$ With a perception verb in the main clause, however, although the temporal location of the complement event is strictly fixed by the main clause verb, the spatial location may be rather lax. That is, the event seen may not be in exactly the same place as the event of seeing, while the event seen and the event of seeing are necessarily simultaneous. This may suggest that the spatial and temporal components of an event location be separated in our representation (cf. Svenonius 1994: 152-153).
} 
Stage/Visible] situation. Therefore, it is rather obvious that $e$ is not present in those clauses.

Let us examine what happens if we embed a sentence describing an eventive, stage-level situation in the complement clause of epistemic verbs.
(40)a. John-ga hon-o yon-dei-ru.
book read-Prog-Pres
'John is reading a book.'

b. [John-wa/\#ga hon-o yon-dei-ru] to Mary-wa it-ta.

book read-Prog-Pres Comp say-Past

'Mary said that John was reading a book.'

c. [John-wa/\#ga hon-o yon-dei-ru] to Mary-wa

book read-Prog-Pres Comp

omot-tei -ru.

think-Prog-Pres

'Mary thinks that John is reading a book.'

The 'stand alone' clause (40a) has a ga-marked subject and yields a dynamic progressive reading, i.e., John's reading is actually progressing at the moment when the sentence is uttered. Interestingly, when the clause is embedded in the complement clause of itta 'said' or that of omot-tei-ru 'is thinking', the neutral ga-marking of the subject and the dynamic progressive reading become unavailable. In (40b) and (40c), the hashes on $-g a$ indicate that if marked with -ga, the subject of the complement clause has to be taken as being in focus. ${ }^{18}$ And the vividness and transience of direct perception in (40a) are lost in the complement clauses in (40b) and (40c). The described situation of John's reading is taken as continuing not dynamically right at the moment of speech but statically in a more loosely defined present time. This suggests that these complement clauses do not have their own $e$ in the subordinate $E$.

${ }^{18}$ Note that verbs of saying can take either a direct or an indirect speech as their complement. While indirect speech is formally embedded in a clause subordinate to the main clause and accordingly affected in its form, a direct speech takes a form identical to the original speech. In (40), I am only considering indirect speech. 
We have discussed in 3.3 above that while the punctual, eventive interpretation (yielded by View $_{\text {part }}$ ) is restricted to [+Stage/Visible] situations, the stative, individual-level interpretation (yielded by Viewall) is generally available. Therefore, we expect that both [+Stage/Visible $]$ and $[-$ Stage/Visible] situations can appear in the complement clause of an epistemic verb. This is borne out by the grammatical (41a) and (41b).

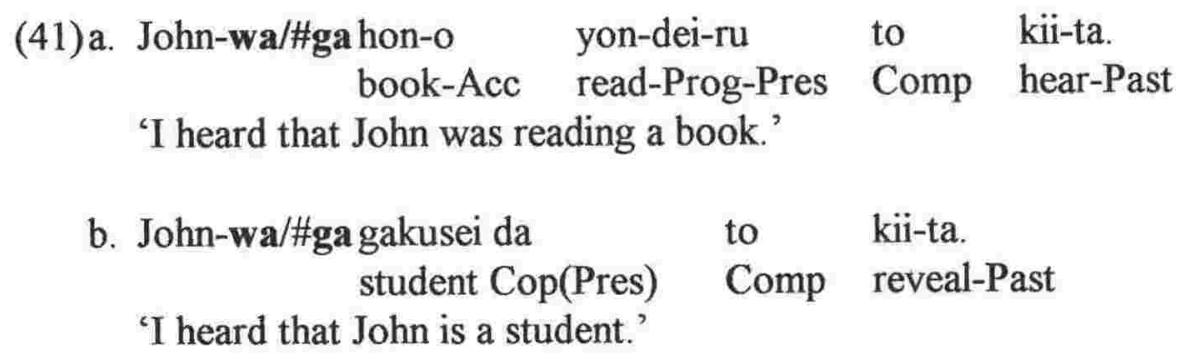

\subsubsection{Abstract states of affairs}

Having seen stage-level and individual-level subordinate clauses, in this section I turn to another type of subordinate clause, which is neither precisely stage-level nor individual-level.

Compare the sentences in (42) below. As observed in (37) above, the small clause receives the individual-level interpretation, when it is the object of consider in (42a). Therefore, in this case, $e$ is absent in the subordinate $E$. In ( $42 \mathrm{~b})$, the same small clause receives the stage-level interpretation, when it is the object of saw. In this case, $e$ is present in the subordinate $E$. What about (42c)? Svenonius (1994: 115) claims that (42c) means that the sheriff is in a want relation with a situation-type, the type of situation characterized by Billy being dead.

(42)a. The sheriff considers Billy dead.

b. The sheriff saw Billy dead.

c. The sheriff wants Billy dead. (Svenonius 1994: 115)

Firstly, compare what is wanted by the sheriff in (42c) with what is considered by the sheriff in (42a). When considered by the sheriff, Billy's being dead is a stative, individual-level situation, in which Billy is and has 
been dead. It in fact constitutes a proposition that Billy is dead. Therefore, literally the sheriff considers that Billy is dead. As a proposition, that Billy is dead is either true or false. The truth must be evaluated in the context to which it is anchored. By contrast, what is wanted by the sheriff is not to be evaluated for its truth. In the sense that it does not constitute an assertion or denial about something, which is either true or false, what is wanted by the sheriff is very different from a proposition that Billy is dead. ${ }^{19}$ Rather, what is wanted by the sheriff is a state of affairs in which Billy is dead. Although a state of affairs may hold or not hold, it is not something that is asserted or denied, and hence true or false.

Secondly, compare what is wanted by the sheriff in (42c) with what is seen by the sheriff in (42b). What is seen by the sheriff is also a state of affairs in which Billy is dead, rather than a proposition that Billy is dead. That is, it is not an assertion or denial, which is either true or false. However, notice that what is seen by the sheriff is a punctual manifestation of Billy being dead at a particular spatiotemporal location. It is a concrete state of affairs at a punctual spatiotemporal location. On the other hand, what is wanted by the sheriff is not located at a particular spatiotemporal location. Without being located at a particular spatiotemporal location, the state of affairs wanted by the sheriff is not a concrete entity but rather an abstract entity.

To illustrate the distinction between concrete and abstract states of affairs, observe how a state of affairs can be parameterized in the representations in (43) below. Svenonius (1994: 112-113) cites a model proposed in Barwise \& Perry (1983), in which a state of affairs is made up of a spatiotemporal location (represented by the variable $l$, which is either indexed or unindexed) and a set of pairs consisting of a polarity ( 0 or 1$)$ and a 'constituent sequence', which is roughly a predicate and a list of arguments for that predicate. (43a) represents a situation, or state-of-affairs, in which John is sleeping at some spatiotemporal location $l_{1}$. (43b) is a situation occupying the same spatiotemporal location, in which John is not sleeping.

${ }^{19}$ However, (42c) can be paraphrased in propositional terms, i.e., The sheriff wants it to be the case that Billy is dead, as pointed out by an examiner. 
(43c) contains a variable, $x$, which ranges over individuals. Thus (43c) represents a state-of-affairs characterized by some individual sleeping at $l_{1}$. Finally and most importantly for our purpose, (43d) contains an unindexed instantiation of $l$, which by convention is a spatiotemporal variable. Thus, (43d) represents a state-of-affairs characterized by John sleeping at some time in some place. Since $l$ is unindexed, this can be considered a situation-type, i.e., a type of situation.

(43) a. $<l_{1},\left\{<1, \operatorname{sleep}^{\prime}(\mathrm{j})>\right\}>$

b. $\left\langle I_{1},\{<0\right.$, sleep' $(\mathrm{j})>\}>$

c. $\left.\left\langle l_{1},\left\{<1, \operatorname{sleep}^{\prime}(\mathrm{x})\right\rangle\right\}\right\rangle$

d. $\left\langle l,\left\{<1\right.\right.$, sleep $\left.^{\prime}(\mathrm{j})>\right\}>$

(Svenonius 1994: 113)

Equipped with an unspecified spatiotemporal location, we can consider the complement of want in (42c) above to be located at some unspecified spatiotemporal location, while the complement of $s a w$ in $(42 \mathrm{~b})$ is located at a specified spatiotemporal location. Accordingly, what is wanted by the sheriff is an abstract state of affairs characterized by Billy being dead, i.e., a situation-type, while what was seen by the sheriff is a concrete state of affairs at a particular spatiotemporal location in which Billy is dead.

Since a situation-type has an $l$ feature or a spatiotemporal location, though it is an unspecified one, it should be regarded as stage-level. However, unlike a concrete state of affairs with a specified $l$ feature, a situation-type with an unspecified $l$ does not receive the vivid dynamic interpretation of a stage-level situation. This is because an unspecified $l$ does not locate a situation at a particular spatiotemporal location in the real world. Thus, while a situation-type should be considered as a variety of stage-level situation, it does not have the real flavour of a stage-level situation (nor of an individuallevel situation).

In my system, an $e$ (occurring in $E$ ) specifies a spatiotemporal location. It corresponds to an indexed $l$, as in (43a-c) above. In order to distinguish between specified and unspecified spatiotemporal locations, I introduce 
another kind of $e$, which corresponds to an unindexed $l$, as in (43d) above. While an ordinary $e$ specifies a particular spatiotemporal location and locates a situation at that particular spatiotemporal location, this $e$ does not specify a particular spatiotemporal location and therefore does not locate a situation at any particular spatiotemporal location. Or, it can be said that with this $e$ a situation is located at some unspecified spatiotemporal location. I call it $e_{\text {un }}$ (where 'un' stands for unspecified). Without specifying a particular spatiotemporal location, $e_{\mathrm{un}}$ does not yield the vivid and dynamic interpretation. The interpretation with an $e_{\mathrm{un}}$ is somewhat motionless.

Thus, an $e_{\mathrm{un}}$ is semantically quite distinct from an ordinary $e$. Nevertheless, it is still a kind of $e$, and I assume it to occur in $E$ and activate $E$, just like an ordinary $e$. Since $E$ is the licenser of $g a$-marked subjects in Japanese, if the occurrence of $e_{\mathrm{un}}$ activates $E$, a clause with an $e_{\mathrm{un}}$ is expected to have a ga-marked subject, just like a clause with an $e$.

\subsubsection{Subordinate clauses describing situation-types}

As seen in (42c) above and also (44a) below, Svenonius (1994) discusses the so-called emotive verbs such as want and like as examples of predicates which take a situation-type as their complement. In addition, I conceive of such verbs as require and suggest as predicates which take a situation-type as their complement, as in (44b-c) below. Just like what is wanted/liked by him in (44a) is not a particular event of her explaining it but a type of situation characterized by her explaining it, what is required and suggested by him is also not a particular event but a type of situation in (44bc) below. Furthermore, conditional types of clauses similarly appear to describe a situation-type, as seen in (44d) below. That is, the if-clause in (44d) does not describe any particular event of her explaining it but a situation-type characterized by her explaining it, in which he will let us know.

(44)a. He wanted/liked her to explain it.

b. He required her to explain it./He required that she (should) explain it. 
c. He suggested that that she (should) explain it.

d. If she explains/should explain it, he will let us know.

It is noticeable that clauses describing a situation-type often contain the optional use of should, as seen in (44b-d). ${ }^{20}$ This leads us to examine other types of clauses that contain should. Some adjectives, including important, strange, funny, natural, surprised, essential, odd, typical, and interesting, can also take clauses containing should as their complement, as shown in (45).

(45)a. It's strange that John should be late. (John is usually on time.)

b. I was surprised that John should say such a thing.

(based on Murphy 1985:70)

While the clauses with the optional should in (44b-d) above imply that the described situation has not yet happened (and therefore is not located at a particular spatiotemporal location), the complement clauses of these adjectives in (45) rather seem to imply that there has been an instance of the described situation, i.e., a situation in which he is late in (45a), and a situation in which he said such a thing in (45b). Notice that these adjectives are in fact factive predicates and their complements are normally taken as describing facts. (cf. 5.2.1.1 above). It is probably the effect of a factive predicate in the main clause that the situation described in the complement clause is taken as having occurred in (45) (cf. Quirk and Greenbaum, 1973: 340). However, there is also an effect of having a modal should in the complement clause. That is, even though there seems to exist a particular event understood as being talked about in the current discourse, the speaker rather abstracts away from the where and when of the situation and only refers to a kind of situation. What is said to be strange in (45a) is a kind of situation characterized by John's being late, and what surprised the speaker in (45b) is a

\footnotetext{
${ }^{20}$ In subordinate clauses should may appear in contexts where a present subjunctive might be expected as in (44b) and (44c), and in if-clauses which express a tentative condition as in (44d). If should is not inserted, a subjunctive form, explain, is used in (44b) and (44c), whereas in (44d) explains is used.
} 
kind of situation in which John says such a thing. It is perhaps more about John or John's character (rather than the particular situation) that is being talked about. Thus, just like the other should-clauses observed in (44) above, I also take should-clauses embedded under factive predicates as not referring to a particular event (even if it is implied) but as describing a situation-type. ${ }^{21}$

Note that the use of a modal should is optional in these subordinate clauses too. The sentences in (46) below are minimal pairs with those in (45) above differing only in the presence or absence of should in the complement clauses.

(46)a. It's strange that John is late. (John is usually on time.)

b. I was surprised that John said such a thing.

Without should, the complement clauses of strange and surprised are taken as factive and as referring to a particular instance of the described situation. Thus, it is the fact that John is late that is said to be strange in (46a), and the fact that John said such a thing surprised the speaker in (46b). Perhaps, the strangeness and the surprisingness here are not so much due to John or John's character but due to some external causes.

This suggests that factive predicates are able to take not only clauses describing facts but also those describing situation-types as their complement. What is described in the complement clause of a factive predicate is distinguished between a situation-type and a fact, depending on whether it contains should or not. However, an alternative view is that the presence and absence of should in those complement clauses may be just a matter of levels, where the presence of should is taken as more formal, as is the case in (44b-d) above. ${ }^{22}$ According to this view, no matter whether they contain should or not, the complement clauses of factive predicates are interpreted as situationtypes (rather than facts). That is, even the complement clauses in (45) without should are also taken as describing situation-types.

${ }^{21}$ Quirk and Greenbaum (1973: 340) say that should-clauses (i.e., that-clauses with should) 'express not a subordinate statement of fact, but a "putative" idea'. 
Related to this is gerundive (or gerundial) constructions in English. As noted in the footnote 4 above, Kiparsky and Kiparsky (1970) show that factive predicates but not non-factive predicates allow gerundial constructions, as shown in (47).

(47)a. His being found guilty is tragic.

$<$ factive $>$

b. *His being found guilty is sure.

$<$ non-factive $>$

c. I regret having agreed to the proposal.

$<$ factive $>$

d. *I believe having agreed to the proposal.

$<$ non-factive $>$

Interestingly enough, Barwise and Perry (1983) use gerundive nominals to illustrate a situation-type. With the examples $(48 \mathrm{a}-\mathrm{b})$ below, they show that gerundive nominals are often used to refer to general types of events, whereas what they call derived nominals in $(48 \mathrm{c}-\mathrm{d})$ refer to specific situations or events. The hashes indicate that the sentences are odd, because the particular events referred to with derived nominals are not the sort of things that can "always mean" something or "always upset" someone.

(48)a. Cat hair being in the butter always means a cat is in the house.

b. Jackie's biting Molly always upsets the Perrys.

c. \#That hair in the butter always means a cat is in the house.

d. \#The situation when Jackie bit Molly always upsets the Perrys.

(Barwise and Perry 1983:77)

If factive predicates are related with gerundive constructions as shown in (47) above and gerundive constructions are related with situation-types as shown in (48) above, factive predicates and situation-types are expected to have some connection. Without going into detailed discussion, here I simply point out the possible correlation between factivity and a situation-type.

${ }^{22}$ I am indebted to Elizabeth Pearce (p.c.) for pointing this out for me. 


\title{
5.3.3.2. $G a$-marked subjects in clauses describing situation-types
}

Let us now turn to Japanese. The subordinate clause in (49a) below is the complement of a predicate equivalent to hope or wish, which typically takes a clause describing a situation-type as its complement. That is, the speaker hopes for or wishes for a situation-type characterized by John's being a student. The subordinate clause in (49b) is an if-clause, which also typically describes a situation-type. That is, Mary would not be interested in John, in a situation-type in which John is a student.

\author{
(49)a. John-\#wa/gagakusei da to ii no da ga... \\ student CopComp good Cop but \\ 'I hope John is a student but ....' \\ b. John-*wa/ga gakusei dat-ta-ra, Mary-wa kyoomi-o \\ mota-nai-daroo. \\ student Cop-Past-if interest-Acc \\ have-Neg-probably \\ 'If John was a student, Mary would not be interested (in him).'
}

Notice that in both (49a) and (49b), the subjects are necessarily marked by - $g a$ (to yield the neutral interpretation). This $g a$-marking of subjects cannot be explained by the presence of $e$, because the situation described in those subordinate clauses, i.e., John's being a student, is intrinsically [Stage/Visible] and cannot be located at a particular spatiotemporal location and interpreted as eventive or stage-level (cf., 3.3 above). Rather, those subordinate clauses are assumed to have an $e_{\text {un }}$, as they describe situationtypes. Since an $e_{\text {un }}$ occurs in and activates their $E$ just like an ordinary $e$, it explains the $g a$-marking of subjects in those subordinate clauses.

This means that although a situation of John's being a student cannot be located at a particular spatiotemporal location by an $e$ (because of its [Stage/Visible] feature), it can be located at some unspecified spatiotemporal location by an $e_{\text {un }}$. This suggests that while the occurrence of $e$ is restricted to situations which can be decomposed into stages, the occurrence of $e_{\mathrm{un}}$ is not.

Furthermore, the presence of $e_{\mathrm{un}}$ in the clauses describing situationtypes can provide an account for the mysterious $g a$-marking of subjects in factive clauses, as observed in (26b-e) above, which are repeated in (50a-d) 
below. Recall that we have explained the absence of wa-marked subjects in those subordinate clauses by showing that these clauses lack $\omega$ in their $W$, which is the licenser of $w a$-marked subjects in 5.2.1.4 above. However, it has been left unexplained why then those subjects are marked with - $g a$.

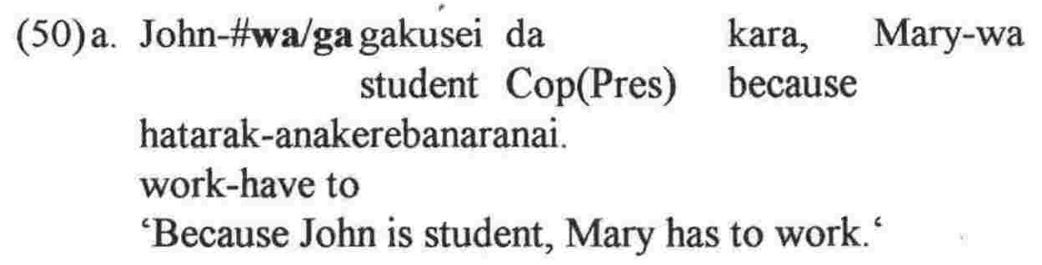

b. John-\#wa/ga gakusei da toyuu koto-ga bare-ta. student Cop(Pres) Comp fact reveal-Past

'The fact that John is a student has been revealed.'

c. John-\#wa/ga gakusei de yokat-ta. student good-Past

'I am glad that John is a student.'

d. John-*wa/ga gakusei no uchi-ni, ryokoo ni ik-oo. student while trip to go-let's 'Let us go on a trip, while John is a student.'

Let me examine the examples in reverse order. The subordinate clause in (50d) is a while-clause. Somewhat similarly to conditionals, such a time adverbial also seems to describe a situation-type. In the case of (50d), the speaker suggests going on a trip in a situation-type characterized by John's being a student.

The subordinate clause in (50c) is the complement of a predicate equivalent to glad. As we have seen in (11c) above, glad is a typical factive predicate and its complement is taken as describing a fact. Accordingly, (50c) translates into that the speaker is glad about the fact that John is a student. However, we have also observed that factive predicates can take clauses describing a situation-type as their complement, especially with the use of a modal should or gerundive construction in English as shown in (45) and (48) above. I take it that in the case of (50c), although it is implied that John is a student is a fact, the speaker expresses his/her gladness not directly about the fact but rather indirectly about a situation-type in which John is a student. I 
hypothesize that factive predicates take situation-types rather than facts as their complements especially in Japanese.

The koto-clause in (50b) is also a typical factive clause. That John is a student is a presupposed fact. Accordingly, $(50 \mathrm{~b})$ translates into that the fact that John is a student has been revealed. However, similarly to the above case in (50c), can we also conceive that what is said to have been revealed is a situation-type characterized by John's being a student? It is rather questionable whether a situation-type is a kind of thing that can be revealed. Nevertheless, in order to maintain the presence of $e_{\mathrm{un}}$ to justify the gamarking of the subject, we might take it as a rule in Japanese that factive clauses necessarily contain $e_{\mathrm{un}}$ and describe a situation-type. This amounts to saying that a presupposed fact is always expressed as a situation-type, as a way of being less direct.

Lastly, the subordinate clause in (50a) is a because-clause. Intuitively, such an adverbial clause of reason also appears factive. That is, what is given as a reason for something seems presupposed to be a fact. Accordingly, (50a) translates into that Mary has to work because of the fact that John is a student. However, similarly to the case in (50c) above, we can also conceive that it is because of a situation-type characterized by John's being a student that Mary has to work. Here again, I take it that the presupposed fact is expressed as a situation-type.

Thus, although it is only hypothetical in some cases, many (if not all) of the subordinate clauses which exhibit the mysterious ga-marking of subjects seem to describe a situation-type and therefore have $e_{\mathrm{un}}$ occurring in and activating their $E$. This provides an account for the mysterious $g a$-marking of subjects in those subordinate clauses.

\subsubsection{Rethinking time adverbial clauses}

With respect to the example (50d) above, I have just said that the time adverbial clause describes a situation-type. This brings us back to the $S / E / R$ representation of a time adverbial clause that I have discussed in 2.2.3.1 above. The example is repeated in (51). 
(51)a. When Mary entered the room, John had just woken.

b. Mary's entering the room

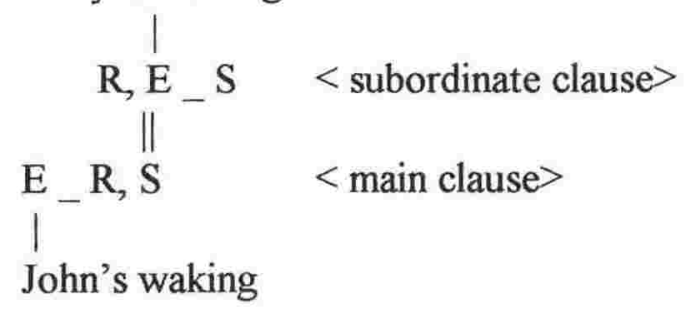

Notice that to the time adverbial clause I have given the representation R,E_S. However, this in fact represents the temporal interpretation of the 'stand alone' clause Mary entered the room, rather than that of the time adverbial clause When Mary entered the room. Crucially, the two are different. While the 'stand alone' clause Mary entered the room asserts that the situation of Mary's entering the room took place at some time in the past, the time adverbial clause When Mary entered the room does not make an assertion. In the interpretation of the time adverbial clause, that Mary entered the room is taken as a fact, or presupposed to be true. In other words, the time adverbial clause is factive and is not to be evaluated for its truth.

In Japanese, this interpretive difference between the 'stand alone' clause and the subordinate clause is manifested in the differing possibility of wamarking of subjects, as shown in (52) below. In (52a), the subject can be marked by $-w a$ (to yield the neutral interpretation), whereas in (52b-c) the subordinate clause subjects cannot be marked by $-w a .^{23}$ This suggests that the 'stand alone' clause has an anchor, $\omega$, occurring in and activating its $W$, whereas the time adverbial clause has inactive $W$ without an anchor, $\omega$. Recall

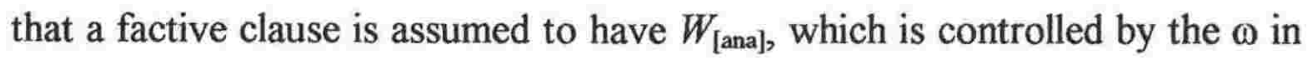
the higher $W$, for its truth is presupposed in the context set in which the main clause assertion is to be evaluated (cf. 5.2.1.4 above).

${ }^{23}$ As discussed in 2.1.2 above, the time adverbial clause takes differing scopes for the two forms of the main clause subject, i.e., $w a$-and $g a$-marked subjects. Also note that the main clause yields the $\mathrm{R}=\mathrm{E}$ with a $w a$-marked subject in $(52 \mathrm{~b})$, whereas it yields the $\mathrm{R}=\mathrm{S}$ interpretation with a ga-marked subject in (52c). 
(52)a. Mary-wa/ga heya-ni hait-ta.

room-to enter-Past

'Mary entered the room.'

b. John-wa Mary-*wa/ga heya-ni hait-ta toki oki-ta
room-to enter-Past when wake-Past

'When Mary entered the room, John woke.'

$\begin{array}{lllr}\text { c. Mary-*wa/ga } & \begin{array}{l}\text { heya-ni hait-ta } \\ \text { room-to enter-Past }\end{array} & \text { toki } & \text { John-ga oki-ta. }\end{array}$

'When Mary entered the room, John had just woken.'

Recall further that the semantic content of $W$ corresponds to the $\mathrm{R}=\mathrm{E}$ interpretation (cf. 4.2 .2 above) in that the $\mathrm{R}=\mathrm{E}$ interpretation obtains when the semantic content of $W$ is present, i.e., $W_{[+]}$. This means that the 'stand alone' clause in (52a) above can receive the $R=E$ interpretation (i.e., $R, E \_S$ ) because it has $W_{[+]}$. In this case, -ta yields the past tense interpretation. (Note that (52a) can alternatively have the $\mathrm{R}=\mathrm{S}$ interpretation with a $g a$-marked subject.) On the other hand, the time adverbial clause in (52b-c) cannot receive the $\mathrm{R}=\mathrm{E}$ interpretation because it has $W_{\text {[ana] }}$ which is semantically (and syntactically) inert. In this case, -ta does not yield the past tense interpretation, despite the English translation. In my view, $-t a$ in the time adverbial clause rather yields the 'hot news' perfect interpretation, though it somehow lacks the vividness and the dynamicity of the 'hot news' perfect interpretation. This is expected if the time adverbial clause describes a situation-type, which is considered as a variety of the $\mathrm{R}=\mathrm{S}$ interpretation, but which is not anchored to a specified spatiotemporal location but to an unspecified spatiotemporal location. Therefore, the representation $E_{-} R, S$ is probably more appropriate than $\mathrm{R}, \mathrm{E}_{-} \mathrm{S}$, but it is not accurate either.

The same can be said about when Mary enters the room. The representation $\mathrm{S}_{-} \mathrm{R}, \mathrm{E}$ given to it in fact represents the future tense of a 'stand alone' clause Mary will enter the room. While the 'stand alone' clause asserts that the situation of Mary's entering the room will take place some time in the future, the time adverbial clause When Mary enters the room does not make an assertion. Rather, it describes a situation-type, which is considered as a variety of the $\mathrm{R}=\mathrm{S}$ interpretation, but which is not anchored 
to a specified spatiotemporal location but to an unspecified spatiotemporal location. Therefore, the representation $\mathrm{R}_{,} \mathrm{S}_{-} \mathrm{E}$ is probably more appropriate than $S_{-} R, E$, but it is not accurate either.

Thus, strictly speaking, the interpretation of the time adverbial is neither that of $\mathrm{R}=\mathrm{E}$ nor of $\mathrm{R}=\mathrm{S}$. In fact, subordinate clauses describing situationtypes fall outside the system with the S/E/R representations I have developed in Chapter 2.

\subsubsection{Summary}

In this section, I have examined the specifications of $E$ in subordinate clauses. Firstly, I have distinguished between stage-level clauses exemplified by the complement clauses of perception and contact verbs and individuallevel clauses exemplified by the complement clauses of the so-called epistemic verbs. While stage-level clauses have $E_{[+]}$(with a spatiotemporal location $e$ ), individual-level clauses have $E_{[-]}$as they totally lack a spatiotemporal location.

In addition to this distinction between $E_{\mathrm{I}^{+} \mathrm{]}}$ and $E_{[-\mathrm{J}}$, there are some subordinate clauses which are neither precisely stage-level nor individuallevel, as exemplified by the complement clauses of the so-called emotive verbs. Those subordinate clauses describe states of affairs with an unspecified spatiotemporal location (i.e., abstract states of affairs), while stage-level clauses describe states of affairs with a specified spatiotemporal location (i.e., concrete states of affairs). Subordinate clauses describing abstract and concrete states of affairs are distinguished by $E_{[\mathrm{un}]}$ (with an $e_{\mathrm{un}}$ which stands for an unspecified spatiotemporal location) and $E_{\left[^{+}\right]}$(with an $e$ which stands for a specified spatiotemporal location). Assuming that $E_{[\mathrm{m}]}$ is syntactically as active as $E_{[+]}$, it provides an account for the mysterious $g a$-marking of subjects in some subordinate clauses. That is, ga-marking of subjects is possible with either $E_{[+]}$or $E_{[u n]}$. 


$$
E \text { specification licensing of } g a \text {-subjects }
$$

States of affairs

$$
\text { concrete }
$$

abstract

un

Propositions

factive

un

non-factive

\subsection{Conclusion}

In 5.2, I have examined the specifications of $W$ and the possibility of $w a$-marking of subjects in subordinate clauses, as summarised in (36) above. In 5.3, I have examined the specifications of $E$ and the possibility of gamarking of subjects in subordinate clauses, as summarised in (53) above. When we put the two sets of findings together, we get four distinct configurations of subordinate tense structure, as summarised in (54). ${ }^{24}$

$$
\text { W } \quad \text { E } \quad \text { Subject marking }
$$

Propositions

$\begin{array}{lccc}\text { factive } & \text { ana } & \text { un } & -g a \\ \text { non-factive } & + & - & -w a \\ \text { tes of affairs } & & & \\ \text { concrete } & - & + & -g a \\ \text { abstract } & - & \text { un } & -g a\end{array}$

There are some points to note in conclusion. First, $W_{\text {[ana] }}$ and $E_{[\text {[un] }}$ are introduced particularly for subordinate clauses. That is, $W_{\text {[ana] }}$ and $E_{\text {[un] }}$ are not found in matrix clauses. Second, $W_{\text {[ana] }}$ is just as incapable as $W_{[-]}$as the licenser of $w a$-marked subjects in Japanese, whereas $E_{\text {[un] }}$ is just as capable as $E_{[+]}$as the licenser of $g a$-marked subjects in Japanese. Third, $E_{[\text {un] }}$ provides an

\footnotetext{
${ }^{24}$ These four types are not meant to exhaust all subordinate clauses.
} 
account for the unexpected $g a$-marking of subjects in some subordinate clauses which have been puzzling Japanese linguists. Fourth, $W_{[-1}$ is also unique to subordinate clauses. Since anything said in a main clause is to be evaluated for its truth, a main clause is necessarily anchored to a certain context, only in which its truth can be evaluated. Therefore, a main clause necessarily has $W_{[+]}$.

Crucially, apart from some differences between main and subordinate clauses, basically the same mechanisms operate in the same functional structure in both main and subordinate clauses. That is, $w a$ - and $g a$-markings of subjects are associated with the semantic properties of the functional heads $W$ and $E$ in subordinate clauses as well.

Lastly, notice in (54) above that $w a$ - and $g a$-markings of subjects fall out of the specifications of $E$, rather irrespective of the specifications of $W^{25}$ This raises a question as to the status of the $W$ specification, i.e., whether it is genuinely necessary. Recall that in matrix clauses, which necessarily have $W_{\left[^{+}\right]}$, the choice between - $w a$ and $-g a$ solely depends on the specification of $E$.

\footnotetext{
${ }^{25} \mathrm{I}$ am indebted to an examiner who pointed this out for me.
} 


\section{Chapter 6}

\section{Concluding remarks}

In this thesis, I have investigated the problem of $w a$ - and ga-markings of 'subjects' in Japanese from a novel perspective of tense and aspect. Crucially, I have argued that there is a correlation between $w a / g a$-marking of subjects and tense/aspect interpretations. I have pinned down such a correlation in terms of (i) two different types of evaluation time, which are distinguished as 'original' and 'new', (ii) two types of Reichenbach's (1947) R; one that coincides with $\mathrm{S}$ but not with $\mathrm{E}(\mathrm{R}=\mathrm{S} / \neq \mathrm{E})$, and the other that coincides with $\mathrm{E}$ but not with $\mathrm{S}(\mathrm{R}=\mathrm{E} / \neq \mathrm{S}$ ), and (iii) two types of viewpoint aspect, one that presents 'part' of a situation manifested at a precise temporal point (View $w_{\text {part }}$ ) and the other that presents 'all' of a situation without decomposing it $\left(\right.$ View $\left._{\text {all }}\right)$.

$\begin{array}{llll} & & -g a & -w a \\ \text { i. } & \text { Evaluation Time } & \text { original }(t) & \text { new }\left(t^{\prime}\right) \\ \text { ii. } & \mathrm{S}, \mathrm{E}, \mathrm{R} & \mathrm{R}=\mathrm{S} / \neq \mathrm{E} & \mathrm{R}=\mathrm{E} / \neq \mathrm{S} \\ \text { iii. } & \text { Viewpoint Aspect } & \text { View }_{\text {part }} & \text { View }_{\text {all }}\end{array}$

Since the semantic distinctions in (1) are syntactically manifested in a Case distinction, they need to be represented in the syntax. That is, our syntactic representation should encode the distinction between the two types of evaluation time, $\mathrm{R}$ or viewpoint aspect in order to account for $w a$ - and $g a$ markings of subjects as syntactic mechanisms. In line with Chomsky's (1995: 240) suggestion that Tense might have "further subdivisions and implications about event structure and perhaps other properties" (in addition to the division of $[+/-$ finite]), I propose subdivisions of Tense (which I call $W$ and $E$ ) that contain the semantic features responsible for the two types of tense/aspect interpretations summarized above. As functional categories, $W$ 
and $E$ are always present in the phrase structure of a clause but they may be syntactically active or inactive in a given clause. Syntactically active $W$ and $E$ have $T$-features to be checked by the relevant features of predicates and $D$ features to be checked by the relevant features of DPs.

Due to the distinct semantic contents of $W$ and $E$, their T-features checked by the relevant features of predicates are responsible for the two distinct temporal and aspectual interpretations of predicates, i.e., the $\mathbf{R}=$ $\mathrm{E} / \mathrm{Viw}_{\text {all }}$ and the $\mathrm{R}=\mathrm{S} / \mathrm{View}_{\text {part }}$ interpretations, and their $\mathrm{D}$-features checked by the relevant features of subject DPs (raised from their predicate-internal base-position to their Spec positions) are responsible for the distinct semantic interpretations of subjects, which are morphologically distinguished by $w a$ and $g a$-markings in Japanese. Thus, the T- and D-features of $W$ and $E$ link $w a / g a$-subjects and distinct temporal and aspectual interpretations of clauses.

Let us return to the three questions which I raised at the beginning of this thesis (in 1.4 above).

(2) i. Why do wa-marked and ga-marked subjects exhibit distinct temporal properties?

ii. What precisely are the syntactic positions for $w a$-marked and $g a$ marked subjects in the phrase structure of Japanese?

iii. Why and how are the subjects of clauses realized in two different positions? I.e., what determines the syntactic position in which the subject of a clause appears?

In answer to the second question, I have argued that wa-marked subjects appear in [Spec, WP] and ga-marked subjects appear in [Spec, EP], as a result of overt raising from their base position within VP (or the maximal projection of a predicate). Such raising of subject DPs is assumed obligatory due to the EPP (extended projection principle), which requires that sentences have subjects. The functional categories, $W$ and $E$, have strong $\mathrm{D}$-features (EPP) (as well as T-features) when they are semantically and syntactically 
active, which need to be checked by the relevant features of DPs through Spec-head agreement. This means that there are two EPP positions, [Spec, $W \mathrm{P}]$ and [Spec, EP], in Japanese and that the EPP is satisfied by filling one of the two positions.

This leads us to the third question: what determines the syntactic position in which the subject of a clause appears, especially if there are two possible positions? In my analysis, the choice between $[\mathrm{Spec}, W \mathrm{P}]$ and $[\mathrm{Spec}$, $E \mathrm{P}]$ as the destination of subject raising depends on the feature-checking system. The functional categories, $W$ and $E$, are specified with + or - values indicating whether they are semantically and syntactically active or inactive. Since $W$ and $E$ need their $\mathrm{D}$-features (as well as T-features) to be checked only when they are active, and subjects raise primarily to check the Dfeatures, the target of subject raising is basically the one which is active and whose D-feature needs to be checked.

I have identified two possible configurations for matrix tense structure and four for subordinate tense structure, as shown in (3).
a. matrix clauses

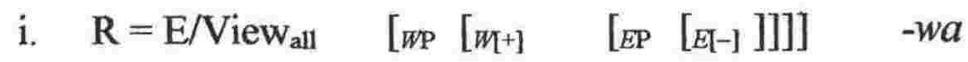

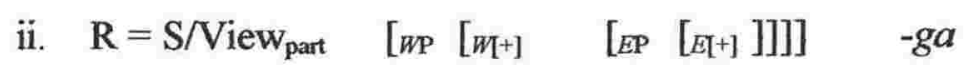

b. subordinate clauses

i. factive [wP [mana $][E P[E[$ unn $]]]]-g a$

ii. non-factive $\left[{ }_{F P}\left[m^{+}\right] \quad[E P[E[-]]]\right]-w a$

iii. concrete SoA [mP $\left.\left.\left[m_{-}-\right] \quad\left[E P\left[{ }^{[E+]}\right]\right]\right]\right]-g a$

iv. abstract SoA [wP $\left[m_{T-1}{ }_{[E P}[\right.$ [E[u] $\left.\left.\left.]\right]\right]\right]-g a$

In simple cases where only one of $W$ and $E$ is active, i.e., (3a.i), (3b.ii) and (3b.iii), subject DPs raise to the Spec of whichever one is active (to check its D-feature) and are accordingly marked by either - $w a$ or $-g a$ in Japanese. When both $W$ and $E$ are active as in (3a.ii), I assume that subject DPs raise to [Spec, $E \mathrm{P}$ ] to check the D-feature of $E$, as Shortest Movement requires that 
the target of movement be no farther than the first appropriate landing site. Therefore, subjects are ga-marked in Japanese. (However, it is a problem what happens to the $\mathrm{D}$-feature (as well as the T-feature) of $W$ which remains unchecked in this configuration. Although I have discussed a possibility that the D-feature of $W$ may be checked by an expletive such as there in English, the problem awaits future study.) In (3b.i) and (3b.iv), we have $W_{\text {[ana] }}$ and/or $E_{\text {[un]. }}$ I assume that $W_{\text {[ana] }}$ is just as inactive as $W_{[-]}$, whereas $E_{\text {[un] }}$ is just as active as $E_{[+]}$. Therefore, in those configurations, subject DPs raise to [Spec, $E \mathrm{P}]$ and are $g a$-marked in Japanese. Note that $E_{[u n]}$ is unique to subordinate clauses (as well as $W_{\text {[ana] }}$ ) and provides an account for the unexpected $g a$ marking of subjects in some subordinate clauses which have been puzzling Japanese linguists.

Now, we are ready to answer the first question: why do wa-marked and $g a$-marked subjects exhibit distinct temporal properties? This is due to the distinct semantic contents of $W$ and $E$, whose D-features are checked by wamarked and ga-marked subjects. The semantic content of $W$ is an anchor to a world and therefore its D-feature checked by the relevant feature of a subject DP (raised to [Spec, WP] and morphologically marked by -wa in Japanese) makes the subject taken as being spatiotemporally transcending (i.e., an 'individual'). On the other hand, the semantic content of $E$ is an anchor to a spatiotemporal location and therefore its D-feature checked by the relevant feature of a subject DP (raised to [Spec, EP] and morphologically marked by $g a$ in Japanese) makes the subject taken as being spatiotemporally bounded (i.e., a 'stage').

While the D-features of $W$ and $E$ are checked by the relevant features of subject DPs (raised to their Spec positions) and are responsible for the distinct semantic interpretations of subjects, the T-features of $W$ and $E$ are checked by the relevant features of predicates and are responsible for the two distinct temporal and aspectual interpretations of predicates, i.e., the $\mathrm{R}=\mathrm{E}$ and the $\mathrm{R}$ $=\mathrm{S}$ interpretations. The $\mathrm{T}$ - and $\mathrm{D}$-features of $W$ connect the $\mathrm{R}=\mathrm{E}\left(\mathrm{View}_{\text {all }}\right)$ interpretation of a clause and the individual interpretation of a subject, which is wa-marked in Japanese. Similarly, the T- and D-features of $E$ connect the R 
$=\mathrm{S}\left(\mathrm{View}_{\mathrm{part}}\right)$ interpretation of a clause and the stage interpretation of a subject, which is ga-marked in Japanese. In other words, the T- and Dfeatures of $W$ assure that the subject and the predicate share the semantic property of continuity beyond spatiotemporal locations, whereas the T- and D-features of $E$ assure that the subject and the predicate share the semantic property of spatiotemporal boundedness. Thus, a subject and a predicate of the same semantic type are necessarily paired.

An interesting consequence of my analysis is that the syntax and semantics of stage- and individual-level predicates fall under the syntax and semantics of tense. The semantics of a stage-level predicate is characterized by the semantic content of $E$, when it is active, whose T-feature is checked by the relevant feature of a predicate. Similarly, the semantics of an individual-level predicate is characterized by the semantic content of $W$, when it is active whose $\mathrm{T}$-feature is checked by the relevant feature of a predicate. The syntax of a stagelevel predicate is characterized by having the subject in [Spec, EP], which is licensed as a 'stage' subject, whereas that of an individual-level predicate is characterized by having the subject in [Spec, WP], which is licensed as an 'individual' subject. It suggests that while the notions of stage-level and individual-level predicates (and those of stages and individuals) provide us with a useful frame of reference, they are essentially reducible to the system of tense, which constitutes the central functional architecture in the phrase structure of languages.

Another point to note is that in the proposed system of subject licensing, the role of Case is rather secondary. Subject raising is triggered by the EPP, i.e., the need to check the D-feature of a functional category with a particular semantic property, and what actually licenses a subject is the semantic property. This raises questions for some of the assumptions underlying the Case checking theory, according to which DP movement is triggered by the need to check a Case feature and what licenses a subject is the matching Case feature. My analysis may suggest that when the semantic feature is checked, the Case feature is also checked as a free rider. That is, the mechanisms of Case checking correspond to interpretive material. 
This raises a question as to the licensing of other arguments, especially 'objects'. Naturally, we are reminded that the direct objects of stative predicates are also marked with -ga to yield the neutral interpretation, as noted in 1.1 .2 above. Since the $g a$-marking of those 'objects' seems to be closely related to the $w a / g a$-marking of subjects I dealt with in this thesis, it probably provides us with a good place to start exploring the possible extension of my analysis.

Apart from wide-ranging theoretical ramifications, we also need to reflect on the connection of my analysis purely as a study of $w a$ - and gasubjects in Japanese. It is important to stress that my analysis should not be taken as going against what is already known about wa/ga-subjects, even if it may appear quite different. As I have said at the very beginning in 1.1.1, in my view the problem of $w a / g a$-subjects is such a huge monster that we cannot see its whole figure in life-size. What we can do is to examine it part by part from various perspectives with various tools. Depending on the perspectives and the tools, we get more or less different pictures of the monster. However, since they are pictures of one and the same monster showing different aspects of it, they are all to be put together to ultimately project a complete picture of the monster. In this analogy, I have only shown another image of the wa/gamonster from a novel perspective of tense/aspect.

Although it is just another piece to be put together with all the other pieces, it seems like a key piece which comes right at the heart of many adjacent pieces to connect them but was missing for a long time. For example, my analysis connects previous work such as Maynard (1987) and Kuroda (1992b) which point out that wa- and $g a$-marked subjects exhibit distinct temporal properties in their interpretations with work such as Takezawa (1987) and Koizumi (1994) which argue for a link between Tense and gamarking in the syntax, as reviewed in 1.2. My analysis also agrees with many analyses that indicate a structural hierarchy between wa-marked and $g a$ marked subjects. These include Kuroda (1965, 1972, 1976, 1992b) and Uetake (1991-1992), which analyse the distinct semantic relations $w a$ - and ga-marked subjects hold to the predicates, and Kuroda (1988), Tateishi (1991) and Endo (1994), which argue for (at least) two distinct syntactic 
positions for $w a$ - and ga-marked subjects, as reviewed in 1.3. Moreover, my analysis goes hand in hand with the popular claim that -wa expresses old information and -ga new information (e.g., Chafe 1976, Halliday 1967-1968, Haviland and Clark 1974, Inoue 1980, Kuno 1972, 1973, Prince 1981). As discussed in 4.5.3, the totality and the temporality of the referents in our perception, which I claim to be signalled by -wa and -ga in Japanese, seem to be interrelated with the familiar and the novel status of the referents in the discourse, i.e., old and new information.

Needless to say, however, there are other related issues which should be incorporated in the analysis presented in this thesis but left unaddressed. For example, because of the approach that unifies $w a$-marked and $g a$-marked phrases as "subjects", this thesis has probably resulted in undervaluing the fact that $w a$-marked phrases are "topics". Another related issue is the multiple subject construction, in which there are more than one subject in a single clause. To cater for this, we might consider the possibility of having multiple specifiers particularly off the functional head $W$. Note that it is not possible to have the $\mathrm{R}=\mathrm{E} / \mathrm{View}_{\text {all }}$ interpretation and the $\mathrm{R}=\mathrm{S} / \mathrm{View}_{\text {part }}$ interpretation at the same time in a single clause. In the multiple subject construction, it always seems to be the case that the clause receives the $\mathrm{R}=\mathrm{E} / \mathrm{View}_{\text {all }}$ interpretation (but not the $\mathrm{R}=\mathrm{S} /$ View $_{\text {part }}$ interpretation) and moreover that the subjects are all taken as 'individuals' (but not 'stages'). (See (4) below, for example.) This suggests that $W$ is active but $E$ is inactive in the tense structure of the multiple subject construction and that $[\mathrm{Spec}, \mathrm{EP}]$ is not a possible position for a subject to appear in. Since there is more than one 'subject' that can only appear in [Spec, WP], we need multiple specifiers from a single $W$.

(4) a. Sakana-wa tai-\#ga ii.

fish snapper good

'As for fish, snapper is good.'

( $=$ it is snapper and not any other fish that is good.)

b. Kono kurasu-wa dansei-\#ga yoku deki-ru. this class male do well-Pres 'Speaking of this class, the boys (and not the girls) do well.' 
Notice also that a phrase appearing in the left-most or outer subject position in the multiple subject construction is often not an argument of the predicate. It may be a pure topic without a theta-role, as seen in (4a) above, or what seems like an argument of a PP whose P has been dropped, as seen in (4b). (As the hashes indicate, the ga-marked phrases cannot yield the neutral interpretation. I.e., they are necessarily interpreted as being in focus.) To allow these non-argument phrases to appear in [Spec, WP], as they share the crucial nature of an 'individual' (and that of a 'topic' if marked with -wa), we need to conceive of [Spec, WP] not simply as one of the EPP positions to which subject arguments may raise but as a more versatile position, in which non-argument pure topic phrases may be base generated and PPs and other forms of adjunct may be moved to from their base positions (or possibly base generated as a pure topic).

Another possible occupant of [Spec, WP] I envisage is ga-marked phrases interpreted as being in focus (as opposed to the neutral ga-marked subjects which have been argued to appear in [Spec, EP]). This is based on the observation that when a ga-marked subject receives the focus interpretation but not the neutral interpretation, the sentence necessarily receives the $\mathrm{R}=\mathrm{E} / \mathrm{View}_{\text {all }}$ interpretation, just like a sentence with a wamarked subject. Moreover, the focus -ga is rather akin to the topic/thematic $w a$ in the sense that it has a function of characterization. Observe that the $g a$ marked and focused John in (5a) below is characterized by the property described by the predicate, i.e., being a student, rather similarly to the way in which the wa-marked and topicalized John in (5b) is characterized by the property described by the predicate.

(5) a. John-ga gakusei da. student Cop

'It is John who is a student.'

b. John-wa gakusei da. student Cop

'As for John, he is a student.' 
With all these issues left open, my theory is far from complete. However, I hope that my analyses of $w a$ - and ga-subjects from a novel perspective of tense have shed light on a new dimension of the problem and provided a basis and a spur for future study. Furthermore, although my arguments and proposals are mainly to provide mechanisms to account for the phenomena of $w a / g a$-subjects in Japanese, I trust that my proposals should find credence in analyzing other languages, and ultimately contribute to the general project of understanding the nature of human language. 


\section{References}

Antinucci, Francesco and Ruth Miller (1976). How children talk about what happened. Journal of Child Language 3, 169-189.

Bach, Emmon 1981. On Time, Tense, and Aspect: An Essay in English Metaphysics. In P. Cole (ed.), pp.63-81.

Bach, Emmon 1986. The Algebra of Events. Linguistics and Philosophy 9, 5-16.

Bahloul, Maher 1994. The Syntax and Semantics of Taxis, Aspect, Tense and Modality in Standard Arabic. $\mathrm{PhD}$ dissertation, Cornell University, Ithaca.

Barwise, Jon and John Perry 1983. Situations and Attitudes. MIT Press, Cambridge, Mass.

Belletti, Adriana 1990. Generalized Verb Movement. Rosenberg \& Sellier, Torino.

Belletti, Adriana 1998. VSO vs. VOS: on the licensing of possible positions for postverbal subjects in Italian (and Romance). Series of lectures presented at ALI98, Brisbane.

Bennett, M. 1981. On Tense and Aspect: One Analysis. In Ph.J. Tedeschi and A. Zaenen (eds.) pp. 13-29.

Bennett, M. and B.H. Partee 1972. Toward the Logic of Tense and Aspect in English. System Development Corporation, Santa Monica, California. [distributed in 1978 by the Indiana University Linguistics Club.]

Bertinetto, Pier Marco 1986. Intrinsic and Extrinsic Temporal References. On Restricting the Notion of 'Reference Time'. Vincenzo Lo Cascio and Co Vet (eds.) Temporal Structure in Sentence and Discourse. Dordrecht, Foris. pp. 4178.

Blackburn, Patrick 1994. Tense, Temporal Reference, and Tense Logic. Journal of Semantics 11, 83-101.

Bloom, Lois, Lifter, Karin, \& Hafitz, Jeremie (1980). Semantics of verbs and the development of verb inflection in child language. Language, 56, 386-412. 
Bobaljik, Jonathan and Dianne Jonas 1996. Subjects Positions and the Role of TP. Linguistics Inquiry 27, 2, 195-236.

Bonet, Eulália 1989. Postverbal Subjects in Catalan. Ms. MT, Cambridge.

Borer, Hagit 1994. The projections of arguments. Functional projections, University of Massachusetts Occasional Papers 17, edited by E. Benedicto \& J. Runner. Amherst, Mass., GLSA, UMass.

Borer, Hagit 1996. Passive without theta grids. Morphological interfaces, edited by P. Farell \& S. Lapoint. Stanford, CSLI.

Brentano, Franz 1924. Psychologie vom Empirischen Standpunkt Vols. 1, 11, Felix Meiner, Hamburg.

Bresnan, Joan 1982. The passive in lexical theory. In J. Bresnan, ed., The mental Representation of Grammatical Relations, Cambridge, MIT Press.

Brugger, Gerhard 1997a. Event Time Properties. To appear in Proceedings of the $21^{s t}$ Annual Penn Linguistics Colloquium. Penn Working Papers in Linguistics 4.

Brugger, Gerhard 1997b. Expletive Auxiliaries. To appear in Linguistics Symposium on Romance Languages 27.

Burzio, Luigi 1986. Italian Syntax, Reidel, Dordrecht.

Bybee, Joan L., Perkins, Revere \& Pagliuca, William (1994). The Evolution of Grammar: Tense, Aspect, and Modality in the Languages of the World (Chicago, The University of Chicago Press).

Calabrese, Andrea 1993. Some Remarks on Focus and Logical Structures in Italian. Harvard Working Paper in Linguistics, Vol.1. 91-127.

Carlson, Gregory 1977. Reference to Kinds in Einglish. PhD dissertation, University of Massachusetts.

Chafe, Wallace 1976. Givenness, Contrastiveness, Definiteness, Subjects, Topics, and Point of View. In Li, Chales (ed.) Subject and Topic. New York, Academic Press. 
Chomsky, Noam 1970. Remarks on Nominalization. In R.A. Jacobs and P.S. Rosenbaum (eds), Readings in English Transformational Grammar, Ginn, Waltham, Mass, pp. 184-221.

Chomsky, Noam 1992. A minimalist program for linguistic theory. MIT Occasional Papers in Linguistics, 1. [Published 1993, in Kenneth Hale and Samuel Jay Keyser (eds), The View from Building 20: Essays in Linguistics in Honor of Sylvain. Bromberger, Cambridge, Mass., MT Press, 1-52.]

Chomsky, Noam. 1995. The Minimalist Program. Cambridge. Mass., The MIT Press.

Chung Sandra and James McCloskey 1987. Government, Barriers and Small Clauses in Modern Irish. Linguistic Inquiry 18, 173-237.

Cinque, Guglielmo 1999. Adverbs and the Universal Hierarchy of Functional Projections. Oxford, Oxford University Press.

Cole, Peter (ed.) 1981. Radical Pragmalics. New York, Academic Press.

Comrie, Bernard 1976. Aspect. Cambridge, Cambridge University Press.

Comrie, Bernard 1985. Tense, Cambridge, Cambridge University Press.

Cowper, Elizabeth 1997. Grammatical aspect in English. Ms. University of Toronto.

Dahl, Östen 1985. Tense and Aspect Systems. London - New York, Basil Blackwell.

Da Silva, Zenia Sacks 1978. Beginning Spanish: A Concept Approach, Fourth Edition. New York, Harper \& Row

Davidson, Donald 1967. The logical form of action sentences. In The Logic of Decision and Action, ed. By Nicholas Rescher, University of Pittsburgh Press, Pittsburgh, Pa. Reprinted in Lissays in Actions and Lvents. Clarendon Press, Oxford. 105-22.

Davis, Henry 1998. Person splits, $\phi$-features and temporal architecture. GLOW Newstetler 40.

Déchaine, Rose-Mary 1991. Predicates and the TP hypothesis. Paper presented at the UQAM Workshop on Lexical-Syntactic Relations, June. 
Demirdache, Hamida and Myriam Uribe-Etxebarria 1998a. On the projection of temporal structure in natural languages. GLOW Newsletter 40.

Demirdache, Hamida and Myriam Uribe-Etxebarria 1998b. The Primitives of Temporal Relations. In Roger, Martin, David Michaels \& Juan Uriagerreka (eds.), Step by Step: Lissays on Minimalist Syntax in Honor of Howard Lasnik. Cambridge, Massachusetts, MIT Press.

Demirdache, Hamida and Myriam Uribe-Etxebarria 1998c. The Syntax of Temporal Relations: a Uniform Approach to Tense and Aspect. To appear in WCCFL 16.

Depraetere, Ilse 1995. On the necessity of distinguishing between (un)boundedness and (a)telicity. Linguistics and Philosophy 18, 1-19.

Diesing, Molly 1992. Bare Plural Subjects and Derivation of Logical Representationist. Linguistic Inquiry 23. 353-380.

Diesing, Molly 1997. Light Verbs and the Syntax of Aspect in Yiddish. Ms. Cornell University, Ithaca.

Dowty, David 1972. Studies in the Logic of Verb Aspect and Time Reference in Linglish. Doctoral Dissertation, University of Texas at Austin.

Dowty, David 1979. Word Meaning in Montague Grammar, Reidel, Dordrecht.

Dowty, David 1991. Thematic Proto-Roles and Argument Selection. Language 67, 547-619.

Enç, Mürvet 1987. Anchoring Conditions for Tense. Linguistic Inquiry 18.4, 633657.

Endo, Yoshio 1994. Stage/Individual-level Nouns. In Koizumi (ed.) pp. 83-99.

Engel, Dulcie and Marie-Eve Ritz 2000. The use of the present perfect in Australian English. A paper presented at Australian Linguistics Conference, The University of Melbourne.

Farmer, Ann Kathleen 1984. Modularity in Syntax: A Siudy of Japanese and English. Cambridge, MIT Press.

Farmer, Ann Kathleen 1985. On the Interaction of Morphology and Syntax. Indiana University Linguistic Club. 
Filip, Hana 1993. Aspect, Situation Types, and Nominal Reference. PhD dissertation, University of California at Berkeley.

Filip, Hana 1994. Aspect and the semantics of noun phrases. In Co Vet and Carl Vetters (eds.) Tense and Aspect in Discourse. Berlin, Mouton de Gruyter, 227255.

Filip, Hana and Gregory Carlson 1997. Sui Generis Genericity. Penn Working Papers in Linguistics, 4. (Proceedings of the twenty-first annual Penn linguistic colloquium). University of Pennsylvania, Philadelphia.

Forsyth, James 1970. A Grammar of Aspect: Usage and Meaning in the Russian Verb. Cambridge, Cambridge University Press.

Fukui, Naoki 1986. A Theory of Category Projection and Its Applications. PhD Thesis, MIT, Cambridge.

Giorgi, Alessandra and Fabio Pianesi 1991. Toward a Syntax of Temporal Representations. Probus 2, 187-213.

Grimshaw, Jane 1979. Complement selection and lexicon. Linguistic Inquiry 10, $279-$ 326.

Grimshaw, Jane 1990. Argument Structure. Cambridge, MTT Press.

Hale, Ken 1980. Remarks on Japanese Phrase Structure: Comments on the Papers on Japanese Syntax. MIT Working Papers in Linguistics 2, 185-203.

Halliday, Michael 1967-1968. Notes on Transitivity and Theme in English, Parts 1, 2 and 3. Journal of Linguistics 3, 37-81, 199-244, and 4, 179-215.

Harley, Heidi 1995. Subjects, Livents and Licensing. PhD thesis, Massachusetts Institute of Technology.

Hasegawa, Yoko 1999. Tense-Aspect Controversy Revisited: The - Ta and -Ru forms in Japanese. Pragmatics in 1998: Selected Papers from the $6^{\text {th }}$ International Pragmatics Conference.

Haviland, Susan and Herbert Clark 1974. What's New? Acquiring New Information as a Process in Comprehension. Journal of Verbal Learning and Verbal behavior $13,512-521$. 
Heinämäkki, O. 1974. The Semantics of English Temporal Connectives. Ph.D. dissertation, University of Texas, Austin.

Heinämäkki, O. 1984. Aspect in Finnish. In de Groot, C. and H. Tommola (eds.) Aspect Bound: A Voyage into the Realm of Germanic, Slavonic, and FinnoUgrian Aspeciology. Dordrecht, Foris, pp.153-178.

Heycock, Caroline 1994. Focus Projection in Japanese. NLLS 24, 1, 157-171.

Higginbotham, James 1985. On Semantics. Linguistic Inquiry 16, 547-94.

Hinds, John 1987. Thematization, Assumed Familiarity, Staging, and Syntactic Binding in Japanese. In Hinds, J., S. Maynard and S. Iwasaki (eds.) pp. 83-106.

Hinds, John, Senko Maynard and Shoichi Iwasaki (eds.) 1987. Perspectives on Topicalization: The Case of Japanese Wa. Amsterdam; Philadelphia, J. Benjamins.

Hinrichs, Erhard 1985. A Compositional Semantics for Aktionsarten and NP Reference in Linglish. Ph.D. Thesis, Ohio State University.

Hoji, Hajime 1985. Logical Form Constraints and Configurational Structures in Japamese. PhD Thesis, University of Washington, Seattle.

Hoji, Hajime (ed.) 1990. Japanese/Korean Linguistics. Stanford, CSLI.

Horie, Kaoru 1990. How languages encode the cognitive notion of directness and indirectness. In Hoji, pp. 61-77.

Hornstein, Norbert 1990. As Time Goes By: Tense and Universal Grammar. Cambridge, Massachusetts, The MIT Press.

Imai, Takashi and Saito, Mamoru (eds.) Issues in Japanese Linguistics. Dordrecht, Foris.

Inoue, Kazuko 1978. Nihongo-no Bunpoo-Kisoku. Tokyo, Taishukan.

Inoue, Kazuko 1980. Furui joho, atarashi joho [Old information, new information]. Gengo [Language] 10, 22-34. Tokyo, Taishukan.

Isoe, Gen 1992. The Japanese Particles 'Wa' and 'Ga': A Quantitative Study of a Text. PhD Thesis, The University of Michigan. 
Jackendoff, Ray 1996. The proper treatment of measuring out, telicity, and perhaps even quantification in English. Natural Language and Linguistic Theory 14, 305-354.

Kamp, Hans and Christian Rohrer 1983. Tense in texts. In Bauerle, Rainer, Christoph Schwarze and Arnim von Stechow (eds.), Meaning, use and interpretation of language, pp. 250-269. Berlin, Mouton de Gruyter.

Karttunen, Lauri 1970. On the semantics of complement sentences. In M. A. Campbell, J. Lindholm, A. Davidson, W. Fisher, L. Furbee, J. Lovins, E. Maxwell, J. Reighard, and S. Straight (Eds.), Papers from the Sixth Regional Meeting of the Chicago Linguistic Society. Chicago, University of Chicago Department of Linguistics, pp. 328-339.

Kawasaki, Noriko 1991. Tense, Agreement, and Nominative Case in Japanese. MIT Working Papers in Linguistics 14. 131-146.

Kayne, Richard 1994. The Antisymmetry of Syntax. Cambridge, Mass., MIT Press. Kenny, Anthony 1963. Action, Lmotion and Will. London, Routledge and Kegan Paul.

Kim, Kwang-sup 1990. Where do the contrastive and focus readings come from? In Hoji, Hajime (ed.) pp. 395-411.

Kindaichi, Haruhiko 1950. Kokugo Doosi no Iti-Bunrui [A Proposal for Japanese Verb Classification]. Gengo Kenkyuu 15, 48-63.

Kindaichi, Haruhiko 1955. Nihongo Doosi no Tensu to Asupekuto [Tense and Aspect of Japanese Verbs]. Nagoya Daigaku Bungaku-bu Kenkyuu-Ronshuu 10, 63-89.

Kindaichi, Haruhiko 1976. Nihongo Doosi no Asupekuto [Aspectual Properties of Japanese Verbs]. Mugi Shoboo, Tokyo.

Kiparsky, Paul 1995a. Aspect and Event Structure in Vedic. ms. Stanford University. Kiparsky, Paul 1995b. Partitive Case and Aspect. ms. Stanford University.

Kiparsky, Paul and Carol Kiparsky 1970. Fact. In Bierwisch, Manfred and Karl Erich Heidolph (eds.) Progress in Linguistics, pp. 143- 173, Mouton, The Hague.

Kitagawa Yoshihisa 1986. Subjects in Japanese and English. PhD Thesis, University of Massachusetts, Amherst. 
Klein, Wolfyang 1995. A Time Relational Analysis of Russian Aspect. Language 71.

Koizumi, Masatoshi (ed.) 1994a. Formal Approaches to Japanese Linguistics 1. MTT Working Papers in Linguistics 24.

Koizumi, Masatoshi 1994b. Nominative Objects: The Role of TP in Japanese. In Koizumi (ed.) pp. 211-230.

Koopman, Hilda and Dominique Sportiche 1988. Subjects. ms. UCLA.

Koopman, Hilda and Dominique Sportiche 1991. 'The position of subjects' Lingua $85,211-258$.

Kratzer, Angelika 1989. Stage-Level and Individual-Level Predicates. In Emmon Bach, Angelika Kratzer and Barbara Partee (eds.) Papers on Quantification, NSF Report BNS 87-19999, University of Massachusetts, Amherst.

Kratzer, Angelika 1994. On external arguments. In E. Benedicto and J. Runner (eds.) Functional projections. University of Massachusetts Occasional Papers 17, Amherst, GLSA, Umass, 103-130.

Krifka, Manfred 1989. Nominal reference, temporal constitution and quantification in event semantics. In R. Bartsch, J. van Benthem and P. van Emde Boas, Semantics and Contextual Lxpressions, Foris Dordrecht, pp. 75-115.

Krifka, Manfred 1992. Thematic relations as links between nominal reference and temporal constitution. In Ivan Sag and Anna Szabolsci (eds.), pp. 29-53.

Kunihiro, Tetsuya 1967. Konzouteki imiron - Niti-ei ryougo taishou kenkyuu [A contrastive study of English and Japanese]. Sanseido, Tokyo

Kuno, Susumu 1972. Functional Sentence Perspective: A Case Study from Japanese and English. Linguistic Inquiry 3, 269-320.

Kuno, Susumu 1973. The Structure of the Japanese Language. MIT Press.

Kuroda, Sige-Yuki 1965. Generative Grammatical Studies in the Japanese Language. Ph.D. dissertation. MIT, Cambridge, Mass.

Kuroda, Sige-Yuki 1972. The Categorical and the Thetic Judgements. Foundations of Language 9, 153-185. [Reprinted in Kuroda (1979) The (W)hole of the Doughnut: Syntax and its Boundaries. E. Ghent, Story-Scientia.] 
Kuroda, Sige-Yuki 1976. Subject. In Shibatani (ed.), pp.1-16.

Kuroda, Sige-Yuki 1986. Movement of Noun Phrases in Japanese. In Imai, T. and Saito, M. (eds.), pp. 229-271. [Reprinted in Kuroda (1992a).]

Kuroda, Sige-Yuki 1988. Whether We Agree or Not: A Comparative Syntax of English and Japanese. In Poser, W. J. (ed.) Papers from the Second International Workshop on Japanese Syntax. Stanford, CSLI, 103-143.

Kuroda, Sige-Yuki 1992a. Japanese syntax and semantics. Dordrecht, Kluwer.

Kuroda, Sige-Yuki 1992b. Judgement Forms and Sentence Forms. In Kuroda (1992a), pp. 13-77.

Lee, Chungmin 1995. Definiteness and specificity. Linguistics in the Morning Calm $3,663-677$.

Levin, Beth and Malka Rappaport 1995. Unaccusativity: At the syntax-lexical semantics interface. Cambridge, MIT Press.

Lewis, Josephs1976. Complementation. In Shibatani (ed.), pp.307-369.

Makino, Seiichi 1987. How relevant is a functional notion of communicative orientation to ga and $w a$ ? In Hinds, J., S. Maynard and S. Iwasaki (eds.) pp. 293-306.

Marantz, Alec 1984. On the Nature of Grammatical Relations. Cambridge, MIT Press.

Marty, Anton 1908. Untersuchungen zur Grundlegung der allgemeinen Grammatik und Sprachphilosophie, Erster Band, Max Niemeyer, Halle a. S. [cited in Kuroda 1992a]

Marty, Anton 1916-1918, Gesammelte Schriften, Max Niemeyer, Halle a. S. [cited in Kuroda 1992a]

Marty, Anton 1940. Psyche und Sprachstruktur, A. Francke AG. Verlag, Bern. [cited in Kuroda 1992a]

Marty, Anton 1950a. Satz und Wort, A. Francke AG. Verlag, Bern. [cited in Kuroda 1992a]

Marty, Anton 1950b. Über Wert und Methode einer allgemeinen beschreibenden Bedeutungslehre, A. Francke AG. Verlag, Bern. [cited in Kuroda 1992a] 
Maynard, Senko 1980. Discourse functions of the Japanese theme marker wa. Dissertation, Northwestern University.

Maynard, Senko 1987. Thematization as a Staging Device in the Japanese Narrative. In Hinds, J., S. Maynard and S. Iwasaki (eds.) pp. 57-82.

McCawley, James D. 1971. 'Tense and time reference in English' In C. Fillmore and D.T. Langendoen (eds.) Studies in Linguistic Semantics. New York: Holt, Rinehart and Winston, 96-113.

McCloskey, Jim 1997. Subjecthood and subject positions. In Haegeman, Liliane (ed.), Llements of Grammar. Kluwer Academic Publishers, Netherlands, 197235.

McClure, Tsuyoshi William 1994. Syntactic Projections of the Semantics of Aspect. $\mathrm{PhD}$ Dissertation, Cornell University.

McGloin, Naomi Hanaoka 1989. A S'tudents' Guide to Japanese Grammar. Tokyo, Taishukan Publishing Co.

Mikami, Akira 1960. Zoo wa hama ga nagai. Tokyo, Kuroshio Shuppan.

Mikami, Akira 1972. Gendai Gohoo Josetsu: Sintakusu-no Kokoromi. Tokyo, Kuroshio.

Milsark, Gary 1974. Lixistential Sentences in English. Doctoral dissertation, MIT, Cambridge, Massachusetts.

Miyagawa, Shigeru 1980. Complex Verbs and the Lexicon. PhD Thesis, University of Arizona, Tucson.

Miyata, S. 1995. The Aki Corpus: Longitudinal speech data of a Japanese boy aged 1;5.7-3;0.0. The Bulletin of Aichi Shukutoku Junior College, 34, 183-191.

Montague, Richard 1974. Formal Philosophy Selected Papers of Richard Montague. R.H. Thomason (ed.), Yale University Press, N.H.

Mourelatos, Alexander P.D. 1978. Events, Processes, and States. Linguistics and Philosophy 2, 415-434.

Murphy, Raymond 1985. English Grammar in Use. Cambridge University Press. 
Nakamura, Akira 1994. Some aspects of temporal interpretation in Japanese. In Koizumi (ed.) pp. 231-246.

Nakau, Minoru 1976. Tense, Aspect, and Modality. In Masayoshi Shibatani (ed.) Syntax and Semantics 5: Japanese Generative Grammar. New York, Academic Press. pp. 421-465.

Ogihara, Toshiyuki 1989. Temporal Reference in Linglish and Japanese. PhD dissertation, University of Texas at Austin.

Okawa, Hideaki 1990. Tense and time in Japanese. $\mathrm{PhD}$ dissertation, University of Illinois at Urbana-Champaign.

Parsons, Terence 1990. Lvents in the Semantics of Linglish: A study in subatomic semantics. MIT Press, Cambridge, Ma.

Partee, Barbara Hall 1973. Some structural analogues between tenses and pronouns in English. The Journal of Philosophy 70, 601-609.

Perlmutter, David 1978. Impersonal Passive and the Unaccusative Hypothesis. Proceedings of the Berkeley Linguistics Society 4.

Prince, Ellen 1981. Toward a Taxonomy of Given-New Information. In P. Cole (ed.), pp. 223-255.

Prior, A. 1967. Past, Present and Future. Oxford, Oxford University Press.

Quirk, Randolph and Greenbaum Sidney 1973. A University Grammar of Linglish.

Ramchand, Gillian Catriona 1996. Two Subject Positions in Scottish Gaelic: The Syntax-Semantics Interface. Natural Language Semantics 4, 165-191.

Raposo, Eduardo and Juan Uriagereka 1993. Two Types of Small Clauses. GLOW Newsletler 30, 68-69.

Raposo, Eduardo and Juan Uriagereka 1995. Two Types of Small Clauses (Toward a Syntax of Theme/Rheme Relations). In Cardinaletti, Anna and Maria

Ritter, E. and S.T. Rosen 1998. Delimiting events in syntax. The projection of arguments: Lexical and syntactic constraints, edited by W. Geuder \& M. Butt. Stanford: CSLI.

Ritter, E. and S.T. Rosen to appear. Event structure and eargativity. Events as grammatical objects, edited by J. Pustejovsky \& C. Tenny. Stanford: CSLI. 
Teresa Guasti (eds.) Syntax and Semantics 28: Small Clauses. San Diego, Academic Press. pp. 179-206.

Reichenbach, Hans 1947. Llements of Symbolic Logic. New York, MacMillan.

Rosen, Sara Thomas 1999. The syntactic representation of linguistics events. Glot International, 4, 2, 3-11.

Ryle, G. 1949. The Concept of Mind. London, Barnes and Noble.

Safir, Ken 1994. Perception, selection, and structural economy. Natural Language Semantics, 2, 47-70.

Sag, Ivan and Anna Szabolsci (eds.) 1992. Lexical Matlers. Stanford, CSLI Publications, Stanford University, CA.

Saito, Mamoru 1985. Some Asymmetries in Japanese and Their Theoretical Implications. PhD Thesis, MIT, Cambridge.

Shibatani, Masayoshi (ed.) 1976. Syntax and Semantics, 5: Japanese Generative Grammar. Academic Press.

Shirai, Ken-ichiro 1986. Japanese noun-phrases and particles wa and ga. In Groenendijk, J. D. de Jongh, and M. Stockhof (eds.) Siudies in Discourse Representation Theory and the Theory of Generalized Quantifiers. Dordrecht and Providence, Foris. pp. 63-80.

Shirai, Yasuhiro 1997. The acquisition of tense-aspect morphology in Japanese: A grammaticization perspective. Paper presented at the LAS Summer Institute held at Cornell University.

Smith, Carlota S. 1991. The Parameter of Aspect. Dordrecht, Kluwer.

Sportiche, Dominique 1988. A theory of floating quantifiers and its corollaries for constituent structure. Linguistic Inquiry 19, 425-449.

Stowell, Tim 1994a. The Phrase Structure of Tense. manuscript, University of California, Los Angeles [Published in Rooryck, Joan and Lauries, Zaring (eds) Phrase Structure and the Lexicon. Dordrecht: Kluwer 1996]

Stowell, Tim 1994b. Syntax of Tense. unpublished manuscript, University of California, Los Angeles. 
Stump, Gregory T. 1985. The Semantic Variability of Absolute Constructions. Reidel, Dordrecht.

Suzuki, Satoko 1993. Topic and presupposition in Japanese. $\mathrm{PhD}$ thesis, University of Minnesota.

Suzuki, Yasuyuki 1977. Nihongo bunpou no kiso [Fundamentals of Japanese]. Sanseido, Tokyo.

Svenonius, Peter 1994. Dependent Nexus: Subordinate predication structures in English and the Scandinavian languages. $\mathrm{PhD}$ dissertation, University of Califomia at Santa Cruz.

Takezawa, Koichi 1987. A Configurational Approach to Case Marking in Japanese. Ph.D. dissertation, University of Washington.

Tateishi, Koichi 1991. The Syntax of "Subjects". Ph.D. Thesis, University of Massachusetts, Amherst. [A slightly revised version published in 1994, Tokyo, Kuroshio.]

Tedeschi, Ph. J. and Annie Zaenen (eds.) Tense and Aspect. Syntax and Semantics 14. New York, Academic Press.

Tenny, Carol 1987. Grammaticalizing Aspect and Affectedness. PhD Thesis, MIT.

Tenny, Carol 1992. The Aspectual Interface Hypothesis. In I.A. Sag and A. Szabolcsi (eds.), pp. 1-27.

Tenny, Carol 1994. Aspectual Roles and the Syntax-Semantic Interface. Kluwer, Dordrecht.

Tonoike, Shigeo 1989. ' $W a, M o, G a$ 'no Ronri-Keishiki: Bun-Bunpoo-to DanwaBunpoo-no Intaafesu. Meiji-Gakuin Ronshuu 446: English Language and Literature 74, 51-75.

Travis, Lisa deMena 1991. Derived Objects, Inner Aspect and the Structure of VP. paper presented at NELS, University of Delaware.

Travis, Lisa deMena 1994. Event phrase and a theory of functional categories. Proceedings of the 1994 Annual Conference of the Canadian Linguistic Association, Toronto Working Papers in Linguistics, edited by P. Koskinen, Toronto. 
Travis, Lisa deMena 1997. The syntax of achievements. To appear in UCLA Working Papers.

Travis, Lisa deMena to appear. The L-syntax/S-syntax boundary: Evidence from Austronesian. Formal issues in Austronesian syntax, edited by 1. Paul, V. Phillips, \& L. Travis. Dordrecht, Kluwer Academic Publishers.

Uetake, Yoichi 1991-1992. Analysis of the theme and rheme structure of a Japanese sentence, Lingua Posnamensis, 125-134.

Valluduví, Enric 1992. The Information Component. New York, Garland.

Vendler, Zeno 1967. Verbs and Times. Linguistics in Philosophy. Cornell University Press, Ithaca, NY. pp.97-121.

Vikner, Sten 1985. Reichenbach Revisited: One, Two, or Three Temporal Relations? Acta linguistica Hafniensia 19.2, 81-98.

Vlach, Frank 1981. The Semantics of the Progressive. In Ph.J. Tedeschi and A. Zaenen (eds.) pp. 271-291.

Whitman, John 1997. Lecture notes for "Introduction to Japanese syntax and semantics". LSA Summer Institute, Cornell University.

Williams, Edwin 1981. Argument Structure and Morphology. The Linguistic Review 4, 203-246.

Zagona, Karen 1990. Times as Temporal Argument Structure. ms. University of Washington. 